UNIVERSIDADE DE SÃO PAULO

ESCOLA DE ENFERMAGEM DE RIBEIRÃO PRETO

LIDIANE APARECIDA MONTEIRO

Ensino do cuidado com os pés para a redução do "risco de integridade tissular prejudicada" das pessoas com diabetes mellitus tipo 2: ensaio clínico randomizado

Ribeirão Preto 


\section{LIDIANE APARECIDA MONTEIRO}

Ensino do cuidado com os pés para a redução do "risco de integridade tissular prejudicada" das pessoas com diabetes mellitus tipo 2: ensaio clínico randomizado

Tese apresentada à Escola de Enfermagem de Ribeirão Preto da Universidade de São Paulo, para obtenção do título de Doutor em Ciências, Programa de Pós-Graduação em Enfermagem Fundamental.

Linha de pesquisa: Fundamentação teórica, metodológica e tecnológica do processo de cuidar

Orientadora: Prof ${ }^{a}$. Dr ${ }^{a}$. Ana Emilia Pace

Co-orientadora: Prof ${ }^{a}$. Dr ${ }^{a}$. Érika Cássia Lopes Chaves

\section{Ribeirão Preto}


Autorizo a reprodução e divulgação total ou parcial deste trabalho, por qualquer meio convencional ou eletrônico, para fins de estudo e pesquisa, desde que citada a fonte.

Monteiro, Lidiane Aparecida

Ensino do cuidado com os pés para a redução do "risco de integridade tissular prejudicada" das pessoas com diabetes mellitus tipo 2: ensaio clínico randomizado. Ribeirão Preto, 2019.

183 p.: il.; $30 \mathrm{~cm}$

Tese de Doutorado, apresentada à Escola de Enfermagem de Ribeirão Preto/USP. Área de concentração: Enfermagem Fundamental.

Orientador: Ana Emília Pace

Coorientador: Érika de Cassia Lopes Chaves

1. Diabetes Mellitus tipo 2. 2. Pé diabético. 3. Educação em saúde. 4. Arco de Charles Maguerez. 5. Ensaio clínico. 
MONTEIRO, Lidiane Aparecida

Ensino do cuidado com os pés para a redução do "risco de integridade tissular prejudicada" das pessoas com diabetes mellitus tipo 2: ensaio clínico randomizado

Tese apresentada à Escola de Enfermagem de Ribeirão Preto da Universidade de São Paulo, para obtenção do título de Doutor em Ciências, Programa de Pós-Graduação em Enfermagem Fundamental.

Aprovado em:

Presidente

Prof. Dr.

Instituição:

Comissão julgadora

Prof. Dr.

Instituição:

Prof. Dr.

Instituição:

Prof. Dr.

Instituição: 


\section{DEDICATÓRIA}

Dedico este trabalho a Deus, o orientador da minha vida. Aquele que me carregou no colo e me fortaleceu nos momentos mais difíceis.

Aos meus pais, meus irmãos, minhas cunhadas, meus sobrinhos, meus amigos, minha sogra e meu sogro por acreditarem em minhas escolhas e me apoiarem em todos os momentos.

Ao meu esposo, por estar sempre ao meu lado e por compreender a minha ausência em vários momentos.

Ao meu filho, que se tornou um dos maiores motivos para esta conquista.

Aos professores Ana Emília Pace, Érika de Cássia Lopes Chaves e Fabrício Avelar, por me estimularem na busca de novos conhecimentos.

Enfim, a todos que torceram por mim e que de alguma forma colaboraram na realização deste sonho. 


\section{AGRADECIMENTOS}

Agradeço a Deus pelo privilégio da vida e por me permitir alcançar esta vitória.

Às pessoas com Diabetes Mellitus que participaram deste estudo, por me proporcionarem maior compreensão do cuidado humanizado.

A todos os profissionais de enfermagem que partilharam comigo seus conhecimentos e suas experiências, principalmente as minhas amigas Luciana, Victória, Liliane, Elzenete e Viviane.

Aos amigos que tornaram esta caminhada mais leve.

Ao amigo João Batista, pela disponibilidade e pela importante contribuição no desenvolvimento deste estudo.

À minha amiga Bruna, que mesmo distante, se fez presente em todos os momentos, por meio de suas orações que me revigoraram e fortaleceram.

Aos gestores da Secretaria Municipal de Saúde de Boa Esperança e aos funcionários da Policlínica Municipal que possibilitaram a concretização deste estudo.

Aos amigos da Nova FAFIBE, pelo incentivo e carinho. 
A orientadora professora Dra ${ }^{\mathrm{a}}$. Ana Emilia Pace e co-orientadora professora Dr ${ }^{\mathrm{a}}$. Érika de Cássia Lopes Chaves, exemplos de dedicação e de competência. Agradeço pela confiança, pela amizade e pelo carinho.

Ao professor Dr $^{\circ}$. Fabricio Avelar, que com dedicação e muita paciência contribuiu para a realização deste estudo.

Aos professores do Programa de Pós-Graduação em Enfermagem da Universidade de São Paulo - Ribeirão Preto, que muito contribuíram para meu crescimento como discente.

Aos funcionários e professores da Escola de Enfermagem da Universidade de São Paulo Ribeirão Preto, pelo carinho e pela acolhida.

Á irmã Deodata, pelo carinho e orações.

Á minha mãe, companheira de todos os momentos, aquela que nunca se cansou de me incentivar para eu realizasse os meus sonhos.

Obrigada por ter me amparado e auxiliado nesta fase tão importante da minha vida. E, ainda, por ter me fortalecido por meio de suas orações. Sem você, mãe, eu não teria conseguido.

Ao meu pai, que mesmo não entendendo o porquê de tanto sacrifício e renúncia, sempre estendeu sua mão para me ajudar e acarinhar nos momentos difíceis.

Aos meus irmãos, Leandro e Leonardo, por acreditarem que eu seria capaz e por incentivarem a realização desse sonho. Vocês são partes fundamentais na minha vida, por isso compartilhamos desta vitória. 
À Heloísa, às minhas cunhadas Bruna, Ana Paula, Shirley e Daniele pelo incentivo e pela amizade incondicional.

Ao meu esposo Júlio, peça fundamental para a realização deste sonho, com quem eu compartilho minhas alegrias, minhas dificuldades e minhas vitórias. Agradeço pelo companheirismo, pelo amor e pela amizade incondicional.

A Dora, José Maurício e familiares, que carinhosamente torceram por mim.

Aos meus sobrinhos, presentes de Deus, por tornarem minha caminhada mais prazerosa.

Ao Davi, que se tornou o maior motivo para a busca desta conquista. Aquele que, junto a Deus, me fortaleceu nas longas madrugadas de estudo, mesmo com os pés edemaciados e com dores nas articulações. Sem você filho, eu não teria a mesma garra!!!

Aos componentes da banca que muito contribuíram com suas sugestões!

A todos que torceram por mim e que, de alguma forma, contribuíram para esta conquista, meu muito obrigado! 
"Desistir... eu já pensei seriamente nisso, mas nunca me levei realmente a sério; é que tem mais chão nos meus olhos do que o cansaço nas minhas pernas, mais esperança nos meus passos, do que tristeza nos meus ombros, mais estrada no meu coração do que medo na minha cabeça" 


\section{RESUMO}

MONTEIRO, L. A. Ensino do cuidado com os pés para a redução do "risco de integridade tissular prejudicada" das pessoas com diabetes mellitus tipo 2: ensaio clínico randomizado. 2019. 183f. Tese (Doutorado) - Escola de Enfermagem de Ribeirão Preto, Universidade de São Paulo, Ribeirão Preto, 2019.

Trata-se de um ensaio clínico randomizado, controlado, mascarado com taxa de alocação de 1:1, cujo objetivo foi avaliar a contribuição do "ensino do cuidado com os pés" para a redução do "risco de integridade tissular prejudicada" das pessoas com DM2, desenvolvido junto a uma amostra de 152 (GI=73/GC=79) pessoas cadastradas em uma Policlínica no sul de Minas Gerais. As intervenções educativas foram embasadas na metodologia do Arco de Charles Maguerez e realizadas na Policlínica por meio de três encontros, com intervalo de trinta dias, por três meses. As avaliações foram realizadas antes do início das intervenções (T1), ao final das intervenções (T2) e três meses após T2 (Tfu), no domicílio dos participantes. Constituíram o estudo, as variáveis sociodemográficas, antropométricas, hábitos de vida, clínicas, informações complementares, integridade da pele e anexos, sensibilidade, deformidades anatômicas, condições vasculares/arteriais, temperatura dos pés, conhecimento sobre as atividades de autocuidado e intenção de realizar as atividades de autocuidado com os pés. Para análise da caracterização da amostra foram utilizados os testes Qui-quadrado, Wilcoxon pareado, Wilcoxon-Mann-Whitney ou Exato de Fisher. Em relação à comparação intergrupo, foi aplicado o teste de Qui-quadrado ou Wilcoxon-Mann-Whitney e para a análise intragrupo, o Teste McNemar ou Wilcoxon, com nível de significância de 5\%. Observou-se maior frequência de pessoas do sexo feminino, idosos, estado civil com conjugê/companheiro, aposentados, que viviam com duas a três pessoas e possuíam baixa/média escolaridade e baixa renda. Foi evidenciado sobrepeso entre os participantes e em relação aos hábitos de vida destacou-se maior frequência de pessoas que referiram não ser tabagista, não consumir bebidas alcoólicas e não praticar exercícios físicos. Para o tempo de diagnóstico, os grupos possuíam médias de 11,71-10,72 (DP=7,75-5,47) anos para o GI e GC respectivamente. Com maior frequência, foram referidos o tipo de tratamento com antidiabéticos orais e a morbidade hipertensão arterial. Na variável glicemia capilar intergrupo e intragrupo foram observadas diferenças $(\mathrm{p}<0,05)$. Destaca-se uma maior frequência de participantes que não tiveram os pés avaliados, não receberam orientações para o autocuidado e não realizavam o autocuidado com os pés. Os indicadores da integridade da pele preservada mostraram diferenças intergrupo e intragrupo, com maior frequência de melhores médias do GI em relação ao GC (p<0,05). Para variável sensibilidade, deformidades anatômicas e temperatura dos pés dos pés não foram observadas diferenças $(\mathrm{p}>0,05)$, assim como para os indicadores de condições vasculares/arteriais $(p>0,05)$, exceto pulsos $(p<0,05)$. Referente a classificação do risco do pé diabético o GI apresentou diferença intragrupo entre os tempos T1 e T $f u$ e T2 e T $f u(p<0,05)$. O conhecimento sobre as atividades de autocuidado com os pés em ambos os grupos foi considerado "baixo" no T1 e após as intervenções educativas, o GI apresentou diferença quando comparado ao GC no T2 e T $f u$ e também na intenção de cuidar dos pés $(\mathrm{p}<0,05)$. As intervenções educativas embasadas na metodologia do Arco de Magueres foram efetivas na melhora do risco de pé diabético, atribuído, principalmente, aos indicadores relacionados às condições dermatológicas, e também nas variáveis conhecimento das atividades de autocuidado e intenção de cuidar dos pés.

Palavras-chave: Diabetes Mellitus tipo 2. Pé diabético. Educação em saúde. Arco de Charles Maguerez. Ensaio clínico. 


\begin{abstract}
MONTEIRO, L. A. Teaching foot care to reduce the "risk of impaired tissue integrity" of people with diabetes mellitus tipo 2: a randomized trial. 2019. 183f. Thesis (Doctoral)University of São Paulo at Ribeirão Preto College of Nursing, Ribeirão Preto, 2019.
\end{abstract}

This is a randomized, controlled, masked clinical trial with a 1:1 allocation ratio, the purpose of which was to evaluate the contribution of "foot care teaching" to reducing the "risk of impaired tissue integrity" of people with DM2, developed with a sample of 152 (GI = $73 / \mathrm{GC}=79$ ) people registered in a Polyclinic in southern Minas Gerais. Educational interventions were based on the methodology of the Charles Maguerez Arch and carried out in the Polyclinic through three meetings, with an interval of thirty days, for three months. Evaluations were performed before the beginning of interventions (T1), at the end of interventions (T2) and three months after T2 (T $f u$ ), at the participants' homes. Study consisted of sociodemographic, anthropometric, lifestyle, clinical, complementary information, skin integrity and appendages, sensitivity, anatomical deformities, vascular/arterial conditions, feet temperature, knowledge about self-care activities and intention to perform self-care foot activities. To analyze the sample characterization, the chi-square, paired Wilcoxon, Wilcoxon-Mann-Whitney or Fisher's exact tests were used. Regarding the intergroup comparison, the Chi-square or Wilcoxon-Mann-Whitney test was applied and for the intragroup analysis, the McNemar or Wilcoxon test, with a significance level of 5\%. There was a higher frequency of females, elderly, marital status with spouse/partner, retirees, who lived with two to three people and had low/medium education and low income. It was evidenced overweight among the participants and in relation to life habits, it was highlighted a higher frequency of people who reported not being a smoker, not consuming alcohol and not practicing physical exercises. For the time of diagnosis, the groups had means of 11.71-10.72 ( $\mathrm{SD}=7.75-5.47)$ years for $\mathrm{GI}$ and $\mathrm{CG}$ respectively. More frequently, the type of oral antidiabetic treatment and hypertension morbidity were reported. In the intergroup and intragroup capillary glucose variable, differences were observed $(\mathrm{p}<0.05)$. We highlight a higher frequency of participants who did not have their feet evaluated, did not receive guidance for self-care and did not perform self-care with their feet. Indicators of preserved skin integrity showed intergroup and intragroup differences, with a higher frequency of better GI means compared to CG $(\mathrm{p}<0.05)$. For variable sensitivity, anatomical deformities and temperature of the feet, no differences were observed ( $>0.05)$, as well as for vascular / arterial condition indicators ( $p>0.05)$, except pulses $(\mathrm{p}<0.05)$. Regarding the risk classification of diabetic foot, GI presented intragroup difference between $\mathrm{T} 1$ and $\mathrm{T} f u$ and $\mathrm{T} 2$ and $\mathrm{T} f u$ $(\mathrm{p}<0.05)$. Knowledge about foot self-care activities in both groups was considered "low" at $\mathrm{T} 1$ and after the educational interventions, the GI presented a difference when compared to the CG at T2 and Tfu and also in the intention to take care of the feet $(p<0.05)$. The educational interventions based on the Magueres Arch methodology were effective in improving the risk of diabetic foot, attributed mainly to indicators related to dermatological conditions, and also to the variables knowledge of self-care activities and intention to take care of the feet.

Keywords: Diabetes Mellitus type 2. Diabetic foot. Health education. Charles Maguerez Arch. Clinical trial. 


\section{RESUMEN}

MONTEIRO, L. A. Enseñanza del cuidado de los pies para reducir el "riesgo de deterioro de la integridad del tejido" de las personas con diabetes mellitus tipo 2: un ensayo aleatorizado. 2019. 183. Tesis (Doctorado) - Escuela de Enfermería de Ribeirão Preto de la Universidad de São Paulo, Ribeirão Preto, 2019.

Este es un ensayo clínico aleatorizado, controlado y enmascarado con una proporción de asignación 1:1, cuyo propósito fue evaluar la contribución de la "enseñanza del cuidado de los pies" para reducir el "riesgo de integridad tisular deteriorada" de las personas con DM2, desarrollado con una muestra de $152(\mathrm{GI}=73 / \mathrm{GC}=79)$ personas registradas en un Policlínico en el sur de Minas Gerais. Las intervenciones educativas se basaron en la metodología del Arco Charles Maguerez y se llevaron a cabo en el Policlínico a través de tres reuniones, con un intervalo de treinta días, durante tres meses. Las evaluaciones se realizaron antes del comienzo de las intervenciones (T1), al final de las intervenciones (T2) y tres meses después de T2 (Tfu), en los hogares de los participantes. El estudio consistió en información sociodemográfica, antropométrica, de estilo de vida, clínica, complementaria, integridad de la piel y apegos, sensibilidad, deformidades anatómicas, afecciones vasculares / arteriales, temperatura de los pies, conocimiento sobre las actividades de autocuidado e intención de realizar el estudio. actividades de autocuidado del pie. Para analizar la caracterización de la muestra, se utilizaron las pruebas exactas de chi-cuadrado, emparejado de Wilcoxon, Wilcoxon-Mann-Whitney o Fisher. En cuanto a la comparación intergrupal, se aplicó la prueba de Chi-cuadrado o Wilcoxon-Mann-Whitney y para el análisis intragrupal, la prueba de McNemar o Wilcoxon, con un nivel de significación del 5\%. Hubo una mayor frecuencia de mujeres, ancianos, estado civil con su cónyuge / pareja, jubilados, que vivían con dos o tres personas y tenían educación baja/media y bajos ingresos. Se evidenció sobrepeso entre los participantes y en relación con los hábitos de vida, se destacó una mayor frecuencia de personas que informaron no fumar, no consumir alcohol y no hacer ejercicio. Para el momento del diagnóstico, los grupos tenían medias de 11.71-10.72 (DE=7.75-5.47) años para GI y CG respectivamente. Con mayor frecuencia, se informó el tipo de tratamiento antidiabético oral y la morbilidad por hipertensión. En las variables de glucosa capilar intergrupo e intragrupo, se observaron diferencias $(\mathrm{p}<0.05)$. Destacamos una mayor frecuencia de participantes que no tuvieron sus pies evaluados, no recibieron orientación para el autocuidado y no realizaron el autocuidado con los pies. Los indicadores de integridad preservada de la piel mostraron diferencias intergrupales e intragrupales, con una mayor frecuencia de mejores medias GI en comparación con CG $(\mathrm{p}<0.05)$. Para la sensibilidad variable, las deformidades anatómicas y la temperatura de los pies, no se observaron diferencias ( $p>0.05)$, así como para los indicadores de condición vascular / arterial ( $p>0.05)$, excepto los pulsos $(\mathrm{p}<0.05)$. Con respecto a la clasificación de riesgo del pie diabético, GI presentó diferencia intragrupo entre $\mathrm{T} 1$ у $\mathrm{T} f u$ у $\mathrm{T} 2$ y $\mathrm{T} f u(\mathrm{p}<0.05)$. El conocimiento sobre las actividades de autocuidado del pie en ambos grupos se consideró "bajo" en T1 y después de las intervenciones educativas, el IG presentó una diferencia en comparación con el CG en T2 y $\mathrm{T} f u$ y también en la intención de cuidar los pies $(\mathrm{p}<0,05)$. Las intervenciones educativas basadas en la metodología del Arco de Magueres fueron efectivas para mejorar el riesgo de pie diabético, atribuido principalmente a indicadores relacionados con afecciones dermatológicas, y también a las variables conocimiento de las actividades de autocuidado e intención de cuidar los pies. 
Palabras clave: Diabetes Mellitus tipo 2. Pie diabético. Educación en salud. Arco Charles Maguerez. Ensayo clínico. 


\section{LISTA DE ILUSTRAÇÕES}

Figura 1 - Método do Arco de Charles Maguerez....................................................... 39

Figura 2 - Teoria do Comportamento Planejado...................................................... 51

Quadro 1 - Intervenção "Ensino do Cuidado com os Pés" por meio do Arco de Maguerez...................................................................................... 72

Figura 3 - Esquematização do estudo................................................................ 76

Figura 4 - Fluxograma dos participantes em cada etapa do estudo............................. 82 


\section{LISTA DE TABELAS}

Tabela 1 - Caracterização dos participantes em relação a frequência das variáveis sexo, estado civil e escolaridade. Boa Esperança, 2019.

Tabela 2 - Caracterização dos participantes em relação a média e desvio padrão das variáveis idade, renda familiar e número de residentes em casa. Boa Esperança, 2019.

Tabela 3 - Caracterização dos participantes em relação a média e desvio padrão das variáveis peso, altura e IMC. Boa Esperança, 2019

Tabela 4 - Caracterização dos participantes em relação a frequência das variáveis tabagismo, consumo de bebidas alcoólicas, frequência do consumo de bebidas alcoólicas, exercícios físicos e frequência dos exercícios físicos.

Boa Esperança, 2019

Tabela 5 - Caracterização dos participantes em relação a frequência das variáveis uso de antidiabéticos orais, uso de insulina, uso de antidiabéticos orais e insulina, tipo de antidiabético oral, tipo de insulina, hipertensão arterial sistêmica, outras doenças associadas, dificuldade visual, história de úlceras e grau de dor ou desconforto nos MMII. Boa Esperança, 2019.......

Tabela 6 - Caracterização dos participantes em relação a média e desvio padrão da variável glicemia capilar nos tempos T1, T2 e Tfu. Boa Esperança, 2019...

Tabela 7 - Caracterização dos participantes em relação a média e desvio padrão da variável glicemia capilar ao considerar os tempos T1 e T2, T1 e Tfu e T2 e Tfu. Boa Esperança, 2019

Tabela 8 - Caracterização dos participantes em relação a frequência das variáveis avaliação prévia dos pés por um profissional de saúde, orientações prévias sobre o cuidado com os pés e realiza autocuidado com os pés. Boa Esperança, 2019.....

Tabela 9 - Resultado da análise intergrupo referente a integridade da pele preservada. Boa Esperança, 2019.

Tabela 10 - Resultado da análise intragrupo da integridade da pele preservada ao considerar os tempos T1 e T2, T1 e Tfu e T2 e Tfu. Boa Esperança, 2019..

Tabela 11 - Resultado da análise intergrupo referente a presença de lesões 
esfoliativas. Boa Esperança, 2019

Tabela 12 - Resultado da análise intragrupo da presença de lesões esfoliativas ao considerar os tempos T1 e T2, T1 e T fu e T2 e Tfu. Boa Esperança, 2019..

Tabela 13 - Resultado da análise intergrupo referente a presença de micose. Boa Esperança, 2019

Tabela 14 - Resultado da análise intragrupo da presença de micose ao considerar os tempos T1 e T2, T1 e Tfu e T2 e Tfu. Boa Esperança, 2019.

Tabela 15 - Resultado da análise intergrupo referente a presença de calosidades nos pés. Boa Esperança, 2019.

Tabela 16 - Resultado da análise intragrupo da presença de calosidades ao considerar os tempos T1 e T2, T1 e Tfu e T2 e T $f u$. Boa Esperança, 2019.

Tabela 17 - Resultado da análise intergrupo referente a presença de pelos nas pernas. Boa Esperança, 2019.

Tabela 18 - Resultado da análise intragrupo da variável presença de pelos nas pernas ao considerar os tempos T1 e T2, T1 e Tfu e T2 e Tfu. Boa Esperança, 2019.

Tabela 19 - Resultado da análise intergrupo referente a presença de pele hidratada. Boa Esperança, 2019

Tabela 20 - Resultado da análise intragrupo da variável presença de pele hidratada ao considerar os tempos T1 e T2, T1 e Tfu e T2 e Tfu. Boa Esperança, 2019..

Tabela 21 - Resultado da análise intergrupo referente a presença de xerodermia. Boa Esperança, 2019.

Tabela 22 - Resultado da análise intragrupo da xerodermia ao considerar os tempos T1 e T2, T1 e Tfu e T2 e Tfu. Boa Esperança, 2019.

Tabela 23 - Resultado da análise intergrupo referente a presença de fissura (rachadura). Boa Esperança, 2019.

Tabela 24 - Resultado da análise intragrupo da presença de fissura (rachadura) ao considerar os tempos T1 e T2, T1 e Tfu e T2 e Tfu. Boa Esperança, 2019..

Tabela 25 - Resultado da análise intergrupo referente a presença de corte correto das unhas. Boa Esperança, 2019.

Tabela 26 - Resultado da análise intragrupo da presença de corte correto das unhas ao considerar os tempos T1 e T2, T1 e Tfu e T2 e Tfu. Boa Esperança, 2019.. 
Tabela 27 - Resultado da análise intergrupo referente a presença de umidade nos espaços interdigitais. Boa Esperança, 2019

Tabela 28 - Resultado da análise intragrupo da presença de umidade nos espaços interdigitais ao considerar os tempos $\mathrm{T} 1$ e $\mathrm{T} 2$, T1 e $\mathrm{T} f u$ e $\mathrm{T} 2$ e $\mathrm{T} f u$. Boa Esperança, 2019

Tabela 29 - Resultado da análise intergrupo referente a presença de maceração nos espaços interdigitais. Boa Esperança, 2019.

Tabela 30 - Resultado da análise intragrupo da presença de maceração nos espaços interdigitais ao considerar os tempos $\mathrm{T} 1$ e $\mathrm{T} 2$, $\mathrm{T} 1$ e $\mathrm{T} f u$ e $\mathrm{T} 2$ e $\mathrm{T} f u$. Boa Esperança, 2019

Tabela 31 - Resultado da análise intergrupo referente a presença de sensibilidade tátil pressórica alterada. Boa Esperança, 2019

Tabela 32 - Resultado da análise intergrupo referente a presença de percepção vibratória alterada. Boa Esperança, 2019

Tabela 33 - Resultado da análise intergrupo referente a presença de reflexo tendíneo alterado. Boa Esperança, 2019

Tabela 34 - Resultado da análise intergrupo referente a presença de deformidades em garras. Boa Esperança, 2019.

Tabela 35 - Resultado da análise intergrupo referente a presença de deformidades em martelo. Boa Esperança, 2019

Tabela 36 - Resultado da análise intergrupo referente a presença de hálux valgo. Boa Esperança, 2019

Tabela 37 - Resultado da análise intergrupo referente a presença de artropatia de Charcot. Boa Esperança, 2019

Tabela 38 - Resultado da análise intergrupo referente a presença de edema. Boa Esperança, 2019

Tabela 39 - Resultado da análise intragrupo da presença de edema ao considerar os tempos T1 e T2, T1 e Tfu e T2 e Tfu. Boa Esperança, 2019

Tabela 40 - Resultado da análise intergrupo referente a presença de varizes. Boa Esperança, 2019

Tabela 41 - Resultado da análise intragrupo referente a presença de varizes considerando os tempos T1 e T2, T1 e Tfu e T2 e Tfu. Boa Esperança, 
2019.

Tabela 42 - Resultado da análise intergrupo referente ao pulso tibial esquerdo. Boa Esperança, 2019

Tabela 43 - Resultado da análise intragrupo do pulso tibial esquerdo ao considerar os tempos T1 e T2, T1 e Tfu e T2 e Tfu. Boa Esperança, 2019

Tabela 44 - Resultado da análise intergrupo referente ao pulso tibial direito. Boa Esperança, 2019

Tabela 45 - Resultado da análise intragrupo do pulso tibial direito ao considerar os tempos T1 e T2, T1 e Tfu e T2 e Tfu. Boa Esperança, 2019

Tabela 46 - Resultado da análise intergrupo referente ao pulso pedioso esquerdo. Boa Esperança, 2019

Tabela 47 - Resultado da análise intragrupo do pulso pedioso esquerdo ao considerar os tempos T1 e T2, T1 e Tfu e T2 e Tfu. Boa Esperança, 2019

Tabela 48 - Resultado da análise intergrupo referente ao pulso pedioso direito. Boa Esperança, 2019

Tabela 49 - Resultado da análise intragrupo do pulso pedioso direito ao considerar os tempos T1 e T2, T1 e Tfu e T2 e Tfu. Boa Esperança, 2019

Tabela 50 - Resultado da análise intergrupo referente a temperatura dos pés. Boa Esperança, 2019

Tabela 51 - Resultado da análise intragrupo da temperatura dos pés ao considerar os tempos T1 e T2, T1 e Tfu e T2 e Tfu. Boa Esperança, 2019

Tabela 52 - Resultado da análise intergrupo referente a classificação do risco de pé diabético. Boa Esperança, 2019

Tabela 53 - Resultado da análise intragrupo da classificação do risco de pé diabético ao considerar os tempos T1 e T2, T1 e Tfu e T2 e Tfu. Boa Esperança, 2019.

Tabela 54 - Resultado da análise intergrupo referente ao conhecimento das atividades de autocuidado com os pés. Boa Esperança, 2019

Tabela 55 - Resultado da análise intragrupo do conhecimento das atividades de autocuidado com os pés ao considerar os tempos T1 e T2, T1 e Tfu e T2 e Tfu. Boa Esperança, 2019

Tabela 56 - Resultado da análise intergrupo referente a intenção de cuidar dos pés. 
Boa Esperança, 2019.

Tabela 57 - Resultado da análise intragrupo da intenção de cuidar dos pés ao considerar os tempos T1 e T2, T1 e Tfu e T2 e Tfu. Boa Esperança, 2019.. 115 


\section{LISTA DE ABREVIATURAS E SIGLAS}

\begin{tabular}{|c|c|}
\hline ADA & American Diabetes Association \\
\hline CEP & Comitê de Ética em Pesquisa \\
\hline COFEN & Conselho Federal de Enfermagem \\
\hline DALY & Disability Adjusted Life of Years \\
\hline DAOP & Doença Arterial Obstrutiva Periférica \\
\hline DCCT & Diabetes Control and Complications Trial Research Group \\
\hline DCNT & Doenças Crônicas Não Transmissíveis \\
\hline DM & Diabetes Mellitus \\
\hline DM1 & Diabetes Mellitus tipo 1 \\
\hline DM2 & Diabetes Mellitus tipo 2 \\
\hline ESF & Estratégia de Saúde da Família \\
\hline GC & Grupo Controle \\
\hline GI & Grupo Intervenção \\
\hline GT & Grupo Tratado \\
\hline HA & Hipertensão Arterial \\
\hline IDF & Internacional Diabetes Federation \\
\hline IMC & Índice de Massa Corporal \\
\hline MEEM & Mini-Exame do Estado Mental \\
\hline MMII & Membros Inferiores \\
\hline MS & Ministério da Saúde \\
\hline NANDA-I & North American Nursing Diagnosis Association \\
\hline NIC & Nursing Interventions Classification \\
\hline NOC & Nursing Outcomes Classification \\
\hline NPH & Neutral Protamine Hagedorn \\
\hline OMS & Organização Mundial de Saúde \\
\hline QCP-CP & $\begin{array}{l}\text { Questionário do Comportamento Planejado no Diabetes - Cuidado com os } \\
\text { Pés }\end{array}$ \\
\hline $\mathrm{R}$ & Insulina Regular \\
\hline SAE & Sistematização da Assistência de Enfermagem \\
\hline SUS & Sistema Único de Saúde \\
\hline
\end{tabular}


$\mathrm{T}$

Número de Repetições

TCLE Termo de Consentimento Livre e Esclarecido

TCP Teoria do Comportamento Planejado

TIC Tecnologias de Informação e Comunicação

Tfu Follow up

T1 Tempo 1

T2 Tempo 2

UKPDS UK Prospective Diabetes Study Group

UPD Úlcera de Pé Diabético 


\section{LISTA DE SÍMBOLOS}

$\begin{array}{ll}\rho & \text { Correlação assumida entre os tempos } \\ > & \text { Maior } \\ \geq & \text { Maior ou igual } \\ < & \text { Menor } \\ \leq & \text { Menor ou igual } \\ \mathrm{r} & \text { Razão assumida (1) entre os tamanhos das amostras dos grupos controle e } \\ & \text { experimental } \\ \sigma^{2} & \text { Variância da amostra (quadrado do desvio padrão) }\end{array}$




\section{SUMÁRIO}

$1 \quad$ INTRODUÇÃ

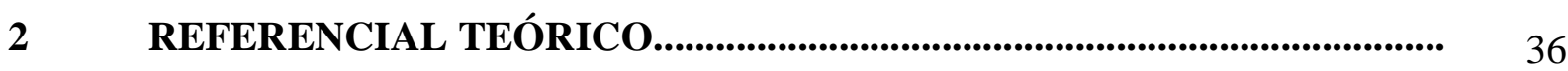

2.1 PRESSUPOSTOS TEÓRICOS PARA A IMPLEMENTAÇÃO DA EDUCAÇÃO EM SAÚDE...................................................................... 37

2.2 ENFERMAGEM NO PROCESSO DE ENSINO E CUIDADO...................... 41

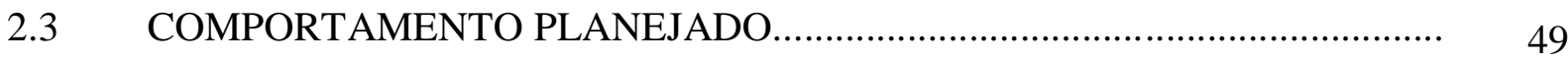

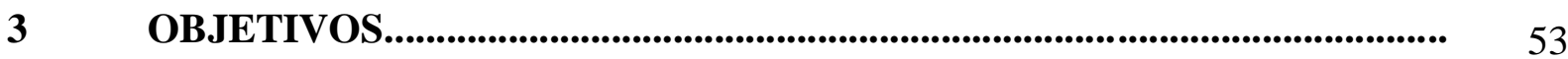

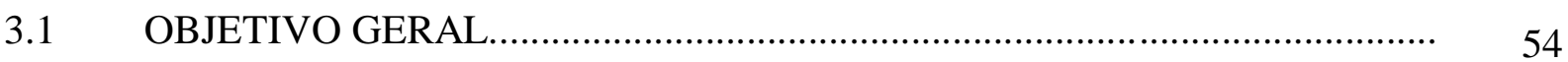

OBJETIVOS ESPECÍFICOS............................................................... 54

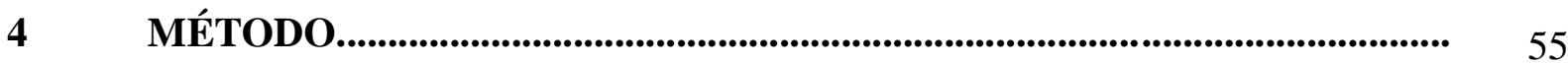

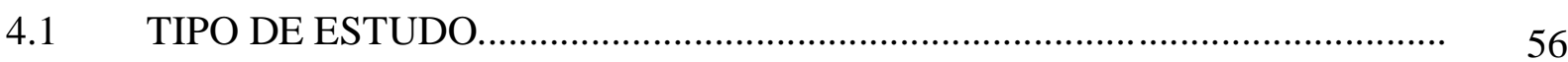

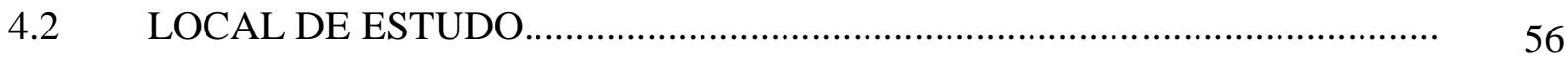

4.3 POPULAÇÃO E AMOSTRA.................................................................... 57

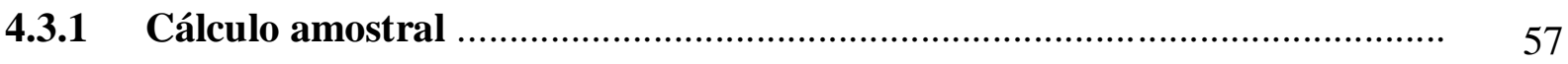

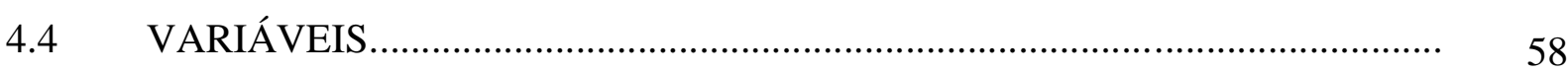

4.4.1 Variável independente........................................................................................... 58

4.4.2 Variáveis para caracterizar a amostra............................................................... 58

4.4.3 Variáveis para a classificação da integridade tissular....................................... 61

4.4.4 Variável conhecimento das atividades de autocuidado com os pés................ 63

4.4.5 Variável intenção de cuidar dos pés..................................................................... 63

4.5 INSTRUMENTOS DE COLETA DE DADOS ......................................... 63

4.6 RASTREAMENTO E RECRUTAMENTO DA AMOSTRA........................... 68 
4.6.1 Randomização............................................................................................................ 69

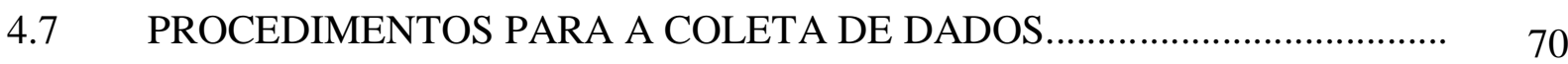

4.7.1 Estudo piloto.................................................................................................................. 70

4.7.2 Avaliação das variáveis do estudo.......................................................... 71

4.7.3 Intervenções................................................................................................................ 71

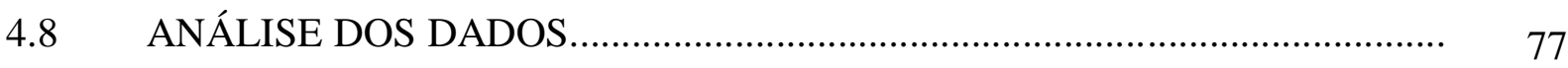

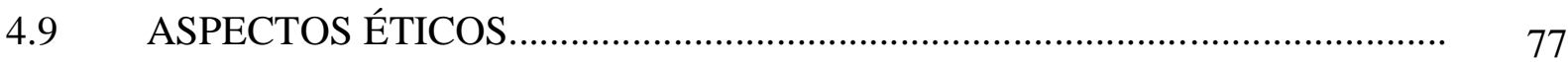

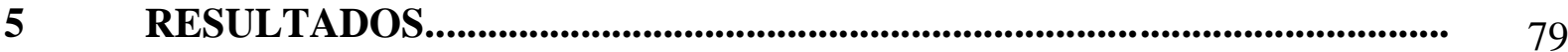

5.1 FLUXO DOS PARTICIPANTES EM CADA ETAPA DO ESTUDO............... 80

5.2 CARACTERIZAÇÃO DA AMOSTRA...................................................... 83

5.2.1 Caracterização da amostra quanto as variáveis sociodemográficas.............. 83

5.2.2 Caracterização da amostra quanto as variáveis antropométricas.................. 84

5.2.3 Caracterização da amostra quanto as variáveis hábitos de vida.................... 85

5.2.4 Caracterização da amostra quanto as variáveis clínicas.................................. 87

Caracterização da amostra quanto às informações complementares sobre cuidados com os pés................................................................................................... 89 DERMATOLÓGICAS) ........................................................................ 90

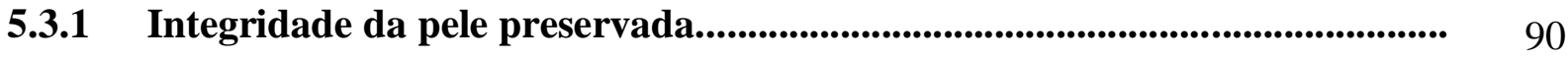

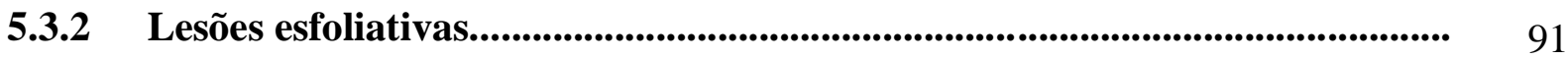

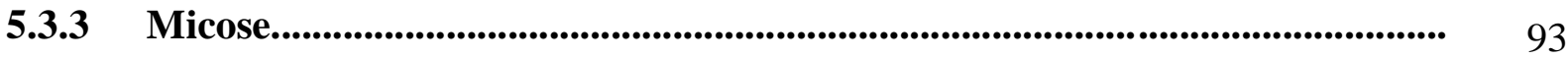

5.3.4 Calosidades..................................................................................................................... 94

5.3.5 Pilosidade.................................................................................................................. 95

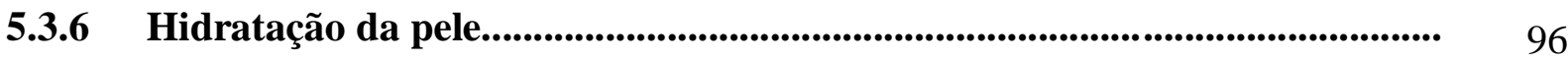


5.3.7 Xerodermia...................................................................................................... 97

5.3.8 Fissura (rachadura) ....................................................................................................... 98

5.3.9 Corte correto das unhas.................................................................................... 99

5.3.10 Umidade nos espaços interdigitais...................................................................... 100

5.3.11 Maceração nos espaços interdigitais................................................................ 102

5.4 SENSIBILIDADE

5.4.1 Sensibilidade tátil pressórica alterada................................................................... 103

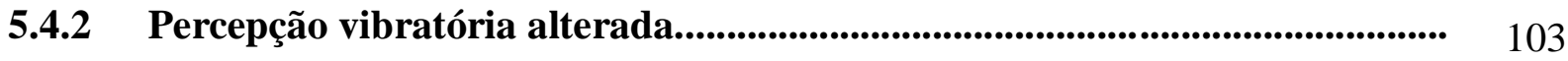

5.4.3 Reflexo tendíneo alterado.................................................................................. 104

5.5 DEFORMIDADES NOS PÉS................................................................ 104

5.5.1 Deformidades em garras.................................................................................. 104

5.5.2 Deformidades em martelo................................................................................... 105

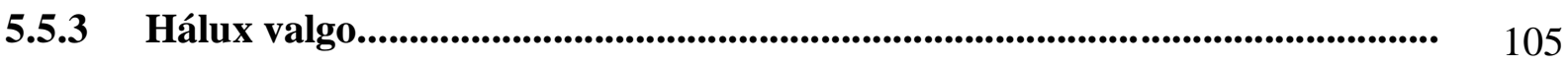

5.5.4 Artropatia de Charcot........................................................................................ 105

5.6 CONDIÇÕES VASCULARES/ARTERIAIS.................................................. 106

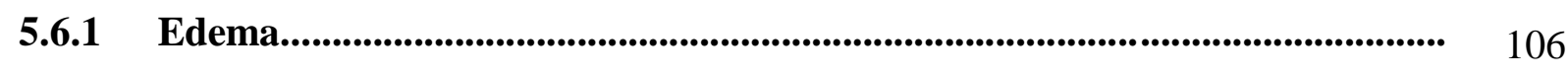

5.6.2 Varizes.......................................................................................................... 107

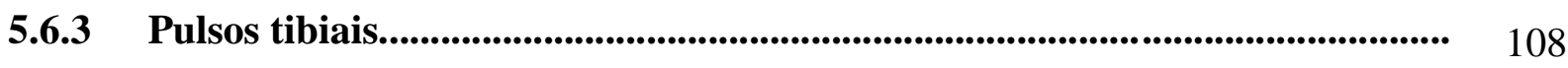

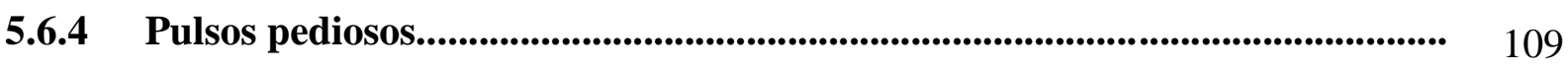

5.7 TEMPERATURA DOS PÉS................................................................. 111

5.8 CLASSIFICAÇÃO DO RISCO DE PÉ DIABÉTICO (RISCO DE INTEGRIDADE TISSULAR PREJUDICADA)............................................. 112

5.9 CONHECIMENTO DAS ATIVIDADES DE AUTOCUIDADO COM OS

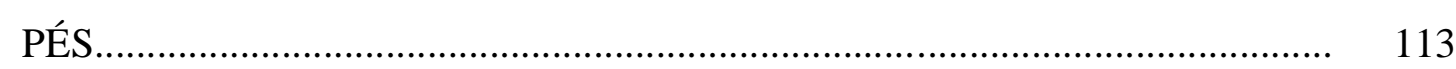


5.10 INTENÇÃO DE CUIDAR DOS PÉS..................................................... 114

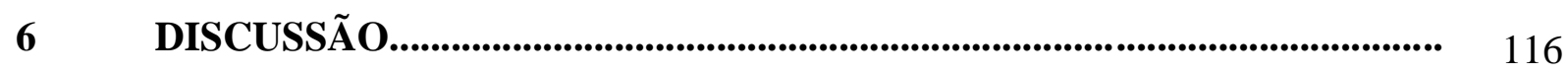

CARACTERIZAÇÃO DA AMOSTRA: VARIÁVEIS

6.1 SOCIODEMOGRÁFICAS, ANTROPOMÉTRICAS, HÁBITOS DE VIDA, CLÍNICAS E INFORMAÇÕES COMPLEMENTARES.................................. 117 INTEGRIDADE DA PELE E ANEXO, SENSIBILIDADE,

6.2 DEFORMIDADES ANATÔMICAS, CONDIÇÕES VASCULARES/ ARTERIAIS E TEMPERATURA DOS PÉS DE PESSOAS COM DM2.......... CONHECIMENTO DAS PESSOAS COM DM2 SOBRE AS ATIVIDADES

6.3 DE AUTOCUIDADO COM OS PÉS E INTENÇÃO DE REALIZAR O AUTOCUIDADO COM OS PÉS................................................................. 130

7 CONCLUSÕES................................................................................................... 134

$8 \quad$ LIMITAÇÕES DO ESTUDO.................................................................................... 137

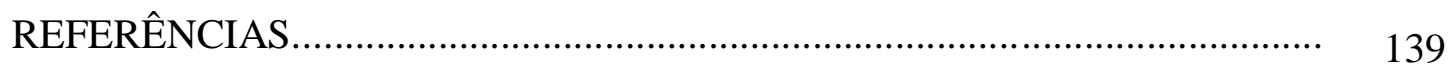

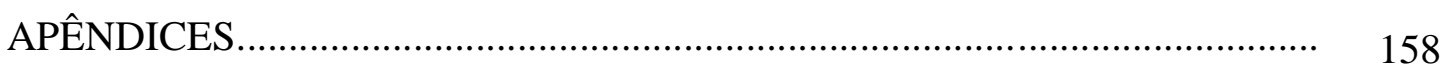

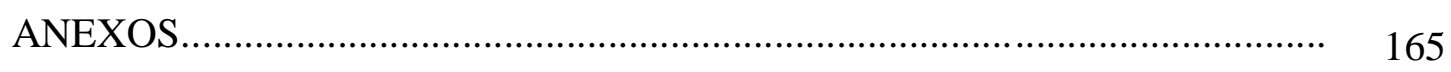



de 2009 
Seguindo uma tendência mundial do século passado, processos de transição produziram significativas alterações no perfil da população brasileira, bem como nas doenças que a acomete (ALVES, 2002). Uma delas é denominada transição demográfica, que proporcionou a transformação de uma sociedade antes tradicional, com numerosas famílias localizadas na zona rural e com risco de morte elevada na infância a uma sociedade predominantemente urbana, com arranjos familiares diversificados, redução do risco de morte na infância (ALVES, 2002; LEONE; MAIA; BALTAR, 2010), sucessivas quedas na natalidade e aumento da população em idades ativas e também idosos (VASCONCELOS; GOMES, 2012).

No processo de transição demográfica, destacam-se o aumento da longevidade, que impulsionou o envelhecimento acelerado da população, relacionado à melhora das condições de vida (AZAMBUJA et al., 2011), acesso a água tratada, rede de esgoto sanitário e ações de saúde pública (VASCONCELOS; GOMES, 2012).

As transformações demográficas, associadas às mudanças sociais e econômicas, contribuíram com o início de outro processo denominado de transição epidemiológica, que culminou no aumento da prevalência de doenças crônicas não transmissíveis (DCNTs) (OMRAM, 2001). Outro processo que colaborou com o aumento das DCNTs foi a transição nutricional, que compreendeu em alterações na estrutura da dieta da população (POPKIN, 2001), tais como, o consumo exagerado de ácidos graxos saturados e açucares, em detrimento de carboidratos complexos, principalmente entre os anos de 1988 e 1996 (MONTEIRO; MONDINI; COSTA, 2000).

O documento "World health statistics - 2018" publicado pela Organização Mundial de Saúde (OMS) destacou que as DCNTs de maior importância para o mundo são as doenças doenças do aparelho circulatório (cerebrovasculares, cardiovasculares), o câncer, o diabetes mellitus (DM) e as doenças crônicas respiratórias (WORLD HEALTH ORGANIZATION, 2018). O estudo sobre a carga de doenças no Brasil mostrou que no ano de 1998 o DM ocupou o primeiro lugar no ranking das principais causas do indicador DALY (Disability Adjusted Life of Years-Anos de Vida Perdidos Ajustados por Incapacidade) (SCHRAMM et al. 2004). O DALY estimado para o Brasil em 2008 apresentou resultados que enfatizam maior carga de doenças no Norte e Nordeste e predomínio das DCNTs nas demais regiões do país, com destaque para as doenças cardiovasculares, os transtornos mentais, o DM e a doença pulmonar obstrutiva crônica. O DM variou entre a quarta e a sexta posições no ranking das causas de cargas de doenças, a depender da região (LEITE et al., 2015). 
De acordo com Malta e colaboradores (2019), a prevalência do DM está associada com o aumento da idade (19,8\% - 18,2-21,4 anos), menor escolaridade (9,6\% - 8,9-10,3 anos de escolaridade), hipertensão arterial (HA) (18,3\% dos participantes do estudo (IC=17-19,5)), colesterol elevado (18,5\% dos participantes do estudo (IC=16,9-20,1)) (MALTA et al., 2019), sobrepeso e obesidade (11,8\% dos participantes do estudo ( $\mathrm{IC}=10,4-13,1)$ ) (MALTA et al., 2019; SARTORELLI; FRANCO, 2003). Sartorelli e Franco (2003) destacam ainda que 80 a 90\% das pessoas acometidas por esta doença são obesas.

No ano de 2013, estimava-se que a população mundial com DM fosse de 382 milhões de pessoas, cuja perspectiva era atingir 592 milhões em 2035 (GUARIGUATA et al., 2014). Em publicação da Internacional Diabetes Federation (IDF) no ano de 2017, havia uma estimativa de que 425 milhões de pessoas no mundo possuíam o diagnóstico da doença, com probabilidade de alcançar 629 milhões em 2045 (INTERNACIONAL DIABETES FEDERATION, 2017).

No Brasil, estimava-se que 14,3 milhões de pessoas possuíam DM no ano de 2015, com tendência de aumento para 23,3 milhões em 2040 (INTERNACIONAL DIABETES FEDERATION, 2015). Em 2017, estimou-se que 12,5 milhões de pessoas na faixa etária de 20 a 79 anos tinham DM, mantendo o país no quarto lugar da classificação de países com mais casos da doença (INTERNACIONAL DIABETES FEDERATION, 2017).

A tendência de crescimento das taxas de DM no Brasil pode ser observada por meio dos estudos epidemiológicos nacionais. O primeiro trata-se do estudo multicêntrico desenvolvido em nove capitais brasileiras, que encontrou uma taxa média brasileira de 7,5\% de homens e 7,6 de mulheres com DM (MALERBI; FRANCO, 1992). A seguir, dois estudos realizados na cidade de Ribeirão Preto, estado de São Paulo, mostraram, respectivamente 12,1\% (TORQUARTO et al., 2003) e 15,02\% (MORAES et al., 2010).

No Nordeste do país, no Maranhão, especificamente na cidade de Caxias, foi desenvolvido um estudo epidemiológico descritivo e retrospectivo, com o objetivo descrever o perfil epidemiológico do DM, identificou 568 novos casos de DM no município, sendo 87,8\% (n=498) tipo 2 (MAGALHÃES et al., 2017).

$\mathrm{Na}$ mesma região, em Alagoas, na cidade de Maceió, foi desenvolvido um estudo epidemiológico exploratório com o objetivo de analisar e descrever o perfil epidemiológico de pessoas com DM avaliados nas ações de saúde desenvolvidas pelos cirurgiões vasculares entre os anos de 2016 e 2017. Os resultados foram extraídos de um banco de dados de 
domínio público e apontaram 112 casos de DM, com um maior número de registro no ano de 2016, 58 (51,78\%) casos e no ano de 2017, 54 (48,22\%) (SANTOS et al., 2018).

O estudo realizado pelo sistema de Vigilância de Doenças Crônicas por Inquérito Telefônico - Vigitel Brasil, desenvolvido nas capitais brasileiras, aponta que a frequência de adultos que referiram diagnóstico médico de DM no ano de 2018 variou de 5,2\% em Rio Branco a 9,8\% no Rio de Janeiro (BRASIL, 2019).

Além da tendência de aumento da taxa de DM, destaca-se que a doença está entre as principais causas de morte no mundo (GUARIGUATA et al., 2014). Um compilado descrito por especialistas aponta que no Brasil a mortalidade pela doença afeta 130.700 pessoas por ano, configurando um sério problema de saúde pública (INTERNACIONAL DIABETES FEDERATION, 2015).

O estudo desenvolvido com o objetivo de comparar os indicadores de saúde entre os anos de 1990 e 2015, por meio das estimativas do estudo de Carga Global de Doença, apresentou um aumento de 12,6\% na taxa de mortalidade por DM no Brasil. O estudo aponta que o DM passou da sétima para a quinta posição no ranking das principais causas de mortalidade entre os anos de 1990 a 2015 (SOUZA et al., 2018).

No Sudeste do país, Estado de Minas Gerais, cidade de Montes Claros, foi realizado um estudo transversal, de análise longitudinal retrospectivo, com dados secundários do DATASUS, com o objetivo de conhecer o perfil de morbimortalidade por DM e analisar o comportamento da cobertura da Estratégia da Família (ESF) no período de 2000 a 2015. Os resultados apresentam um padrão de estabilidade na mortalidade por DM no município com algumas pequenas oscilações, 13,42\% no ano de 2000 e 13,58\% em 2014 e maior discrepância no ano de 2010 com uma taxa de 17,96\% (FERNANDES et al., 2018). No mesmo período, o Estado de Minas Gerais apresentou grandes variações com aumento significativo na taxa de mortalidade por DM, passando de 18,27\% em 2000 para 24,66\% em 2014 (FERNANDES et al., 2018).

As complicações crônicas representam as principais causas de morbidade e mortalidade das pessoas com DM (BRASIL, 2011; GROSS; NEHME, 1999; INTERNACIONAL DIABETES FEDERATION, 2015).

Conforme evidenciado em estudos o controle glicêmico é fundamental na prevenção e/ou retardo de complicações crônicas (DIABETES CONTROL AND COMPLICATIONS TRIAL RESEARCH GROUP, 1993; UK PROSPECTIVE DIABETES STUDY GROUP - 33, 1998). Vale lembrar que a definição clássica do DM traz que se trata de um grupo de doenças 
metabólicas que tem como característica comum a hiperglicemia, resultante da deficiência na secreção ou ação da insulina (THE EXPERT COMMITTEE ON THE DIAGNOSIS AND CLASSIFICATION OF DIABETES MELLITUS, 1997).

O ensaio clínico multicêntrico desenvolvido pelo Diabetes Control and Complications Trial Research Group (DCCT) (DIABETES CONTROL AND COMPLICATIONS TRIAL RESEARCH GROUP, 1993) com o objetivo de identificar se o tratamento intensivo para manter as concentrações de glicose no sangue próximas à faixa normal, poderia diminuir a frequência e a gravidade das complicações neurológicas e microvasculares, junto a norteamericanos diagnosticados com DM tipo 1, apresentou como resultados a redução da incidência e da progressão de complicações como a retinopatia, a nefropatia e a neuropatia.

Outro ensaio clínico desenvolvido pelo UK Prospective Diabetes Study Group (UKPDS) (UK PROSPECTIVE DIABETES STUDY GROUP - 33, 1998), com o objetivo de fornecer diretrizes para o gerenciamento do diabetes tipo 2 (DM2), junto a uma amostra do Reino Unido, demonstrou como resultados que o controle glicêmico diminuiu os riscos de complicações microvasculares.

No sul do Brasil, em Santa Catarina, Florianópolis, foi desenvolvido um estudo descritivo de corte transversal, com o objetivo de descrever o perfil epidemiológico e o estado nutricional de hipertensos e diabéticos cadastrados na atenção básica, mostrou que 9,2\% das pessoas entrevistadas tinham diagnóstico de DM autorreferido e 28,5\% tinham a doença associada à HA (FAGUNDES; CORSO; GONZÁLEZ-CHICA, 2017).

As doenças crônicas associadas ao DM estão agrupadas em dois principais grupos, as doenças microvasculares $\mathrm{e}$ as macrovasculares (SOCIEDADE BRASILEIRA DE DIABETES, 2017; WORLD HEALTH ORGANIZATION, 1999). As microvasculares compreendem a nefropatia, a retinopatia e a neuropatia diabéticas. As lesões nos grandes vasos correspondem às macrovasculares, responsáveis pela doença vascular periférica, infarto agudo do miocárdio e acidente vascular encefálico (UK PROSPECTIVE DIABETES STUDY GROUP- 38, 1998; TSCHIEDEL, 2014). Destacam-se também as complicações dermatológicas, que abrangem infecções cutâneas superficiais ou profundas, infeções secundárias, úlceras neurotróficas, úlceras microangiopáticas, entre outras (HUNTLEY, 1986; SIBBALD, 1984; MINELLI et al., 2003).

No presente estudo, destaca-se a condição clínica denominada "pé diabético", determinada, prioritariamente, pela neuropatia diabética e doença vascular periférica, a qual se caracteriza pela presença de infecção, ulceração e/ou destruição de tecidos profundos 
(GRUPO DE TRABALHO INTERNACIONAL SOBRE PÉ DIABÉTICO, 2001), e pode apresentar como desfecho final a amputação de parte ou todo o membro inferior acometido. Esta condição é considerada relevante para a saúde pública pelos danos pessoais/familiares e ônus financeiro ao sistema de saúde (CAIAFA et al., 2011, SOCIEDADE BRASILEIRA DE DIABETES, 2017).

A neuropatia diabética conduz as alterações estruturais e funcionais de fibras nervosas sensitivas, motoras e autonômicas, de caráter reversível ou permanente. A mais comum é a polineuropatia sensitivo-motora periférica, que pode acometer fibras finas, grossas ou mistas e apresentar sinais e sintomas como parestesia, dor nas pernas e nos pés, hiperestesia, diminuição ou perda da sensibilidade tátil, térmica ou dolorosa, perda dos reflexos tendinosos profundos, úlceras nos pés (TSCHIEDEL, 2014), perda da motricidade distal, variação da atrofia muscular e da anatomia (NEWRICK et al., 2000). Já a neuropatia autonômica é caracterizada pela diminuição do diâmetro pupilar, disfunção sudomotora, cardiovascular e metabólica, entre outras, e podem resultar em ressecamento e fissuras na pele (TSCHIEDEL, 2014).

A doença vascular periférica nos membros inferiores ocorre devido aos danos no endotélio e nas pequenas artérias dos troncos arteriais, os quais desencadeiam a doença arterial obstrutiva periférica (DAOP), caracterizada pela obstrução aterosclerótica progressiva das artérias dos membros inferiores (WILLIAMS; PRICE; HARDING, 2006; VIRGINIMAGALHÃES; BOUSKELA, 2008). A vasoconstrição se sobrepõe a vasodilatação, o que favorece a perda do controle vasomotor, alteração da relação endotélio e célula sanguínea, principalmente das plaquetas e dos leucócitos e espessamento do endotélio vascular (VIRGINI-MAGALHÃES; BOUSKELA, 2008). A degeneração da circulação torna a cicatrização ineficiente (NEWRICK et al., 2000).

O estudo multicêntrico nacional de Parisi et al. (2016) mostrou os fatores que influenciam o risco de úlcera e amputação entre as pessoas com DM e destaca que para o desenvolvimento de úlcera, a maior chance de ocorrência está na situação clínica denominada "pé neuroisquêmico" (OR=20,34 - CI 9,31; 44,38), enquanto que para a amputação encontrase na situação clínica denominada "pé isquêmico" (OR=19,63 - CI 3,43; 112,5). Dados estes reiteram a importância da neuropatia no desfecho de úlcera e a isquemia no mau prognóstico de sua evolução (PARISI et al., 2016).

As situações clínicas dermatológicas podem ocorrer em consequência das outras complicações, tais como úlcera neurotrófica plantar provocadas pela neuropatia e formação de 
calosidades que precedem as fissuras (SAYE, 1994), úlcera microangiopática, originada da disfunção de pequenos vasos (SAYE, 1994; MINELLI et al.,, 2003), lesões isquêmicas por arteriopatia troncular causada pela doença arteriosclerótica (JELINEK, 1994; MINELLI et al.,, 2003) e infecções superficiais e profundas que podem se desenvolver por meio de fungos e bactérias, principalmente devido a umidade interdigitais e a ocorrência de lesões (SIBBALD, 1984; MINELLI et al.,, 2003). De acordo com Minelli e colaboradores (2003), mais da metade das complicações dermatológicas poderiam ser evitadas mediante cuidados apropriados com os pés.

Gamba e colaboradores (2004) destacam que a retinopatia e a nefropatia diabética, as quais são responsáveis por distúrbios visuais, edema generalizado e outros comprometimentos, também implicam na deficiência do autocontrole, tratamento e cuidados com os pés pelas pessoas com diagnóstico de DM, o que as tornam mais expostas ao risco de ulceração cutânea de extremidades inferiores.

As úlceras de membros inferiores em pessoas com DM constituem situações clínicas complexas, onerosas e, muitas vezes, incapacitantes, principalmente pela predisposição à amputação. A prevalência e a incidência das úlceras de MMII são mais elevadas do que as outras morbidades do DM (ARMSTRONG et al., 2011).

Nos Estados Unidos, por exemplo, 3\% da população tem DM, 1 a $4 \%$ desenvolvem úlceras nos pés uma vez por ano, $15 \%$ uma vez na vida e mais de $50 \%$ são submetidas à amputação de MMII (LEE et al., 2013). Ainda, estima-se que 50\% das pessoas com DM morrerão dentro de cinco anos após a primeira amputação e, entre um a três anos, 30 a 50\% dos que realizaram amputação, necessitarão de amputações secundárias (ARMSTRONG et al., 2011).

No Sul do Brasil, estado do Paraná, em Londrina, foi desenvolvido um estudo transversal descritivo-exploratório, com o objetivo de analisar as implicações do autocuidado nos fatores de risco de ulceração nos pés de pessoas com DM, relacionados às alterações dermatológicas, ortopédicas, neurológicas e vasculares. Os resultados apontaram que 12,3\% da população estudada apresentava pé com risco de ulceração, predominando alterações grau $2(7,1 \%)$, seguido por grau $1(3,5 \%)$ e grau $3(1,7 \%)$ (SMANIOTO; HADDAD; ROSSANEIS, 2014).

Em Piauí, Teresina, um estudo epidemiológico transversal, analítico, com o objetivo de analisar a prevalência de lesão por pressão, úlcera diabética e vasculogênica, realizado nos 
serviços de atenção básica com 339 idosos, demonstrou que 25,9\% amostra do estudo apresentavam úlceras diabéticas, sendo 80\% em região plantar (VIEIRA; ARAÚJO, 2018).

Apesar da complexidade das úlceras é possível preveni-las com cuidados básicos e de baixo custo (OCHOA-VIGO; PACE, 2005) e intervenções educativas são destacadas entre os cuidados a pessoa com DM para o controle da doença e prevenção das complicações agudas e crônicas advindas, principalmente, do seu mau controle.

Na região sudeste, em São Paulo, Ribeirão Preto foi desenvolvido um ensaio clínico randomizado com 164 pessoas com DM e com o objetivo de avaliar a contribuição do apoio social familiar por meio de intervenções educativas. Os resultados mostraram que o grupo intervenção apresentou diferenças na pressão arterial sistêmica e hemoglobina glicada quando comparado ao grupo controle (GOMES et al., 2017).

A educação em saúde é uma estratégia para o ensino do autocuidado da pessoa com o DM, uma vez que seus objetivos principais englobam a sensibilização e a motivação para as mudanças e atitudes pessoais necessárias com a doença (PEREIRA, 2003). Para implementar a educação em saúde, é fundamental escolher a estratégia pedagógica que melhor se adequa a uma determinada situação e grupo de pessoas.

Estudos apresentam estratégias de ensino para o autocuidado com o DM (GOMES et al., 2017; PEREIRA et al., 2012; MENEZES, 2016; MAKKIAWOUDA; ELMUKASHFI; AL-TOM, 2014), contudo, não há um padrão estabelecido como o melhor método de ensinar o autocuidado mediante o resultado pretendido, que no presente estudo trata-se de manter a integridade tissular de um grupo de pessoas com DM.

O método de ensino deve ser capaz de proporcionar a compreensão da realidade, a intervenção crítica e a disposição para transformá-la (BERBEL, 1998; FREITAS, 2012). Entre os métodos de ensino que oferece essa abrangência, destacam-se os referenciais educacionais baseados na problematização, que possibilitam estimular o potencial político, social e ético dos educandos, uma vez que estes são conduzidos a observar a realidade, identificar os problemas e transforma-los a partir da criatividade que envolve ação-reflexão sobre um aspecto da prática observado (BERBEL; GAMBOA, 2012).

A primeira referência para a Metodologia da Problematização é o Método do Arco, de Charles Maguerez (BORDENAVE; PEREIRA, 1982), representado pelas seguintes etapas: Observação da Realidade; Pontos-Chave; Teorização; Hipóteses de Solução e Aplicação à Realidade (BORDENAVE; PEREIRA, 1982; BERBEL, 1996). 
Nesta perspectiva, o ensaio clínico randomizado de Pereira et al. (2012), desenvolvido em amostra constituída por 62 pessoas com DM2 cadastradas em um serviço de referência para o tratamento da HA, identificou que, após a aplicação da intervenção, no grupo intervenção (GI), o conhecimento sobre o DM aumentou significativamente. A intervenção foi realizada em 12 encontros durante seis meses, e utilizada a metodologia problematizadora proposta por Freire (2002), a qual postula que o aprendizado deve estar relacionado à conscientização de uma situação real vivida pelo educando, permeada pelo protagonismo e pelo trabalho em grupo (PEREIRA et al., 2012).

No nordeste, Estado do Ceará, no município de Fortaleza foi realizado um ensaio clínico com o objetivo de avaliar os efeitos do filme educativo de curta-metragem para a habilidade do autocuidado na prevenção do pé diabético. Foram recrutadas 82 pessoas com DM2 de seis unidades básicas de saúde. O grupo controle (GC) $(n=39)$ recebeu orientações por meio de uma palestra educativa e o GI $(n=43)$, assistiu ao filme em dois momentos, que contou com cenas fictícias para a aproximação da realidade dos expectadores. De acordo com Menezes (2016), o filme contribuiu para efetivar a ação educativa e desenvolver atitudes que possibilitam o autocuidado, o que favorece a compreensão do pé diabético como uma grave situação clínica da pessoa com DM. Como resultados do estudo, destaca-se que a adequação das habilidades do autocuidado com os pés, o que contribuiu para o aumento do conhecimento sobre a doença, sobre os cuidados adequados com os pés e na melhora das habilidades do autocuidado, com consequente prevenção de complicações plantares (MENEZES, 2016).

Ao considerar que o autocuidado é um dos fatores fundamentais para a prevenção de lesões nos pés de pessoas com DM (ANDRADE et al., 2010), é necessário que este comportamento seja incorporado no cotidiano das pessoas por meio do conhecimento sobre a prevenção das úlceras de pé diabético (UPD) e cuidados com os pés (MONTEIRO, 2015).

No Sudão, na cidade de Cartum, MakkiAwouda e colaboradores (2014) desenvolveram um estudo quase experimental do tipo pré e pós-intervenção, com o objetivo de avaliar o conhecimento de 152 pessoas com DM antes e após um programa de educação em saúde. O programa foi desenvolvido individualmente, por meio de consultas e ligações telefônicas por um período de três meses. O propósito do estudo era a prevenção e o manejo do pé em risco neuropático. Os resultados apresentaram melhora estatística significativa no conhecimento sobre a doença, sobre as complicações e sobre os cuidados com os pés após a atividade educativa (MAKKIAWOUDA; ELMUKASHFI; AL-TOM, 2014). 
No que se refere aos programas de prevenção e cuidados com os pés, o que inclui a educação para o desenvolvimento de habilidades para o autocuidado de pessoas com DM, destaca-se, particularmente, o papel do enfermeiro (MOREIRA, 2017). Assim, na busca da consolidação do conhecimento técnico científico para alicerçar o desenvolvimento profissional, o enfermeiro tem utilizado os sistemas de classificação (CORDOVA et al., 2010), para os diagnósticos (North American Nursing Diagnosis Association - NANDA-I), resultados esperados (Nursing Outcomes Classification, NOC) e intervenções de enfermagem (Nursing Interventions Classification, NIC) (LUNNEY, 2006).

A partir da prática clínica, para o presente estudo, foi determinado o diagnóstico de enfermagem "Risco de integridade tissular prejudicada (00248)", mediante as condições associadas que podem ser identificadas nas pessoas com DM, tais como circulação prejudicada, estado nutricional desequilibrado, alteração no metabolismo, alteração na sensibilidade e neuropatia periférica (HERDMAN; KAMITSURU, 2018).

A intervenção de enfermagem estabelecida pela NIC, mediante o diagnostico determinado seria "Ensino: cuidados com os pés (5603)", (BULECHECK et al., 2016), contudo, devido a falta de especificidade para as pessoas com DM, a intervenção da NIC e outras recomendadas pela literatura para a prevenção das úlceras plantares passaram por um processo de refinamento, o que deu origem a intervenção "Ensino do cuidado com os pés" (MONTEIRO et al., 2015a).

O presente estudo destaca a intervenção de enfermagem "Ensino do cuidado com os pés", e pretende contribuir para a prevenção de agravos relacionados ao risco de integridade tissular prejudicada dos pés das pessoas com DM2, por meio da metodologia de ensino da Problematização apoiada pelo Arco de Maguerez. A principal justificativa baseia-se no fato de que a lesão plantar pode evoluir para um quadro de maior gravidade e como consequência, acarretar limitações e/ou incapacidades físicas importantes, internações hospitalares prolongadas, prejuízos emocionais, diminuição da qualidade de vida, custos financeiros elevados, entre outros. No entanto, é possível de ser prevenida, por meio de intervenções básicas e de baixo custo.

Métodos de pesquisas estão disponíveis para os enfermeiros apoiarem a prática clínica, tais como os ensaios clínicos controlados, que permitem avaliar a eficácia de intervenções, e, somado a esse aspecto, destaca-se que metodologias de ensino como a "problematização" pode se apresentar como uma estratégia capaz de proporcionar a compreensão da realidade, o que deve ser utilizada e difundida na área da saúde. 


\subsection{PRESSUPOSTOS TEÓRICOS PARA A IMPLEMENTAÇÃO DA EDUCAÇÃO EM SAÚDE}

Por muitos anos a educação em saúde no Brasil foi desenvolvida de forma tradicional com a principal característica de transmissão de normas e conhecimentos de forma prescritiva. Cabia às pessoas acatar as regras impostas para que não ficassem doentes; ao contrário, seriam culpadas pelos seus próprios problemas de saúde. A "culpabilização da vítima" individualizava o processo de adoecimento ao mesmo tempo em que eximia os profissionais da responsabilidade das condições de saúde da população (VASCONCELOS, 1999).

Os propósitos e conceitos da educação em saúde adaptaram-se de acordo com as mudanças de paradigma tanto no setor da saúde, quanto nos processos pedagógicos da educação escolar de maneira geral (KWAMOTO, 1995), pois, o método de educação empregado era a mera transmissão de conhecimentos sem o intuito de proporcionar uma reflexão crítica (FREIRE, 2002). Com essas transformações, as ações educacionais em saúde passaram a ter o objetivo de capacitar os indivíduos ou grupos de modo a contribuir para a melhoria das condições de vida e saúde de si próprios e da população (KWAMOTO, 1995) e, ainda, proporcionar a reflexão crítica das causas dos problemas e as ações necessárias para sua resolução (MACIEL, 2009).

No que se refere às estratégias educacionais em saúde, nas últimas décadas, também houve mudanças na estrutura tradicional, que substituiu as apresentações didáticas pelas intervenções pedagógicas, com objetivo de propiciar a autonomia, participação e colaboração das pessoas que utilizam os serviços de saúde (RHEE et al., 2005). A essas estratégias é dado o nome de metodologias ativas, posto que representam o processo em que os educandos assumem uma posição central na realização de atividades que necessitam de atuação, reflexão de ideias, e desenvolvimento da capacidade de usá-las, declinando a colocação secundária de expectador dos conteúdos apresentados (BERBEL, 2012).

Ao contrário do método tradicional, que primeiro apresenta a teoria e assim é elaborado o processo de ensino, o método ativo busca a prática e, posteriormente, os princípios, fundamentos e conceitos (ABREU, 2009). Dewey (1978), afirma que só se aprende o que se pratica, contudo, não basta apenas praticar, é preciso haver uma reconstrução consciente da experiência. O aprendizado se dá por associação, ao passo que não se aprende uma única coisa, toda aprendizagem deve ser integrada à vida (DEWEY, 1978). 
Nesse contexto, há um desvio do foco do educador para o educando, que assume a corresponsabilidade pelo seu aprendizado, desenvolvendo a autonomia individual e as habilidades de comunicação (SOUZA; IGLESIAS; PAZIN-FILHO, 2014).

Referenciais educacionais baseados na problematização possibilitam estimular o potencial político, social e ético dos educandos, uma vez que são conduzidos a observar a realidade, identificar os problemas e transformar a realidade a partir da criatividade que envolve ação-reflexão sobre um aspecto da prática observado (BERBEL; GAMBOA, 2012).

A educação problematizadora está pautada na busca dos homens pelo mundo, com o mundo e com os outros, se contrapondo as características da educação bancária, ou seja, ao ato de depositar ou transferir conhecimentos (FREIRE, 2005). A problematização propõe novas compreensões, novos desafios, em que os educandos constroem sua compreensão de mundo por meio de suas relações com este e a realidade vivenciada, que não é estática, uma vez que está em constante processo de transformação (FREIRE, 2005).

A primeira referência para a Metodologia da Problematização é o Método do Arco, de Charles Maguerez, conforme o clássico esquema apresentado por Bordenave e Pereira (1982) que consta das seguintes etapas a partir de um recorte da realidade: Observação da Realidade; Pontos-Chave; Teorização; Hipóteses de Solução e Aplicação à Realidade (BORDENAVE; PEREIRA, 1998; BERBEL, 1996; BERBEL, 1998) (Figura 1). 
Figura 1 - Método do Arco de Charles Maguerez

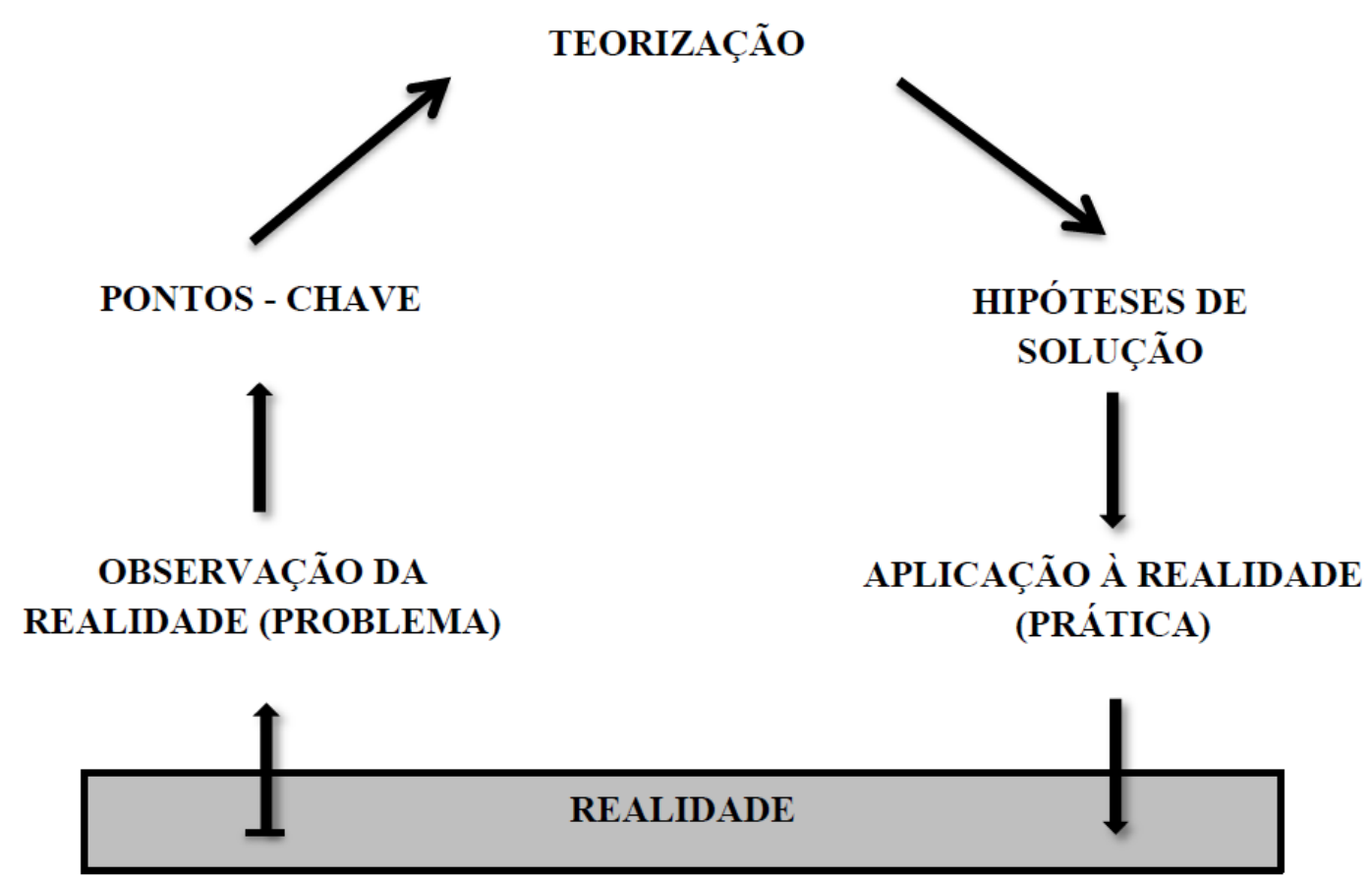

Fonte: Adaptado de Bordenave e Pereira (1998).

1. Observação da Realidade: a primeira etapa constitui-se da observação da realidade social e factual, baseado em um tema específico. A partir daí os educandos são encorajados a olhar atentamente e registrar onde e com quem as questões reais estão acontecendo. Para facilitar esse processo, os educadores podem utilizar conteúdos gerais que ajudam a focalizar o assunto. Tal observação proporcionará a identificação de dificuldades, carências, discrepâncias, de várias ordens, que serão problematizadas. As discussões entre o grupo e o educando darão origem a síntese e redação do problema, que passará a ser a referência para todas as outras etapas do estudo (BORDENAVE; PEREIRA, 2004).

2. Determinação dos Pontos-chave: nesta fase os educandos são incentivados a refletir sobre os possíveis fatores associados às causas da existência do problema em estudo e, então, retratam os determinantes prioritários, tais como, os relacionados a política, a economia e a ética. A partir dessa reflexão, os educandos sintetizam os pontos essenciais do problema, visando compreendê-lo profundamente e encontrar formas para solucioná-lo (BORDENAVE; PEREIRA, 2004).

3. Teorização: a teorização está relacionada com a busca de informações sobre o problema, por meio da consulta a livros, revistas especializadas, pesquisas prévias, jornais, atas de 
congressos, entre outros; consulta a especialistas sobre o assunto; aplicação de questionários para obter informações quantitativas ou qualitativas; participação de palestras e aulas. As informações adquiridas são analisadas e avaliadas quanto a sua colaboração para resolver o problema, de modo a possibilitar conclusões que facilitem o desenvolvimento da etapa posterior (BORDENAVE; PEREIRA, 2004).

4. Hipóteses de solução: todo o processo percorrido anteriormente deve fornecer subsídios aos educandos para que proponham as possíveis soluções para o problema de modo crítico e criativo. Para isso, podem ser utilizadas as seguintes questões: Como podemos solucionar o problema? O que precisa ser providenciado? O que pode realmente ser feito (BORDENAVE; PEREIRA, 2004)?

Os educandos devem projetar ideias para transformar as ações concretas e solucionar o problema, ou, pelo menos, apontar meios para isso. As hipóteses construídas após o estudo são frutos da compreensão profunda que se obteve sobre o problema, entendendo-o de todos os possíveis ângulos (BORDENAVE; PEREIRA, 2004).

5. Aplicação prática à realidade: devem ser analisadas e selecionadas as propostas mais viáveis, as quais serão capazes de superar o problema na prática, no seu todo ou em parte, e assim contribuir para a transformação da realidade. É neste momento que se planeja a execução das propostas, ou seja, desenvolver um compromisso social, profissional e político, que permita o educando aplicar os seus conhecimentos, e atuar como cidadão ativo na transformação das realidades (BORDENAVE; PEREIRA, 2004).

A Metodologia da Problematização é uma estratégia de ensino capaz de estimular o pensamento crítico e reflexivo, a tomada de decisão e a resolução de problemas de forma compartilhada. É importante ressaltar que a reflexão individual é necessária, contudo o grupo trabalha o problema em conjunto, com a supervisão de um educador para a idealização das etapas do Arco, o que possibilitará a construção do conhecimento (BERBEL, 1998).

De acordo com Santos e colaboradores (2006), as metodologias educativas realizadas em grupos são pautadas por intervenções coletivas, as quais se constituem de um processo para o desenvolvimento de atitudes e comportamentos com o objetivo de melhorar a saúde e as condições de vida de seus participantes. As estratégias didáticas escolhidas devem propiciar a transformação das pessoas, ampliando sua capacidade de compreensão dos determinantes relacionados à saúde e dos fatores sociais, o que as tornam protagonistas nos processos de saúde e doença (SANTOS et al., 2006). 
Osório (2003) define grupo como um conjunto de pessoas capazes de se reconhecerem em suas singularidades por meio do exercício de uma ação interativa com objetivos compartilhados, ou seja, é um conjunto de pessoas movidas pelas mesmas necessidades em torno de um propósito específico.

Os grupos estão inseridos cada vez mais no cuidado à saúde, principalmente na atenção primária, e tem demonstrado resultados positivos na promoção, prevenção e educação em saúde, mesmo com as adversidades que circundam o trabalho entre-indivíduos caracterizados por histórias distintas (MENEZES; AVELINO, 2016).

A American Diabetes Association (ADA) (2017) recomenda trabalhar grupos de pessoas com DM para proporcionar a troca de conhecimentos, o que facilita o aprendizado pela aproximação das situações e experiências vivenciadas. De acordo com Silva e colaboradores (2014), os grupos são meios de convivência e descontração que possibilitam o compartilhar de ideias e experiências e, por essa razão, são consideradas ações privilegiadas para a construção do saber em saúde.

Destaca-se o estudo de Rego et al. (2006) que utiliza a problematização por meio da metodologia do Arco de Maguerez, especificamente, no processo de educação em saúde da pessoa com DM com o objetivo de analisar o processo de educação para a saúde em grupo, enquanto estratégia de intervenção de enfermagem. Assim, o ponto de partida para o desenvolvimento da educação em saúde, nesse estudo, foi a observação da realidade, relatos das experiências dos participantes, bem como suas expectativas e necessidades. Após a identificação dos conhecimentos que se faziam necessários aprofundar, procedeu-se a teorização de forma dialógica e participativa e, para encerrar as etapas do arco, os participantes relataram a aplicação dos novos conhecimentos ao seu cotidiano (REGO; NAKATANI; BACHION, 2006). Os resultados do estudo contribuíram para que os participantes desenvolvessem a autonomia e à independência para o enfrentamento de seu problema de saúde, ao passo que mediaram o processo de construção do conhecimento, na perspectiva emancipadora (REGO; NAKATANI; BACHION, 2006).

\subsection{ENFERMAGEM NO PROCESSO DE ENSINO E CUIDADO}

$\mathrm{O}$ processo de trabalho do enfermeiro está relacionado às esferas assistencial e gerencial, perpassando os campos da pesquisa e do ensino, diretamente interligados às práticas do cuidado humano (TREVISO et al., 2017). Na atenção básica, seja na gestão e/ou 
na execução das práticas assistenciais, preventivas e educativas, o trabalho do enfermeiro é estratégico e indispensável, assegurado por meio dos marcos históricos e legais do Sistema Único de Saúde (SUS) (BRASIL, 2012a).

Em relação às competências no âmbito da educação, o profissional enfermeiro é considerado um educador nato por desempenhar atividades educativas em saúde com o intuito de orientar a população acerca de doenças, prevenção, tratamentos entre outras particularidades (PINHEIRO et al., 2016). Além de ser objetivo da Estratetégia de Saúde da Família, a educação em saúde é uma atividade inerente ao enfermeiro, regulamentada pela lei do exercício profissional, que descreve o enfermeiro como integrante da equipe de saúde, o qual deve desenvolver educação com o objetivo de melhorar a saúde do indivíduo, da família e da população em geral (BRASIL, 1986).

O processo educativo desenvolvido pelo enfermeiro consiste muito mais do que o simples ato de ensinar, uma vez que as pessoas que utilizam os serviços de saúde são potencialmente sensíveis e criativas, o que requer uma relação horizontal, dialógica, recíproca e verdadeiramente humana. A educação deve ser voltada para o cotidiano do indivíduo, com base numa proposta que enfatize a promoção da saúde ao invés do cuidado da doença (ALVIM; FERREIRA, 2007).

As ações educativas em saúde devem ser sistematizadas e organizadas, como um método eficaz na formação de pessoas mais conscientes para desenvolver o autocuidado (MONTEIRO, 2015). O enfermeiro deve basear-se em fundamentos teóricos, que em conformidade com o conhecimento científico contribui para o desenvolvimento de suas competências (BORK, 2003).

Os profissionais de enfermagem possuem o conhecimento empírico, que tem o objetivo explicar e predizer fenômenos de interesse e, embora seja preditor do reconhecimento do saber empreendido na área, apenas com ele, é impossível entender a riqueza e a complexidade que envolve esse trabalho, uma vez que o cuidado requer conhecimentos da ciência da enfermagem e imaginação criativa (MADUREIRA, 2004).

Para que a enfermagem, enquanto ciência promotora de cuidado eleve a qualidade da assistência prestada à população, é necessário fundamentar-se cientificamente e legalmente suas ações práticas, por meio de métodos como a Sistematização da Assistência de Enfermagem (SAE), imprescindível para organizar o processo de trabalho da enfermagem (CARVALHO; BOMFIM; DOMICINIANO, 2017). 
A implementação da SAE, além de proporcionar a organização da assistência de enfermagem, possibilita processos interativos e resolutivos por integrar diferentes elementos que a compõem, o que destaca a profissão como ciência do cuidado e promove a autonomia e segurança profissional (DOTTO et al., 2017).

O processo de enfermagem, conforme artigo $2^{\circ}$ da Resolução do Conselho Federal de Enfermagem (COFEN) (2016) $n^{\circ} 358 / 2009$, organiza-se de acordo com cinco etapas interrelacionadas, interdependentes e recorrentes:

I - Coleta de dados de Enfermagem (ou Histórico de Enfermagem) processo deliberado, sistemático e contínuo, realizado com o auxílio de métodos e técnicas variadas, que tem por finalidade a obtenção de informações sobre a pessoa, família ou coletividade humana e sobre suas respostas em um dado momento do processo saúde e doença.

II - Diagnóstico de Enfermagem - processo de interpretação e agrupamento dos dados coletados na primeira etapa, que culmina com a tomada de decisão sobre os conceitos diagnósticos de enfermagem que representam, com mais exatidão, as respostas da pessoa, família ou coletividade humana em um dado momento do processo saúde e doença; e que constituem a base para a seleção das ações ou intervenções com as quais se objetiva alcançar os resultados esperados.

III - Planejamento de Enfermagem - determinação dos resultados que se espera alcançar; e das ações ou intervenções de enfermagem que serão realizadas face às respostas da pessoa, família ou coletividade humana em um dado momento do processo saúde e doença, identificadas na etapa de Diagnóstico de Enfermagem.

IV - Implementação - realização das ações ou intervenções determinadas na etapa de Planejamento de Enfermagem.

V - Avaliação de Enfermagem - processo deliberado, sistemático e contínuo de verificação de mudanças nas respostas da pessoa, família ou coletividade humana em um dado momento do processo saúde doença, para determinar se as ações ou intervenções de enfermagem alcançaram o resultado esperado; e de verificação da necessidade de mudanças ou adaptações nas etapas do Processo de Enfermagem.

A taxonomia NANDA-I tem o propósito de classificar os diagnósticos de enfermagem, que são definidos a partir do julgamento clínico sobre as respostas humanas da pessoa, da família ou de uma comunidade com relação a problemas reais ou potenciais de saúde (HERDMAN; KAMITSURU, 2018). Particularmente para este estudo, em que o objetivo é implementar uma intervenção para prevenir úlceras plantares, é possível determinar o diagnóstico de enfermagem "Risco de integridade tissular prejudicada (00248)", tendo em vista que as pessoas com DM podem apresentar condições associadas, tais como circulação prejudicada, estado nutricional desequilibrado, alteração no metabolismo, alteração na sensibilidade e neuropatia periférica. De acordo com a NANDA-I o diagnóstico "Risco de 
integridade tissular prejudicada (00248)" é definido como: "suscetibilidade a dano em membrana mucosa, córnea, sistema tegumentar, fáscia muscular, músculo, tendão, osso, cartilagem, cápsula articular e/ou ligamento que pode comprometer a saúde" (HERDMAN; KAMITSURU, 2018).

Fatores de risco externos:

- Agente químico lesivo

- Conhecimento insuficiente sobre manutenção da integridade tissular

- Conhecimento insuficiente sobre proteção da integridade tissular

- Estado nutricional desequilibrado

- Umidade

- Volume de líquidos deficiente

- Volume de líquidos excessivo

Populações em risco

- Exposição à rede elétrica de alta voltagem

- Extremos de idade

- Extremos de temperatura ambiental

Condições associadas

- Agente farmacêutico

- Alteração na sensibilidade

- Alteração no metabolismo

- Circulação prejudicada

- Mobilidade prejudicada

- Neuropatia periférica

- Procedimento cirúrgico

- Punção arterial

- Radioterapia

- Trauma vascular (HERDMAN; KAMITSURU, 2018, p. 779-780).

Os diagnósticos da NANDA-I constituem a base para as intervenções de enfermagem da NIC, as quais são definidas como qualquer tratamento fundamentado no julgamento e no conhecimento clínico de um enfermeiro para melhorar os resultados de uma pessoa (BULECHECK et al., 2016). 
A classificação NOC determina os resultados esperados para cada intervenção e se estes resultam de intervenções favoráveis ou não, no atual e no potencial estado de saúde das pessoas. Os escores obtidos pelos indicadores de cada escala permitem acompanhar o efeito da assistência prestada pela equipe de enfermagem, seja na prevenção, no tratamento ou na recuperação dos pés de pessoas com DM, para obter melhores resultados na saúde e melhor qualidade de vida (MOORHEAD et al., 2016).

Seguem os indicadores propostos pela NOC para o resultado esperado "Integridade Tissular: Pele e Mucosas" (1101) (MOORHEARD et al., 2016, p. 398):

- Temperatura da pele

- Sensação

- Elasticidade

- Hidratação

- Transpiração

- Textura

- Espessura

- Perfusão tecidual

- Crescimento de pelos na pele

- Integridade tecidual

- Pigmentação anormal

- Lesões de pele

- Lesões nas mucosas

- Tecido cicatricial

- Cânceres de pele

- Descamação de pele

- Fissuras (rachaduras) de pele

- Eritema

- Empalidecimento

- Necrose

- Endurecimento

- Abrasão da camada córnea (MOORHEARD et al., 2016, p. 398). 
Para atenuar o "Risco de integridade tissular prejudicada (00248)", destaca-se a intervenção de enfermagem, descrita na NIC, "Ensino: Cuidado com os Pés (5603)" por meio das seguintes atividades (BULECHECK et al., 2016, p. 241):

- Determinar o grau ou o conhecimento atual de habilidades relacionadas aos cuidados com os pés

- Determinar as práticas atuais de cuidados com os pés

- Fornecer informações relacionadas ao grau de risco de lesões

- Recomendar o corte das unhas dos pés e calos por especialista, conforme apropriado

- Fornecer as diretrizes, por escrito, de cuidados com os pés

- Auxiliar no desenvolvimento de um plano diário para cuidados e avaliação dos pés no domicílio

- Determinar a capacidade de realizar cuidados com os pés, e (observar acuidade visual, mobilidade física e julgamento)

- Recomendar o apoio de uma pessoa significativa nos cuidados com os pés, se a visão estiver prejudicada ou se houver problemas com a mobilidade

- Recomendar inspeção diária sobre todas as regiões dos pés, com destaque nas regiões entre os dedos à procura de eritema, edema, calor, ressecamento, maceração, sensibilidade ou áreas expostas

- Orientar o uso de um espelho ou outro auxiliar para realizar a inspeção do pé quando necessária

- Recomendar a lavagem diária dos pés com água morna e sabão suave

- Recomendar a secagem completa dos pés após a lavagem, especialmente entre os dedos

- Orientar a hidratação diária da pele com imersão ou lavagem em temperatura ambiente seguida de aplicação de um emoliente

- Fornecer informação sobre a relação entre lesão, neuropatia e doença vascular, bem como o risco de amputação de membros inferiores em pessoas com DM, consequente a estas alterações

- Aconselhar sobre quando é apropriado entrar em contato com um profissional da saúde, incluindo na presença de não cicatrização ou lesão infectada

- Aconselhar sobre as medidas de autocuidado apropriadas para pequenos problemas com os pés 
- Alertar sobre potenciais fontes de lesão aos pés (calor, frio, corte de cantos ou calosidades, produtos químicos, uso de antissépticos fortes ou adstringentes, uso de fita adesiva, andar descalço ou como sapatos abertos)

- Orientar sobre a técnica adequada para corte da unha (observar corte rente, ao longo do contorno do dedo e lixamento de bordas afiadas)

- Orientar sobre os cuidados com calosidades macias, incluindo polimento suave com toalha ou pedra-pomes após o banho

- Recomendar os cuidados especializados para unhas espessas com fungos ou unhas encravadas, cantos ou calosidades, conforme indicado

- Indicar sapatos apropriados (salto baixo com forma que coincida com o formato do pé; profundidade adequada do sapato; solas feitas de material que irá absorver choques; ajuste feito por cadarços ou tiras; parte superior feita com material arejado, macios e flexíveis, as disfunções de marcha e de comprimento dos membros e potencial para modificação, se necessário)

- Indicar meias apropriadas (material absorvente e que não aperta os pés)

- Recomendar diretrizes a serem seguidas na compra de novos sapatos, incluindo ter os pés devidamente medidos e ajustados no momento da compra

- Recomendar o uso de sapatos novos só por algumas horas pelas primeiras duas semanas

- Orientar a inspeção diária dentro dos sapatos, a procura de objetos estranhos, pregos, lonas rasgadas e áreas ásperas

- Orientar a mudança de sapatos duas vezes ao dia (por exemplo, às 12 horas e às 17 horas) para evitar pressão local repetitiva

- Explicar a necessidade de prescrição de calçados ou órteses, conforme apropriado

- Alertar sobre as atividades que causam pressão sobre os nervos e vasos sanguíneos, incluindo faixas elásticas em meias ou cruzamento de pernas

- Aconselhar a parar de fumar

- Incluir os familiares/outros na orientação, conforme apropriado

- Reforçar as informações fornecidas por outros profissionais de saúde, conforme apropriado (BULECHECK et al., 2016, p. 241)

As atividades para o "Ensino: Cuidado com os pés (5603)" não são específicas para o cuidado com os pés de pessoas com DM e também não foram identificados estudos que validaram essas intervenções para as pessoas diagnosticadas com DM2, portanto, 
desenvolveu-se um processo de revisão de conteúdo das atividades de autocuidado com os pés, que contou com o método de revisão integrativa da literatura, para identificar as atividades de ensino do cuidado com os pés, específicas para pessoas com DM e, posteriormente, a sua validação, por meio de um comitê de peritos, que se reuniu duas vezes, até se obter a seguinte versão da intervenção (MONTEIRO et al., 2018):

- Manter os pés limpos, usando sabão e água morna

- Secar os pés, principalmente entre os dedos

- Hidratar os pés, exceto entre os dedos

- Usar meias limpas

- Usar meias macias, de lã ou algodão

- Usar meias sem costura e sem elástico

- Antes de calçar os sapatos, verificar se há objetos estranhos que possam ferir os pés

- Preferir sapatos fechados

- Não andar descalço

- Usar sapatos confortáveis

- Sapatos novos devem ser usados aos poucos (2 horas por dia)

- Trocar de sapatos duas vezes por dia

- Observar os pés diariamente

- Não cortar calos

- Não remover cutículas

- Apenas lixar as unhas em linha reta

- Não usar substâncias quentes, frias e químicas, pois podem provocar lesão nos pés

- Solicitar auxilio de alguém da família ou amigos, para cuidar dos pés

- Parar de fumar

- Cuidar da alimentação

- Evitar doces

- Procurar a equipe de saúde na presença de qualquer alteração nos pés

Paralelo ao embasamento teórico científico, necessário no desenvolvimento do processo de trabalho do enfermeiro, destaca-se os avanços da contemporaneidade, com as tecnologias de informação e comunicação (TIC), que são fundamentais na área da saúde, principalmente quando somadas a intervenções de mobilização social (ABOOTT; BARBOSA, 2015). 
O desenvolvimento tecnológico e a valorização da ciência no campo de trabalho na área da saúde iniciaram com a introdução da informática e o incremento de aparelhos cada vez mais modernos e sofisticados. Assim, a TIC é capaz de melhorar a qualidade do cuidado em saúde centrado na pessoa, bem como na sua educação (ROULEAU et al., 2017).

Ainda que, na área da saúde, a tecnologia enfrente alguns preconceitos, é importante ressaltar sua necessidade, principalmente no que tange a constante tendência de qualificação do trabalho e assistência dos serviços (PISSAIA et al., 2017). A revolução tecnológica dispõe de inúmeras possibilidades para construir o conhecimento. A propagação das informações revolucionou não apenas o desenvolvimento tecnológico, mas também o científico, o que proporcionou modificações visíveis nos modelos de trabalho, inclusive na enfermagem (LANDEIRO et al., 2016).

Em destaque nos últimos anos está a tecnologia móvel, que utilizada em favor da saúde, é capaz de armazenar dados que permitem aos profissionais o acesso rápido das informações referente a diagnósticos e tratamento de doenças (VÁZQUEZ et al., 2016).

Destaca-se que neste estudo foi utilizado um aplicativo móvel (MURO, 2018) para avaliar o risco de integridade tissular, conforme indicadores do Ministério da Saúde (MS) para o risco de pé diabético (BRASIL, 2016).

De acordo com o estudo de Muro (2018), ao comparar o aplicativo para identificar alterações nos pés, com a versão impressa, houve concordância de satisfatória a excelente entre os métodos, o que permite aos profissionais de saúde utilizar uma tecnologia digital, interativa e econômica (MURO, 2018).

\subsection{COMPORTAMENTO PLANEJADO}

A Teoria do Comportamento Planejado (TCP) de Adjen (1991) busca compreender e prever as condutas do ser humano, a partir do pressuposto que o comportamento é determinado pela atitude, pela intenção e pelo controle percebido.

A atitude está associada a fatores pessoais relacionados ao comportamento e aos resultados gerados a partir deste. A intenção é consequência dos valores e das crenças individuais, além da motivação para implementar determinada conduta (HAUSENBLAS; CARRON; MACK, 1997).

A intenção de realizar um comportamento está diretamente relacionada às percepções pessoais sobre as imposições da sociedade. Sendo assim, as normas subjetivas são 
consideradas como a opinião de pessoas importantes no que concerne a um determinado comportamento. Contudo, tal opinião pode ser considerada ou não, cabendo a quem executa o comportamento decidir a relevância de tal influência (AJZEN; FISHBEIN, 1970).

Outro fator determinante é o controle comportamental percebido, pois a capacidade de dominar fatores internos e externos pode intervir no comportamento e consequentemente no sucesso de sua execução. O controle percebido também pode ser utilizado como um preditor direto do comportamento, quando a pessoa percebe um alto grau de controle ou nenhum controle sobre este (AJZEN, 2002).

A intenção comportamental é o fator que antecedente o comportamento, o que significa, quanto maior a intenção de desenvolver um comportamento, maior é a probabilidade de realiza-lo (AJZEN; MADDEN, 1986).

Os questionários embasados no comportamento planejado são divididos por domínios específicos. O domínio atitude é determinado pelas crenças que a pessoa possui e também, pela repercussão dos resultados e efeitos do comportamento. A intensidade da crença implica no desenvolvimento de atitudes (AJZEN; MADDEN, 1986). A crença também está intimamente relacionada ao domínio de normas, que se importa com a opinião de pessoas significativas na aprovação ou desaprovação do comportamento executado (AJZEN; DRIVER, 1991).

O controle percebido é o domínio que esclarece que intenções isoladas, em alguns casos, não são capazes de predizer o comportamento (AJZEN, 2002).

Em síntese a TCP é embasada nos seguintes princípios (Figura 2):

- Comportamentais: reflete as consequências prováveis de um comportamento

- Normativas: representa as expectativas normativas das outras pessoas (pressão social)

- Controle: considera a existência de fatores de possa impedir ou não a realização do comportamento 
Figura 2 - Teoria do Comportamento Planejado

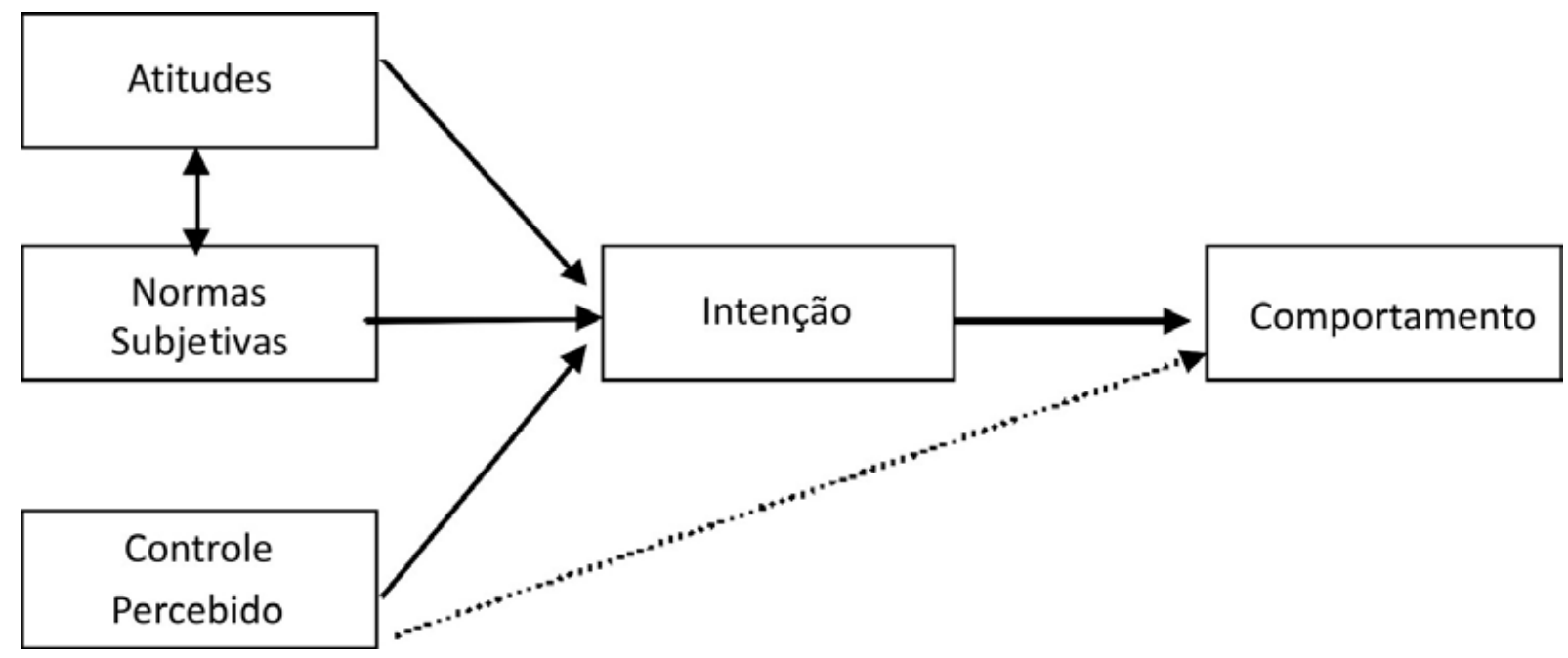

Fonte: Beck e Ajzen (1991, p. 287).

Em busca de aplicar a teoria de Adjen como base teórica para as intervenções comportamentais, tendo em vista a identificação dos fatores psicológicos que antecedem a realização de comportamentos de saúde, a TCP foi adotada, com diferentes fins, tais como, para realizar o autoexame da mama, para a adesão a dietas saudáveis e para a prática de exercício físico (AJZEN; MANSTEAD, 2007).

Para identificar a intenção das pessoas com DM de desenvolver atividades de autocuidado com os pés, foi construído, em Portugal, um instrumento denominado "Questionário do Comportamento Planeado na Diabetes - Cuidado Com os Pés (QCP-CP)", o qual possui 22 itens distintos, com respostas do tipo Likert, relacionados aos cuidados de lavagem, secagem e observação diária dos pés. Os itens do instrumento são agrupados em seis domínios: intenções, atitudes, normas subjetivas, controle comportamental percebido, planejamento da ação e planejamento do coping (PEREIRA; ARAÚJO-SOARES; COSTA, 2008).

O QCP-CP que foi fundamentado na TCP (PEREIRA; ARAÚJO-SOARES; COSTA, 2009), possibilita avaliar o autocuidado com os pés implementado por pessoas com DM e pode ser utilizado por profissionais de saúde para uma abordagem mais efetiva, de forma a identificar não apenas a intenção de desenvolver o autocuidado, mas também as lacunas no conhecimento, as quais impossibilitam a pratica de atividades preventivas (MONTEIRO et al., 2015). 
O ensaio clínico, desenvolvido no sul de Minas Gerais em amostra composta por 109 pessoas com DM2, cujo objetivo foi avaliar o efeito do grupo operativo no ensino do autocuidado com os pés para prevenção do pé diabético, apresentou como resultado global na intenção de desenvolver o autocuidado com os pés, melhoras significativa das médias do grupo tratado (GT) em todos os tempos de avaliação intragrupo. Já o GC apresentou melhores médias apenas no primeiro e no terceiro tempo de avaliação. Na avaliação intergrupo, o GT apresentou melhora significativa no segundo e terceiro tempo de avaliação quando comparado ao GC. O que comprovou que a intervenção educativa aumentou a intenção das pessoas com DM2 em realizar o autocuidado com os pés (MOREIRA, 2017).

Mediante a fundamentação teórica da intenção para realizar o autocuidado, bem como do processo de ensino no cuidado à saúde, desenvolveu-se o presente estudo cujos objetivos e métodos estão descritos a seguir. 


\subsection{OBJETIVO GERAL}

Avaliar a contribuição do "ensino do cuidado com os pés" para a redução do "risco de integridade tissular prejudicada" das pessoas com DM2.

\subsection{OBJETIVOS ESPECÍFICOS}

- Caracterizar a amostra do estudo quanto as variáveis sociodemográficas, antropométricas, hábitos de vida, clínicas e outras informações complementares;

- Avaliar a integridade da pele e anexos (condições dermatológicas), a sensibilidade, as deformidades anatômicas, as condições vasculares/arteriais e a temperatura dos pés de pessoas com DM2 antes e após a intervenção de enfermagem "ensino do cuidado com os pés";

- Avaliar o conhecimento das pessoas com DM2 sobre as atividades de autocuidado com os pés, antes e após a intervenção de enfermagem "ensino do cuidado com os pés";

- Avaliar a intenção das pessoas com DM2 de realizar as atividades de autocuidado com os pés, antes e após a intervenção de enfermagem "ensino do cuidado com os pés". 
4 MÉTODO 


\subsection{TIPO DE ESTUDO}

Trata-se de um ensaio clínico paralelo, randomizado, controlado, mascarado com taxa de alocação de $1: 1$.

Os ensaios clínicos são estudos prospectivos que possibilitam testar intervenções ou tratamentos inovadores (POLIT; BECK, 2014). Para Oliveira e Parente (2010), essa metodologia permite que um grupo de interesse seja acompanhado durante a exposição a procedimentos ou terapias e, logo após, comparado a um GC em uso de terapias semelhantes ou placebo.

Estudos clínicos paralelos são desenvolvidos com dois grupos individuais, dos quais um é controle do outro (SCHULZ; ALTMAN; MOHER, 2010). A randomização ocorre quando os participantes são alocados nos grupos aleatoriamente. Já o controle permite que o pesquisador manipule fatores que podem influenciar a amostra (POLIT; BECK, 2014; HULLEY et al., 2015).

$\mathrm{O}$ mascaramento representa o desconhecimento quanto à alocação dos participantes nos grupos, sejam eles os participantes, os pesquisadores e/ou os avaliadores (SCHULZ; GRIMES, 2007). Destaca-se que neste estudo, o mascaramento ocorreu com o avaliador.

Este tipo de estudo é visto como uma poderosa ferramenta para a avaliação de intervenções para a saúde e, por isso, é considerado padrão-ouro para orientar a prática profissional (POLIT; BECK; HUNGLER, 2004).

\subsection{LOCAL DE ESTUDO}

O estudo foi desenvolvido em uma Policlínica do Sistema Único de Saúde do município de Boa Esperança, estado de Minas Gerais, referência no atendimento de especialidades, com aproximadamente, 19.500 pessoas cadastradas em atendimento clínico.

As pessoas diagnosticadas com DM são atendidas por uma equipe multiprofissional composta por um enfermeiro, dois técnicos de enfermagem, um clínico geral, um endocrinologista e um nutricionista. Os profissionais de enfermagem ficam responsáveis pelas pré-consultas e pós-consultas médicas. 


\subsection{POPULAÇÃO E AMOSTRA}

Do total de pessoas em atendimento clínico, 460 possuíam o diagnóstico médico de DM, portanto este número corresponde a população base. A amostra do presente estudo foi constituída a partir dos critérios de inclusão e exclusão, bem como pelos resultados inerentes aos procedimentos de recrutamento dos participantes.

a) Critérios de inclusão: pessoas com idade acima de 18 anos e com DM2 diagnosticadas há, no mínimo, cinco anos. De acordo com Boulton et al. (2008) o tempo de doença relaciona-se diretamente com o risco para o desenvolvimento de complicações neuropáticas e vasculopatias.

b) Critérios de exclusão: pessoas com DM2 que apresentavam úlceras ativas, trombose, fratura ou amputações nos membros inferiores (MMII) e déficit na capacidade cognitiva, identificado pelo Mini-Exame do Estado Mental (MEEM) (ANEXO A).

Destacam-se também que os participantes que não puderam ou não quiseram comparecer nas avaliações, bem como aqueles que não participaram de mais de uma intervenção educativa foram descontinuados.

O número de participantes para o desenvolvimento do estudo foi estimado por meio do cálculo amostral conforme critério de Monami e colaboradores (2015), que considera os resultados de estudo realizados anteriormente, cujo objetivo principal e método são similares aos do presente estudo (MONTEIRO, 2015).

\subsubsection{Cálculo amostral}

Para o cálculo do tamanho amostral optou-se pelo uso da variável do risco de integridade tissular, medida por meio da Escala de Avaliação da "Integridade Tissular: Pele e Mucosas" dos Pés de Pacientes com Diabetes Mellitus tipo 2 (SILVA et al., 2013), a partir dos resultados do estudo de Monteiro (2015), cuja média dos itens que compõem o instrumento para avaliar o risco para integridade tissular obtida para o GI na segunda avaliação foi de 85,74 pontos, e para o GC foi de 81,31 pontos. Destaca-se que foi considerado risco de integridade tissular extremamente comprometida quando valores de 20 a 35 , substancialmente comprometido de 36 a 51, moderadamente comprometido de 52 a 66 , levemente comprometido de 67 a 84 e não comprometido de 85 a 100 (SILVA et al., 2013). 
Adicionalmente, foi considerado um nível de significância de 5\% $\left(z_{1-\alpha}=1.96\right)$, um poder de $80 \%\left(z_{1-\beta}=1.96\right)$, desvio padrão de 20 e correlação $(\rho)$ entre os tempos de 0.50 .

Fórmula utilizada para o cálculo amostral:

$$
N=\frac{\sigma^{2}\left(z_{1-\alpha}+z_{1-\beta}\right)^{2}(r+1)[1+(T-1) * \rho]}{v^{2} r T}
$$

$\sigma^{2}=$ Variância da amostra (quadrado do desvio padrão);

$\rho$ = Correlação assumida entre os tempos;

r = Razão assumida (1) entre os tamanhos das amostras dos grupos controle e experimental;

$\mathrm{T}$ = Número de Repetições (3).

O resultado do teste determinou para este estudo um total de 140 participantes (70 em cada grupo). Contudo, ao considerar uma perda de 20\%, optou-se por incluir no mínimo 168 participantes.

\subsection{VARIÁVEIS}

\subsubsection{Variável independente}

A variável independente deste estudo trata-se da intervenção educativa junto às pessoas com DM2 por meio do Arco de Maguerez.

\subsubsection{Variáveis para caracterizar a amostra}

- Variáveis sociodemográficas

- Sexo (variável qualitativa dicotômica): classificada em masculino ou feminino;

- Idade (variável quantitativa contínua): em anos completos, autorreferido;

- Estado civil (variável qualitativa dicotômica): classificada em com cônjuge/companheiro e sem cônjuge/companheiro;

- Escolaridade (variável qualitativa ordinal): classificada em baixa (<8anos), média (8-12 anos) e alta ( $\geq 12$ anos); 
- Ocupação (variável qualitativa nominal): tipo de trabalho, remunerado ou não, autorreferido;

- Número de residentes na casa (variável quantitativa contínua): número de pessoas autorreferidas que residem na mesma casa que o participante do estudo;

- Renda familiar (variável quantitativa contínua): renda familiar mensal autorreferida em reais.

\section{- Variáveis antropométricas}

- Peso (variável quantitativa contínua): peso em quilogramas, autorreferido;

- Altura (variável quantitativa contínua): altura em centímetros, autorreferida;

- Índice de massa corporal (IMC) (variável quantitativa contínua): avaliada pela divisão do peso pela altura ${ }^{2}$ e classificada em normal $\left(<25 \mathrm{~kg} / \mathrm{m}^{2}\right)$, sobrepeso $\left(\geq 25 \mathrm{~kg} / \mathrm{m}^{2}\right)$ e obesidade $\left(\geq 30 \mathrm{~kg} / \mathrm{m}^{2}\right)$.

\section{- Hábitos de vida}

- Hábito de fumar (variável qualitativa nominal): classificada em um maço ou mais por dia, menos de um maço por dia, apenas cigarro de palha/cachimbo, não fuma/ parou há menos de 1 ano, não fuma/ parou há 1 ano ou mais, nunca fumou;

- Período em anos que fuma ou fumou (variável quantitativa contínua): período autorreferido em anos que o participante do estudo fuma ou fumou;

- Hábito de beber (variável qualitativa nominal): classificada em não bebe, faz uso de cerveja, vinho ou destilados;

- Frequência do consumo de bebidas alcoólicas (variável qualitativa nominal): classificada em não bebe, faz uso de bebida alcoólica 4 a 7 vezes por semana, até 3 vezes por semana, eventualmente/raramente;

- Prática de exercício físico - Tipo de exercício físico (variável qualitativa nominal): classificada em não faz exercício físico, dança, futebol, natação, caminhadas, bicicleta, ginástica;

- Frequência do exercício físico (variável qualitativa nominal): classificada em não pratica exercício físico, pratica 5 a 7 vezes por semana, 3 a 4 vezes por semana, até 2 vezes por semana ou eventualmente. 


\section{- Aspectos clínicos}

- Uso de insulina (variável qualitativa dicotômica): classificada em sim ou não;

- Tempo de uso de insulina (variável quantitativa contínua): quantidade autorreferida de anos de uso de insulina;

- Tipos de insulina (variável qualitativa nominal): classificada em Lispro, Regular (R), Neutral Protamine Hagedorn (NPH)/lenta, Ultra lenta, Pré-mistura, NPH+R, outra ou não sabe informar;

- Uso de antidiabéticos orais (variável qualitativa dicotômica): classificada em sim ou não;

- Tempo de uso de antidiabéticos orais (variável quantitativa contínua): quantidade autorreferida de anos de uso de antidiabéticos orais;

- Tipos de antidiabéticos orais (variável qualitativa nominal): classificada em sulfoniluréias, biguanidas, toglitazone, acarbose, associações ou não sabe informar;

- Possui HA (variável qualitativa dicotômica): classificada em sim ou não;

- Associação de outras doenças (variável qualitativa dicotômica): classificada em sim ou não;

- Dificuldade visual (variável qualitativa dicotômica): classificada em sim ou não;

- História de úlceras (variável qualitativa dicotômica): classificada em sim ou não;

- Amputação (variável qualitativa dicotômica): classificada em sim ou não;

- Nível de dor ou desconforto nas pernas (variável qualitativa ordinal): classificada em nenhuma dor, dor moderada ou a pior dor;

- Tempo de diagnóstico de DM2 (variável quantitativa contínua): quantidade autorreferida de anos de diagnóstico de DM2;

- Glicemia (variável quantitativa contínua): valor médio da glicemia capilar em jejum automonitorizada, por no mínimo três vezes durante a semana.

\section{- Outras informações complementares}

- Recebimento de orientação prévia sobre os cuidados com os pés (variável qualitativa dicotômica): classificada em sim ou nunca;

- Avaliação dos pés por um profissional da saúde (variável qualitativa dicotômica): classificada em sim ou nunca;

- Realiza autocuidado com os pés (variável qualitativa dicotômica): classificada em sim ou não. 


\subsubsection{Variáveis para a classificação da integridade tissular}

- Características da pele e anexos (condições dermatológicas): foi observada a presença das seguintes alterações.

- Integridade da pele preservada (variável qualitativa dicotômica): classificada em sim ou não; - Apresenta lesões esfoliativas (variável qualitativa dicotômica): classificada em sim ou não; - Apresenta micose (variável qualitativa dicotômica): classificada em sim ou não;

- Apresenta ulcerações (variável qualitativa dicotômica): classificada em sim ou não;

- Apresenta calos (variável qualitativa dicotômica): classificada em sim ou não;

- Ausência de pelos nas pernas (variável qualitativa dicotômica): classificada em sim ou não;

- Apresenta pele hidratada (variável qualitativa dicotômica): classificada em sim ou não;

- Apresenta xerodermia (variável qualitativa dicotômica): classificada em sim ou não;

- Apresenta fissuras (rachadura) (variável qualitativa dicotômica): classificada em sim ou não;

- Corte de unhas corretos (variável qualitativa dicotômica): classificada em sim ou não;

- Espaços interdigitais úmidos (variável qualitativa dicotômica): classificada em sim ou não;

- Espaços interdigitais macerados (variável qualitativa dicotômica): classificada em sim ou não;

\section{- Sensibilidade:}

- Sensibilidade tátil pressórica alterada (variável qualitativa dicotômica): classificada em sim ou não, analisada pela incapacidade de sentir o toque leve e a sensação de pressão profunda do monofilamento de nylon, em pelo menos 1 dos 4 pontos dos pés: hálux, $1^{\mathrm{a}}, 3^{\mathrm{a}}$ e $5^{\mathrm{a}}$ cabeças de metatarsos (BRASIL, 2006).

- Sensibilidade vibratória alterada (variável qualitativa dicotômica): classificada em sim ou não, analisada por meio de três aplicações do diapasão de $128 \mathrm{~Hz}$ na parte óssea no lado dorsal da falange distal do hálux. O teste foi considerado negativo quando o participante respondia corretamente duas das três aplicações do diapasão e, positivo quando o participante respondia de forma incorreta duas das três aplicações com o mesmo instrumento.

- Percepção vibratória alterada (variável qualitativa dicotômica): classificada em sim ou não, analisada por meio da percussão com o martelo de reflexos no tendão de Aquiles. O teste foi considerado alterado quando a flexão plantar reflexa do pé estava ausente ou diminuída. 
- Deformidades nos pés: foi observada a presença das seguintes deformidades anatômicas nos pés:

- Apresenta deformidades em garras (variável qualitativa dicotômica): classificada em sim ou não;

- Apresenta deformidades em martelo (variável qualitativa dicotômica): classificada em sim ou não;

- Apresenta hálux valgo direito ou esquerdo (variável qualitativa dicotômica): classificada em sim ou não;

- Apresenta artropatia de Charcot (variável qualitativa dicotômica): classificada em sim ou não.

- Condição vascular/arterial: foram observados os seguintes sinais de insuficiência arterial/venosa:

- Apresenta edema (variável qualitativa dicotômica): classificada em sim ou não;

- Apresenta varizes (variável qualitativa dicotômica): classificada em sim ou não;

- Pulso tibial esquerdo (variável qualitativa nominal): classificado em presente, diminuído ou ausente (No presente estudo considerou-se a nomenclatura "pulso não palpável" em substituição a "pulso ausente");

- Pulso tibial direito (variável qualitativa nominal): classificado em presente, diminuído ou ausente (No presente estudo considerou-se a nomenclatura "pulso não palpável" em substituição a "pulso ausente");

- Pulso pedioso esquerdo (variável qualitativa nominal): classificado em presente, diminuído ou ausente (No presente estudo considerou-se a nomenclatura "pulso não palpável" em substituição a "pulso ausente");

- Pulso pedioso direito (variável qualitativa nominal): classificado em presente, diminuído ou ausente (No presente estudo considerou-se a nomenclatura "pulso não palpável" em substituição a "pulso ausente");

- Cor da pele (variável qualitativa nominal): classificada em normal, pálida, azulada/arroxeada ou avermelhada.

- Temperatura (variável qualitativa ordinal): classificada em normal, quente ou fria. 
- Classificação do risco do pé diabético (variável qualitativa ordinal): classificada em zero (0) corresponde ao risco baixo, um (1), moderado, dois (2), alto ou três (3) risco muito alto (A classificação final do aplicativo "Cuidando do pé” é denominada Risco do pé diabético, o que no presente estudo, por algumas vezes, está nomeado como Risco de integridade titular).

\subsubsection{Variável conhecimento sobre as atividades de autocuidado com os pés}

A variável conhecimento das atividades de autocuidado com os pés (variável qualitativa dicotômica) foi classificada em sim ou não, em que "Sim" significa conhecimento sobre as atividades de prevenção do risco de integridade tissular prejudicada e "Não" o desconhecimento de tais atividades. Foi considerado baixo conhecimento (até quatro respostas "Sim"), moderado conhecimento (quatro a oito respostas "Sim"), alto conhecimento (oito a 12 respostas "Sim") ou muito alto conhecimento (12 a 16 respostas "Sim").

\subsubsection{Variável intenção de cuidar dos pés}

A variável intenção de cuidar dos pés (variável qualitativa ordinal) foi classificada de acordo com os domínios específicos do instrumento, como por exemplo, no domínio "normas subjetivas" as respostas são: devia, talvez devesse, é indiferente, talvez não devesse e não devia. As respostas do instrumento são descritas em uma escala tipo Likert de cinco pontos, quanto maior a pontuação, melhor a intenção de cuidar dos pés.

\subsection{INSTRUMENTOS DE COLETA DE DADOS}

- Ficha de identificação e de informações complementares de pessoas com DM2: foi utilizada para descrever os dados sociodemográficos, antropométricos, hábitos de vida, clínicos e outras informações complementares dos participantes. A ficha de identificação e de informações complementares foi elaborada por Monteiro (2015) e reestruturada a partir do instrumento formulado pelo Grupo de Pesquisa na Atenção Multiprofissional em Diabetes da Escola de Enfermagem de Ribeirão Preto da Universidade de São Paulo, cadastrado no diretório CNPq (APÊNDICE A). 
- MEEM: foi utilizado para avaliar o estado mental no primeiro contato com o participante, ou seja, na fase de recrutamento, na qual foram reavaliados os critérios de inclusão e exclusão do presente estudo. O instrumento é composto por questões agrupadas em sete categorias. Cada uma delas possui o objetivo de avaliar funções cognitivas específicas: orientação para tempo e local; registro de palavras; atenção e cálculo; lembrança das palavras registradas; linguagem e capacidade construtiva visual.

O MEEM foi construído por Folstein e colaboradores (1975) e foi traduzido no Brasil por Bertolucci et al. (1994), os quais propuseram a utilização de pontos de cortes diferenciados de acordo com a escolaridade, para o diagnóstico genérico de "declínio cognitivo". (ANEXO A). Destaca-se que a sua utilização foi mediante a autorização dos autores do instrumento (ANEXO B).

- Aplicativo Cuidando do pé: para avaliar a integridade tissular dos MMII foi utilizado um aplicativo desenvolvido por Muro (2018), a partir dos critérios preconizados pelo manual do pé diabético do MS (BRASIL, 2016). Neste instrumento informatizado, os itens de avaliação estão apresentados de forma organizada e resumida, o que permite que o exame dos pés seja realizado de forma interativa na prática clínica (MURO, 2018).

Os recursos da informática neste instrumento contam com 19 telas principais, dispostas da seguinte forma: uma tela de apresentação com opções de entrada para o usuário acessar as informações sobre o aplicativo e sobre instruções de uso. Em seguida, encontra-se a tela inicial com recursos para cadastrar a pessoa com DM, para exportação dos dados e a listagem das pessoas que já foram avaliadas. Posteriormente, o aplicativo segue com as telas de avaliação propriamente ditas, as quais contêm símbolos que permitem o acesso a fotos para identificar as deformidades, por exemplo, e, vídeos que demonstram o procedimento dos testes de sensibilidade e reflexo.

As telas iniciais exibem os dados de identificação, seguidos das informações complementares que consiste em investigar a história de tabagismo; consumo de álcool; HA; dificuldade visual; história de úlceras; amputação; dor ou desconforto; além disso, permite identificar se a pessoa com DM já teve os pés avaliados por profissionais de saúde, se conhece os cuidados com os pés e se realiza frequentemente os cuidados com os pés (ANEXO C).

$\mathrm{O}$ exame dos MMII compõe quatro etapas. A primeira refere-se à pele e os anexos (condições dermatológicas) e inclui os itens: integridade da pele; cor; pilificação; hidratação; 
unhas; e espaços interdigitais. A segunda consiste na avaliação das condições neurológicas, que compreende: teste com o monofilamento de Semmes-Weinstein; sensibilidade vibratória com diapasão $128 \mathrm{~Hz}$ e reflexo tendíneo de Aquileu. A terceira etapa está relacionada às condições vasculares/arteriais, que inclui os sinais de insuficiência arterial/venosa como varizes, edema, pulsos e temperatura. A quarta etapa refere-se à avaliação das deformidades dos pés (para a apresentação e discussão dos resultados a ordem das etapas foi alterada).

A seguir serão detalhados os dados sobre os itens que compõem a avaliação da integridade da pele e anexos (condições dermatológicas), a sensibilidade, as deformidades anatômicas, as condições vasculares/arteriais e a temperatura dos pés e respectiva semiotécnica (ANEXO C).

- PELE E ANEXOS (condições dermatológicas) : avaliada por meio da inspeção e toque das mãos, quando necessário. Os aspectos relacionados à integridade geral da pele foram verificados por meio da presença ou ausência de qualquer alteração na pele, tais como lesões, aberturas e/ou fissuras (ANEXO C).

- Lesões esfoliativas: verificou-se a presença ou ausência de descamação na pele.

- Micoses: verificou-se a presença ou ausência descamação pruriginosa na pele.

- Calosidades: verificou-se a presença ou ausência de espessamento epidérmico.

- Pilosidade: verificou-se a presença ou ausência de pelos nas pernas.

- Hidratação: verificou-se a presença ou ausência de pele hidratada e macia ao toque.

- Xerodermia: verificou-se a presença ou ausência de ressecamento extremo da pele.

- Fissuras (rachaduras): verificou-se a presença ou ausência de fissuras na pele, principalmente na região do calcâneo.

- Corte correto de unhas: verificou-se a presença ou ausência de corte de unha de forma reta ou quadrada.

- Espaços interdigitais: verificou-se a presença ou ausência de umidade ou maceramento entre os pododáctilos.

- SENSIBILIDADE: avaliada mediante testes específicos (ANEXO C).

- Sensibilidade tátil pressórica: avaliada por meio do Monofilamento de Semmes-Weinstein 5.07, de 10g (cor laranja), preconizado pelo Manual do Pé diabético (BRASIL, 2016). A sensibilidade tátil pressórica foi avaliada em quatro regiões plantares específicas: hálux, $1^{\mathrm{a}}, 3^{\mathrm{a}}$ e $5^{\mathrm{a}}$ cabeças de metatarsos (BRASIL, 2006). 
Em momento prévio ao teste, os participantes foram convidados a se familiarizarem com o Monofilamento, no intuito de reconhecerem a sensação causada no contato com a pele.

Durante o teste, os participantes permaneceram em decúbito dorsal e com os pés isolados por uma placa de papelão, para evitar a visualização do toque do filamento pelo observador, e foram orientados a responderem "estou sentindo" a cada toque percebido.

- Sensibilidade vibratória com diapasão de $128 \mathrm{~Hz}$ : foi avaliada com o uso de um diapasão de $128 \mathrm{~Hz}$. O teste foi realizado em proeminência óssea no dorso da falange distal do hálux, em ambos os pés. Mediante a necessidade, a outra opção para pesquisar essa sensibilidade, era a região maleolar (BOULTON et al., 2008) (ANEXO C).

Da mesma forma do teste anterior, os participantes foram convidados a se familiarizarem com o diapasão $128 \mathrm{~Hz}$, no intuito de reconhecerem a sensação vibratória causada com o contato na pele, consequente ao toque do instrumento. Durante o teste, os participantes permaneceram em decúbito dorsal.

- Reflexo tendíneo de Aquileu: avaliado por meio da percussão com o martelo de reflexos ou com a digitopercussão do tendão de Aquiles. O teste foi considerado alterado quando a flexão plantar reflexa do pé estava ausente ou diminuída (ANEXO C).

Antes do teste os participantes foram convidados a conhecer o martelo. Durante o teste permaneceram sentados, com os pés relaxados, passivamente em discreta dorsoflexão.

- DEFORMIDADES NOS PÉS: foi verificada a presença de deformidades anatômicas nos pés, tais como garras, martelo, hálux valgo e artropatia de Charcot (ANEXO C).

- CONDIÇÕES VASCULARES/ARTERIAIS: foram avaliados os sinais de insuficiência venosa/arterial por meio da presença de edema e varizes e da palpação dos pulsos tibiais e pediosos (ANEXO C).

- Edema: verificou-se a presença ou ausência de edema por meio da pressão digital sobre a pele por 5 segundos.

- Varizes: verificou-se a presença ou ausência de veias dilatadas, tortuosas e de coloração púrpuro-azulada.

- Pulsos tibiais: verificou-se a presença, diminuição ou "ausência" dos pulsos tibiais na região maleolar externa, por meio da pressão com os dedos indicador e médio. (No presente estudo considerou-se a nomenclatura "pulso não palpável" em substituição a "pulso ausente") 
- Pulsos pediosos: verificou-se a presença, diminuição ou "ausência" dos pulsos pediosos no dorso do pé, por meio da pressão com os dedos indicador e médio. (No presente estudo considerou-se a nomenclatura "pulso não palpável” em substituição a "pulso ausente")

- Cor da pele: verificou-se a presença ou ausência de cor da pele normal, pálida, azulada/arroxeada ou avermelhada.

- TEMPERATURA: avaliada por meio da palpação para identificar se um pé estava mais quente ou mais frio que o outro e, após, categorizar em normal, quente ou fria (ANEXO C).

Após as avaliações realizadas e consequentemente, os dados inseridos no aplicativo, foi obtida a classificação do risco do pé diabético (risco de integridade tissular prejudicada), atribuindo os valores de zero (0) a três (3), cujo valor zero (0) corresponde ao risco baixo, valor um (1) moderado, dois (2) alto e três (3) risco muito alto (BRASIL, 2016). Ainda, o aplicativo oferece, além da classificação do risco da pessoa avaliada, a alteração que sugeriu tal risco, as recomendações de acordo com o problema apresentado, a frequência de avaliação e as condutas que deverão ser tomadas pelo profissional de saúde (MURO, 2018) (ANEXO C).

O aplicativo "Cuidando do pé" mostrou-se um instrumento confiável na mensuração do risco do pé diabético (risco de integridade tissular prejudicada) uma vez que, apresentou excelente taxa de concordância entre juízes (Kappa=0,788) e confiabilidade para mais de 80\% dos indicadores da avaliação do pé diabético, tanto na análise interexaminadores quanto na intraexaminador. Ainda, os resultados da comparação entre dois instrumentos (aplicativo versus impresso) revelou concordância de satisfatória a excelente, e, predomínio dos itens com concordância perfeita. Esse fato evidencia que as respostas do aplicativo correspondem seguramente aos dados do critério, nesse caso, o instrumento impresso (MURO, 2018).

Para utilizar o aplicativo, obteve-se autorização previa do autor (ANEXO D).

- Questionário de avaliação do conhecimento sobre o autocuidado com os pés: foi utilizado o questionário para avaliar o conhecimento dos participantes do estudo sobre as atividades de prevenção da integridade tissular dos pés das pessoas com DM, desenvolvido por Monteiro (2015), a partir das orientações propostas pelo MS (BRASIL, 2013). Destaca-se que as atividades de autocuidado com os pés recomendadas pelo MS foram submetidas a um 
processo de refinamento por um comitê de juízes peritos no assunto, os quais propuseram adequações para se obter a versão ideal do questionário.

O questionário é composto por 16 perguntas com respostas dicotômicas (Sim-0 e Não-1), em que "Sim" significa conhecimento sobre as atividades de prevenção da integridade da pele. Foi considerado baixo conhecimento (até quatro respostas "Sim"), moderado conhecimento (quatro a oito respostas "Sim"), alto conhecimento (oito a 12 respostas "Sim") ou muito alto conhecimento (12 a 16 respostas “Sim”). (MONTEIRO, 2015) (ANEXO E).

- QCP-CP: foi utilizado para identificar a intenção das pessoas com DM em realizar as atividades de autocuidado com os pés.

O QCP-CP é um instrumento de origem portuguesa embasado na Teoria do Comportamento Planejado, que considera a intenção para realizar um comportamento como o determinante para que as pessoas possam executá-lo, pois reflete seu nível de motivação e de prontidão (PEREIRA; COSTA; ARAÚJO-SOARES, 2009).

Este instrumento foi adaptado para a cultura brasileira e validado, apresentando-se estável ( $p>0,05$ para a maioria dos itens, Coeficiente de Correlação Intraclasse $($ ICC)=0,675), boa consistência interna (Alfa de Cronbach: >0,7 em quatro domínios), ótima relação entre os domínios (Kaiser-Meyer-Olkin $(\mathrm{KMO})=0,741)$ e estabilidade na estrutura fatorial (MONTEIRO et al., 2015) (ANEXO F).

O instrumento não tem ponto de corte definido, quanto maior a pontuação, melhor é a intenção de cuidar dos pés. Vale lembrar que os domínios "Atitudes" e "Normas Subjetivas" possuem escores invertidos (PEREIRA; COSTA; ARAÚJO-SOARES, 2009).

\subsection{RASTREAMENTO E RECRUTAMENTO DA AMOSTRA}

Para rastrear e recrutar os participantes do presente estudo, foram seguidas as seguintes etapas:

- análise dos 460 prontuários cadastrados na Policlínica e no SIAB para identificar as pessoas que atendiam aos critérios de inclusão do estudo;

- os possíveis participantes do estudo receberam ligações telefônicas para o agendamento de atendimento individualizado e, no caso de insucesso neste contato, eram realizadas até três visitas domiciliares; 
- as pessoas contatadas por telefone ou encontradas no domicílio foram convidadas a participar de atendimento individualizado;

- durante o atendimento individualizado a pesquisadora oficializava o convite para participarem da pesquisa, oferecia esclarecimentos sobre o estudo, e aos concordantes, era apresentado o Termo de Consentimento Livre e Esclarecido (TCLE) em duas vias. Nessa fase os critérios de exclusão estabelecidos também eram observados.

\subsubsection{Randomização}

Os participantes foram randomizados em dois grupos distintos, denominados GI e GC. O GI recebeu a intervenção educativa "Ensino do cuidado com os pés", enquanto o GC se manteve em acompanhamento conforme a rotina do serviço. A formação dos grupos foi realizada por uma pessoa externa à pesquisa, antes de iniciar a primeira avaliação, obedecendo aos seguintes passos:

- Processo de randomização em blocos de 30 pessoas, na proporção 1:1;

- Para cada bloco, foi gerada uma sequência de números aleatórios por meio do site http://www.randomization.com/. Para isso:

$\checkmark$ Foi escolhida a opção First (and Original) Generator, que randomizou cada participante para um tratamento simples, usando o método de blocos permutados aleatoriamente;

$\checkmark$ Em Treatment labels, foi digitado as duas opções de tratamento: Intervenção "Ensino do cuidado com os pés" ou acompanhamento de rotina pela unidade;

$\checkmark$ Em Number of subjects per block/number of blocks, foi descrito o tamanho do bloco (30 pessoas);

$\checkmark$ Por último foi selecionado a opção Generate Plan;

$\checkmark$ Uma nova página com o plano de randomização foi gerada.

- A lista com a sequência dos grupos, gerada pelo programa, foi recortada e colocada em envelope opaco, numerado e fechado, com acesso apenas da intervencionista.

- Durante a primeira avaliação, denominada de tempo 1 (T1), os participantes receberam envelopes numerados aleatoriamente de acordo com a lista gerada na randomização. 


\subsection{PROCEDIMENTOS PARA A COLETA DE DADOS}

A coleta de dados foi constituída por três sessões de avaliação, no tempo 1 (T1), tempo 2 (T2) e tempo follow up (Tfu). Antes de iniciar a coleta de dados a equipe de trabalho recebeu treinamento específico.

As avaliações e as intervenções foram realizadas por dois enfermeiros. $\mathrm{O}$ treinamento do avaliador ocorreu por meio de dois encontros com a equipe de trabalho, no intuito de padronizar os procedimentos para a coleta de dados e esclarecer dúvidas sobre o preenchimento dos questionários e instrumentos.

A intervencionista, junto à equipe de trabalho, descreveu os passos a serem seguidos durante a intervenção, os quais foram embasados na Metodologia do Arco de Charles Maguerez.

Para assegurar a compreensão do avaliador e da intervencionista, bem como estimar o tempo para aplicação dos instrumentos, foi desenvolvido um estudo piloto entre pessoas com DM acompanhadas na modalidade da ESF do município de Boa Esperança, MG.

\subsubsection{Estudo piloto}

De acordo com Hulley e colaboradores (2015), é possível identificar as dificuldades quanto a implementação de um estudo, avaliar a aplicabilidade de instrumentos, bem como precisar o tempo utilizado para coleta de dados por meio de um pequeno número de participantes.

O estudo piloto foi desenvolvido em uma ESF no município de Boa Esperança, MG, nos meses de Março a Abril de 2018. A amostra inicial contou com a participação de 22 pessoas, que foram estratificadas por conhecimento das atividades de autocuidado com os pés, randomizadas e alocadas igualmente no GC e no GI $(n=11)$.

No seguimento do estudo piloto houve perda de três participantes no GI e um no GC, o que não foi considerado um obstáculo para se identificar a aplicabilidade dos instrumentos, bem como a conformidade do tempo gasto durante a coleta de dados, o que não gerou desgastes no avaliador, nem nos participantes desta etapa.

Desta forma, o estudo piloto contribui para os seguintes ajustes: realizar as avaliações no domicilio, mediante a dificuldade os participantes comparecerem na unidade de saúde, bem como excluir o processo de estratificação da amostra por conhecimento, devido a 
homogeneidade dos grupos para essa variável, conforme observado também em estudos anteriores (MONTEIRO, 2015; MOREIRA, 2017).

A seguir deu-se continuidade ao presente estudo entre os participantes recrutados, provenientes da Policlínica para o desenvolvimento da pesquisa, mediante os procedimentos metodológicos estabelecidos. Ressalta-se que a amostra do estudo piloto não foi considerada para a análise final.

\subsubsection{Avaliação das variáveis do estudo}

As avaliações foram realizadas em três momentos:

- Antes do início das intervenções educativas, denominada avaliação inicial - T1;

- Três meses após T1, ao final das intervenções, denominada avaliação final - T2;

- Em um período de seguimento de três meses após T2 - Tfu (FERNANDES; REIS; TORRES, 2016).

As avaliações foram previamente agendadas e realizadas no domicílio dos participantes pela mesma pessoa, um enfermeiro instruído e capacitado durante treinamento, o qual desconhecia a alocação dos participantes nos grupos intervenção e controle, garantindo o mascaramento.

\subsubsection{Intervenções}

As intervenções foram realizadas por meio de três encontros, previamente agendados, com intervalo de trinta dias, por um período de aproximadamente três meses (Quadro 1).

Para o desenvolvimento das intervenções educativas, os participantes do GI foram divididos em seis grupos compostos por no máximo 15 pessoas. 
Quadro 1 - Intervenção "Ensino do Cuidado com os Pés" por meio do Arco de Maguerez

\begin{tabular}{|c|l|}
\hline ENCONTRO & \multicolumn{1}{c|}{ ATIVIDADES } \\
\hline $\mathbf{1}^{\mathbf{0}}$ & - Dinâmica para integração dos participantes \\
& - Dinâmica para a observação da realidade/problema \\
& - Determinação dos Pontos-chave \\
\hline $\mathbf{2}^{\mathbf{0}}$ & - Teorização \\
& - Hipóteses de solução \\
\hline $\mathbf{3}^{\mathbf{0}}$ & - Dinâmica para a aplicação prática à realidade \\
\hline
\end{tabular}

Fonte: do autor.

Intervenção "Ensino do Cuidado com os Pés" por meio do Arco de Maguerez: os encontros com o GI foram desenvolvidos a partir dos pressupostos teóricos da Metodologia da Problematização, por meio do Arco de Charles Maguerez, conforme esquema apresentado por Bordenave e Pereira (1982) que consta das seguintes etapas a partir de um recorte da realidade: Observação da Realidade; Pontos-chave; Teorização; Hipóteses de Solução e Aplicação à Realidade (BORDENAVE; PEREIRA, 1982; BERBEL, 1996).

- $\mathbf{1}^{\mathrm{a}}$ encontro

$\checkmark$ Foi realizada uma dinâmica para integração dos participantes.

$1^{\text {a }}$ dinâmica: o grupo foi dividido em pares, assim, cada pessoa deveria descrever-se para o seu par a partir da seguinte pergunta norteadora: “Quem sou eu?" Após esse momento, cada participante apresentou as características do seu par para os demais integrantes do grupo. Essa dinâmica possuiu o intuito de facilitar a interação e o conhecimento de todos os participantes e, inclusive da intervencionista.

$\checkmark$ Observação da Realidade: outra dinâmica foi aplicada no intuito de observar a realidade/problema, adaptado do estudo de Rêgo e colaboradores (2006).

$2^{\text {a }}$ dinâmica: foi distribuído um bilhete para cada participante com perguntas facilitadoras para a observação do problema/realidade. As perguntas, descritas a seguir, estão relacionadas ao autocuidado com os pés:

O senhor (a) observa seus pés? Como? Quando?

O que o senhor (a) faz quando apresenta calos, fissuras (rachaduras), alterações de cor ou machucados nos pés?

O senhor (a) usa meias limpas, de algodão e sem elástico? 
O senhor (a) usa calçados/sapatos que apertam os pés?

O senhor (a) usa calçado/sapatos fechados e macios?

Como o senhor (a) usa sapatos novos?

O senhor (a) anda descalço?

Como o senhor (a) lava os pés? Qual a frequência?

Como o senhor (a) seca os pés?

O senhor (a) usa hidratante nos pés? Como?

Como o senhor (a) corta as unhas? Com que material?

Como o senhor (a) remove calos ou unhas encravadas?

Quando o senhor (a) apresenta uma ferida ou bolha nos pés o que o senhor faz?

Esta dinâmica teve o intuito de identificar os problemas relacionados ao autocuidado com os pés, a partir do conhecimento e atitudes dos participantes.

Após este momento, foi confeccionada, junto à intervencionista, uma síntese do problema, a qual norteou os demais encontros.

$\checkmark$ Determinação dos Pontos-chave: nesta fase os participantes foram encorajados a refletir sobre os fatores associados às falhas na execução do autocuidado com os pés, o que foi considerado um problema e, após a reflexão, houve discussão com os demais integrantes do grupo. Os pontos-chave foram identificados no intuito de encontrar soluções posteriores.

\section{- $\quad 2^{\mathrm{a}}$ encontro}

$\checkmark$ Teorização: a teorização está relacionada com a busca de informações sobre o problema. Desta forma, a intervencionista abordou o problema de forma simples, por meio de discussão com os integrantes do grupo. Neste momento foi explicada a importância das atividades de autocuidado para a prevenção de integridade tissular dos pés, a partir do problema vivenciado pelo grupo e redefinido os pontos-chave. Este encontro poderia ter acontecido mais de uma vez, por depender do conhecimento e atitude prévia dos integrantes do grupo.

$\checkmark$ Hipóteses de solução: todo o processo percorrido forneceu subsídios aos participantes para que propusessem possíveis soluções de modo crítico e criativo. Para isso, foram utilizadas as seguintes questões: Como podemos solucionar o problema? O que precisa ser providenciado? O que pode realmente ser feito? 
Após a reflexão dos participantes, foi iniciada uma discussão com o objetivo de elucidar as informações recebidas. As hipóteses construídas após o estudo foram frutos da compreensão profunda que se obteve sobre o problema, possíveis perspectivas ou compreensões pessoais.

- $\quad 3^{a}$ encontro

Aplicação prática à realidade: neste momento foi reprisada a segunda dinâmica, cujo cada integrante do grupo recebeu um bilhete com perguntas que facilitaram o relato da aplicação dos novos conhecimentos no cotidiano. Quando necessário, as informações sobre atividades de autocuidado foram reforçadas pela intervencionista, visando sanar as dúvidas, anseios e medos. Tais perguntas estavam relacionadas ao autocuidado dos pés:

O senhor (a) observa seus pés? Como? Quando?

O que o senhor (a) faz quando apresenta calos, fissuras, alterações de cor ou machucados nos pés?

O senhor (a) usa meias limpas, de algodão e sem elástico?

O senhor (a) usa calçados/sapatos que apertam os pés?

O senhor (a) usa calçado/sapatos fechados e macios?

Como o senhor (a) usa sapatos novos?

O senhor (a) anda descalço?

Como o senhor (a) lava os pés? Qual a frequência?

Como o senhor (a) seca os pés?

O senhor (a) usa hidratante nos pés? Como?

Como o senhor (a) corta as unhas? Com que material?

Como o senhor (a) remove calos ou unhas encravadas?

Quando o senhor (a) apresenta uma ferida ou bolha nos pés o que o senhor faz?

Os participantes discutiram sobre as mudanças ocorridas durante os encontros por meio da comparação das primeiras e as últimas respostas da dinâmica, o que os fizeram refletir sobre a importância da mudança de comportamento em relação ao autocuidado dos pés.

Referente ao GC, os participantes seguiram o acompanhamento de rotina na unidade, a qual consistia em consulta de enfermagem antes e após as consultas médicas. Contudo, após $\mathrm{T} f u$ o GC recebeu a intervenção "Ensino do cuidado com os pés", no intuito de promover a 
oportunidade de desenvolverem o autocuidado com os pés e consequente prevenção de úlceras plantares.

A seguir está apresentada a esquematização do estudo com as avaliações e intervenções (Figura 3). 
Figura 3 - Esquematização do estudo

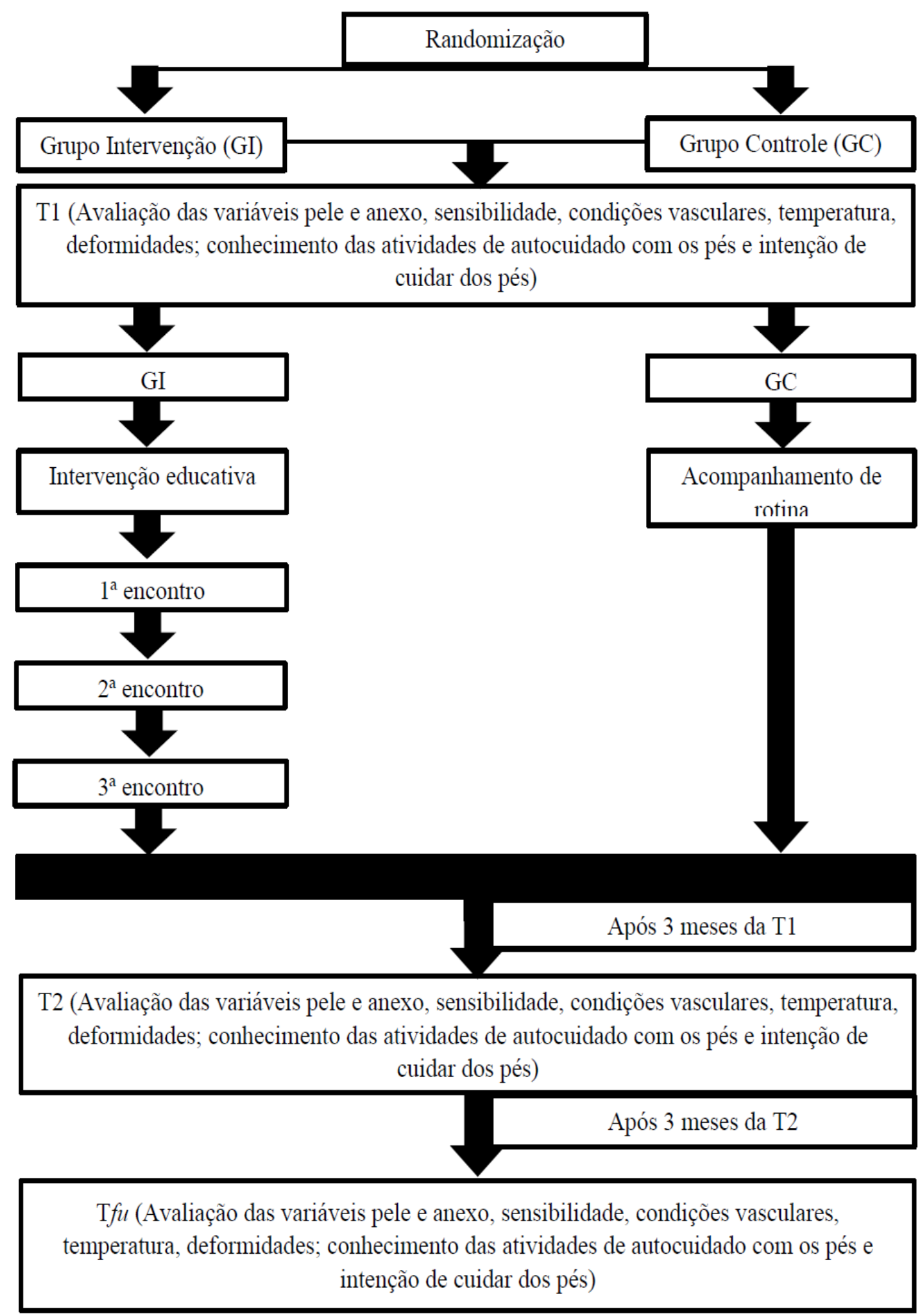

Fonte: do autor. 


\subsection{ANÁLISE DOS DADOS}

Os dados coletados foram digitados em uma planilha eletrônica do programa MSExcel e posteriormente analisados com o auxílio dos programas R, versão 3.6.1, e BioEstat, versão 5.3.

Para analise das características sociodemográficas, antropométricas, hábitos de vida, aspectos clínicos e outras informações foram utilizados os testes Qui-quadrado, Wilcoxon ou Wilcoxon-Mann-Whitney.

O Qui-quadrado ou o teste Exato de Fisher foram aplicados nas variáveis qualitativas nominais para análise de amostras independentes (SIEGEL, 1975). Para as variáveis qualitativas ordinais e contínuas foi utilizado Wilcoxon pareado, no caso de duas amostras relacionadas e Wilcoxon-Mann-Whitney para amostras independentes (SIEGEL, 1975).

Em relação à comparação intergrupo, foi aplicado o teste de Qui-quadrado para as variáveis nominais ou Wilcoxon-Mann-Whitney para variáveis ordinais. Destaca-se que ambos os testes são utilizados para análise de amostras independentes (SIEGEL, 1975).

A análise intragrupo foi realizada para as amostras relacionadas por meio do Teste McNemar para variáveis nominais ou Wilcoxon pareado, no caso de variáveis ordinais (SIEGEL, 1975).

Destaca-se que todos os testes foram aplicados considerando-se um nível de significância de $5 \%$.

\subsection{ASPECTOS ÉTICOS}

O projeto de pesquisa foi encaminhado ao Comitê de Ética em Pesquisa da Universidade Federal de Alfenas (CEP) no mês de Novembro do ano de 2017, por meio da Plataforma Brasil, conforme Resolução 196/96 versão 2012, que trata das diretrizes e das normas de pesquisa envolvendo seres humanos (BRASIL, 2012b), cuja aprovação encontra-se sob número 2.398.216 (ANEXO G). O projeto também foi registrado na Plataforma de Registro Brasileiro de Ensaios Clínicos (http://www.ensaiosclinicos.gov.br) e aprovado sob o número 2.398.216. 
O secretário de saúde do município de Boa Esperança - MG permitiu o desenvolvimento do presente estudo na Policlínica do município por meio da assinatura do termo de autorização da instituição coparticipante (APÊNDICE B).

Antes de iniciar a intervenção educativa, os voluntários foram esclarecidos sobre os objetivos da pesquisa e foi solicitada a assinatura do TCLE em duas vias, garantindo o anonimato e o direito de desistência em qualquer fase da pesquisa (APÊNDICE C). 
5 RESULTADOS 
Nesse item, primeiramente estão apresentados os resultados obtidos do processo de composição da amostra do estudo, seguido da caracterização da amostra e resultados da intervenção "Ensino do cuidado com os pés" na integridade da pele e anexos (condições dermatológicas), na sensibilidade, nas deformidades anatômicas, nas condições vasculares/arteriais, na temperatura dos pés, no conhecimento das atividades de autocuidado e intenção de cuidar dos pés.

\subsection{FLUXO DOS PARTICIPANTES EM CADA ETAPA DO ESTUDO}

Conforme já descrito, para o rastreamento da amostra foram analisados dados cadastrais de 460 pessoas com DM em atendimento clínico na Policlínica de Boa Esperança, MG. Após a análise inicial dos dados cadastrais, 47 pessoas foram excluídas pelo diagnóstico de DM1 e 93 por terem menos de cinco anos de diagnóstico de DM2.

Assim, 320 pessoas foram selecionadas para o primeiro contato, realizado por meio de ligação telefônica ou por visita domiciliar, cujo objetivo era efetivar o convite para participar do estudo e agendar o atendimento individualizado. Reitera-se que no insucesso dessa primeira abordagem, realizavam-se outras três tentativas de contato. Contudo, já haviam ocorridos cinco óbitos, 12 pessoas estavam hospitalizadas ou acompanhando familiares nessa condição e 63 não atenderam as ligações telefônicas e/ou não foram encontradas no domicílio, de forma que 240 pessoas apresentaram, inicialmente, os critérios para o primeiro atendimento individualizado.

$\mathrm{O}$ primeiro atendimento individualizado objetivou oficializar o convite para participação e oferecer maiores esclarecimentos sobre o estudo. Aos concordantes era apresentado o Termo de Consentimento Livre e Esclarecido (TCLE) em duas vias para ser lido e assinado. Nesse momento também foram analisados os critérios de exclusão e desta forma, 24 pessoas foram descontinuadas, sete por apresentar UPD ativa, um por trombose, quatro por amputação de MMII e 12 por déficit cognitivo avaliado pelo MEEM.

Das 216 pessoas convidadas para o atendimento individualizado, 34 não compareceram na Policlínica em horário previamente agendado e 15 não quiseram participar da pesquisa. Assim, 167 pessoas preencheram aos critérios de elegibilidade para participar do estudo, e foram alocadas nos respectivos grupos, por meio do processo de randomização, da seguinte maneira: GI $(n=84)$ e GC $(n=83)$. Durante o estudo 15 participantes perderam o 
seguimento, dos quais 11 do GI e 4 do GC, de modo que concluíram o estudo 73 e 79 pessoas, respectivamente (Figura 4). 
Figura 4 - Fluxograma dos participantes em cada etapa do estudo

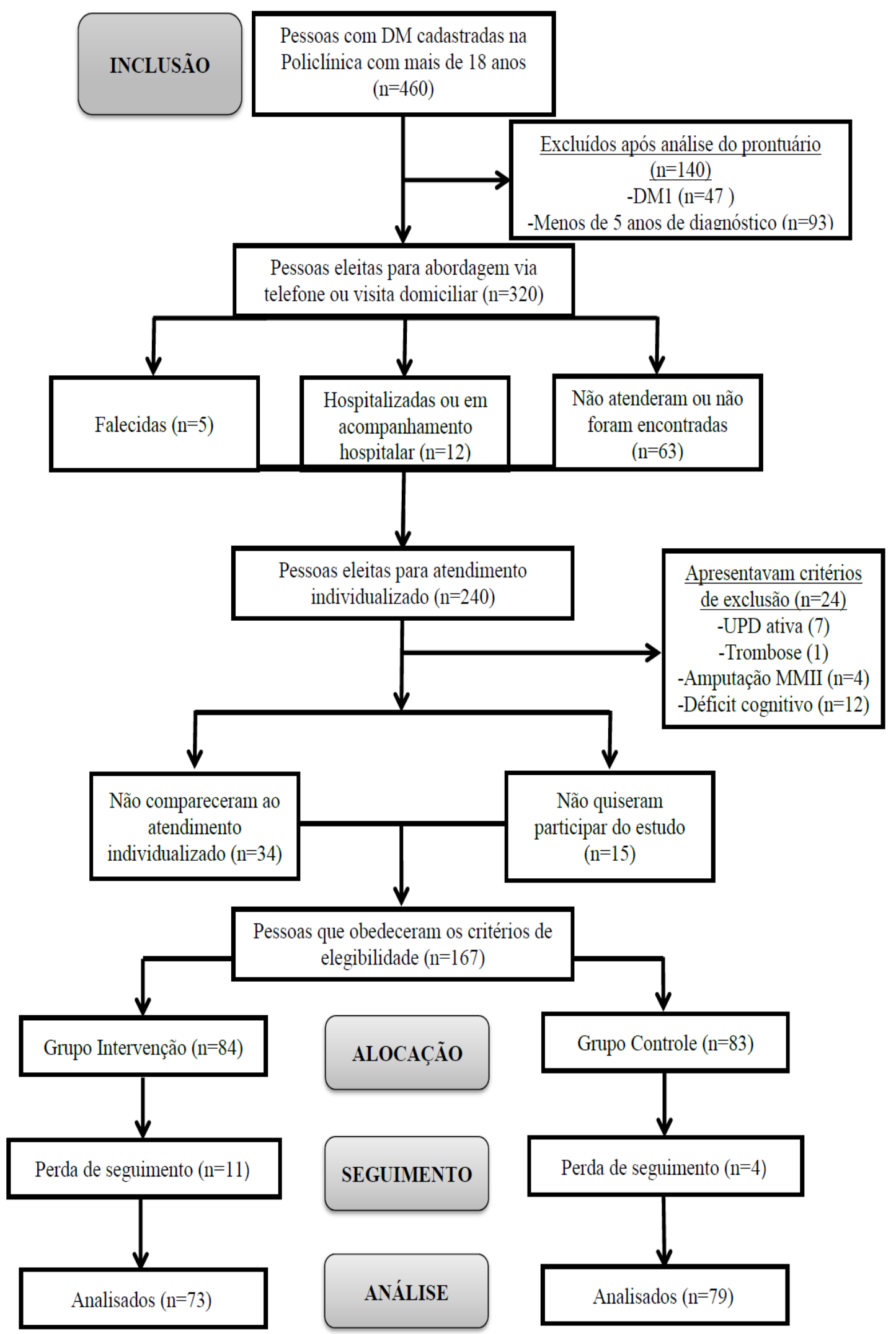

Fonte: Adaptado de CONSORT (2010). 


\subsection{CARACTERIZAÇÃO DA AMOSTRA}

Para caracterizar os participantes do estudo, estão apresentadas as variáveis relacionadas aos aspectos sociodemográficos, antropométricos, hábitos de vida, clínicos e outras informações complementares.

\subsubsection{Caracterização da amostra quanto as variáveis sociodemográficas}

Quanto aos dados sociodemográficos, destaca-se que os grupos eram homogêneos em relação ao sexo e ao estado civil, com predominância de participantes do sexo "feminino" ( $\mathrm{GI}=75 \%$ e $\mathrm{GC}=56 \%)$ e estado civil "com cônjuge/companheiro" (GI=57\% e GC=48\%). Referente à escolaridade os grupos apresentaram diferenças significativas entre eles, o GI possuía 56\% (n=41) dos seus participantes com "média escolaridade" e o GC, 63\% (n=50) com "baixa escolaridade" (Tabela 1).

Tabela 1 - Caracterização dos participantes em relação a frequência das variáveis sexo, estado civil e escolaridade. Boa Esperança, 2019.

\begin{tabular}{|c|c|c|c|c|}
\hline & ARIÁVEIS & $\begin{array}{c}\text { GI }(n=73) \\
\text { f }(\%)\end{array}$ & $\begin{array}{c}\text { GC(n=79) } \\
\mathbf{f}(\%)\end{array}$ & Valor $\mathbf{p}$ \\
\hline \multirow{2}{*}{ Sexo } & Feminino & $55(75,34 \%)$ & $45(56,97 \%)$ & \multirow{2}{*}{0,0170} \\
\hline & Masculino & $18(24,66 \%)$ & $34(43,03 \%)$ & \\
\hline \multirow{2}{*}{ Estado civil } & Sem cônjuge/companheiro & $31(42,47 \%)$ & $31(39,24 \%)$ & \multirow{2}{*}{0,4156} \\
\hline & Com cônjuge/companheiro & $42(57,53 \%)$ & $48(60,76 \%)$ & \\
\hline \multirow{3}{*}{ Escolaridade } & Baixa $(<8$ anos $)$ & $26(35,60 \%)$ & $50(63,30 \%)$ & \multirow{3}{*}{$* 0,0199$} \\
\hline & Média (8 - 12 anos) & $41(56,13 \%)$ & $29(36,70 \%)$ & \\
\hline & Alta $(\geq 12$ anos $)$ & $6(8,27 \%)$ & $0(0,00 \%)$ & \\
\hline
\end{tabular}

Fonte: do autor

Teste Qui-quadrado e Wilcoxon - Mann-whitney

*valor $\mathrm{p}<0,05$

Para a variável ocupação, houve predomínio de pessoas "aposentadas", das quais $57 \%$ $(n=42)$ do GI e 49\% (n=39) do GC.

Nas variáveis idade e número de "residentes na mesma casa", observa-se que os grupos eram homogêneos. A média de "idade" dos participantes dos grupos foi de 62 anos e o "número de residentes na mesma casa" que o participante do estudo, variou de 2,73 
$(\mathrm{DP}=1,26)$ a 3,24 $(\mathrm{DP}=1,65)$ no GI e $\mathrm{GC}$, respectivamente. Já a "renda familiar" apresentou diferença significativa entre os grupos $(\mathrm{p}=0,0271)$. O GI em média apresentou renda familiar de $\mathrm{R} \$ 3.261,80$ (DP=R $\$ 1.496,00)$ e, o GI $\mathrm{R} \$ 2.551,98$ (DP=R $\$ 1.403,00)$ (Tabela 2).

Tabela 2 - Caracterização dos participantes em relação a média e desvio padrão das variáveis idade, renda familiar e número de residentes em casa. Boa Esperança, 2019.

\begin{tabular}{cccc}
\hline VARIÁVEIS & $\begin{array}{c}\text { GI }(\mathbf{n}=\mathbf{7 3}) \\
\text { Média (DP) }\end{array}$ & $\begin{array}{c}\text { GC }(\mathbf{n}=\mathbf{7 9}) \\
\text { Média (DP) }\end{array}$ & Valor p intergrupos \\
\hline Idade & $62,02(11,36)$ & $62,17(11,24)$ & 0,9351 \\
Renda familiar & $\begin{array}{c}\mathrm{R} \$ 3.261,80 \\
(\mathrm{R} \$ 1.496,00)\end{array}$ & $\begin{array}{c}\mathrm{R} \$ 2.551,98 \\
(\mathrm{R} \$ 1.403,00)\end{array}$ & $* \mathbf{0 , 0 2 7 1}$ \\
$\begin{array}{c}\text { Número de residentes } \\
\text { em casa }\end{array}$ & $2,73(1,26)$ & $3,24(1,65)$ & 0,0959 \\
\hline
\end{tabular}

Fonte: do autor

Teste Wilcoxon - Mann-whitney

*valor $\mathrm{p}<0,05$

Salário mínimo: $\mathrm{R} \$ 954,00$

\subsubsection{Caracterização da amostra quanto as variáveis antropométricas}

A análise das variáveis antropométricas, "peso" $(p=0,1205)$, "altura" $(p=0,4376)$ e "IMC" ( $p=0,3872)$, não apresentaram diferenças significativas entre os grupos e evidenciou o sobrepeso dos participantes (Tabela 3).

Tabela 3 - Caracterização dos participantes em relação a média e desvio padrão das variáveis peso, altura e IMC. Boa Esperança, 2019.

\begin{tabular}{cccc}
\hline VARIÁVEIS & $\begin{array}{c}\text { GI }(\mathrm{n}=73) \\
\text { Média (DP) }\end{array}$ & $\begin{array}{c}\text { GC }(\mathrm{n}=79) \\
\text { Média (DP) }\end{array}$ & Valor p intergrupos \\
\hline Peso & $73,27(11,51)$ & $77,46(15,01)$ & 0,1205 \\
Altura & $1,61(0,071)$ & $1,63(0,095)$ & 0,4376 \\
IMC & $28,08(4,42)$ & $29,19(6,06)$ & 0,3872 \\
\hline
\end{tabular}

Fonte: do autor

Teste Wilcoxon - Mann-whitney 


\subsubsection{Caracterização da amostra quanto as variáveis hábitos de vida}

Os grupos apresentaram homogeneidade nas variáveis "tabagismo" ( $p=0,9168)$, "consumo de bebidas alcoólicas" ( $p=0,8852)$, "frequência do consumo de bebidas alcoólicas" ( $p=0,5637)$, “exercício físico" ( $p=0,8983$,$) e "frequência do exercício físico" (p=0,6015)$. Observa-se que os participantes do estudo, em sua maioria não eram "tabagistas" (GI e $\mathrm{GC}=54 \%$ ), não faziam "uso de bebidas alcoólicas" ( $\mathrm{GI}=58 \%$ e $\mathrm{GC}=75 \%$ ) e "não praticavam exercícios físicos" (GI=64\% e GC=53\%) (Tabela 4). 
Tabela 4 - Caracterização dos participantes em relação a frequência das variáveis tabagismo, consumo de bebidas alcoólicas, frequência do consumo de bebidas alcoólicas, exercícios físicos e frequência dos exercício físico. Boa Esperança, 2019.

\begin{tabular}{|c|c|c|c|c|}
\hline \multicolumn{2}{|c|}{ VARIÁVEIS } & $\begin{array}{c}\text { GI }(\mathbf{n = 7 3 )} \\
\mathbf{f}(\%)\end{array}$ & $\begin{array}{c}\text { GC }(n=79) \\
f(\%)\end{array}$ & $\begin{array}{c}\text { Valor } \\
\text { p }\end{array}$ \\
\hline \multirow{5}{*}{ Tabagismo } & Não & $40(54,79 \%)$ & $43(54,43 \%)$ & \multirow{5}{*}{0,9168} \\
\hline & $\begin{array}{l}\text { Sim - Um maço ou mais } \\
\text { por dia }\end{array}$ & $8(10,95 \%)$ & $16(20,25 \%)$ & \\
\hline & $\begin{array}{l}\text { Sim - apenas cigarro de } \\
\text { palha/cachimbo }\end{array}$ & $0(0,00 \%)$ & $2(2,53 \%)$ & \\
\hline & $\begin{array}{l}\text { Não - Parou há menos de } \\
\text { um ano }\end{array}$ & $4(5,5 \%)$ & $1(1,28 \%)$ & \\
\hline & $\begin{array}{l}\text { Não - Parou há um ano ou } \\
\text { mais }\end{array}$ & $21(28,76 \%)$ & $17(21,51 \%)$ & \\
\hline \multirow{4}{*}{$\begin{array}{c}\text { Consumo de bebidas } \\
\text { alcoólicas }\end{array}$} & Não & $43(58,85 \%)$ & $59(75,94 \%)$ & \multirow{4}{*}{0,8852} \\
\hline & Sim-Cerveja & $26(35,65 \%)$ & $15(18,98 \%)$ & \\
\hline & Sim - Vinho & $4(5,50 \%)$ & $4(5,06 \%)$ & \\
\hline & $\begin{array}{l}\text { Sim - Destilados } \\
\text { (Whisky/pinga) }\end{array}$ & $0(0,00 \%)$ & $1(1,28 \%)$ & \\
\hline \multirow{4}{*}{$\begin{array}{c}\text { Frequência do } \\
\text { consumo de bebidas } \\
\text { alcoólicas }\end{array}$} & Não bebe & $44(60,27 \%)$ & $59(74,68 \%)$ & \multirow{4}{*}{0,5637} \\
\hline & 4 a 7 vezes por semana & $2(2,74 \%)$ & $0(0,00 \%)$ & \\
\hline & Até 3 vezes por semana & $5(6,85 \%)$ & $0(0,00 \%)$ & \\
\hline & Eventualmente/raramente & $22(30,14 \%)$ & $20(25,32 \%)$ & \\
\hline \multirow{7}{*}{ Exercícios físicos } & Não faz exercício físico & $47(64,38 \%)$ & $42(53,16 \%)$ & \multirow{7}{*}{0,8983} \\
\hline & Dança & $1(1,37 \%)$ & $0(0,00 \%)$ & \\
\hline & Futebol & $0(0,00 \%)$ & $1(1,28 \%)$ & \\
\hline & Natação & $3(4,11 \%)$ & $0(0,00 \%)$ & \\
\hline & Caminhada & $12(16,44 \%)$ & $9(11,39 \%)$ & \\
\hline & Bicicleta & $0(0,00 \%)$ & $2(2,53 \%)$ & \\
\hline & Ginástica & $10(13,70 \%)$ & $25(31,64 \%)$ & \\
\hline \multirow{5}{*}{$\begin{array}{l}\text { Frequência do } \\
\text { exercício físico }\end{array}$} & Não pratica & $47(64,38 \%)$ & $42(53,16 \%)$ & \multirow{5}{*}{0,6015} \\
\hline & 5 a 7 vezes por semana & $14(19,18 \%)$ & $8(10,13 \%)$ & \\
\hline & 3 a 4 vezes por semana & $7(9,59 \%)$ & $12(15,19 \%)$ & \\
\hline & Até 2 vezes por semana & $5(6,85 \%)$ & $15(18,98 \%)$ & \\
\hline & Eventualmente & $0(0,00 \%)$ & $2(2,54 \%)$ & \\
\hline
\end{tabular}

Fonte: do autor

Teste Qui-quadrado e Wilcoxon - Mann-whitney 
Quanto a média e desvio padrão do "tempo em anos que os participantes foram ou são tabagistas" $(\mathrm{GI}=13,10(\mathrm{DP}=18,19), \mathrm{GC}=10,54(\mathrm{DP}=15,09))$, destaca-se que os grupos não apresentaram diferenças significativas $(\mathrm{p}=0,7414)$.

\subsubsection{Caracterização da amostra quanto as variáveis clínicas}

No que se refere ao "tempo de diagnóstico" de DM em anos, observa-se que não houve diferença entre os grupos $(\mathrm{GI}=11,71(\mathrm{DP}=7,75), \mathrm{GC}=10,72(\mathrm{DP}=5,47))(\mathrm{p}=1,0000)$.

O mesmo ocorreu quando comparado os grupos em relação às variáveis "uso de antidiabéticos orais" ( $p=0,1280)$, "uso de insulina" ( $p=0,6854)$, "uso de antidiabéticos e insulina" ( $p=0,3905)$, “tipo de antidiabético oral" $(p=0,8728)$, “tipo de insulina" $(p=1,0000)$, "HAS autorreferida" ( $p=0,8092)$, “associação de outras doenças" ( $p=0,1697)$, "dificuldade visual" ( $p=0,3217)$, "história de úlceras" $(p=1,0000)$ e "grau de dor nas pernas" $(p=0,4174)$. Destaca-se que os participantes dos grupos faziam mais uso de "antidiabéticos orais" $(\mathrm{GI}=86 \%$ e $\mathrm{GC}=93 \%)$ em relação à "insulina" $(\mathrm{GI}=27 \%$ e $\mathrm{GC}=30 \%)$, sendo as "biguanidas" $(\mathrm{GI}=27 \%$ e $\mathrm{GC}=40 \%)$ e as "associações de mais de um tipo de antidiabético oral" (GI=35\% e GC $=46 \%$ ) as mais utilizadas. Em relação ao tipo de "insulina", a mais consumida pelos participantes dos grupos foi a "NPH/lenta" ( $\mathrm{GI}=24 \%$ e $\mathrm{GC}=27 \%)$. Os participantes também relataram apresentar "HAS" autorreferida (GI=79\% e $\mathrm{GC}=81 \%)$ e "outras doenças associadas" (GI=72\% e GC=60\%) (Tabela 5).

A maioria dos participantes de ambos os grupos não relataram dificuldade visual ( $\mathrm{GI}=56 \%$ e GC=64\%) e história de úlceras (GI e GC=87\%) (Tabela 5).

O grau de dor ou desconforto nos MMII permaneceu equilibrado entre as opções "nenhuma dor", “dor moderada" e a "pior dor", e, também entre os grupos, sendo que o 39\% do GI relatou a pior dor e 35\% do GC, dor moderada (Tabela 5).

Em relação a média e desvio padrão do "tempo de uso", em anos, de "antidiabéticos orais" $(\mathrm{GI}=6,27(\mathrm{DP}=4,86) \mathrm{GC}=5,69(\mathrm{DP}=3,58))(\mathrm{p}=0,5576)$ e “insulina' $(\mathrm{GI}=2,10(\mathrm{DP}=5,40)$ $\mathrm{GC}=1,58(\mathrm{DP}=3,25))(\mathrm{p}=0,8988)$, os grupos continuaram homogêneos. 
Tabela 5 - Caracterização dos participantes em relação a frequência das variáveis uso de antidiabéticos orais, uso de insulina, uso de antidiabéticos orais e insulina, tipo de antidiabético oral, tipo de insulina, hipertensão arterial sistêmica, outras doenças associadas, dificuldade visual, história de úlceras em MMII e grau de dor ou desconforto nos MMII. Boa Esperança, 2019.

\begin{tabular}{|c|c|c|c|c|}
\hline \multicolumn{2}{|l|}{ VARIÁVEIS } & \multirow{2}{*}{$\begin{array}{c}\text { GI }(\mathbf{n}=73) \\
\text { f (\%) } \\
63(86,31 \%)\end{array}$} & \multirow{2}{*}{$\begin{array}{c}\text { GC }(\mathbf{n}=79) \\
\mathbf{f}(\%) \\
74(93,67 \%)\end{array}$} & \multirow{3}{*}{$\begin{array}{c}\text { Valor p } \\
0,1280\end{array}$} \\
\hline & Sim & & & \\
\hline Uso de Antidiabeticos orais & Não & $10(13,69 \%)$ & $5(6,33 \%)$ & \\
\hline \multirow{2}{*}{ Uso de Insulina } & Sim & $20(27,39 \%)$ & $24(30,38 \%)$ & \multirow{2}{*}{0,6854} \\
\hline & Não & $53(72,61 \%)$ & $55(69,62 \%)$ & \\
\hline \multirow{2}{*}{$\begin{array}{l}\text { Uso de antidiabéticos orais e } \\
\text { insulina }\end{array}$} & Sim & $15(20,54 \%)$ & $22(27,84 \%)$ & \multirow{2}{*}{0,3905} \\
\hline & Não & $58(79,46 \%)$ & $57(72,16 \%)$ & \\
\hline \multirow{5}{*}{ Tipo de antidiabético oral } & Não faz uso & $12(16,43 \%)$ & $6(7,59 \%)$ & \multirow{5}{*}{0,8728} \\
\hline & Sulfoniluréias & $12(16,43 \%)$ & $3(3,79 \%)$ & \\
\hline & Biguanidas & $20(27,39 \%)$ & $32(40,51 \%)$ & \\
\hline & Toglitazone & $3(4,10 \%)$ & $1(1,28 \%)$ & \\
\hline & Associações & $26(35,65 \%)$ & $37(46,83 \%)$ & \\
\hline \multirow{3}{*}{ Tipo de insulina } & Não faz uso & $53(72,61 \%)$ & $57(72,16 \%)$ & \multirow{3}{*}{1,0000} \\
\hline & NPH/lenta & $18(24,66 \%)$ & $22(27,84 \%)$ & \\
\hline & $\mathrm{NPH}+\mathrm{R}$ & $2(2,73 \%)$ & $0(0,00 \%)$ & \\
\hline \multirow{2}{*}{$\begin{array}{l}\text { Hipertensão Arterial } \\
\text { Sistêmica }\end{array}$} & Sim & $58(79,46 \%)$ & $64(81,02 \%)$ & \multirow{2}{*}{0,8092} \\
\hline & Não & $15(20,54 \%)$ & $15(18,98 \%)$ & \\
\hline \multirow{2}{*}{ Outras doenças } & Sim & $53(72,61 \%)$ & $48(60,76 \%)$ & \multirow{2}{*}{0,1697} \\
\hline & Não & $20(27,39 \%)$ & $31(39,24 \%)$ & \\
\hline \multirow{2}{*}{ Dificuldade visual } & Sim & $32(43,84 \%)$ & $28(35,45 \%)$ & \multirow{2}{*}{0,3217} \\
\hline & Não & $41(56,16 \%)$ & $51(64,55 \%)$ & \\
\hline \multirow{2}{*}{$\begin{array}{c}\text { História de úlceras em } \\
\text { MMII }\end{array}$} & Sim & $9(12,33 \%)$ & $10(12,66 \%)$ & \multirow{2}{*}{1,0000} \\
\hline & Não & $64(87,67 \%)$ & $69(87,34)$ & \\
\hline \multirow{3}{*}{$\begin{array}{l}\text { Grau de dor ou desconforto } \\
\text { nos MMII }\end{array}$} & Nenhuma dor & $24(32,88 \%)$ & $27(34,17 \%)$ & \multirow{3}{*}{0,4174} \\
\hline & Dor moderada & $20(27,39 \%)$ & $28(35,45 \%)$ & \\
\hline & A pior dor & $29(39,73 \%)$ & $24(30,38 \%)$ & \\
\hline
\end{tabular}


Fonte: do autor

Teste Qui-quadrado e Wilcoxon - Mann-whitney

Referente a "glicemia capilar", observa-se que o GI apresentou menores médias, o que pode ter contribuído para que os grupos apresentassem diferenças significativas em todos os tempos de avaliação, inclusive antes de iniciar a intervenção educativa (Tabela 6).

Tabela 6 - Caracterização dos participantes em relação a média e desvio padrão da variável glicemia capilar nos tempos T1, T2 e Tfu. Boa Esperança, 2019.

\begin{tabular}{ccccc}
\hline \multirow{2}{*}{ VARIÁ VEL } & GI (n=73) & GC $(\mathbf{n = 7 9 )}$ & \multirow{2}{*}{ Valor p intergrupos } \\
& & Média (DP) & Média (DP) & \\
\hline \multirow{2}{*}{ Glicemia } & T1 & $164,54(56,07)$ & $197,02(60,65)$ & $* \mathbf{0 , 0 0 4}$ \\
& T2 & $143,36(49,39)$ & $204,63(68,18)$ & $*<\mathbf{0 , 0 0 0 1}$ \\
& $\mathrm{T} f u$ & $145,42(57,60)$ & $199,75(67,17)$ & $*<\mathbf{0 , 0 0 0 1}$ \\
\hline
\end{tabular}

Fonte: do autor

Teste Wilcoxon - Mann-whitney

*valor $\mathrm{p}<0,05$

$\mathrm{Na}$ caracterização intergrupo da variável "glicemia capilar", observou-se que o GI apresentou diferenças significativas nos tempos T1 e T2 e, T1 e Tfu (Tabela 7).

Tabela 7 - Caracterização dos participantes em relação a média e desvio padrão da variável glicemia capilar ao considerar os tempos T1 e T2, T1 e Tfu e T2 e Tfu. Boa Esperança, 2019.

\begin{tabular}{ccccc}
\hline \multirow{2}{*}{ TEMPO } & \multicolumn{2}{c}{ GRUPO INTERVENÇÃO } & \multicolumn{2}{c}{ GRUPO CONTROLE } \\
\cline { 2 - 5 } & $\mathbf{T}$ & Valor $\mathbf{p}$ & $\mathbf{T}$ & Valor $\mathbf{p}$ \\
\hline $\mathrm{T} 1-\mathrm{T} 2$ & 623 & $\boldsymbol{* 0 , 0 0 0 2}$ & 1199 & 0,5187 \\
$\mathrm{~T} 1-\mathrm{T} f u$ & 726 & $\boldsymbol{* 0 , 0 0 1 0}$ & 1496 & 0,8246 \\
$\mathrm{~T} 2-\mathrm{T} f u$ & 869 & 0,909 & 919 & 0,6868 \\
\hline
\end{tabular}

Fonte: Do autor.

Teste Wilcoxon

*valor $\mathrm{p}<0,05$

\subsubsection{Caracterização da amostra quanto às informações complementares sobre cuidados com os pés}

No que se refere à "avaliação prévia dos pés por um profissional de saúde", $100 \%$ dos participantes do estudo relataram que nunca tiveram seus pés examinados. Aproximadamente na mesma proporção, os participantes afirmaram que não receberam "orientações sobre o autocuidado com os pés" (GI=98\% e GC=100\%) e, portanto, observou-se que os mesmos não 
"realizavam o autocuidado" (GI=95\% e GC=100\%). Destaca-se que essas variáveis não apresentaram diferenças significativas entre os grupos (Tabela 8).

Tabela 8 - Caracterização dos participantes em relação a frequência das variáveis avaliação prévia dos pés por um profissional de saúde, orientações prévias sobre o cuidado com os pés e realiza autocuidado com os pés. Boa Esperança, 2019.

\begin{tabular}{ccccc}
\hline \multicolumn{2}{c}{ VARIÁVEIS } & GI (n=73) & $\begin{array}{c}\text { GC (n=79) } \\
\mathbf{f}(\mathbf{\%})\end{array}$ & $\begin{array}{c}\text { Valor } \\
\mathbf{p}\end{array}$ \\
\hline $\begin{array}{c}\text { Já teve os pés avaliados por } \\
\text { um profissional de saúde }\end{array}$ & Sim & $0(0,00 \%)$ & $0(0,00 \%)$ & 1,0000 \\
$\begin{array}{c}\text { Recebeu orientações sobre os } \\
\text { cuidados com os pés }\end{array}$ & Sim & $73(100 \%)$ & $79(100 \%)$ & \\
$\begin{array}{c}\text { Realiza autocuidado com os } \\
\text { pés }\end{array}$ & Sim & $1(1,37 \%)$ & $0(0,00 \%)$ & 0,4803 \\
& Não & $72(98,63 \%)$ & $79(100 \%)$ & \\
\hline
\end{tabular}

Fonte: do autor

Teste Exato de Fisher

\subsection{INTEGRIDADE DA PELE E ANEXOS (CONDIÇÕES DERMATOLÓGICAS)}

No protocolo de avaliação do aplicativo "Cuidando do pé" o domínio Integridade da pele e anexos (condições dermatológicas) é composto por aspectos relacionados a integridade da pele, lesões esfoliativas, micose, calosidades, pelos nas pernas, hidratação da pele, xerodermia, fissura (rachadura), corte correto das unhas e espaços interdigitais úmidos e/ou macerados.

\subsubsection{Integridade da pele preservada}

$\mathrm{Na}$ análise intergrupo sobre a "integridade da pele preservada" observa-se que o GI e o GC foram homogêneos em T1 e em T2, contudo, apresentaram diferença significativa em Tfu ( $\mathrm{p}=0,0043$ ), o que refletiu na melhora do GI em relação ao GC após a intervenção educativa (Tabela 9). 
Tabela 9 - Resultado da análise intergrupo referente a integridade da pele preservada. Boa Esperança, 2019.

\begin{tabular}{ccccccc}
\hline \multirow{2}{*}{ TEMPO } & \multicolumn{2}{c}{ GRUPO INTERVENÇÃO } & \multicolumn{2}{c}{ GRUPO CONTROLE } & \multirow{2}{*}{$\boldsymbol{x}^{2}$} & \multirow{2}{*}{ Valor $\mathbf{p}$} \\
\cline { 2 - 5 } & Sim & Não & Sim & Não & & \\
\cline { 3 - 6 } T1 & 13 & 60 & 14 & 65 & $1,14 \times 10^{-4}$ & 0,9915 \\
T2 & 20 & 53 & 12 & 67 & 2,262 & 0,1326 \\
$\mathbf{T} \boldsymbol{f} \boldsymbol{u}$ & 28 & 45 & 12 & 67 & 8,145 & $* \mathbf{0 , 0 0 4 3}$ \\
\hline
\end{tabular}

Fonte: Do autor.

Teste Qui-quadrado

*valor $\mathrm{p}<0,05$

$\mathrm{Na}$ análise intragrupo nos tempos T1 e T2, é possível observar que, tanto o GI quanto o GT não apresentaram diferenças significativas. Entretanto, entre os tempos T1 e Tfu $(\mathrm{p}=0,0023)$ e também T2 e T $f u(\mathrm{p}=0,0433)$ foi possível identificar que, no GI, houve melhora significativa da "integridade da pele" (Tabela 10).

Tabela 10 - Resultado da análise intragrupo da integridade da pele preservada ao considerar os tempos T1 e T2, T1 e Tfu e T2 e Tfu. Boa Esperança, 2019.

\begin{tabular}{|c|c|c|c|c|c|c|c|c|c|}
\hline & & \multicolumn{4}{|c|}{ GRUPO INTERVENÇÃO } & \multicolumn{4}{|c|}{ GRUPO CONTROLE } \\
\hline & & & & Estatística & Valor & & & Estatística & Valor \\
\hline & & Sim & Não & McNemar & $\mathbf{P}$ & Sim & Não & McNemar & $\mathbf{p}$ \\
\hline T1 & Sim & 8 & 5 & 2,118 & 0,1456 & 5 & 9 & 0,062 & 0,8026 \\
\hline
\end{tabular}

\begin{tabular}{|c|c|c|c|c|c|c|c|c|c|}
\hline & \multicolumn{2}{|c|}{$\mathbf{T} f u$} & \multirow{2}{*}{$\begin{array}{l}\text { Estatística } \\
\text { McNemar }\end{array}$} & \multirow{2}{*}{$\begin{array}{c}\text { Valor } \\
\mathbf{P}\end{array}$} & \multicolumn{2}{|c|}{$\mathbf{T} f u$} & \multirow{2}{*}{$\begin{array}{l}\text { Estatística } \\
\text { McNemar }\end{array}$} & \multirow{2}{*}{$\begin{array}{c}\text { Valor } \\
\text { p }\end{array}$} \\
\hline & & Sim & Não & & & Sim & Não & & \\
\hline T1 & Sim & $\begin{array}{l}10 \\
18\end{array}$ & $\begin{array}{c}3 \\
42\end{array}$ & 9,333 & $* \mathbf{0 , 0 0 2 3}$ & $\begin{array}{l}5 \\
7\end{array}$ & $\begin{array}{c}9 \\
58\end{array}$ & 0,062 & 0,8026 \\
\hline
\end{tabular}

\begin{tabular}{|c|c|c|c|c|c|c|c|c|c|}
\hline & \multicolumn{2}{|c|}{ T $f u$} & \multirow{2}{*}{$\begin{array}{l}\text { Estatística } \\
\text { McNemar }\end{array}$} & \multirow{2}{*}{$\begin{array}{c}\text { Valor } \\
\mathbf{P}\end{array}$} & \multicolumn{2}{|c|}{ T $f u$} & \multirow{2}{*}{$\begin{array}{l}\text { Estatística } \\
\text { McNemar }\end{array}$} & \multirow{2}{*}{$\begin{array}{c}\text { Valor } \\
\text { p }\end{array}$} \\
\hline & & Sim & Não & & & Sim & Não & & \\
\hline \multirow{2}{*}{ T2 } & Sim & 18 & 2 & \multirow{2}{*}{4,083} & \multirow{2}{*}{$* \mathbf{0 , 0 4 3 3}$} & 11 & 1 & \multirow{2}{*}{0,000} & \multirow{2}{*}{1,0000} \\
\hline & Não & 10 & 43 & & & 1 & 66 & & \\
\hline
\end{tabular}

Fonte: Do autor.

Teste McNemar

*valor $\mathrm{p}<0,05$

\subsubsection{Lesões esfoliativas}

$\mathrm{Na}$ análise da variável "presença de lesões esfoliativas", observou-se que o GI e o GC foram homogêneos apenas no $\mathrm{T} 1$, dado que nos tempos $\mathrm{T} 2(\mathrm{p}=0,0001)$ e $\mathrm{T} f u(\mathrm{p}<0,0001)$ os 
grupos apresentaram diferenças significativas, com destaque na diminuição desse tipo de lesão no GI (Tabela 11).

Tabela 11 - Resultado da análise intergrupo referente a presença de lesões esfoliativas. Boa Esperança, 2019.

\begin{tabular}{cccccccc}
\hline \multirow{2}{*}{ TEMPO } & \multicolumn{2}{c}{ GRUPO INTERVENÇÃO } & \multicolumn{2}{c}{ GRUPO CONTROLE } & \multirow{2}{*}{$\boldsymbol{x}^{2}$} & \multirow{2}{*}{ Valor $\mathbf{p}$} \\
\cline { 2 - 5 } & Sim & Não & Sim & Não & & \\
\hline T1 & 58 & 15 & 63 & 16 & 0,001 & 0,9710 \\
T2 & 30 & 43 & 57 & 22 & 14,637 & $* \mathbf{0 , 0 0 0 1}$ \\
$\mathbf{T} \boldsymbol{f} \boldsymbol{u}$ & 15 & 58 & 59 & 20 & 44,477 & $*<\mathbf{0 , 0 0 0 1}$ \\
\hline
\end{tabular}

Fonte: Do autor.

Teste Qui-quadrado

*valor $\mathrm{p}<0,05$

$\mathrm{Na}$ análise intragrupo o GI apresentou melhora significativa nas "lesões esfoliativas" entre T1 e T2 (p<0,0001), T1 e Tfu $(\mathrm{p}<0,0001)$ e também T2 e Tfu $(0,0013)$, o que não ocorreu no GC nos mesmos tempo avaliados (Tabela 12).

Tabela 12 - Resultado da análise intragrupo da presença de lesões esfoliativas ao considerar os tempos T1 e T2, T1 e Tfu e T2 e Tfu. Boa Esperança, 2019.

\begin{tabular}{|c|c|c|c|c|c|c|c|c|c|}
\hline & & \multicolumn{4}{|c|}{ GRUPO INTERVENÇÃO } & \multicolumn{4}{|c|}{ GRUPO CONTROLE } \\
\hline & & \multicolumn{2}{|c|}{ T2 } & \multirow{2}{*}{$\begin{array}{l}\text { Estatística } \\
\text { McNemar }\end{array}$} & \multirow{2}{*}{$\begin{array}{c}\text { Valor } \\
\mathbf{p}\end{array}$} & \multicolumn{2}{|c|}{ T2 } & \multirow{2}{*}{$\begin{array}{l}\text { Estatística } \\
\text { McNemar }\end{array}$} & \multirow{2}{*}{$\begin{array}{c}\text { Valor } \\
\mathbf{p}\end{array}$} \\
\hline & & Sim & Não & & & Sim & Não & & \\
\hline \multirow{4}{*}{ T1 } & Sim & 25 & 33 & \multirow{2}{*}{19,184} & \multirow{2}{*}{$<0,0001$} & 50 & 13 & \multirow{2}{*}{1,250} & \multirow{2}{*}{0,2636} \\
\hline & Não & 5 & 10 & & & 7 & 9 & & \\
\hline & & \multicolumn{2}{|c|}{$\mathbf{T} f u$} & \multirow{2}{*}{$\begin{array}{l}\text { Estatística } \\
\text { McNemar }\end{array}$} & \multirow{2}{*}{$\begin{array}{c}\text { Valor } \\
\mathbf{p}\end{array}$} & \multicolumn{2}{|c|}{$\mathbf{T} f u$} & \multirow{2}{*}{$\begin{array}{l}\text { Estatística } \\
\text { McNemar }\end{array}$} & \multirow{2}{*}{$\begin{array}{c}\text { Valor } \\
\mathbf{p}\end{array}$} \\
\hline & & Sim & Não & & & Sim & Não & & \\
\hline \multirow{4}{*}{$\mathbf{T 1}$} & Sim & 12 & 46 & \multirow{2}{*}{36,000} & \multirow{2}{*}{$<0,0001$} & 50 & 13 & \multirow{2}{*}{0,409} & \multirow{2}{*}{0,5224} \\
\hline & Não & 3 & 12 & & & 9 & 7 & & \\
\hline & & \multicolumn{2}{|c|}{$\mathbf{T} f u$} & \multirow{2}{*}{$\begin{array}{l}\text { Estatística } \\
\text { McNemar }\end{array}$} & \multirow{2}{*}{$\begin{array}{c}\text { Valor } \\
\mathbf{p}\end{array}$} & \multicolumn{2}{|c|}{$\mathbf{T} f u$} & \multirow{2}{*}{$\begin{array}{l}\text { Estatística } \\
\text { McNemar }\end{array}$} & \multirow{2}{*}{$\begin{array}{c}\text { Valor } \\
\mathbf{p}\end{array}$} \\
\hline & & Sim & Não & & & Sim & Não & & \\
\hline \multirow{2}{*}{$\mathbf{T} 2$} & Sim & 13 & 17 & \multirow{2}{*}{10,316} & \multirow{2}{*}{0,0013} & 54 & 3 & \multirow{2}{*}{0,125} & \multirow{2}{*}{0,7237} \\
\hline & Não & 2 & 41 & & & 5 & 17 & & \\
\hline
\end{tabular}

Fonte: Do autor.

Teste McNemar

*valor $\mathrm{p}<0,05$ 


\subsubsection{Micose}

Referente à "presença de micoses" observa-se que, o GI e GC apresentaram diferenças significativas em T1 ( $\mathrm{p}=0,0293)$, com destaque a um maior número de pessoas com micose no GI $(\mathrm{n}=24)$. No T1 e Tfu o número de pessoas com "micose" no GI diminuiu consideravelmente, $n=11$ e $n=8$, respectivamente, assim, os grupos se tornaram homogêneos após as intervenções educativas (T2 p=0,8643 e T $f u$ p=0,4983) (Tabela 13).

Tabela 13 - Resultado da análise intergrupo referente a presença de micose. Boa Esperança, 2019.

\begin{tabular}{ccccccc}
\hline \multirow{2}{*}{ TEMPO } & \multicolumn{2}{c}{ GRUPO INTERVENÇÃ̃ } & \multicolumn{2}{c}{ GRUPO CONTROLE } & \multirow{2}{*}{$\boldsymbol{x}^{2}$} & \multirow{2}{*}{ Valor $\mathbf{p}$} \\
\cline { 2 - 5 } & Sim & Não & Sim & Não & & \\
\hline T1 & 24 & 49 & 12 & 67 & 4,748 & $\mathbf{0 , 0 2 9 3}$ \\
T2 & 11 & 62 & 13 & 66 & 0,029 & 0,8643 \\
T $\boldsymbol{u} \boldsymbol{u}$ & 8 & 65 & 13 & 66 & 0,459 & 0,4983 \\
\hline
\end{tabular}

Fonte: Do autor.

Teste Qui-quadrado

*valor $\mathrm{p}<0,05$

$\mathrm{Na}$ analise intragrupo o GI apresentou melhora significativa tanto na "presença de micoses" entre os T1 e T2 ( $\mathrm{p}=0,0019)$, como também entre T1 e T $f u(p=0,0004)$, o que não foi observado no GC (Tabela 14). 
Tabela 14 - Resultado da análise intragrupo da presença de micose ao considerar os tempos T1 e T2, T1 e T $f u$ e T2 e Tfu. Boa Esperança, 2019.

\begin{tabular}{|c|c|c|c|c|c|c|c|c|c|}
\hline & \multicolumn{5}{|c|}{ GRUPO INTERVENÇÃO } & \multicolumn{3}{|c|}{ GRUPO CONTROLE } & \multirow{3}{*}{$\begin{array}{c}\text { Valor } \\
\mathbf{p} \\
\end{array}$} \\
\hline & & \multicolumn{2}{|c|}{ T2 } & \multirow{2}{*}{$\begin{array}{l}\text { Estatística } \\
\text { McNemar }\end{array}$} & \multirow{2}{*}{ Valor p } & \multicolumn{2}{|c|}{$\mathbf{T 2}$} & \multirow{2}{*}{$\begin{array}{l}\text { Estatística } \\
\text { McNemar }\end{array}$} & \\
\hline & & Sim & Não & & & Sim & Não & & \\
\hline T1 & Sim & 10 & 14 & 9,600 & $* 0,0019$ & 12 & $\begin{array}{c}0 \\
66\end{array}$ & 0,000 & 1,000 \\
\hline
\end{tabular}

\begin{tabular}{|c|c|c|c|c|c|c|c|c|c|}
\hline & \multicolumn{2}{|c|}{$\mathbf{T} f u$} & \multirow{2}{*}{$\begin{array}{l}\text { Estatística } \\
\text { McNemar }\end{array}$} & \multirow{2}{*}{ Valor $\mathbf{p}$} & \multicolumn{2}{|c|}{$\mathbf{T} f u$} & \multirow{2}{*}{$\begin{array}{l}\text { Estatística } \\
\text { McNemar }\end{array}$} & \multirow{2}{*}{$\begin{array}{c}\text { Valor } \\
\mathbf{p}\end{array}$} \\
\hline & & Sim & Não & & & Sim & Não & & \\
\hline $\mathbf{T 1}$ & Sim & 7 & 17 & 12,500 & $* 0,0004$ & 13 & 9 & 0,000 & 1,000 \\
\hline
\end{tabular}

\begin{tabular}{|c|c|c|c|c|c|c|c|c|c|}
\hline & & \multicolumn{2}{|c|}{$\mathbf{T} f u$} & \multirow{2}{*}{$\begin{array}{l}\text { Estatística } \\
\text { McNemar }\end{array}$} & \multirow{2}{*}{ Valor $\mathbf{p}$} & \multicolumn{2}{|c|}{$\mathbf{T} \boldsymbol{f u}$} & \multirow{2}{*}{$\begin{array}{l}\text { Estatística } \\
\text { McNemar }\end{array}$} & \multirow{2}{*}{$\begin{array}{c}\text { Valor } \\
\mathbf{p}\end{array}$} \\
\hline & & Sim & Não & & & Sim & Não & & \\
\hline \multirow{2}{*}{$\mathbf{T 2}$} & Sim & 8 & 3 & \multirow{2}{*}{1,333} & \multirow{2}{*}{0,2482} & 13 & 0 & \multirow{2}{*}{$* * *$} & \multirow{2}{*}{$* * *$} \\
\hline & Não & 0 & 62 & & & 0 & 66 & & \\
\hline
\end{tabular}

Fonte: Do autor.

Teste McNemar

*valor $\mathrm{p}<0,05$

*** O teste de McNemar não pode ser realizado por não haver alteração das opções de "Não" para "Sim" e vice versa

\subsubsection{Calosidades}

Quanto a variável "calosidades nos pés" observou-se que os grupos permaneceram homogêneos em todos os tempos de avaliação (Tabela 15).

Tabela 15 - Resultado da análise intergrupo referente a presença de calosidades nos pés. Boa Esperança, 2019.

\begin{tabular}{ccccccc}
\hline \multirow{2}{*}{ TEMPO } & \multicolumn{2}{c}{ GRUPO INTERVENÇÃO } & \multicolumn{2}{c}{ GRUPO CONTROLE } & \multirow{2}{*}{$\boldsymbol{x}^{2}$} & \multirow{2}{*}{ Valor $\mathbf{p}$} \\
\cline { 2 - 5 } & Sim & Não & Sim & Não & & \\
\cline { 2 - 5 } T1 & 30 & 43 & 31 & 48 & 0,0052 & 0,8192 \\
T2 & 31 & 42 & 31 & 48 & 0,158 & 0,6911 \\
T $\boldsymbol{f u}$ & 31 & 42 & 32 & 47 & 0,058 & 0,8093 \\
\hline
\end{tabular}

Fonte: Do autor.

Teste Qui-Quadrado

Da mesma forma, na análise intragrupo da variável "presença de calosidades" é possível inferir que a intervenção educativa não influenciou os grupos ao longo das avaliações (Tabela 16). 
Tabela 16 - Resultado da análise intragrupo da presença de calosidades ao considerar os tempos T1 e T2, T1 e Tfu e T2 e Tfu. Boa Esperança, 2019.

\begin{tabular}{|c|c|c|c|c|c|c|c|c|c|}
\hline & & \multicolumn{4}{|c|}{ GRUPO INTERVENÇÃO } & \multicolumn{4}{|c|}{ GRUPO CONTROLE } \\
\hline & & \multicolumn{2}{|c|}{ T2 } & \multirow{2}{*}{$\begin{array}{l}\text { Estatística } \\
\text { McNemar }\end{array}$} & \multirow{2}{*}{$\begin{array}{c}\text { Valor } \\
\mathbf{p}\end{array}$} & \multicolumn{2}{|c|}{ T2 } & \multirow{2}{*}{$\begin{array}{l}\text { Estatística } \\
\text { McNemar } \\
\end{array}$} & \multirow{2}{*}{$\begin{array}{c}\text { Valor } \\
\text { p }\end{array}$} \\
\hline & & Sim & Não & & & Sim & Não & & \\
\hline \multirow{4}{*}{$\mathbf{T 1}$} & Sim & 30 & 0 & \multirow{2}{*}{0,000} & \multirow{2}{*}{1,000} & 31 & 0 & \multirow{2}{*}{$* * *$} & \multirow{2}{*}{$* * *$} \\
\hline & Não & 1 & 42 & & & 0 & 47 & & \\
\hline & & \multicolumn{2}{|c|}{$\mathbf{T} f u$} & \multirow{2}{*}{$\begin{array}{l}\text { Estatística } \\
\text { McNemar }\end{array}$} & \multirow{2}{*}{$\begin{array}{c}\text { Valor } \\
\mathbf{p}\end{array}$} & \multicolumn{2}{|c|}{$\mathbf{T f u}$} & Estatística & Valor \\
\hline & & Sim & Não & & & Sim & Não & McNemar & $\mathbf{p}$ \\
\hline \multirow{4}{*}{$\mathbf{T 1}$} & Sim & 30 & 0 & \multirow{2}{*}{0,000} & \multirow{2}{*}{1,000} & 31 & 0 & \multirow{2}{*}{$* * *$} & \multirow{2}{*}{$* * *$} \\
\hline & Não & 1 & 42 & & & 0 & 47 & & \\
\hline & & \multicolumn{2}{|c|}{$\mathbf{T} f u$} & \multirow{2}{*}{$\begin{array}{l}\text { Estatística } \\
\text { McNemar }\end{array}$} & \multirow{2}{*}{$\begin{array}{c}\text { Valor } \\
\mathbf{p} \\
\end{array}$} & \multicolumn{2}{|c|}{$\mathrm{T} f u$} & Estatística & Valor \\
\hline & & Sim & Não & & & Sim & Não & McNemar & $\mathbf{p}$ \\
\hline \multirow{2}{*}{$\mathbf{T 2}$} & Sim & 31 & 0 & \multirow{2}{*}{$* * *$} & \multirow{2}{*}{$* * *$} & 31 & 0 & \multirow{2}{*}{$* * *$} & \multirow{2}{*}{$* * *$} \\
\hline & Não & 0 & 42 & & & 0 & 47 & & \\
\hline
\end{tabular}

Fonte: Do autor.

Teste McNemar

*** O teste de Mc Nemar não pode ser realizado por não haver alteração das opções de "Não" para "Sim" e vice versa

\subsubsection{Pilosidade}

Os grupos também não apresentaram diferença significativa para a variável "presença de pelos nas pernas", nos respectivos tempos do presente estudo (Tabela 17).

Tabela 17 - Resultado da análise intergrupo referente a presença de pelos nas pernas. Boa Esperança, 2019.

\begin{tabular}{cccccccc}
\hline \multirow{2}{*}{ TEMPO } & \multicolumn{2}{c}{ GRUPO INTERVENÇÃO } & \multicolumn{2}{c}{ GRUPO CONTROLE } & \multirow{2}{*}{$\boldsymbol{x}^{2}$} & \multirow{2}{*}{ Valor $\mathbf{p}$} \\
\cline { 2 - 5 } & Sim & Não & Sim & Não & & \\
\hline T1 & 29 & 44 & 40 & 39 & 1,805 & 0,1791 \\
T2 & 30 & 43 & 39 & 40 & 0,854 & 0,3554 \\
T $\boldsymbol{u} \boldsymbol{u}$ & 30 & 43 & 39 & 40 & 0,854 & 0,3554 \\
\hline
\end{tabular}

Fonte: Do autor.

Teste Qui-Quadrado

O indicador de "presença de pelos nas pernas" também não sofreu alteração quando analisado nos grupos isoladamente (Tabela 18). 
Tabela 18 - Resultado da análise intragrupo da variável presença de pelos nas pernas ao considerar os tempos T1 e T2, T1 e Tfu e T2 e Tfu. Boa Esperança, 2019.

\begin{tabular}{|c|c|c|c|c|c|c|c|c|c|}
\hline & & \multicolumn{4}{|c|}{ GRUPO INTERVENÇÃO } & \multicolumn{4}{|c|}{ GRUPO CONTROLE } \\
\hline & & \multicolumn{2}{|c|}{ T2 } & \multirow{2}{*}{$\begin{array}{l}\text { Estatística } \\
\text { McNemar }\end{array}$} & \multirow{2}{*}{$\begin{array}{c}\text { Valor } \\
\text { p }\end{array}$} & \multicolumn{2}{|c|}{$\mathbf{T} 2$} & \multirow{2}{*}{$\begin{array}{l}\text { Estatística } \\
\text { McNemar }\end{array}$} & \multirow{2}{*}{$\begin{array}{c}\text { Valor } \\
\text { p }\end{array}$} \\
\hline & & Sim & Não & & & Sim & Não & & \\
\hline \multirow{4}{*}{ T1 } & Sim & 29 & 0 & \multirow{2}{*}{0,000} & \multirow{2}{*}{1,000} & 38 & 2 & \multirow{2}{*}{0,000} & \multirow{2}{*}{1,000} \\
\hline & Não & 1 & 43 & & & 1 & 38 & & \\
\hline & & \multicolumn{2}{|c|}{ Tfu } & \multirow{2}{*}{$\begin{array}{l}\text { Estatística } \\
\text { McNemar }\end{array}$} & \multirow{2}{*}{$\begin{array}{c}\text { Valor } \\
\mathbf{p}\end{array}$} & \multicolumn{2}{|c|}{$\mathbf{T} f u$} & \multirow{2}{*}{$\begin{array}{l}\text { Estatística } \\
\text { McNemar }\end{array}$} & \multirow{2}{*}{$\begin{array}{c}\text { Valor } \\
\text { p }\end{array}$} \\
\hline & & Sim & Não & & & Sim & Não & & \\
\hline \multirow{4}{*}{$\mathbf{T 1}$} & Sim & 29 & 0 & \multirow{2}{*}{0,000} & \multirow{2}{*}{1,000} & 38 & 2 & \multirow{2}{*}{0,000} & \multirow{2}{*}{1,000} \\
\hline & Não & 1 & 43 & & & 1 & 38 & & \\
\hline & & \multicolumn{2}{|c|}{$\mathbf{T} f u$} & \multirow{2}{*}{$\begin{array}{l}\text { Estatística } \\
\text { McNemar }\end{array}$} & \multirow{2}{*}{$\begin{array}{c}\text { Valor } \\
\mathbf{p}\end{array}$} & \multicolumn{2}{|c|}{$\mathbf{T} f u$} & \multirow{2}{*}{$\begin{array}{l}\text { Estatística } \\
\text { McNemar }\end{array}$} & \multirow{2}{*}{$\begin{array}{c}\text { Valor } \\
\text { p }\end{array}$} \\
\hline & & Sim & Não & & & Sim & Não & & \\
\hline \multirow{2}{*}{$\mathbf{T} 2$} & Sim & 30 & 0 & \multirow{2}{*}{$* * *$} & \multirow{2}{*}{$* * *$} & 39 & 0 & \multirow{2}{*}{$* * *$} & \multirow{2}{*}{$* * *$} \\
\hline & Não & 0 & 43 & & & 0 & 40 & & \\
\hline
\end{tabular}

Fonte: Do autor.

Teste McNemar

*** O teste de Mc Nemar não pode ser realizado por não haver alteração das opções de "Não" para "Sim" e vice versa

\subsubsection{Hidratação da pele}

Referente a variável "hidratação da pele", observou-se diferença significativa entre os grupos em T2 $(\mathrm{p}=0,0003)$ e $\mathrm{T} f u(\mathrm{p}<0,0001)$, o que pode estar relacionada a melhora do GI quando comparado ao GC, após as intervenções educativas (Tabela 19).

Tabela 19 - Resultado da análise intergrupo referente a presença de pele hidratada. Boa Esperança, 2019.

\begin{tabular}{ccccccc}
\hline \multirow{2}{*}{ TEMPO } & \multicolumn{2}{c}{ GRUPO INTERVENÇÃO } & \multicolumn{2}{c}{ GRUPO CONTROLE } & \multirow{2}{*}{$\boldsymbol{x}^{2}$} & \multirow{2}{*}{ Valor $\mathbf{p}$} \\
\cline { 2 - 5 } & Sim & Não & Sim & Não & & \\
\hline T1 & 8 & 65 & 12 & 67 & 0,272 & 0,6022 \\
T2 & 42 & 31 & 22 & 57 & 13,374 & $* \mathbf{0 , 0 0 0 3}$ \\
$\mathbf{T} \boldsymbol{f} \boldsymbol{u}$ & 55 & 18 & 18 & 61 & 41,922 & $*<\mathbf{0 , 0 0 0 1}$ \\
\hline
\end{tabular}

Fonte: Do autor.

Teste Qui-Quadrado

*valor $\mathrm{p}<0,05$

Para a variável "hidratação da pele", o GI apresentou melhora significativa na análise intragrupo entre os tempos T1 e T2 $(<0,0001)$, T1 e T $f u(<0,0001)$ e, também T2 e Tfu 
( $\mathrm{p}=0,0020)$. Resultado semelhante ocorreu no GC entre os tempos 1 e $2(\mathrm{p}=0,0339)$ (Tabela 20).

Tabela 20 - Resultado da análise intragrupo da variável presença de pele hidratada ao considerar os tempos T1 e T2, T1 e Tfu e T2 e Tfu. Boa Esperança, 2019.

\begin{tabular}{|c|c|c|c|c|c|c|c|c|c|}
\hline & & \multicolumn{4}{|c|}{ GRUPO INTERVENÇÃO } & \multicolumn{4}{|c|}{ GRUPO CONTROLE } \\
\hline & & \multicolumn{2}{|c|}{ T2 } & \multirow{2}{*}{$\begin{array}{l}\text { Estatística } \\
\text { McNemar }\end{array}$} & \multirow{2}{*}{$\begin{array}{c}\text { Valor } \\
\text { p }\end{array}$} & \multicolumn{2}{|c|}{$\mathbf{T} 2$} & \multirow{2}{*}{$\begin{array}{l}\text { Estatística } \\
\text { McNemar }\end{array}$} & \multirow{2}{*}{$\begin{array}{c}\text { Valor } \\
\mathbf{p}\end{array}$} \\
\hline & & Sim & Não & & & Sim & Não & & \\
\hline \multirow{4}{*}{$\mathbf{T 1}$} & Sim & 7 & 1 & \multirow{2}{*}{30,250} & \multirow{2}{*}{$*<0,0001$} & 8 & 4 & \multirow{2}{*}{4,500} & \multirow{2}{*}{$* 0,0339$} \\
\hline & Não & 35 & 30 & & & 14 & 53 & & \\
\hline & & \multicolumn{2}{|c|}{$\mathbf{T} f u$} & \multirow{2}{*}{$\begin{array}{l}\text { Estatística } \\
\text { McNemar }\end{array}$} & \multirow{2}{*}{$\begin{array}{c}\text { Valor } \\
\mathbf{p}\end{array}$} & \multicolumn{2}{|c|}{$\mathbf{T} f u$} & \multirow{2}{*}{$\begin{array}{l}\text { Estatística } \\
\text { McNemar }\end{array}$} & \multirow{2}{*}{$\begin{array}{c}\text { Valor } \\
\mathbf{p}\end{array}$} \\
\hline & & Sim & Não & & & Sim & Não & & \\
\hline \multirow{4}{*}{ T1 } & Sim & 7 & 1 & \multirow{2}{*}{43,184} & \multirow{2}{*}{$*<0,0001$} & 6 & 6 & \multirow{2}{*}{1,389} & \multirow{2}{*}{0,2386} \\
\hline & Não & 48 & 17 & & & 12 & 55 & & \\
\hline & & \multicolumn{2}{|c|}{$\mathbf{T} f u$} & \multirow{2}{*}{$\begin{array}{l}\text { Estatística } \\
\text { McNemar }\end{array}$} & \multirow{2}{*}{$\begin{array}{c}\text { Valor } \\
\mathbf{p}\end{array}$} & \multicolumn{2}{|c|}{$\mathbf{T} f u$} & \multirow{2}{*}{$\begin{array}{l}\text { Estatística } \\
\text { McNemar }\end{array}$} & \multirow{2}{*}{$\begin{array}{c}\text { Valor } \\
\mathbf{p}\end{array}$} \\
\hline & & Sim & Não & & & Sim & Não & & \\
\hline \multirow{2}{*}{$\mathbf{T 2}$} & Sim & 41 & 1 & \multirow{2}{*}{9,600} & \multirow{2}{*}{$* 0,0020$} & 16 & 6 & \multirow{2}{*}{1,125} & \multirow{2}{*}{0,2888} \\
\hline & Não & 14 & 17 & & & 2 & 55 & & \\
\hline
\end{tabular}

Fonte: Do autor.

Teste McNemar

*valor $\mathrm{p}<0,05$

\subsubsection{Xerodermia}

O GI apresentou melhora na variável "xerodermia" quando comparado ao GC no T2 $(\mathrm{p}<0,0001)$ e $\mathrm{T} f u(\mathrm{p}<0,0001)$, o que pode estar relacionado a influência positiva da intervenção educativa (Tabela 21).

Tabela 21 - Resultado da análise intergrupo referente a presença de xerodermia. Boa Esperança, 2019.

\begin{tabular}{ccccccc}
\hline \multirow{2}{*}{ TEMPO } & \multicolumn{2}{c}{ GRUPO INTERVENÇÃ̃ } & \multicolumn{2}{c}{ GRUPO CONTROLE } & \multirow{2}{*}{$\boldsymbol{x}^{2}$} & \multirow{2}{*}{ Valor p } \\
\cline { 2 - 5 } & Sim & Não & Sim & Não & & \\
\hline T1 & 65 & 8 & 67 & 12 & 0,272 & 0,6022 \\
T2 & 21 & 52 & 49 & 30 & 16,787 & $*<\mathbf{0 , 0 0 0 1}$ \\
T $\boldsymbol{f} \boldsymbol{u}$ & 14 & 59 & 53 & 26 & 34,836 & $*<\mathbf{0 , 0 0 0 1}$ \\
\hline
\end{tabular}

Fonte: Do autor.

Teste Qui-Quadrado

*valor $\mathrm{p}<0,05$ 
Na análise intragrupo o GI e o GC apresentaram melhora na "presença de xerodermia" entre os tempos T1 e T2 (GI p=0,0001, GC p=0,0009) e, também T1 e Tfu (GI p=0,0001, GC $\mathrm{p}=0,0108)$ (Tabela 22).

Tabela 22 - Resultado da análise intragrupo da xerodermia ao considerar os tempos T1 e T2, T1 e T fu e T2 e Tfu. Boa Esperança, 2019.

\begin{tabular}{|c|c|c|c|c|c|c|c|c|c|}
\hline & \multicolumn{4}{|c|}{ GRUPO INTERVENÇÃO } & \multicolumn{4}{|c|}{ GRUPO CONTROLE } \\
\hline & & \multicolumn{2}{|c|}{$\mathbf{T 2}$} & \multirow{2}{*}{$\begin{array}{l}\text { Estatística } \\
\text { McNemar }\end{array}$} & \multirow{2}{*}{$\begin{array}{c}\text { Valor } \\
\mathbf{p}\end{array}$} & \multicolumn{2}{|c|}{$\mathbf{T} 2$} & \multirow{2}{*}{$\begin{array}{l}\text { Estatística } \\
\text { McNemar }\end{array}$} & \multirow{2}{*}{$\begin{array}{c}\text { Valor } \\
\mathbf{p}\end{array}$} \\
\hline & & Sim & Não & & & Sim & Não & & \\
\hline \multirow{4}{*}{$\mathbf{T 1}$} & Sim & 20 & 45 & \multirow{2}{*}{40,196} & \multirow{2}{*}{$*<0,0001$} & 45 & 22 & \multirow{2}{*}{11,115} & \multirow{2}{*}{$* 0,0009$} \\
\hline & Não & 1 & 7 & & & 4 & 8 & & \\
\hline & & \multicolumn{2}{|c|}{$\mathbf{T} f u$} & Estatística & Valor & \multicolumn{2}{|c|}{$\mathbf{T} f u$} & Estatística & Valor \\
\hline & & Sim & Não & McNemar & $\mathbf{P}$ & Sim & Não & McNemar & $\mathbf{p}$ \\
\hline \multirow{4}{*}{$\mathbf{T 1}$} & Sim & 13 & 52 & \multirow{2}{*}{47,170} & \multirow{2}{*}{$*<0,0001$} & 47 & 20 & \multirow{2}{*}{6,500} & \multirow{2}{*}{$* 0,0108$} \\
\hline & Não & 1 & 7 & & & 6 & 6 & & \\
\hline & & \multicolumn{2}{|c|}{$\mathbf{T} f u$} & Estatística & Valor & \multicolumn{2}{|c|}{$\mathbf{T} f u$} & Estatística & Valor \\
\hline & & Sim & Não & McNemar & $\mathbf{p}$ & Sim & Não & McNemar & $\mathbf{p}$ \\
\hline \multirow{2}{*}{$\mathbf{T 2}$} & Sim & 10 & 11 & \multirow{2}{*}{2,400} & \multirow{2}{*}{0,1213} & 44 & 5 & \multirow{2}{*}{0,643} & \multirow{2}{*}{0,4227} \\
\hline & Não & 4 & 48 & & & 9 & 21 & & \\
\hline
\end{tabular}

Fonte: Do autor.

Teste McNemar

*valor $\mathrm{p}<0,05$

\subsubsection{Fissura (rachadura)}

$\mathrm{Na}$ análise intergrupo da presença de "fissura (rachadura)" é possível verificar melhora significativa do GI em relação ao GC nos tempos T2 (0,0003) e Tfu (p<0,0001) (Tabela 23).

Tabela 23 - Resultado da análise intergrupo referente a presença de fissura (rachadura). Boa Esperança, 2019.

\begin{tabular}{|c|c|c|c|c|c|c|}
\hline \multirow{2}{*}{ TEMPO } & \multicolumn{2}{|c|}{ GRUPO INTERVENÇÃO } & \multicolumn{2}{|c|}{ GRUPO CONTROLE } & \multirow{2}{*}{$x^{2}$} & \multirow{2}{*}{ Valor $\mathbf{p}$} \\
\hline & Sim & Não & Sim & Não & & \\
\hline T1 & 56 & 17 & 58 & 21 & 0,165 & 0,6848 \\
\hline $\mathbf{T} 2$ & 21 & 52 & 46 & 33 & 13,172 & $* 0,0003$ \\
\hline $\mathbf{T} f u$ & 10 & 63 & 48 & 31 & 33,611 & $*<0,0001$ \\
\hline
\end{tabular}

Fonte: Do autor.

Teste Qui-Quadrado

*valor $\mathrm{p}<0,05$ 
$\mathrm{Na}$ análise intragrupo, o GI também apresentou melhora significativa das "fissuras (rachadura)" entre tempos T1 $(<0,0001), \mathrm{T} 2(0,0001)$ e T $f u(\mathrm{p}=0,0026)$. O GC também apresentou melhora, contudo, somente entre os tempos T1 e T2 (p=0,0139) e T1 e Tfu $(\mathrm{p}=0,0442)$ (Tabela 24).

Tabela 24 - Resultado da análise intragrupo da presença de fissura (rachadura) ao considerar os tempos T1 e T2, T1 e Tfu e T2 e Tfu. Boa Esperança, 2019.

\begin{tabular}{|c|c|c|c|c|c|c|c|c|c|}
\hline & & \multicolumn{4}{|c|}{ GRUPO INTERVENÇÃO } & \multicolumn{4}{|c|}{ GRUPO CONTROLE } \\
\hline & & \multicolumn{2}{|c|}{ T2 } & \multirow{2}{*}{$\begin{array}{l}\text { Estatística } \\
\text { McNemar }\end{array}$} & \multirow{2}{*}{$\begin{array}{c}\text { Valor } \\
\text { p }\end{array}$} & \multicolumn{2}{|c|}{ T2 } & \multirow{2}{*}{$\begin{array}{l}\text { Estatística } \\
\text { McNemar }\end{array}$} & \multirow{2}{*}{$\begin{array}{c}\text { Valor } \\
\mathbf{p}\end{array}$} \\
\hline & & Sim & Não & & & Sim & Não & & \\
\hline $\mathbf{T 1}$ & Sim & 19 & 37 & 29,641 & $*<0,0001$ & 42 & $\begin{array}{l}16 \\
17\end{array}$ & 6,050 & $* 0,0139$ \\
\hline
\end{tabular}

\begin{tabular}{|c|c|c|c|c|c|c|c|c|c|}
\hline & \multicolumn{2}{|c|}{$\mathbf{T} \boldsymbol{f u}$} & \multirow{2}{*}{$\begin{array}{l}\text { Estatística } \\
\text { McNemar }\end{array}$} & \multirow{2}{*}{$\begin{array}{c}\text { Valor } \\
\mathbf{p}\end{array}$} & \multicolumn{2}{|c|}{$\mathbf{T} f u$} & \multirow{2}{*}{$\begin{array}{l}\text { Estatística } \\
\text { McNemar }\end{array}$} & \multirow{2}{*}{$\begin{array}{c}\text { Valor } \\
\mathbf{p}\end{array}$} \\
\hline & & Sim & Não & & & Sim & Não & & \\
\hline T1 & Sim & 8 & 48 & 40,500 & $*<0,0001$ & 43 & 15 & 4,050 & $* 0,0442$ \\
\hline & Não & 2 & 15 & & & 5 & 16 & & \\
\hline
\end{tabular}

\begin{tabular}{|c|c|c|c|c|c|c|c|c|c|}
\hline & \multicolumn{2}{|c|}{$\mathbf{T} \boldsymbol{f u}$} & \multirow{2}{*}{$\begin{array}{l}\text { Estatística } \\
\text { McNemar }\end{array}$} & \multirow{2}{*}{$\begin{array}{c}\text { Valor } \\
\mathbf{p}\end{array}$} & \multicolumn{2}{|c|}{$\mathbf{T} f u$} & \multirow{2}{*}{$\begin{array}{l}\text { Estatística } \\
\text { McNemar }\end{array}$} & \multirow{2}{*}{$\begin{array}{c}\text { Valor } \\
\mathbf{p}\end{array}$} \\
\hline & & Sim & Não & & & Sim & Não & & \\
\hline \multirow{2}{*}{$\mathbf{T} 2$} & Sim & 10 & 11 & \multirow{2}{*}{9,090} & \multirow{2}{*}{$* 0,0026$} & 45 & 1 & \multirow{2}{*}{0,250} & \multirow{2}{*}{0,6171} \\
\hline & Não & 0 & 52 & & & 3 & 30 & & \\
\hline
\end{tabular}

Fonte: Do autor.

Teste McNemar

*valor $\mathrm{p}<0,05$

\subsubsection{Corte correto das unhas}

$\mathrm{Na}$ análise intergrupo da "presença de corte correto de unhas", observou-se que os grupos eram homogêneos em T1 e Tfu. Em T2 o GI apresentou diferença significativa ( $\mathrm{p}=0,0014)$ quando comparado ao GC (Tabela 25). 
Tabela 25 - Resultado da análise intergrupo referente a presença de corte correto das unhas. Boa Esperança, 2019.

\begin{tabular}{ccccccc}
\hline \multirow{2}{*}{ TEMPO } & \multicolumn{2}{c}{ GRUPO INTERVENÇãO } & \multicolumn{2}{c}{ GRUPO CONTROLE } & \multirow{2}{*}{$\boldsymbol{x}^{2}$} & \multirow{2}{*}{ Valor $\mathbf{p}$} \\
\cline { 2 - 5 } & Sim & Não & Sim & Não & & \\
\hline T1 & 20 & 53 & 11 & 68 & 2,755 & 0,0970 \\
$\mathbf{T} 2$ & 30 & 43 & 12 & 67 & 10,185 & $* \mathbf{0 , 0 0 1 4}$ \\
$\mathbf{T} \boldsymbol{f} \boldsymbol{u}$ & 15 & 58 & 20 & 59 & 0,345 & 0,5569 \\
\hline
\end{tabular}

Fonte: Do autor.

Teste Qui-Quadrado

*valor $\mathrm{p}<0,05$

$\mathrm{Na}$ análise intragrupo "da presença de corte de unhas corretos", o GI apresentou diferenças significativas em todos os tempos de avaliação, T1 e T2 (p<0,0001), T1 e Tfu ( $\mathrm{p}<0,0001)$ e, também T2 e T $u$ ( $\mathrm{p}=0,0003)$. O GC também apresentou significância, contudo, apenas em T1 e T $f u(\mathrm{p}=0,0265)$ e, T2 e T $f u(\mathrm{p}=0,0287)$ (Tabela 26).

Tabela 26 - Resultado da análise intragrupo da presença de corte correto das unhas ao considerar os tempos T1 e T2, T1 e Tfu e T2 e Tfu. Boa Esperança, 2019.

\begin{tabular}{|c|c|c|c|c|c|c|c|c|c|}
\hline & & \multicolumn{4}{|c|}{ GRUPO INTERVENÇÃO } & \multicolumn{4}{|c|}{ GRUPO CONTROLE } \\
\hline & & \multicolumn{2}{|c|}{ T2 } & \multirow{2}{*}{$\begin{array}{l}\text { Estatística } \\
\text { McNemar }\end{array}$} & \multirow{2}{*}{$\begin{array}{c}\text { Valor } \\
\mathbf{p}\end{array}$} & \multicolumn{2}{|c|}{ T2 } & \multirow{2}{*}{$\begin{array}{l}\text { Estatística } \\
\text { McNemar }\end{array}$} & \multirow{2}{*}{$\begin{array}{c}\text { Valor } \\
\text { p }\end{array}$} \\
\hline & & Sim & Não & & & Sim & Não & & \\
\hline \multirow{3}{*}{ T1 } & Sim & 20 & 0 & 21,044 & $*<0,0001$ & 8 & 3 & 0,000 & 1,000 \\
\hline & & \multicolumn{2}{|c|}{$\mathbf{T} f u$} & \multirow{2}{*}{$\begin{array}{l}\text { Estatística } \\
\text { McNemar }\end{array}$} & \multirow{2}{*}{$\begin{array}{c}\text { Valor } \\
\text { p }\end{array}$} & \multicolumn{2}{|c|}{ Tfu } & \multirow{2}{*}{$\begin{array}{l}\text { Estatística } \\
\text { McNemar }\end{array}$} & \multirow{2}{*}{$\begin{array}{c}\text { Valor } \\
\text { p }\end{array}$} \\
\hline & & Sim & Não & & & Sim & Não & & \\
\hline \multirow{4}{*}{ T1 } & Sim & 20 & 0 & \multirow{2}{*}{36,026} & \multirow{2}{*}{$*<0,0001$} & 9 & 2 & \multirow{2}{*}{4,923} & \multirow{2}{*}{$* 0,0265$} \\
\hline & Não & 38 & 15 & & & 11 & 57 & & \\
\hline & & \multicolumn{2}{|c|}{$\mathbf{T} f u$} & \multirow{2}{*}{$\begin{array}{l}\text { Estatística } \\
\text { McNemar }\end{array}$} & \multirow{2}{*}{$\begin{array}{c}\text { Valor } \\
\mathbf{p}\end{array}$} & \multicolumn{2}{|c|}{$\mathbf{T} f u$} & \multirow{2}{*}{$\begin{array}{l}\text { Estatística } \\
\text { McNemar }\end{array}$} & \multirow{2}{*}{$\begin{array}{c}\text { Valor } \\
\text { p }\end{array}$} \\
\hline & & Sim & Não & & & Sim & Não & & \\
\hline \multirow{2}{*}{ T2 } & Sim & 43 & 0 & \multirow{2}{*}{13,067} & \multirow{2}{*}{$* 0,0003$} & 11 & 1 & \multirow{2}{*}{4,900} & \multirow{2}{*}{$* \mathbf{0 , 0 2 8 7}$} \\
\hline & Não & 15 & 15 & & & 9 & 58 & & \\
\hline
\end{tabular}

Fonte: Do autor.

Teste McNemar

*valor $\mathrm{p}<0,05$

\subsubsection{Umidade nos espaços interdigitais}

Para a variável referente a "umidade nos espaços interdigitais", não foi observada diferença entre os grupos no T1, mas apresentaram diferença significativa no T2 (p<0,0001) e 
$\mathrm{T} f u$ ( $\mathrm{p}<0,0001)$, o que está relacionado a melhora da umidade interdigital do GI após as intervenções educativas (Tabela 27).

Tabela 27 - Resultado da análise intergrupo referente a presença de umidade nos espaços interdigitais. Boa Esperança, 2019.

\begin{tabular}{|c|c|c|c|c|c|c|}
\hline \multirow{2}{*}{ TEMPO } & \multicolumn{2}{|c|}{ GRUPO INTERVENÇÃO } & \multicolumn{2}{|c|}{ GRUPO CONTROLE } & \multirow{2}{*}{$x^{2}$} & \multirow{2}{*}{ Valor $\mathbf{p}$} \\
\hline & Sim & Não & Sim & Não & & \\
\hline T1 & 21 & 52 & 33 & 46 & 2,567 & 0,1091 \\
\hline $\mathbf{T} 2$ & 6 & 67 & 41 & 38 & 28,955 & $*<0,0001$ \\
\hline $\mathbf{T} f u$ & 2 & 71 & 38 & 41 & 31,228 & $*<0,0001$ \\
\hline
\end{tabular}

Fonte: Do autor.

Teste Qui-Quadrado

*valor $\mathrm{p}<0,05$

$\mathrm{Na}$ análise intragrupo o GI também apresentou melhora da "umidade nos espaços interdigitais" entre os T1 e T2 (p=0,0007) e, também T1 e Tfu $(\mathrm{p}<0,0001)$ (Tabela 28).

Tabela 28 - Resultado da análise intragrupo da presença de umidade nos espaços interdigitais ao considerar os tempos T1 e T2, T1 e Tfu e T2 e Tfu. Boa Esperança, 2019.

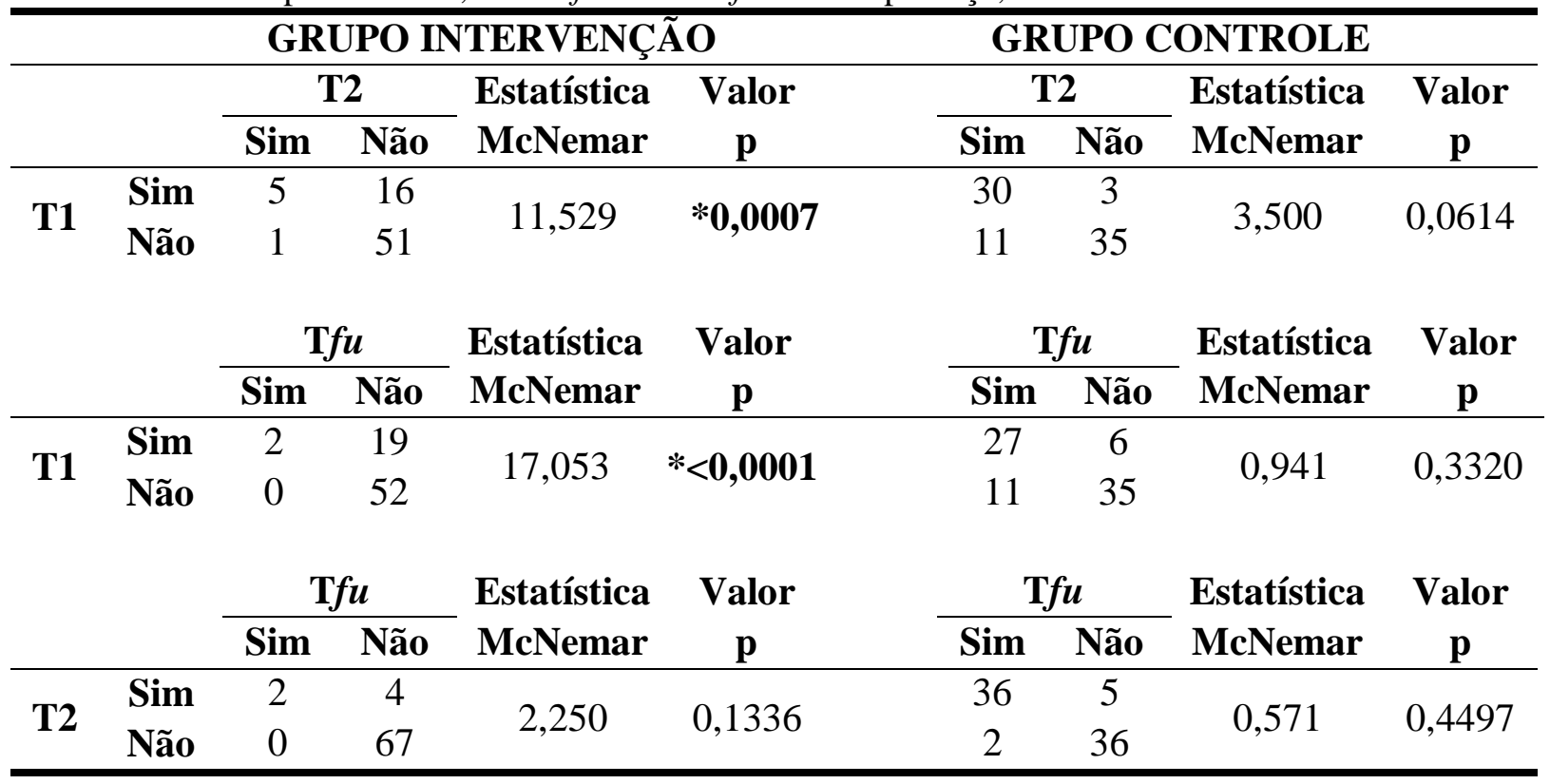

Fonte: Do autor.

Teste McNemar

*valor $\mathrm{p}<0,05$ 


\subsubsection{Maceração nos espaços interdigitais}

Referente à variável "maceração nos espaços interdigitais", observou-se que na análise intergrupo o GI apresentou melhora quando comparado ao GC nos tempos T2 ( $\mathrm{p}=0,0063$ ) e $\mathrm{T} f u(\mathrm{p}=0,0007)$ (Tabela 29).

Tabela 29 - Resultado da análise intergrupo referente a presença de maceração nos espaços interdigitais. Boa Esperança, 2019.

\begin{tabular}{ccccccc}
\hline \multirow{2}{*}{ TEMPO } & \multicolumn{2}{c}{ GRUPO INTERVENÇÃo } & \multicolumn{2}{c}{ GRUPO CONTROLE } & \multirow{2}{*}{$\boldsymbol{x}^{2}$} & \multirow{2}{*}{ Valor $\mathbf{p}$} \\
\cline { 2 - 5 } & Sim & Não & Sim & Não & & \\
\hline T1 & 15 & 58 & 18 & 61 & 0,076 & 0,783 \\
T2 & 6 & 67 & 24 & 55 & 7,453 & $* \mathbf{0 , 0 0 6 3}$ \\
T $\boldsymbol{f} \boldsymbol{u}$ & 3 & 70 & 25 & 54 & 11,507 & $* \mathbf{0 , 0 0 0 7}$ \\
\hline
\end{tabular}

Fonte: Do autor.

Teste Qui-Quadrado

*valor $\mathrm{p}<0,05$

Já na análise intragrupo da presença de maceração nos espaços interdigitais, o GI apresentou melhora entre os tempos T1 e T2 ( $\mathrm{p}=0,0159)$, o que não foi identificado no GC (Tabela 30).

Tabela 30 - Resultado da análise intragrupo da presença de maceração nos espaços interdigitais ao considerar os tempos T1 e T2, T1 e Tfu e T2 e Tfu. Boa Esperança, 2019.

\begin{tabular}{|c|c|c|c|c|c|c|c|c|c|}
\hline & & \multicolumn{4}{|c|}{ GRUPO INTERVENCCÃO } & \multicolumn{4}{|c|}{ GRUPO CONTROLE } \\
\hline & & \multicolumn{2}{|c|}{ T2 } & \multirow{2}{*}{$\begin{array}{l}\text { Estatística } \\
\text { McNemar }\end{array}$} & \multirow{2}{*}{$\begin{array}{c}\text { Valor } \\
\mathbf{p}\end{array}$} & \multicolumn{2}{|c|}{$\mathbf{T 2}$} & \multirow{2}{*}{$\begin{array}{l}\text { Estatística } \\
\text { McNemar }\end{array}$} & \multirow{2}{*}{$\begin{array}{c}\text { Valor } \\
\text { p }\end{array}$} \\
\hline & & Sim & Não & & & Sim & Não & & \\
\hline $\mathbf{T 1}$ & Sim & 5 & 10 & 5,812 & *0,0159 & 16 & 2 & 2,500 & 0,1138 \\
\hline
\end{tabular}

\begin{tabular}{|c|c|c|c|c|c|c|c|c|c|}
\hline & \multicolumn{2}{|c|}{$\mathbf{T} \boldsymbol{f u}$} & \multirow{2}{*}{$\begin{array}{l}\text { Estatística } \\
\text { McNemar }\end{array}$} & \multirow{2}{*}{$\begin{array}{c}\text { Valor } \\
\mathbf{p}\end{array}$} & \multicolumn{2}{|c|}{$\mathbf{T} f u$} & \multirow{2}{*}{$\begin{array}{l}\text { Estatística } \\
\text { McNemar }\end{array}$} & \multirow{2}{*}{$\begin{array}{c}\text { Valor } \\
\mathbf{p}\end{array}$} \\
\hline & & Sim & Não & & & Sim & Não & & \\
\hline \multirow{2}{*}{ T1 } & Sim & 1 & 4 & \multirow{2}{*}{2,250} & \multirow{2}{*}{0,1336} & 15 & 3 & \multirow{2}{*}{2,769} & \multirow{2}{*}{0,0961} \\
\hline & Não & 0 & 68 & & & 10 & 51 & & \\
\hline
\end{tabular}

\begin{tabular}{|c|c|c|c|c|c|c|c|c|c|}
\hline & \multicolumn{2}{|c|}{$\mathbf{T} f u$} & \multirow{2}{*}{$\begin{array}{l}\text { Estatística } \\
\text { McNemar }\end{array}$} & \multirow{2}{*}{$\begin{array}{c}\text { Valor } \\
\text { p }\end{array}$} & \multicolumn{2}{|c|}{$\mathbf{T} \boldsymbol{f u}$} & \multirow{2}{*}{$\begin{array}{l}\text { Estatística } \\
\text { McNemar }\end{array}$} & \multirow{2}{*}{$\begin{array}{c}\text { Valor } \\
\text { p }\end{array}$} \\
\hline & & Sim & Não & & & Sim & Não & & \\
\hline $\mathrm{T} 2$ & Sim & 1 & $\begin{array}{c}5 \\
67\end{array}$ & 3,200 & 0,0736 & 23 & 1 & 0,000 & 1,000 \\
\hline & Não & 0 & 67 & & & 2 & 53 & & \\
\hline
\end{tabular}

Fonte: Do autor.

Teste McNemar

*valor $\mathrm{p}<0,05$ 


\subsection{SENSIBILIDADE}

No aplicativo "Cuidando do pé" o domínio Sensibilidade é composto por aspectos relacionados a sensibilidade tátil pressórica, percepção vibratória e reflexo tendíneo de pessoas com DM. Destaca-se que não foram feitas análises intragrupo, tendo em vista a ausência de alterações observadas nas análises intergrupos.

\subsubsection{Sensibilidade tátil pressórica alterada}

$\mathrm{Na}$ análise da "sensibilidade tátil pressórica" intergrupo não houve diferenças significativas nos tempos de avaliação (Tabela 31).

Tabela 31- Resultado da análise intergrupo referente a presença de sensibilidade tátil pressórica alterada. Boa Esperança, 2019.

\begin{tabular}{ccccccc}
\hline \multirow{2}{*}{ TEMPO } & \multicolumn{2}{c}{ GRUPO INTERVENÇÃO } & \multicolumn{2}{c}{ GRUPO CONTROLE } & \multirow{2}{*}{$\boldsymbol{x}^{2}$} & \multirow{2}{*}{ Valor $\mathbf{p}$} \\
\cline { 2 - 5 } & Sim & Não & Sim & Não & & \\
\hline T1 & 12 & 61 & 15 & 64 & 0,169 & 0,8427 \\
$\mathbf{T} 2$ & 12 & 61 & 15 & 64 & 0,169 & 0,8427 \\
$\mathbf{T} \boldsymbol{f} \boldsymbol{u}$ & 12 & 61 & 15 & 64 & 0,169 & 0,8427 \\
\hline
\end{tabular}

Fonte: Do autor.

Teste Qui-Quadrado

\subsubsection{Percepção vibratória alterada}

Diferenças significativas também não foram encontradas entre os grupos na variável presença de percepção vibratória alterada (Tabela 32).

Tabela 32 - Resultado da análise intergrupo referente a presença de percepção vibratória alterada. Boa Esperança, 2019.

\begin{tabular}{ccccccc}
\hline \multirow{2}{*}{ TEMPO } & \multicolumn{2}{c}{ GRUPO INTERVENÇÃO } & \multicolumn{2}{c}{ GRUPO CONTROLE } & \multirow{2}{*}{$\boldsymbol{x}^{2}$} & \multirow{2}{*}{ Valor $\mathbf{p}$} \\
\cline { 2 - 5 } & Sim & Não & Sim & Não & & \\
\hline T1 & 2 & 71 & 2 & 77 & 0,006 & 0,9362 \\
T2 & 2 & 71 & 2 & 77 & 0,006 & 0,9362 \\
$\mathbf{T} \boldsymbol{f u}$ & 2 & 71 & 2 & 77 & 0,006 & 0,9362 \\
\hline
\end{tabular}

Fonte: Do autor.

Teste Qui-Quadrado 


\subsubsection{Reflexo tendíneo alterado}

$\mathrm{Na}$ análise intergrupo da presença de reflexo tendíneo, observou-se homogeneidade entre os grupos em todos os tempos de avaliação (Tabela 33).

Tabela 33 - Resultado da análise intergrupo referente a presença de reflexo tendíneo alterado. Boa Esperança, 2019.

\begin{tabular}{cccccccc}
\hline \multirow{2}{*}{ TEMPO } & \multicolumn{2}{c}{ GRUPO INTERVENÇÃO } & \multicolumn{2}{c}{ GRUPO CONTROLE } & \multirow{2}{*}{$\boldsymbol{x}^{2}$} & \multirow{2}{*}{ Valor $\mathbf{p}$} \\
\cline { 2 - 5 } & Sim & Não & Sim & Não & & \\
\hline T1 & 3 & 70 & 2 & 77 & 0,038 & 0,8459 \\
T2 & 3 & 70 & 2 & 77 & 0,038 & 0,8459 \\
T $\boldsymbol{f} \boldsymbol{u}$ & 3 & 70 & 2 & 77 & 0,038 & 0,8459 \\
\hline
\end{tabular}

Fonte: Do autor.

Teste Qui-Quadrado

\subsection{DEFORMIDADES NOS PÉS}

O domínio deformidades nos pés contempla as deformidades anatômicas como garras, martelo, hálux valgo e artropatia de Charcot. As análises intragrupo da presença de deformidades nos pés não foram feitas, visto que não foi observada nenhuma mudança na análise intergrupo.

\subsubsection{Deformidades em garras}

Os grupos apresentaram homogeneidade na análise intergrupo da "presença de deformidades em garras" (Tabela 34).

Tabela 34 - Resultado da análise intergrupo referente a presença de deformidades em garras. Boa Esperança, 2019.

\begin{tabular}{ccccccc}
\hline \multirow{2}{*}{ TEMPO } & \multicolumn{2}{c}{ GRUPO INTERVENÇÃO } & \multicolumn{2}{c}{ GRUPO CONTROLE } & \multirow{2}{*}{$\boldsymbol{x}^{2}$} & \multirow{2}{*}{ Valor $\mathbf{p}$} \\
\cline { 2 - 5 } & Sim & Não & Sim & Não & & \\
\hline T1 & 47 & 26 & 47 & 32 & 0,384 & 0,6506 \\
T2 & 47 & 26 & 47 & 32 & 0,384 & 0,6506 \\
$\mathbf{T} \boldsymbol{f} \boldsymbol{u}$ & 47 & 26 & 47 & 32 & 0,384 & 0,6506 \\
\hline
\end{tabular}

Fonte: Do autor.

Teste Qui-quadrado 


\subsubsection{Deformidades em martelo}

$\mathrm{Na}$ análise intergrupo da "presença de deformidade em martelo", observou-se que os grupos não apresentaram diferenças nos tempos de avaliação (Tabela 35).

Tabela 35 - Resultado da análise intergrupo referente a presença de deformidades em martelo. Boa Esperança, 2019.

\begin{tabular}{ccccccc}
\hline \multirow{2}{*}{ TEMPO } & \multicolumn{2}{c}{ GRUPO INTERVENÇÃO } & \multicolumn{2}{c}{ GRUPO CONTROLE } & \multirow{2}{*}{$\boldsymbol{x}^{2}$} & \multirow{2}{*}{ Valor $\mathbf{p}$} \\
\cline { 2 - 5 } & Sim & Não & Sim & Não & & \\
\hline T1 & 4 & 69 & 2 & 77 & 0,870 & 0,3511 \\
T2 & 4 & 69 & 2 & 77 & 0,870 & 0,3511 \\
$\mathbf{T} \boldsymbol{f} \boldsymbol{u}$ & 4 & 69 & 2 & 77 & 0,870 & 0,3511 \\
\hline
\end{tabular}

Fonte: Do autor.

Teste Qui-quadrado

\subsubsection{Hálux valgo}

Quanto a presença de "hálux valgo", observou-se que na avaliação intergrupo não houve diferenças entre os grupos (Tabela 36).

Tabela 36 - Resultado da análise intergrupo referente a presença de hálux valgo. Boa Esperança, 2019.

\begin{tabular}{ccccccc}
\hline \multirow{2}{*}{ TEMPO } & \multicolumn{2}{c}{ GRUPO INTERVENÇÃO } & \multicolumn{2}{c}{ GRUPO CONTROLE } & \multirow{2}{*}{$\boldsymbol{x}^{2}$} & \multirow{2}{*}{ Valor $\mathbf{p}$} \\
\cline { 2 - 5 } & Sim & Não & Sim & Não & & \\
\hline T1 & 32 & 41 & 36 & 43 & 0,046 & 0,9589 \\
T2 & 32 & 41 & 36 & 43 & 0,046 & 0,9589 \\
$\mathbf{T} \boldsymbol{f} \boldsymbol{u}$ & 32 & 41 & 36 & 43 & 0,046 & 0,9589 \\
\hline
\end{tabular}

Fonte: Do autor.

Teste Qui-quadrado

\subsubsection{Artropatia de Charcot}

A análise da "presença de artropatia de Charcot" não demostrou diferenças entre os grupos nos tempos de avaliação (Tabela 37). 
Tabela 37 - Resultado da análise intergrupo referente a presença de artropatia de Charcot. Boa Esperança, 2019.

\begin{tabular}{|c|c|c|c|c|c|c|}
\hline \multirow{2}{*}{ TEMPO } & \multicolumn{2}{|c|}{ GRUPO INTERVENÇÃO } & \multicolumn{2}{|c|}{ GRUPO CONTROLE } & \multirow{2}{*}{$x^{2}$} & \multirow[b]{2}{*}{ Valor $\mathrm{p}$} \\
\hline & Sim & Não & Sim & Não & & \\
\hline T1 & 0 & 73 & 0 & 79 & 0,000 & 1,0000 \\
\hline $\mathbf{T 2}$ & 0 & 73 & 0 & 79 & 0,000 & 1,0000 \\
\hline $\mathbf{T} f u$ & 0 & 73 & 0 & 79 & 0,000 & 1,0000 \\
\hline
\end{tabular}

Fonte: Do autor.

Teste Qui-quadrado

\subsection{CONDIÇÕES VASCULARES/ARTERIAIS}

No protocolo de avaliação das pessoas com DM, o domínio referente às condições vasculares/arteriais é composto por aspectos relacionados a edema, presença de varizes, pulsos pediosos e tibiais.

\subsubsection{Edema}

Para a variável "presença de edema" os grupos não apresentaram diferenças significativas na análise intergrupo (Tabela 38).

Tabela 38 - Resultado da análise intergrupo referente a presença de edema. Boa Esperança, 2019.

\begin{tabular}{cccccccc}
\hline \multirow{2}{*}{ TEMPO } & \multicolumn{2}{c}{ GRUPO INTERVENÇÃO } & \multicolumn{2}{c}{ GRUPO CONTROLE } & \multirow{2}{*}{$\boldsymbol{x}^{2}$} & \multirow{2}{*}{ Valor $\mathbf{p}$} \\
\cline { 2 - 5 } & Sim & Não & Sim & Não & & \\
\hline T1 & 21 & 52 & 22 & 57 & 0,0160 & 0,9565 \\
T2 & 19 & 54 & 24 & 55 & 0,3540 & 0,6781 \\
$\mathbf{T} \boldsymbol{f} \boldsymbol{u}$ & 17 & 56 & 23 & 56 & 0.6640 & 0,5283 \\
\hline
\end{tabular}

Fonte: Do autor.

Teste Qui-Quadrado

Diferenças significativas também não foram observadas na avaliação intragrupo da “presença de edemas” (Tabela 39). 
Tabela 39 - Resultado da análise intragrupo da presença de edema ao considerar os tempos T1 e T2, T1 e T $f u$ e T2 e Tfu. Boa Esperança, 2019.

\begin{tabular}{|c|c|c|c|c|c|c|c|c|c|}
\hline & & \multicolumn{4}{|c|}{ GRUPO INTERVENÇÃO } & \multicolumn{4}{|c|}{ GRUPO CONTROLE } \\
\hline & & \multicolumn{2}{|c|}{ T2 } & \multirow{2}{*}{$\begin{array}{l}\text { Estatística } \\
\text { McNemar }\end{array}$} & \multirow{2}{*}{$\begin{array}{c}\text { Valor } \\
\text { p }\end{array}$} & \multicolumn{2}{|c|}{ T2 } & \multirow{2}{*}{$\begin{array}{l}\text { Estatística } \\
\text { McNemar }\end{array}$} & \multirow{2}{*}{$\begin{array}{c}\text { Valor } \\
\text { p }\end{array}$} \\
\hline & & Sim & Não & & & Sim & Não & & \\
\hline \multirow{4}{*}{ T1 } & Sim & 15 & 6 & \multirow{2}{*}{0,000} & \multirow{2}{*}{0,7539} & 13 & 9 & \multirow{2}{*}{0,050} & \multirow{2}{*}{0,8231} \\
\hline & Não & 4 & 48 & & & 11 & 46 & & \\
\hline & & \multicolumn{2}{|c|}{$\mathbf{T} f u$} & \multirow{2}{*}{$\begin{array}{l}\text { Estatística } \\
\text { McNemar }\end{array}$} & \multirow{2}{*}{$\begin{array}{c}\text { Valor } \\
\mathbf{p}\end{array}$} & \multicolumn{2}{|c|}{$\mathbf{T f u}$} & \multirow{2}{*}{$\begin{array}{l}\text { Estatística } \\
\text { McNemar }\end{array}$} & \multirow{2}{*}{$\begin{array}{c}\text { Valor } \\
\mathbf{p}\end{array}$} \\
\hline & & Sim & Não & & & Sim & Não & & \\
\hline \multirow{4}{*}{ T1 } & Sim & 13 & 8 & \multirow{2}{*}{0,000} & \multirow{2}{*}{0,3877} & 13 & 9 & \multirow{2}{*}{0,000} & \multirow{2}{*}{1,000} \\
\hline & Não & 4 & 48 & & & 10 & 47 & & \\
\hline & & \multicolumn{2}{|c|}{$\mathbf{T} f u$} & \multirow{2}{*}{$\begin{array}{l}\text { Estatística } \\
\text { McNemar }\end{array}$} & \multirow{2}{*}{$\begin{array}{c}\text { Valor } \\
\mathbf{p}\end{array}$} & \multicolumn{2}{|c|}{$\mathbf{T} f u$} & \multirow{2}{*}{$\mathbf{T} f u$} & \multirow{2}{*}{$\begin{array}{c}\text { Valor } \\
\text { p }\end{array}$} \\
\hline & & Sim & Não & & & Sim & Não & & \\
\hline \multirow{2}{*}{$\mathbf{T} 2$} & Sim & 14 & 5 & \multirow{2}{*}{0,000} & \multirow{2}{*}{0,7266} & 20 & 4 & \multirow{2}{*}{0,000} & \multirow{2}{*}{1,000} \\
\hline & Não & 3 & 51 & & & 3 & 52 & & \\
\hline
\end{tabular}

Fonte: Do autor.

Teste McNemar

\subsubsection{Varizes}

$\mathrm{Na}$ análise intergrupo da "presença de varizes", observa-se que os grupos não apresentaram diferenças significativas (Tabela 40).

Tabela 40 - Resultado da análise intergrupo referente a presença de varizes. Boa Esperança, 2019.

\begin{tabular}{ccccccc}
\hline \multirow{2}{*}{ TEMPO } & \multicolumn{2}{c}{ GRUPO INTERVENÇÃ̃O } & \multicolumn{2}{c}{ GRUPO CONTROLE } & \multirow{2}{*}{$\boldsymbol{x}^{2}$} & \multirow{2}{*}{ Valor $\mathbf{p}$} \\
\cline { 2 - 5 } & Sim & Não & Sim & Não & & \\
\hline T1 & 51 & 22 & 47 & 32 & 1,781 & 0,2440 \\
T2 & 53 & 20 & 50 & 29 & 1,506 & 0,2921 \\
$\mathbf{T} \boldsymbol{f} \boldsymbol{u}$ & 53 & 20 & 50 & 29 & 1,506 & 0,2921 \\
\hline
\end{tabular}

Fonte: Do autor.

Teste Qui-quadrado

*p valor $<0,05$

Os grupos também não apresentaram diferenças significativas quando foram avaliados isoladamente para a "presença de varizes" (Tabela 41). 
Tabela 41 - Resultado da análise intragrupo referente a presença de varizes considerando os tempos T1 e T2, T1 e Tfu e T2 e Tfu. Boa Esperança, 2019.

\begin{tabular}{|c|c|c|c|c|c|c|c|c|c|}
\hline & & \multicolumn{4}{|c|}{ GRUPO INTERVENÇÃO } & \multicolumn{4}{|c|}{ GRUPO CONTROLE } \\
\hline & & \multicolumn{2}{|c|}{ T2 } & \multirow{2}{*}{$\begin{array}{l}\text { Estatística } \\
\text { McNemar }\end{array}$} & \multirow{2}{*}{$\begin{array}{c}\text { Valor } \\
\text { p }\end{array}$} & \multicolumn{2}{|c|}{ T2 } & \multirow{2}{*}{$\begin{array}{l}\text { Estatística } \\
\text { McNemar }\end{array}$} & \multirow{2}{*}{$\begin{array}{c}\text { Valor } \\
\text { p }\end{array}$} \\
\hline & & Sim & Não & & & Sim & Não & & \\
\hline \multirow{4}{*}{ T1 } & Sim & 51 & 0 & \multirow{2}{*}{0,000} & \multirow{2}{*}{0,500} & 47 & 0 & \multirow{2}{*}{0,000} & \multirow{2}{*}{0,2500} \\
\hline & Não & 2 & 20 & & & 3 & 29 & & \\
\hline & & \multicolumn{2}{|c|}{$\mathbf{T} \boldsymbol{f u}$} & \multirow{2}{*}{$\begin{array}{l}\text { Estatística } \\
\text { McNemar }\end{array}$} & \multirow{2}{*}{$\begin{array}{c}\text { Valor } \\
\text { p }\end{array}$} & \multicolumn{2}{|c|}{$\mathbf{T} f u$} & Estatística & Valor \\
\hline & & Sim & Não & & & Sim & Não & McNemar & p \\
\hline \multirow{4}{*}{ T1 } & Sim & 51 & 0 & \multirow{2}{*}{0,000} & \multirow{2}{*}{0,500} & 47 & 0 & \multirow{2}{*}{0,000} & \multirow{2}{*}{0,2500} \\
\hline & Não & 2 & 20 & & & 3 & 29 & & \\
\hline & & \multicolumn{2}{|c|}{$\mathbf{T} f u$} & \multirow{2}{*}{$\begin{array}{l}\text { Estatística } \\
\text { McNemar }\end{array}$} & \multirow{2}{*}{$\begin{array}{c}\text { Valor } \\
\text { p }\end{array}$} & \multicolumn{2}{|c|}{$\mathbf{T} f u$} & \multirow{2}{*}{$\begin{array}{l}\text { Estatística } \\
\text { McNemar }\end{array}$} & \multirow{2}{*}{$\begin{array}{c}\text { Valor } \\
\mathbf{p}\end{array}$} \\
\hline & & Sim & Não & & & Sim & Não & & \\
\hline \multirow{2}{*}{$\mathbf{T} 2$} & Sim & 53 & 0 & \multirow{2}{*}{0,000} & \multirow{2}{*}{1,0000} & 50 & 0 & \multirow{2}{*}{0,000} & \multirow{2}{*}{1,0000} \\
\hline & Não & 0 & 20 & & & 0 & 29 & & \\
\hline
\end{tabular}

Fonte: Do autor.

Teste McNemar

\subsubsection{Pulsos tibiais}

O resultado da análise intergrupo do "pulso tibial esquerdo" não apresentou diferença significativa entre os grupos (Tabela 42).

Tabela 42 - Resultado da análise intergrupo referente ao pulso tibial esquerdo. Boa Esperança, 2019.

\begin{tabular}{|c|c|c|c|c|c|c|c|c|}
\hline \multirow[b]{2}{*}{ TEMPO } & \multicolumn{3}{|c|}{ GRUPO INTERVENÇÃO } & \multicolumn{3}{|c|}{ GRUPO CONTROLE } & \multirow[b]{2}{*}{$U$} & \multirow[b]{2}{*}{$\begin{array}{c}\text { Valor } \\
\mathbf{p}\end{array}$} \\
\hline & Presente & Diminuído & $\begin{array}{c}\text { Não } \\
\text { palpável }\end{array}$ & Presente & Diminuído & $\begin{array}{c}\text { Não } \\
\text { palpável }\end{array}$ & & \\
\hline T1 & 44 & 29 & 0 & 49 & 30 & 0 & 2934,0 & 0,8271 \\
\hline $\mathbf{T 2}$ & 57 & 16 & 0 & 54 & 25 & 0 & 2603,0 & 0,1792 \\
\hline $\mathbf{T} f u$ & 59 & 14 & 0 & 56 & 23 & 0 & 2597,0 & 0,1559 \\
\hline
\end{tabular}

Fonte: Do autor.

Teste Wilcoxon-Mann-Whitney

Observando-se a análise intragrupo do "pulso tibial esquerdo" é possível perceber que o GI apresentou diferença significativa entre os tempos T1 e T2 (p=0,0009), T1 e Tfu $(\mathrm{p}=0,0011)($ Tabela 43). 
Tabela 43 - Resultado da análise intragrupo do pulso tibial esquerdo ao considerar os tempos T1 e T2, T1 e Tfu e T2 e Tfu. Boa Esperança, 2019.

\begin{tabular}{ccccc}
\hline \multirow{2}{*}{ TEMPO } & \multicolumn{2}{c}{ GRUPO INTERVENÇÃO } & \multicolumn{2}{c}{ GRUPO CONTROLE } \\
\cline { 2 - 5 } & $\mathbf{V}$ & Valor $\mathbf{~}$ & $\mathbf{V}$ & Valor $\mathbf{p}$ \\
\hline $\mathrm{T} 1-\mathrm{T} 2$ & 112,0 & $* \mathbf{0 , 0 0 0 9}$ & 63,0 & 0,1779 \\
$\mathrm{~T} 1-\mathrm{T} f u$ & 198,0 & $* \mathbf{0 , 0 0 1 1}$ & 3397,0 & 0,2405 \\
$\mathrm{~T} 2-\mathrm{T} f u$ & 22,5 & 0,5297 & 14,0 & 0,4840 \\
\hline
\end{tabular}

Fonte: Do autor.

Teste McNemar

*valor $\mathrm{p}<0,05$

A análise intergrupo do "pulso tibial direto" não apresentou diferença significativa entre os grupos (Tabela 44).

Tabela 44 - Resultado da análise intergrupo referente ao pulso tibial direito. Boa Esperança, 2019.

\begin{tabular}{|c|c|c|c|c|c|c|c|c|}
\hline \multirow[b]{2}{*}{ TEMPO } & \multicolumn{3}{|c|}{ GRUPO INTERVENÇÃO } & \multicolumn{3}{|c|}{ GRUPO CONTROLE } & \multirow[b]{2}{*}{$\boldsymbol{U}$} & \multirow{2}{*}{$\begin{array}{c}\text { Valor } \\
\mathbf{p}\end{array}$} \\
\hline & Presente & Diminuído & $\begin{array}{c}\text { Não } \\
\text { palpável }\end{array}$ & Presente & Diminuído & $\begin{array}{c}\text { Não } \\
\text { palpável }\end{array}$ & & \\
\hline T1 & 47 & 26 & 0 & 56 & 23 & 0 & 3071 & 0,3943 \\
\hline $\mathbf{T} 2$ & 62 & 11 & 0 & 60 & 19 & 0 & 2624,5 & 0,1667 \\
\hline $\mathbf{T} f u$ & 63 & 10 & 0 & 62 & 17 & 0 & 2658 & 0,2101 \\
\hline
\end{tabular}

Fonte: Do autor.

Teste Wilcoxon-Mann-Whitney

Observa-se que na análise intragrupo do "pulso tibial direito" o GI apresentou diferença significativa entre os tempos $\mathrm{T} 1$ e $\mathrm{T} 2$ ( $\mathrm{p}=0,0003), \mathrm{T} 1$ e $\mathrm{T} f u(\mathrm{p}=0,0007)$ (Tabela 45).

Tabela 45 - Resultado da análise intragrupo do pulso tibial direito ao considerar os tempos T1 e T2, T1 e Tfu e T2 e T $f u$. Boa Esperança, 2019.

\begin{tabular}{ccccc}
\hline \multirow{2}{*}{ TEMPO } & \multicolumn{2}{c}{ GRUPO INTERVENÇÃO } & \multicolumn{2}{c}{ GRUPO CONTROLE } \\
\cline { 2 - 5 } & $\mathbf{V}$ & Valor $\mathbf{p}$ & $\mathbf{V}$ & Valor $\mathbf{p}$ \\
\hline $\mathrm{T} 1-\mathrm{T} 2$ & 144,0 & $\boldsymbol{* 0 , 0 0 0 3}$ & 67,5 & 0,3014 \\
$\mathrm{~T} 1-\mathrm{T} f u$ & 218,5 & $* \mathbf{0 , 0 0 0 7}$ & 3278,5 & 0,4741 \\
$\mathrm{~T} 2-\mathrm{T} f u$ & 16,0 & 0,7768 & 7,5 & 0,4237 \\
\hline
\end{tabular}

Fonte: Do autor.

Teste McNemar

*valor $\mathrm{p}<0,05$

\subsubsection{Pulsos pediosos}

Em relação à análise intergrupo do pulso pedioso esquerdo, observa-se diferença significativa entre os grupos no $\mathrm{T} 1(\mathrm{p}=0,0175)$ e em $\mathrm{T} f u(\mathrm{p}=0,0439)$ (Tabela 46). 
Tabela 46 - Resultado da análise intergrupo referente ao pulso pedioso esquerdo. Boa Esperança, 2019.

\begin{tabular}{cccccccccc}
\hline \multirow{2}{*}{ TEMPO } & \multicolumn{2}{c}{ GRUPO INTERVENÇÃO } & \multicolumn{2}{c}{ GRUPO CONTROLE } & & \multicolumn{2}{c}{ Valor } \\
\cline { 2 - 7 } & Presente & Diminuído & $\begin{array}{c}\text { Não } \\
\text { palpável }\end{array}$ & Presente & Diminuído & $\begin{array}{c}\text { Não } \\
\text { palpável }\end{array}$ & U & p \\
\hline T1 & 50 & 23 & 0 & 67 & 12 & 0 & 3354,0 & $* \mathbf{0 , 0 1 7 5}$ \\
T2 & 65 & 8 & 0 & 65 & 14 & 0 & 2688,5 & 0,2393 \\
T $\boldsymbol{u} \boldsymbol{u}$ & 68 & 5 & 0 & 65 & 14 & 0 & 2570,0 & $* \mathbf{0 , 0 4 3 9}$ \\
\hline
\end{tabular}

Fonte: Do autor.

Teste Wilcoxon-Mann-Whitney

*valor $\mathrm{p}<0,05$

Observa-se que na análise intragrupo do "pulso pedioso esquerdo" o GI apresentou diferença significativa entre os tempos T1 e T2 (p<0,0001), T1 e T $f u(p<0,0001)$ (Tabela 47).

Tabela 47 - Resultado da análise intragrupo do pulso pedioso esquerdo ao considerar os tempos T1 e T2, T1 e T $f u$ e T2 e Tfu. Boa Esperança, 2019.

\begin{tabular}{ccccc}
\hline \multirow{2}{*}{ TEMPO } & \multicolumn{2}{c}{ GRUPO INTERVENÇÃO } & \multicolumn{2}{c}{ GRUPO CONTROLE } \\
\cline { 2 - 5 } & $\mathbf{V}$ & Valor $\mathbf{p}$ & $\mathbf{V}$ & Valor $\mathbf{p}$ \\
\hline $\mathrm{T} 1-\mathrm{T} 2$ & 120,0 & $\boldsymbol{*}<\mathbf{0 , 0 0 0 1}$ & 32,5 & 0,5941 \\
$\mathrm{~T} 1-\mathrm{T} f u$ & 199,5 & $\boldsymbol{*}<\mathbf{0 , 0 0 0 1}$ & 3041,5 & 0,6708 \\
$\mathrm{~T} 2-\mathrm{T} f u$ & 12,0 & 0,2330 & 1,5 & 1,0000 \\
\hline
\end{tabular}

Fonte: Do autor.

Teste McNemar

*valor $\mathrm{p}<0,05$

$\mathrm{Na}$ análise intergrupo do "pulso pedioso direito" os resultados apresentaram diferença significativa entre os grupos no $\mathrm{T} 1(\mathrm{p}=0,0108)$ e em $\mathrm{T} f u(\mathrm{p}=0,0229)$. Destaca-se que no T1 o GC apresentava melhores médias e no Tfu ocorreu o inverso (Tabela 48).

Tabela 48 - Resultado da análise intergrupo referente ao pulso pedioso direito. Boa Esperança, 2019.

\begin{tabular}{cccccccccc}
\hline & \multicolumn{2}{c}{ GRUPO INTERVENÇÃO } & \multicolumn{2}{c}{ GRUPO CONTROLE } & & \multicolumn{2}{c}{ Valor } \\
\cline { 2 - 7 } TEMPO & Presente & Diminuído & $\begin{array}{c}\text { Não } \\
\text { palpável }\end{array}$ & Presente & Diminuído & $\begin{array}{c}\text { Não } \\
\text { palpável }\end{array}$ & & p \\
\hline T1 & 49 & 24 & 0 & 67 & 12 & 0 & 3393,5 & $* \mathbf{0 , 0 1 0 8}$ \\
T2 & 59 & 14 & 0 & 63 & 16 & 0 & 2852,5 & 0,8704 \\
$\mathbf{T} \boldsymbol{f} \boldsymbol{u}$ & 67 & 6 & 0 & 62 & 17 & 0 & 2500,0 & $* \mathbf{0 , 0 2 2 9}$ \\
\hline
\end{tabular}

Fonte: Do autor.

Teste Wilcoxon-Mann-Whitney

$*_{\text {valor }} \mathrm{p}<0,05$ 
É possível perceber que na análise intragrupo do "pulso pedioso direito" o GI apresentou diferença significativa entre os tempos T1 e T2 (p=0,0197), T1 e Tfu $(\mathrm{p}<0,0001)$ e $\mathrm{T} 2$ e $\mathrm{T} f u(\mathrm{p}=0,0134)$ (Tabela 49).

Tabela 49 - Resultado da análise intragrupo do pulso pedioso direito ao considerar os tempos T1 e T2, T1 e Tfu e T2 e Tfu. Boa Esperança, 2019.

\begin{tabular}{|c|c|c|c|c|}
\hline \multirow{2}{*}{ TEMPO } & \multicolumn{2}{|c|}{ GRUPO INTERVENÇÃO } & \multicolumn{2}{|c|}{ GRUPO CONTROLE } \\
\hline & $\mathbf{V}$ & Valor $\mathbf{p}$ & $\mathbf{V}$ & Valor p \\
\hline $\mathrm{T} 1-\mathrm{T} 2$ & 133,0 & $* 0,0197$ & 37,5 & 0,3014 \\
\hline $\mathrm{T} 1-\mathrm{T} f u$ & 171,0 & $*<0,0001$ & 2962,5 & 0,4076 \\
\hline $\mathrm{T} 2-\mathrm{T} f u$ & 49,5 & $* 0,0134$ & 0,0 & 1,0000 \\
\hline
\end{tabular}

Fonte: Do autor.

Teste McNemar

*valor $\mathrm{p}<0,05$

Em relação a análise intergrupo da variável "cor da pele" observa-se que os participantes não apresentaram diferenças significativas (T1-p=0,7728, T2-p=0,6650, Tfu$\mathrm{p}=0,5637)$. O mesmo ocorreu na análise intragrupo $(\mathrm{p}>0,05)$.

\subsection{TEMPERATURA DOS PÉS}

$\mathrm{Na}$ análise intergrupo da variável "temperatura dos pés" não houve diferença significativa (Tabela 50).

Tabela 50 - Resultado da análise intergrupo referente a temperatura dos pés. Boa Esperança, 2019.

\begin{tabular}{|c|c|c|c|c|c|c|c|c|}
\hline \multirow{2}{*}{ TEMPO } & \multicolumn{3}{|c|}{ GRUPO INTERVENÇÃO } & \multicolumn{3}{|c|}{ GRUPO CONTROLE } & \multirow{2}{*}{$\boldsymbol{U}$} & \multirow{2}{*}{ Valor $\mathrm{p}$} \\
\hline & Normal & Quente & Fria & Normal & Quente & Fria & & \\
\hline T1 & 47 & 1 & 25 & 51 & 1 & 27 & 2885,5 & 1,0000 \\
\hline $\mathbf{T} 2$ & 50 & 1 & 22 & 52 & 1 & 26 & 2802,5 & 0,7652 \\
\hline $\mathbf{T} f u$ & 54 & 1 & 18 & 52 & 1 & 26 & 2646,5 & 0,3821 \\
\hline
\end{tabular}

Fonte: Do autor.

Teste Wilcoxon-Mann-Whitney

$\mathrm{Na}$ análise intragrupo da variável "temperatura dos pés" também não foi possível observar diferença estatística significativa (Tabela 51). 
Tabela 51 - Resultado da análise intragrupo da temperatura dos pés ao considerar os tempos T1 e T2, T1 e Tfu e T2 e T $f u$. Boa Esperança, 2019.

\begin{tabular}{ccccc}
\hline \multirow{2}{*}{ TEMPO } & \multicolumn{2}{c}{ GRUPO INTERVENÇÃO } & \multicolumn{2}{c}{ GRUPO CONTROLE } \\
\cline { 2 - 5 } & $\mathbf{V}$ & Valor $\mathbf{p}$ & $\mathbf{V}$ & Valor $\mathbf{p}$ \\
\hline $\mathrm{T} 1-\mathrm{T} 2$ & 0 & 0,1088 & 0 & 0,3173 \\
$\mathrm{~T} 1-\mathrm{T} f u$ & 4,0 & 0,0910 & 0 & 0,3173 \\
$\mathrm{~T} 2-\mathrm{T} f u$ & 0 & 0,0679 & 0 & $* * *$ \\
\hline
\end{tabular}

Fonte: Do autor.

Teste McNemar

*** O teste de McNemar não pode ser realizado por não haver alteração das opções de "Não" para "Sim" e vice versa

\subsection{CLASSIFICAÇÃO DO RISCO DE PÉ DIABÉTICO (RISCO DE INTEGRIDADE TISSULAR PREJUDICADA)}

A classificação do risco de pé diabético (risco de integridade tissular prejudicada) inclui os resultados da avaliação dos pés por meio dos domínios integridade da pele e anexos, sensibilidade, condições vasculares/arteriais, temperatura e deformidades plantares. A classificação do risco atribuiu o valor zero para risco baixo, um (1) para risco moderado, dois (2) para risco alto e três (3) para risco muito alto.

$\mathrm{Na}$ análise global da "classificação do risco de pé diabético (risco de integridade tissular prejudicada)", observou-se que os grupos não apresentaram diferenças estatísticas significativas em nenhum dos tempos de avaliação (Tabela 52).

Tabela 52 - Resultado da análise intergrupo referente a classificação do risco de pé diabético. Boa Esperança, 2019.

\begin{tabular}{|c|c|c|c|c|c|c|c|c|c|c|}
\hline \multirow[b]{2}{*}{ TEMPO } & \multicolumn{4}{|c|}{ GRUPO INTERVENÇÃO } & \multicolumn{4}{|c|}{ GRUPO CONTROLE } & \multirow[b]{2}{*}{$\boldsymbol{U}$} & \multirow[b]{2}{*}{ Valor $\mathbf{p}$} \\
\hline & Baixo & Moderado & Alto & $\begin{array}{c}\text { Muito } \\
\text { alto }\end{array}$ & Baixo & Moderado & Alto & $\begin{array}{c}\text { Muito } \\
\text { alto }\end{array}$ & & \\
\hline T1 & 5 & 1 & 56 & 11 & 7 & 1 & 61 & 10 & 2995 & 0,5778 \\
\hline $\mathbf{T} 2$ & 10 & 0 & 53 & 10 & 7 & 1 & 54 & 17 & 2595 & 0,1857 \\
\hline $\mathbf{T} f u$ & 14 & 0 & 49 & 10 & 7 & 1 & 58 & 13 & 2587 & 0,1741 \\
\hline
\end{tabular}

Fonte: Do autor.

Teste Wilcoxon-Mann-Whitney

Observa-se que na análise intragrupo da "classificação do risco de pé diabético (risco de integridade tissular prejudicada)" o GI apresentou diferença significativa entre os tempos T1 e T $f u(p=0,0121)$ e T2 e T $f u(p<0,0001)$, após a intervenção de enfermagem (Tabela 53). 
Tabela 53 - Resultado da análise intragrupo da classificação do risco de pé diabético ao considerar os tempos T1 e T2, T1 e Tfu e T2 e Tfu. Boa Esperança, 2019.

\begin{tabular}{ccccc}
\hline \multirow{2}{*}{ TEMPO } & \multicolumn{2}{c}{ GRUPO INTERVENÇÃ̄O } & \multicolumn{2}{c}{ GRUPO CONTROLE } \\
\cline { 2 - 5 } & $\mathbf{T}$ & Valor $\mathbf{p}$ & $\mathbf{T}$ & Valor $\mathbf{p}$ \\
\hline $\mathrm{T} 1-\mathrm{T} 2$ & 55,5 & 0,1790 & 34,0 & 0,2416 \\
$\mathrm{~T} 1-\mathrm{T} f u$ & 60,0 & $* \mathbf{0 , 0 1 2 1}$ & 31,5 & 0,9272 \\
$\mathrm{~T} 2-\mathrm{T} f u$ & 1484,0 & $*<\mathbf{0 , 0 0 0 1}$ & 23,0 & 0,5182 \\
\hline
\end{tabular}

Fonte: Do autor.

Teste Wilcoxon

*valor $\mathrm{p}<0,05$

\subsection{CONHECIMENTO DAS ATIVIDADES DE AUTOCUIDADO COM OS PÉS}

A identificação da percepção dos participantes do estudo quanto às atividades de autocuidado com os pés é fundamental para mensurar as lacunas do conhecimento, de modo a favorecer o desenvolvimento da educação em saúde de acordo com as singularidades de cada grupo.

$\mathrm{Na}$ análise intergrupo do "conhecimento sobre as atividades de autocuidado com os pés", observou-se que os grupos eram homogêneos na primeira avaliação e, após o desenvolvimento da intervenção educativa, o GI apresentou melhora significativa nos tempos $\mathrm{T} 1(\mathrm{p}<0,0001)$ e T $f u(\mathrm{p}<0,0001)$ quando comparado ao GC (Tabela 54).

Tabela 54 - Resultado da análise intergrupo referente ao conhecimento sobre as atividades de autocuidado com os pés. Boa Esperança, 2019.

\begin{tabular}{|c|c|c|c|c|c|c|c|c|c|c|}
\hline \multirow[b]{2}{*}{ TEMPO } & \multicolumn{4}{|c|}{ GRUPO INTERVENÇÃO } & \multicolumn{4}{|c|}{ GRUPO CONTROLE } & \multirow[b]{2}{*}{$\boldsymbol{U}$} & \multirow[b]{2}{*}{ Valor $\mathbf{p}$} \\
\hline & Baixo & Moderado & Alto & $\begin{array}{c}\text { Muito } \\
\text { alto }\end{array}$ & Baixo & Moderado & Alto & $\begin{array}{c}\text { Muito } \\
\text { alto }\end{array}$ & & \\
\hline T1 & 45 & 21 & 6 & 1 & 48 & 22 & 6 & 3 & 2836,0 & 0,8609 \\
\hline $\mathbf{T} 2$ & 0 & 0 & 2 & 71 & 22 & 36 & 16 & 5 & 203,50 & $*<0,0001$ \\
\hline $\mathbf{T} f u$ & 0 & 0 & 2 & 71 & 19 & 38 & 17 & 5 & 204,50 & $*<0,0001$ \\
\hline
\end{tabular}

Fonte: Do autor.

Teste Wilcoxon-Mann-Whitney

*valor $\mathrm{p}<0,05$

Diferenças significativas também foram encontradas em ambos os grupos na avaliação intragrupo nos tempos T1 e T2 (p<0,0001) e T1 e Tfu (p<0,0001) na análise da variável "conhecimento sobre as atividades de autocuidado com os pés" (Tabela 55). 
Tabela 55 - Resultado da análise intragrupo do conhecimento sobre as atividades de autocuidado com os pés ao considerar os tempos T1 e T2, T1 e Tfu e T2 e Tfu. Boa Esperança, 2019.

\begin{tabular}{ccccc}
\hline \multirow{2}{*}{ TEMPO } & \multicolumn{2}{c}{ GRUPO INTERVENÇÃO } & \multicolumn{2}{c}{ GRUPO CONTROLE } \\
\cline { 2 - 5 } & $\mathbf{T}$ & Valor $\mathbf{p}$ & $\mathbf{T}$ & Valor $\mathbf{p}$ \\
\hline $\mathrm{T} 1-\mathrm{T} 2$ & 0 & $*<\mathbf{0 , 0 0 0 1}$ & 0 & $*<\mathbf{0 , 0 0 0 1}$ \\
$\mathrm{T} 1-\mathrm{T} f u$ & 0 & $*<\mathbf{0 , 0 0 0 1}$ & 0 & $*<\mathbf{0 , 0 0 0 1}$ \\
$\mathrm{T} 2-\mathrm{T} f u$ & 0 & 0,1797 & 0 & 0,0679 \\
\hline
\end{tabular}

Fonte: Do autor.

Teste Wilcoxon

*valor $\mathrm{p}<0,05$

\subsection{INTENÇÃO DE CUIDAR DOS PÉS}

Desenvolver o cuidado em saúde está relacionado à intenção de cuidar. Desta forma, identificar a intenção dos participantes em cuidar dos pés pode ser uma estratégia para subsidiar a implementação das ações de autocuidado específicas com os pés de pessoas com DM.

$\mathrm{Na}$ análise intergrupo da "intenção de cuidar dos pés", observa-se homogeneidade no primeiro tempo de avaliação e diferença significativa entre os grupos em T1 (p<0,0001) e T $f u$ ( $\mathrm{p}<0,0001)$, relacionada à melhores médias do GI em relação ao GC (Tabela 56).

Tabela 56 - Resultado da análise intergrupo referente a intenção de cuidar dos pés. Boa Esperança, 2019.

\begin{tabular}{cccccc}
\hline \multirow{2}{*}{ TEMPO } & GRUPO INTERVENÇÃO & $\begin{array}{c}\text { GRUPO } \\
\text { CONTROLE }\end{array}$ & \multirow{U}{*}{$\boldsymbol{U}$} & Valor p \\
\cline { 2 - 3 } & Média (DP) & Média (DP) & & \\
\hline $\mathrm{T} 1$ & $301,09(33,70)$ & $331,86(41,79)$ & 2726,00 & 0,5614 \\
$\mathrm{~T} 2$ & $361,09(30,95)$ & $305,94(53,56)$ & 792,50 & $*<\mathbf{0 , 0 0 0 1}$ \\
$\mathrm{T} f u$ & $369,23(36,22)$ & $329,49(54,75)$ & 1480,00 & $*<\mathbf{0 , 0 0 0 1}$ \\
\hline
\end{tabular}

Fonte: Do autor.

Teste Wilcoxon-Mann-Whitney

*valor $\mathrm{p}<0,05$

Diferenças significativas também foram encontradas em ambos os grupos na avaliação intragrupo nos tempos T1 e T2 (GI p<0,0001, GC p<0,0277) e T1 e Tfu (p=0,0001) e, especificamente no GC no tempo T2 e T $f u(p=0,0006)$ (Tabela 57). 
Tabela 57 - Resultado da análise intragrupo da intenção de cuidar dos pés ao considerar os tempos T1 e T2, T1 e Tfu e T2 e Tfu. Boa Esperança, 2019.

\begin{tabular}{ccccc}
\hline \multirow{2}{*}{ TEMPO } & \multicolumn{2}{c}{ GRUPO INTERVENÇÃO } & \multicolumn{2}{c}{ GRUPO CONTROLE } \\
\cline { 2 - 5 } & $\mathbf{T}$ & Valor $\mathbf{p}$ & $\mathbf{T}$ & Valor $\mathbf{p}$ \\
\hline $\mathrm{T} 1-\mathrm{T} 2$ & 118 & $*<\mathbf{0 , 0 0 0 1}$ & 0 & $*<\mathbf{0 , 0 2 7 7}$ \\
$\mathrm{T} 1-\mathrm{T} f u$ & 137 & $*<\mathbf{0 , 0 0 0 1}$ & 1 & $\boldsymbol{0} 0, \mathbf{0 0 0 1}$ \\
$\mathrm{T} 2-\mathrm{T} f u$ & 898 & 0,0642 & 36 & $\boldsymbol{* 0 , 0 0 0 6}$ \\
\hline
\end{tabular}

Fonte: Do autor.

Teste Wilcoxon

*valor $\mathrm{p}<0,05$ 
A discussão está apresentada conforme a sequência dos objetivos e resultados apresentados nos itens anteriores.

\subsection{CARACTERIZAÇÃO DA AMOSTRA: VARIÁVEIS SOCIODEMOGRÁFICAS, ANTROPOMÉTRICAS, HÁBITOS DE VIDA, CLÍNICAS E INFORMAÇÕES COMPLEMENTARES}

A amostra do estudo foi composta por participantes do sexo feminino (GI=75,34\% e $\mathrm{GC}=56,97 \%)$, idosos com média de idade de 62 anos, $(\mathrm{GI}=62,02$ (DP=11,36), GC=62,17 (DP=11,24), estado civil com conjugê/companheiro $(\mathrm{GI}=57,53 \%$ e $\mathrm{GC}=60,76 \%)$, aposentados $(\mathrm{GI}=57 \%$ e $\mathrm{GC}=49 \%)$ e que viviam em média com duas a três pessoas na mesma residência, dados que se assemelham aos de estudos descritivos (LUCOVEIS et al., 2018, TRAJANO et al., 2018) e ensaios clínicos (MOREIRA et al., 2017, SILVA et al., 2015), desenvolvidos também em ambulatórios das unidades de atenção primária, em amostras compostas por pessoas diagnosticadas com DM, não somente no estado de Minas Gerais como também em outros estados brasileiros. Dados estes poderiam sugerir um possível perfil das pessoas atendidas em unidades de atenção primária com o diagnóstico médico de DM.

A escolaridade e a renda variaram entre os grupos. No GI 56,13\% dos participantes possuíam escolaridade de 8 a 12 anos, com renda familiar média de $\mathrm{R} \$ 3.261,80$ $(\mathrm{DP}=\mathrm{R} \$ 1.496,00)$, enquanto que no $\mathrm{GC}, 63,30 \%$ dos participantes apresentaram grau de escolaridade menor do que oito anos e renda familiar média $\mathrm{R} \$ 2.551,98$ ( $\mathrm{DP}=\mathrm{R} \$ 1.403,00)$.

Segundo a publicação clássica de Doak, Doak e Root (1995), o baixo grau de escolaridade pode comprometer as habilidades de leitura, escrita, compreensão, e de modo semelhante, o estudo descritivo de Pace et al (2002) reitera que o baixo grau de escolaridade pode representar uma barreira para o acesso às informações e oportunidades de aprendizagem pertinentes ao cuidado à saúde.

Apesar de não ser objetivo do presente estudo, foram realizadas análises de correlação-teste de Spearman (dados não apresentados nos resultados) entre as variáveis escolaridade e renda com o escore de risco de pé diabético (integridade tissular prejudicada). Os resultados mostraram não haver relação entre as variáveis escolaridade e risco de pé diabético (integridade tissular prejudicada) no GI, nos T1 ( p=0,0642), T2 (p=0,0888) e T $f u$ $(\mathrm{p}=0,0885)$, bem como no GC entre os T1 $(\mathrm{p}=0,9202), \mathrm{T} 2(\mathrm{p}=0,5474)$ e $\mathrm{T} f u(\mathrm{p}=0,4682) . \mathrm{O}$ mesmo foi observado na análise da relação das variáveis renda com o risco de pé diabético 
(integridade tissular prejudicada) no GI, entre os T1 (GI p=0,1374), T2 (p=0,4673) e Tfu $(\mathrm{p}=0,1374)$ e da mesma forma no GC nos T1 ( $\mathrm{p}=0,5302), \mathrm{T} 2(\mathrm{p}=0,2506)$ e T $f u(\mathrm{p}=0,1702)$.

A variável antropométrica IMC, avaliada pela média do peso e altura, mostrou sobrepeso entre os participantes de ambos os grupos, o que pode representar a atual situação das pessoas com DM nas regiões Sul, Sudeste, Centro-oeste e Nordeste do Brasil. O estudo observacional, analítico, de delineamento transversal, de base populacional e multicêntrico, desenvolvido por Gomes e colaboradores (2006), teve como objetivo avaliar a prevalência de sobrepeso e obesidade em pessoas com DM2 em atendimento ambulatorial em diferentes regiões do Brasil. O resultado da análise do IMC foi de $28,3 \pm 5,2 \mathrm{~kg} / \mathrm{m}^{2}$ na amostra estudada e ainda, os autores reiteraram que as pessoas da região Nordeste apresentaram menor IMC em comparação com os das regiões Centro-Oeste, Sudeste e Sul, respectivamente (26,4 \pm 4,7 vs. $27,9 \pm 4,8$ vs. $29,2 \pm 5,1$ vs. $29,4 \pm 5,4 \mathrm{~kg} / \mathrm{m} 2$; p<0,001) (GOMES et al., 2006). Resultados estes reiteram a importância do controle de sobrepeso na população brasileira, os quais pode resultar dentre outros fatores de hábitos de vida inadequados (FERREIRA; SZWARCWALD; DAMACENA, 2019).

Referente aos hábitos de vida, destaca-se uma maior frequência de pessoas que referiram não serem tabagistas ( $\mathrm{GI}=54,79 \%$ e $\mathrm{GC}=54,43 \%)$, e da mesma forma para o consumo de bebidas alcoólicas $(\mathrm{GI}=58,85 \%$ e $\mathrm{GC}=75,94 \%)$ e para a prática de exercícios físicos $(\mathrm{GI}=64,38 \%$ e $\mathrm{GC}=53,16 \%)$. As diretrizes da SBD, a partir de estudos científicos, mostram que estes hábitos podem ser comuns aos brasileiros com DM, e ainda, reitera que fatores, tais como o consumo de bebidas alcoólicas, ausência da prática regular de exercícios físicos e alimentação inadequada podem contribuir para a obesidade (SOCIEDADE BRASILEIRA DE DIABETES, 2017).

O estudo transversal de Malta e colaboradores (2019), cujo objetivo foi analisar os fatores associados ao DM autorreferido entre adultos entrevistados na Pesquisa Nacional de Saúde (PNS), mostra que 11,8\% das pessoas classificadas como obesas, referiram ter DM e 6,5\% dessas, também faziam uso de bebidas alcoólicas e, especialmente os homens relataram consumo abusivo de álcool. Desta forma, os programas de promoção à saúde para redução do sobrepeso e obesidade, assim como de outros fatores de risco comuns às DCNT, são fundamentais para prevenir e controlar o DM, principalmente quando relacionados a intervenções para a alimentação saudável, a restrição do tabaco e o consumo de álcool e também para a prática de exercícios físicos (MALTA et al., 2019). 
Para o tempo de diagnóstico de DM o GI possuía em média 11,71 (DP=7,75) anos e o GC 10,72 (DP=5,47) anos, e o tipo de tratamento referido com maior frequência entre os participantes foram os antidiabéticos orais $(\mathrm{GI}=86,31 \%$ e $\mathrm{GC}=93,67 \%)$ ao comparar com o uso de insulina ( $\mathrm{GI}=27,39 \%$ e $\mathrm{GC}=30,38 \%)$, em ambos os grupos. Entre os antidiabéticos orais, os referidos com maiores frequências foram as biguanidas e associações com mais de um tipo antidiabético oral e, a insulina mais utilizada foi a NPH/lenta.

Os tratamentos referidos pelos participantes se assemelham com os de outros estudos realizados em unidades de saúde primárias, tais como o estudo quase experimental desenvolvido no México, em cinco centros de saúde do estado de São Luis Potosí, em uma amostra de 77 pessoas com DM (PÉREZ-RODRÍGUEZ, 2015) e também com os resultados do ensaio clínico randomizado desenvolvido na ESF, cuja amostra foi constituída por 109 pessoas com DM, na cidade de Boa Esperança, estado de Minas Gerais (MOREIRA et al., 2017).

Os tipos de tratamento referidos pelos participantes deste estudo estão em consonância com as diretrizes da SBD (2017) e com a IDF (2017), que preconizam o tratamento inicial com o uso de biguanidas, tal como a metformina e, se indicado, associada com outros tipos de antidiabéticos orais e/ou insulina.

Para as pessoas com DM2 que apresentam glicemia em jejum entre $200 \mathrm{mg} / \mathrm{dL}$ e 299 $\mathrm{mg} / \mathrm{dL}$ e ausência de critérios para manifestação graves, tais como, perda significativa de peso, sintomas graves e/ou cetonúria, a conduta terapêutica é o uso de metformina em terapia combinada com um segundo agente antidiabético. Para a insulinoterapia parcial ou intensiva a glicemia em jejum deve ser >300 $\mathrm{mg} / \mathrm{dL}$ e presença de manifestações graves (INTERNACIONAL DIABETES FEDERATION, 2017; SOCIEDADE BRASILEIRA DE DIABETES, 2017).

O tipo de tratamento a ser utilizado pelas pessoas com DM é determinado pelo tempo de diagnóstico, presença de comorbidades e controle glicêmico (SOCIEDADE BRASILEIRA DE DIABETES, 2017; INTERNACIONAL DIABETES FEDERATION, 2017).

Entre as morbidades referidas pelos participantes do GI e GC estão a HA com maiores frequências ( $\mathrm{GI}=79,46 \%$ e $\mathrm{GC}=81,02 \%)$, seguida, pela dificuldade visual ( $\mathrm{GI}=43,84 \%$ e $\mathrm{GC}=35,45 \%)$, grau de dor ou desconforto em MMII (GI=39,73\%, para a categoria de pior dor e $\mathrm{GC}=35,45 \%$ para dor moderada) e com menores frequências história de úlceras em MMII $(\mathrm{GI}=12,33 \%$ e $\mathrm{GC}=12,66 \%)$. 
Os diagnósticos de DM e HA são estabelecidos mediante dados clínicos comuns, particularmente aqueles relacionados à obesidade e a resistência à insulina, os quais são fatores de risco para as doenças cardiovasculares (PETRIE et al., 2018).

Para o controle do DM e prevenção/retardo das complicações crônicas consequentes do longo tempo de duração do diagnóstico e mau controle da doença, foram propostos sete comportamentos de autocuidado e respectivos indicadores para avaliação dos resultados, os quais correspondem à alimentação saudável, exercícios físicos, medicação, monitorização, resolução de problemas, enfrentamento saudável e redução de riscos (PEEPLES et al., 2007) .

Entre as atividades indicadas são destacadas a monitorização, por meio do exame clínico dos olhos e dos pés (BRASIL, 2016; PEEPLES et al., 2007; SECRETARIA DE ESTADO DE SAÚDE DE BRASÍLIA, 2001), tendo em vista que a baixa acuidade visual em pessoas com DM interfere diretamente no autocuidado com os pés (PACE et al, 2002).

Para as pessoas com histórico de úlceras nos MMII é fundamental o seguimento sistematizado para o cuidado, uma vez que frequentemente as úlceras precedem as amputações de MMII e são responsáveis por elevada morbimortalidade e hospitalização entre pessoas com DM (LEVIN, 1996). E, o tipo e a intensidade da dor ou desconforto nos MMII de pessoas com DM, principalmente quando se apresenta em forma de queimação ou formigamento, com piora no período noturno e alivio durante o movimento, podem indicar a presença de neuropatia. Já para a suspeita de doença vascular periférica, os sintomas caracterizam-se por cãibras ou peso nos MMII ao caminhar e alivio durante o repouso (BRASIL, 2016).

Ao finalizar a apresentação da discussão sobre as variáveis clínicas, destaca-se o controle glicêmico, o qual já foi ressaltado pela sua importância no controle da doença e complicações agudas e crônicas consequentes (INTERNACIONAL DIABETES FEDERATION, 2017; SOCIEDADE BRASILEIRA DE DIABETES, 2017).

Os valores médios e respectivos desvios padrão do controle glicêmico, avaliado por meio da glicemia capilar em jejum, foram, respectivamente nos $\mathrm{T} 1$, T2 e $\mathrm{T} f u$, entre os participantes do GI de 164,5 (DP=56,07) mg/dL, 143,36 (DP=49,39) mg/dL e 145,32 $(\mathrm{DP}=57,60) \mathrm{mg} / \mathrm{dL}$, e entre os participantes do GC $197(\mathrm{DP}=60,65) \mathrm{mg} / \mathrm{dL}, 204,63$ $(\mathrm{DP}=68,18) \mathrm{mg} / \mathrm{dL}$ e 199,75 $(\mathrm{DP}=67,17) \mathrm{mg} / \mathrm{dL}$. Apesar de não ser o objetivo do estudo, avaliar os resultados da intervenção educativa no controle glicêmico, e sim como um dos fatores clínicos de risco para a integridade tissular prejudicada, pode-se observar, na análise intergrupos que no GI os valores dessa variável se apresentavam menores desde a primeira 
avaliação, quando comparado aos valores glicêmicos do $\mathrm{GC}(\mathrm{p}<0,05)$. Na análise intragrupos os participantes do GI apresentaram melhores médias nos tempos T1 e T2 e nos T1 e Tfu.

Após o diagnostico do DM, o estudo do UK Prospective Diabetes Study Group (UKPDS 33), desenvolvido em população com DM1, mostrou que existe uma piora progressiva do controle glicêmico, independente do uso de antidiabéticos. O mesmo estudo demostrou também que o controle da glicemia diminuiu os riscos de complicações microvasculares (UK PROSPECTIVE DIABETES STUDY GROUP 33, 1998) além da redução da incidência e da progressão de complicações como a retinopatia, a nefropatia e a neuropatia (DIABETES CONTROL AND COMPLICATIONS TRIAL RESEARCH GROUP- DCCT, 1993).

Entre as morbidades consequentes do DM, destacam-se as úlceras nos pés, que geralmente tem como o principal precursor a neuropatia diabética, com prognostico agravado pela arteriopatia e outros fatores, tais como cuidados podiátricos e/ou calçados inadequados, falta de conhecimentos quanto aos cuidados com os pés, dentre outros (GAMBA et al., 2004; PARISI et al., 2016).

O último item da caracterização da amostra, intitulado outras informações complementares, contempla o recebimento de informações sobre os cuidados com os pés, avaliação dos pés por profissionais da saúde e realização de autocuidado com os pés.

O MS (BRASIL, 2016) e a SBD (2017) preconizam entre os cuidados na atenção a pessoa com DM, a avaliação dos pés de forma periódica, de acordo com o grau de risco para desenvolver as lesões.

No presente estudo, $100 \%$ dos participantes de ambos os grupos, referiram não terem tido os pés avaliados por profissionais da saúde e $98,63 \%$ dos participantes do GI e 100\% do GC referiram não terem recebido orientações sobre cuidados com os pés. Quanto a última variável desse item referente a prática do autocuidado com os pés, 95,89\% dos participantes do GI e $100 \%$ do GC referiram não realizar.

Dados do estudo multicêntrico desenvolvido no Brasil com o objetivo de avaliar fatores de risco cardiovascular, controle glicêmico e disponibilidade de triagem para as complicações crônicas, em uma amostra de 2.233 pessoas com DM2 atendidas em centros especializados e não especializados, mostraram que apenas $58 \%$ (1.300) dos participantes tiveram registro de exame dos pés (GOMES et al., 2006).

O estudo epidemiológico transversal, realizado em uma ESF do Recife, com 48 pessoas com DM, cujo objetivo foi avaliar o risco para desenvolvimento do pé diabético em 
usuários cadastrados em uma USF do município do Recife, mostrou que 83,3\% dos participantes referiram não ter seus pés examinados durante as consultas e 62,5\% relataram a não realização do autocuidado com os pés (BEZERRA et al., 2015).

O estudo epidemiológico de corte transversal, desenvolvido em Pernambuco, em unidades de atenção primária, cujo objetivo foi determinar a prevalência de amputações por pé diabético e analisar associações com fatores relacionados à pessoa e à atenção primária, junto a uma amostra de 214 pessoas com DM, mostrou que 61,3\% dos participantes que foram submetidas à amputação, não tiveram os pés examinados nas consultas no último ano e que 55,4\% destes não receberam orientação sobre os cuidados com os pés (SANTOS et al., 2013).

Ao considerar os pressupostos teóricos da estratégia ensino aprendizagem dos cuidados com os pés, "Problematização por meio do Arco de Charles Maguerez", a pessoa é estimulada a refletir sobre a situação considerada "problema", e por meio do processo de teorização mediado por um especialista no assunto, é estimulada a buscar informações e interagir com pessoas que buscam resolução de problemas semelhantes (BORDENAVE; PEREIRA, 1982; BERBEL, 1996).

Receber informações sobre um determinado assunto de interesse é considerado o primeiro passo para formular hipótese na solução do problema, e desta forma, construir o conhecimento e aplicá-lo na prática de modo crítico e criativo (BORDENAVE; PEREIRA, 2004).

Estas três ultimas variáveis apresentadas, nos remete a uma situação preocupante mediante a importância de reconhecer precocemente os sinais e sintomas precursores de úlceras em pés, uma vez que a depender do número de fatores de risco podem ser graves e o desfecho pode ser amputação de parte ou de todo o MMII. Situação esta que leva a perda da qualidade de vida, diminuição da expectativa de vida e comprometimento de recursos financeiros da família e do sistema de saúde, entre outros agravos pessoais e sociais (BRASIL, 2006).

A educação em saúde desenvolvida na consulta de enfermagem deve vir acompanhada do exame minucioso dos MMII (BRASIL, 2001). As pessoas com DM devem ter os pés avaliados, por um profissional da saúde, pelo menos uma vez ao ano se não apresentar alterações na avaliação de risco de pé diabético (AMERICAN DIABETES ASSOCIATION, 2017; BRASIL, 2016; BOULTON et al., 2008). As queixas clínicas devem ser abordadas em 
todas as consultas com o intuito de prevenir complicações (SECRETARIA DE ESTADO DE MINAS GERAIS, 2013).

A seguir estão apresentados os dados referente a integridade da pele e anexo (condições dermatológicas), sensibilidade, deformidades anatômicas, condições arteriais/vasculares e temperatura dos pés de pessoas com DM2.

\subsection{INTEGRIDADE DA PELE E ANEXO (CONDIÇÕES DERMATOLÓGICAS), SENSIBILIDADE, DEFORMIDADES ANATÔMICAS, CONDIÇÕES VASCULARES/ARTERIAIS E TEMPERATURA DOS PÉS DE PESSOAS COM DM2}

Mediante as recomendações do MS (BRASIL, 2016) e ADA (2006), o exame dos pés inclui, dados que abrangem a avaliação dermatológica, neurológica e vascular.

No presente estudo o primeiro item apresentado é a integridade da pele e anexos (condições dermatológicas) avaliada por meio dos indicadores: “integridade da pele preservada", "presença de lesões esfoliativas", "presença de micose", "presença de calosidades", "presença de pelos nas pernas (pilosidade)", "presença de hidratação da pele", "presença de xerodermia", "presença de fissura", "presença de corte correto das unhas", "presença de umidade nos espaços interdigitais" e "presença de maceração nos espaços interdigitais".

Os resultados da variável integridade da pele preservada (condições dermatológicas) não apresentaram diferenças entre os grupos no T1 para os seguintes indicadores: integridade da pele, presença de lesões esfoliativas, presença de hidratação, xerodermia, fissura (rachadura), corte de unhas, presença de umidade e maceração interdigitais $(p>0,05)$. Entretanto, no GI houve melhora desses indicadores em relação ao GC nos tempos T2 e/ou $\mathrm{T} f u(\mathrm{p}<0,05)$. Na análise intragrupo, o GI também apresentou melhora nos indicadores anteriormente apresentados, após as intervenções educativas $(\mathrm{p}<0,05)$. Destaca-se que diferenças também foram observadas na avaliação intragrupo do GC, entre alguns tempos de avaliação, contudo, sem a mesma proporção que o GI (presença de hidratação da pele, xerodermia, fissura (rachadura) e corte correto das unhas) $(\mathrm{p}<0,05)$.

$\mathrm{Na}$ análise da variável presença de micoses, o GI e o GC apresentaram diferenças no $\mathrm{T} 1$, relacionadas às melhores médias do $\mathrm{GC}(\mathrm{p}<0,05)$. Entretanto, após as intervenções educativas, houve melhora pra essa variável no GI e, portanto, os grupos se tornaram 
homogêneos $(p>0,05)$. Na análise intragrupo o GI apresentou melhora para a variável presença de micose entre os T1 e T2 e T1 e Tfu $(\mathrm{p}<0,05)$.

As variáveis que não apresentaram diferença antes e após as intervenções educativas, nas análises intergrupo e intragrupo foram à presença de calosidades e pilosidade nos MMII $(\mathrm{p}>0,05)$.

Considera-se o primeiro fator na etiopatogenia das lesões em pés a hiperglicemia, responsável pelas alterações morfológicas e funcionais dos nervos, vasos sanguíneos e sistema imunológico. As alterações neurológicas, vasculares e dermatológicas podem comprometer a integridade tissular (HERDMAN; KAMITSURU, 2018). De acordo com especialistas as situações clínicas relacionadas ao desenvolvimento de UPD e infecção em pessoas com DM são: neuropatia motora periférica, responsável pelos distúrbios na anatomia e biomecânica dos pés que contribuem para o excesso de pressão plantar, formação de calos e UPD; neuropatia sensorial periférica responsável pela perda da sensibilidade protetora, e consequentes ferimentos causados por traumas mecânico, térmico e/ou químico (BOULTON et al., 2005; LIPSKY et al., 2006); neuropatia autonômica periférica que interfere na transpiração, ressecamento de pele, fissura, entre outras situações graves contributivas com a etiopatogenia da artropatia de Charcot; insuficiência vascular/arterial consequente as alterações estruturais e funcionais das artérias e veias, as quais comprometem a oxigenação, nutrição, e consequente viabilidade da cicatrização dos tecidos; retinopatia, mobilidade limitada e histórico de amputação anterior; hábitos e comportamentos inadequados quanto as medidas de prevenção e cuidados com os pés; falhas no sistema de saúde; educação e monitoramento inadequados quanto ao controle glicêmico e cuidados com os pés (LIPSKY et al., 2006).

A falta de cuidado com a pele, como a não utilização de cremes hidratantes ou dificuldade de reconhecer precocemente um trauma dermatológico, contribuem para o desenvolvimento de UPD e infecção invasiva nos tecidos moles. A infecção ao se aprofundar pode acometer os músculos, as articulações e os tendões (BANDIK, 2018). As pessoas com DM devem ser orientadas e estimuladas a adotarem o hábito de inspecionar os pés, incluindo os espaços interdigitais, na busca de alterações como fissuras, macerações, bolhas, calos, edema, hiperemia entre outras, e na presença dessas alterações, devem procurar ajuda de um profissional da saúde (AMERICAN DIABETES ASSOCIATION, 2017; BRASIL, 2016, INTERNACIONAL DIABETES FEDERATION, 2011; MONTEIRO et al., 2018). 
O uso de calçados em formatos adequados, principalmente os adaptados às alterações biomecânicas e deformidades também são fundamentais na prevenção das UPD. As pessoas com DM que possuem doença vascular periférica e/ou neuropatias e deformidades devem receber orientações para o uso de calçados adaptados a sua necessidade (BAKKER; DOOREN, 1994). Outro cuidado importante é quanto a utilização de calçados novos por curtos períodos de tempo, o ideal é trocá-los várias vezes ao dia, evitando pressão repetitiva nas proeminências ósseas (BAKKER; DOOREN, 1994; MONTEIRO et al., 2018).

Assim como os resultados do presente estudo, o estudo quase experimental, desenvolvido na Índia com o objetivo de avaliar a eficácia da educação grupal em saúde para a melhoria do autocuidado dos pés de pessoas com DM, apresentou melhora das práticas de cuidados com os pés após duas semanas de educação em saúde ( $p<0,001)$. As atividades de autocuidado discutidas em grupo estavam relacionadas a inspeção dos pés e espaços interdigitais, higiene, secagem e hidratação dos pés, uso de calçados fechados e confortáveis, corte de unhas adequado, entre outros. Os autores concluíram que educação embasada no autocuidado com os pés na atenção primária, melhora a prática de cuidados com os pés, o que provavelmente é eficaz na redução do desenvolvimento de UPD em pessoas com DM (SAURABH et al., 2014).

A seguir, serão apresentados os dados sobre a sensibilidade pressórica, vibratória e reflexo tendíneo, os quais estão diretamente relacionados com a integridade da pele (condições dermatológicas), apresentada anteriormente.

Para variável sensibilidade tátil pressórica, não houve diferenças nos tempos de avaliação entre os grupos. O mesmo pode ser observado nos resultados das variáveis percepções vibratória e reflexo tendíneo presentes. Mediante a irreversibilidade das manifestações clínicas neuropáticas, não há mudanças nessas variáveis (BOIKE; HALL, 2002).

Em Porto Alegre, Rio Grande do Sul, foi desenvolvido um estudo experimental com o objetivo de avaliar a eficácia de um programa de educação terapêutica associada a calçados para proteção dos pés quanto à incidência e a recorrência de úlceras neuropáticas por DM. Os resultados apontaram que o grupo tratado apresentou menores índices de recorrência e maior sobrevida sem úlceras plantares, contudo, o programa educativo não foi capaz de prevenir a ocorrência e recorrência de úlceras neuropáticas em pessoas com DM (CISNEROS, 2010).

Os dados deste último estudo apresentado reiteram que a neuropatia é a principal causa de úlceras nos MMII das pessoas com DM, por meio do comprometimento das fibras 
nervosas sensoriais, motoras e autonômicas (BOIKE; HALL, 2002; LIPSKY et al., 2006). As alterações neuropáticas nos pés progridem na direção distal para a proximal e são irreversíveis, portanto o controle glicêmico é fundamental para a sua prevenção e o diagnóstico precoce para evitar sua progressão (BOIKE; HALL, 2002).

A neuropatia diabética também está associada ao comprometimento motor, hipotrofia muscular e deformidades esqueléticas (BONA et al., 2010; DUARTE; GONÇALVES, 2011). Neste estudo, observou-se que referente às deformidades, tais como, garras, martelo, hálux valgo e artropatia de Charcot, os grupos apresentaram homogeneidade na análise intergrupo em todos os tempos de avaliação e, portanto, as análises intragrupo não foram feitas. $\mathrm{O}$ que era esperado, pois tais características clínicas, relacionadas a deformidades, podem apresentar caráter permanente (STANLEY, COLLIER, 2008).

Destaca-se que intervenções fisioterápicas, o que não foi objetivo do presente estudo, podem contribuir para o restabelecimento da funcionalidade nas articulações dos tornozelos e pés (SACCO et al., 2009); assim como para tonificar a musculatura intrínseca dos pés e fortalecer extensores e flexores do tornozelo (SARTOR et al.,2012; BUS et al., 2002); e ainda recuperar o sistema musculoesquelético (ALLET et al.,2010).

Reiber e colaboradores (1999) destacam que além da neuropatia e as deformidades, a combinação do trauma é uma tríade que está presente em quase dois terços das pessoas que apresentam diagnóstico de UPD.

A neuropatia periférica está relacionada a atrofia muscular intrínseca, que leva a alterações anatômicas e funcionais (BANDYK, 2018; LIPSKY et al., 2006; LEVIN, 1997), formação dos dedos em martelo, desenvolvimento de áreas com alta pressão na superfície plantar, inclusive nas cabeças dos metatarsos (BANDYK, 2018; LIPSKY et al., 2006), formação de calos e garras nos dedos dos pés, e, consequente desenvolvimento de UPD (LIPSKY et al., 2006).

Outra deformidade avaliada foi a artropatia de Charcot, porém não foram encontradas pessoas com DM e essa condição clínica no presente estudo. As deformidades neuroosteoartropáticas, tais como a artropatia de Charcot, caracterizada por mobilidade articular limitada, devido a anormalidade da anatomia e biomecânica plantar que causa excesso de pressão, principalmente na região centro-plantar (LIPSKY et al., 2006) e, a perda de sensibilidade protetora dos pés causada pela neuropatia sensitiva que associada a neuropatia autonômica resultam em osteopenia, o que predispõe à destruição óssea que piora durante o ato de caminhar (JEFFCOATE, 2008; JEFFCOATE; LIMA; NOBREGA, 2000). 
A artropatia de Charcot acomete, aproximadamente, 0,15\% das passoas com DM e como a possibilidade de fraturas ósseas e deformidade definitiva se faz presente, há necessidade de diagnóstico e intervenção precoce (CHANTELAU, 2005).

De acordo com a revisão de estudos prospectivos e retrospectivos sobre a descarga do pé diabético para prevenção e cura de úlceras, a redução da pressão plantar, que pode ser causada pelas deformidades, pode ser obtida por meio de dispositivos tecnológicos como palmilhas e calçados especiais, que podem favorecer inclusive a cicatrização de úlceras plantares em seis a oito semanas, devido à adequação da descarga plantar (CAVANAGH; BUS, 2010).

Armstrong e colaboradores (1998) ressaltam que a neuropatia e a doença arterial periférica estão relacionadas a um alto risco de desenvolver UPD. O estudo multicêntrico nacional, cujo objetivo foi levantar informações clínicas e epidemiológicas dos fatores associados ao risco de desenvolver úlcera e amputação em pessoas com DM, destaca que o pé neuroisquêmico está associado a maior possibilidade de desenvolvimento de UPD, enquanto que o pé isquêmico está relacionado ao maior risco de amputação (PARISI et al., 2016).

A insuficiência venosa que é uma comorbidade comum em pessoas com DM e, frequentemente predispõe a UPD e amputação (PARISI et al., 2016; PEREIRA et al., 2013), manifesta-se por meio de edema, eczema, hiperpigmentação da pele, dermatolipoesclerose e/ou úlcera venosa (PEREIRA et al., 2013).

A doença arterial periférica (DAP) que está relacionada à amputação de MMII em pessoas com DM (PARISI et al., 2016), manifesta-se por meio de diminuição ou ausência de pulsos periféricos, claudicação intermitente (LEVIN O’NEAL, 2001; SCHEFFEL et al., 2004) e anormalidades da coloração da pele, tais como, pele pálida, avermelhada, azulada ou arroxeada (DEALEY, 2006).

Ao avaliar os resultados dos indicadores de condições vasculares/arteriais neste estudo, destaca-se que em relação às variáveis edema, varizes e cor da pele, não foram encontradas diferenças entre os grupos e nem intragrupo.

Em relação aos pulsos tibiais esquerdo e direito não foram encontradas diferenças significativas entre os grupos nos tempos de avaliação. Diferenças significativas foram observadas na análise intragrupo do GI nos T1 e T2 e, T1 e T $f u$, tanto no pulso tibial esquerdo como no direito.

A análise dos pulsos pediosos esquerdo e direito mostrou resultados significativos quando comparados os dois grupos nos tempos $\mathrm{T} 1$ e $\mathrm{T} f u$. Na análise intragrupo o GI 
apresentou diferenças significativas no pulso pedioso esquerdo entre os tempos T1 e T2 e T1 e T $f u$ e, no direito entre os tempos $\mathrm{T} 1$ e T2, T1 e T $f u$ e, T2 e T $f u$.

A avaliação não invasiva da circulação periférica durante o exame físico, como a palpação dos pulsos, é recomendada principalmente se houver sinais ou sintomas sugestivos de isquemia periférica (ADA, 2003; BOULTON et al., 2005). Durante o exame clínico, se os pulsos estiverem diminuídos ou não palpáveis, é necessário suspeitar de vasculopatia e encaminhar a pessoa com DM para avaliação vascular complementar (ADA, 2013).

Alguns autores acreditam que a palpação dos pulsos pode apresentar variações e por isso não é considerada um método sensível para a detecção de doença arterial periférica (ABOYANS et al., 2008, COLLINS; SUAREZ-ALMAZOR; PETERSON, 2006). Contudo, é um método indicado durante o exame físico da pessoa com DM, particularmente descrito por diversos especialistas (ADA, 2003; ADA, 2017; BRASIL, 2016; MAFFE et al., 1995).

Reda e colaboradores (2012) desenvolveram um estudo no Canadá, com o objetivo de avaliar as complicações em MMII de pessoas com DM em tratamento hemodialítico antes e após participarem de um programa embasado no cuidado com os pés, o qual consistia em inspeção dos pés durante a sessão de hemodiálise, orientações quanto ao tipo de sapato adequado, hidratação dos pés, desenvolvimento de calos e UPD e manutenção de hábitos de vida saudáveis. Os resultados mostraram que a intervenção educativa foi efetiva na redução do número de pessoas que apresentavam pulsos pediosos não palpáveis e na frequência de neuropatia periférica, quando comparado a um estudo anterior desenvolvido no mesmo lugar, em um recorte de tempo de cinco anos (REDA et al., 2012).

O comprometimento vascular significativo associado à neuropatia avançada estão relacionados a diminuição da temperatura dos pés de pessoas com DM (BHARARA; COBB; CLAREMONT, 2006). Chand e colaboradores (2012) apontam que a lesão de nervos periféricos predispõe à diminuição da temperatura dos pés em pessoas com DM. Contudo, Bharara e colaboradores (2006) afirmam que nos estágios iniciais da neuropatia pode ser evidenciado um aumento da temperatura plantar.

O aumento da temperatura dos pés de pessoas com DM é um sinal comum do processo inflamatório presente em fase inicial do desenvolvimento de úlceras (ARMSTRONG et al., 2007; FOLTYNSKI et al., 2014; LAVERY et al., 2004; NISHIDE et al., 2009; SIVANANDAM et al., 2012), por isso a importância da avaliação da temperatura plantar.

No presente estudo, não foi observada diferença na análise da variável temperatura dos pés, após a implementação da intervenção educativa ( $p>0,05)$. Destaca-se que a temperatura 
foi avaliada e classificada em normal, quente ou fria, conforme descrito no manual do pé diabético que considera a temperatura quente relacionada a situação clínica denominada pé neuropático e fria, pé isquêmico (BRASIL, 2016; DEALEY, 2006; INTERNATIONAL DIABETES FEDERATION, 2006).

Outros estudos embasados no processo educativo e avaliação do pé em risco que utilizaram o termômetro infravermelho (MONTEIRO, 2015; BANUELOS-BARRERA; ARIAS-MERINO; BANUELOS-BARRERA, 2013) ou a câmera termográfica para aferir a temperatura dos pés de pessoas com DM (MOREIRA et. al., 2017), apontam a falta de influência do processo educativo na temperatura dos pés de pessoas com DM.

De acordo com Bharara e colaboradores (2006) ainda não há precisão quanto à importância das mudanças térmicas no desenvolvimento UPD. As aplicações de termografia e termometria em úlceras de MMII, complicações vasculares e complicações neuropáticas progrediram de acordo com o desenvolvimento de softwares de imagem e da tecnologia do transdutor, que se tornaram cada vez mais modernos, contudo, ainda existe incerteza quanto à modalidade térmica específica a ser utilizado (BHARARA, COBBE CLAREMONT, 2006).

As alterações térmicas estão relacionadas a muitas causas, tais como processo infeccioso, insuficiência vascular, neuropatia, distúrbios musculoesqueléticos ou a combinação de mais de um desses fatores (BHARARA, COBBE CLAREMONT, 2006).

O estudo descritivo, realizado em Puebla, no México, cujo objetivo foi descrever a termorregulação de pessoas saudáveis, com sobrepeso e DM por meio do termograma da pele dos pés, destaca que pessoas com DM quando possui vasos periféricos e nervos danificados, produz uma termorregulação irregular e assimétrica em ambos os pés e, nas regiões da pele fria circula menos sangue pelos vasos. A redução sanguínea periférica pode ser tanto um indicativo da constrição ou dilatação dos vasos sanguíneos, quanto da perda de sensibilidade (RENERO, 2017).

Em síntese, os dados do presente estudo mostraram melhora nos escores finais da classificação do risco do pé diabético (integridade tissular prejudicada) entre os participantes do GI uma vez que apresentou diferença na análise intragrupo entre os tempos T1 e T $f u$ e T2 e $\mathrm{T} f u,(\mathrm{p}>0,05)$, contudo, vale ressaltar que na análise intergrupo não foi observada diferenças entre os grupos $(p>0,05)$. Destaca-se que a melhora pode ser atribuída aos aspectos das condições dermatológicas, ou seja, nos indicadores da integridade da pele e anexos, tais como integridade da pele, presença de lesões esfoliativas, presença de hidratação, xerodermia, fissura (rachadura), corte de unhas, presença de umidade, maceração interdigitais e micoses. 
Reitera-se a importância do exame e cuidados com os pés para diminuir o risco de integridade tissular prejudicada. O estudo epidemiológico transversal, realizado em uma ESF do Recife, com 48 pessoas com DM, cujo objetivo foi avaliar o risco para desenvolvimento do pé diabético em usuários cadastrados em uma ESF do município do Recife, mostrou que $83,3 \%$ da amostra relataram não possuir seus pés examinados durante a consulta, e o exame dos pés, realizado pelos pesquisadores, mostrou que 39,6\% dos usuários apresentaram risco para desenvolver o pé diabético, variando entre grau 1 e 3 . Os principais objetivos da assistência às pessoas com DM são reconhecer os fatores de risco e estimular o autocuidado. Nesse contexto, a ESF tem papel fundamental no processo de acompanhamento e prevenção de complicações, visando a redução da ocorrência do pé diabético (BEZERRA et al,. 2015).

Especialistas ressaltam a importância dos profissionais de saúde desenvolver atividades educativas voltadas para o autocuidado dos pés de pessoas com DM, o que associado a avaliação minuciosa dos MMII podem prevenir o desenvolvimento de UPD e consequente amputação (LEVIN, 1996; PEDROSA et al., 1998; BOULTON, 1998).

\subsection{CONHECIMENTO DAS PESSOAS COM DM2 SOBRE AS ATIVIDADES DE AUTOCUIDADO COM OS PÉS E INTENÇÃO DE REALIZAR O AUTOCUIDADO COM OS PÉS}

O conhecimento referido sobre as atividades de autocuidado com os pés, na amostra estudada não apresentou diferenças entre os grupos. Em ambos os grupos as frequências foram maiores para a categoria "baixo conhecimento" (61,64\% dos participantes do GI e 60,75\% para os GC). Após as intervenções educativas, o GI apresentou diferença quando comparado ao GC $(\mathrm{p}<0,05)$, atribuído ao maior conhecimento dos participantes do grupo no T2 e Tfu. Na avaliação intragrupo ambos os grupos apresentaram melhora $(\mathrm{p}<0,05)$.

Dada a importância da educação para o conhecimento sobre o autocuidado com os pés, apresenta-se estudos comparativos que focaram a educação da pessoa com DM em relação aos cuidados com os pés, inclusive com referenciais educacionais diversos e, a seguir, para finalizar o tópico, estudos que utilizaram a problematização por meio do Arco de Charles Maguerez, o ensino de pessoas com DM.

No estudo quase experimental desenvolvido no México, em São Luis Potosí, cujo objetivo foi determinar o efeito de uma intervenção educativa baseada na metodologia participativa com intuito de aumentar o grau de conhecimento e hábitos de cuidado e 
melhorar as condições físicas dos pés de pessoas com DM, foram encontrados resultados semelhantes, uma vez que antes das intervenções educativas $55,8 \%$ dos participantes tinham um conhecimento classificado como "Bom" e após as intervenções o 89,6\% apresentaram um conhecimento classificado como "muito bom" (PÉREZ-RODRÍGUEZ, 2015).

$\mathrm{Na}$ Malásia o ensaio clínico randomizado, realizado com uma amostra de 76 idosos diagnosticados com DM, teve como objetivo avaliar a eficácia de um programa de educação em saúde em grupo, com base na teoria da autoeficácia no comportamento relacionado ao autocuidado com os pés. Os participantes foram avaliados antes de iniciar as intervenções, na quarta e na décima segunda semana, após o início das intervenções educativas. O estudo mostrou que o conhecimento dos participantes do grupo que recebeu intervenções sobre os cuidados com os pés, aumentou $(\mathrm{p}<0,005)$ quando comparado a primeira com a segunda avaliação (SHARONI et al., 2018).

O ensaio clínico randomizado, desenvolvido na cidade de Ribeirão Preto, São Paulo, junto a uma amostra de 101 pessoas com DM, cujo objetivo foi avaliar uma proposta de cuidado para pessoas com DM2 atendidas em ambulatórios de unidades de atenção secundaria, com ênfase na prevenção de lesão nos pés, mostrou que na primeira avaliação houve melhora nas variáveis relacionadas ao conhecimento sobre DM $(\mathrm{p}<0,005)$ e cuidados com os pés $(p<0,000)$. Na segunda avaliação, ambas as variáveis mantiveram-se estáveis $(p<0,0000)$. Também foi observado melhora nas condições dermatológicas dos pés $(p<0,000)$ e no uso de calçados apropriados (p<0,0005) (OCHOA-VIGO; PACE, 2009).

O estudo descritivo, desenvolvido no município de Campinas, o qual teve o objetivo de avaliar o conhecimento das pessoas com DM sobre as medidas preventivas do pé diabético, identificou que as pessoas possuíam o conhecimento da importância das atividades de prevenção do pé diabético, mas deixam de realizar algumas dessas (BRAGANÇA et al., 2010).

Ao considerar que a educação em saúde é um instrumento capaz de favorecer a redução da alta prevalência de complicações relacionadas ao DM (FUNNELL, 2008), é fundamental que seja desenvolvida por meio da estratégia pedagógica que melhor se adequa a uma determinada situação e grupo, uma vez que de acordo com Santos e colaboradores (2006), as estratégias didáticas devem propiciar a transformação das pessoas, ampliando sua capacidade de compreensão dos determinantes relacionados à saúde e dos fatores sociais, buscando construir protagonistas nos processos de saúde e doença. 
Assim, a metodologia da problematização mostrou-se uma estratégia viável para o ensino do cuidado em saúde, por estimular o pensamento crítico e reflexivo, a tomada de decisão e a resolução de problemas, o que possibilita a construção do conhecimento (BERBEL, 1998). A problematização embasada nos princípios do Arco de Maguerez é desenvolvida por meio da observação da realidade, descrição dos pontos-chave, teorização, hipóteses de solução do problema e aplicação à realidade, o que permite aos educandos serem protagonistas do conhecimento pela aproximação da realidade (BORDENAVE; PEREIRA, 1998; BERBEL, 1996; BERBEL, 1998).

Destaca-se a pesquisa avaliativa processual, com abordagem qualitativa, desenvolvida por Rego e colaboradores (2006) no município de Nova Aurora estado de Goiás, a qual utilizou a problematização por meio da metodologia do Arco de Maguerez, especificamente, no processo de educação em saúde da pessoa com DM. O objetivo do estudo foi analisar o processo de educação para a saúde em grupo, enquanto estratégia de intervenção de enfermagem. Como resultados, os autores apontam que a metodologia do arco contribuiu para que os participantes desenvolvessem a autonomia e à independência para o enfrentamento dos problemas de saúde, o que está relacionado com o conhecimento adquirido pelo processo educacional embasado na ação-reflexão-ação. A capacidade de refletir possibilitou buscar soluções para os problemas que antes não eram percebidos (REGO; NAKATANI; BACHION, 2006).

Outra pesquisa avaliativa processual com abordagem qualitativa, desenvolvida também no município de Nova Aurora, objetivou elaborar um processo de educação, por meio dos pressupostos de Paulo Freire e do método do Arco de Maguerez, para avaliar os resultados de hemoglobina glicada, antes e após a implementação do processo educativo junto a pessoas com DM. Quanto a hemoglobina glicada, os resultados apresentaram diferença $(\mathrm{p}<0,05)$, com diminuição dos níveis plasmáticos após o processo educativo. A autora destaca que a educação dialógica é uma importante estratégia a ser desenvolvida pelo enfermeiro, uma vez que despertou o potencial crítico, reflexivo e criativo dos participantes do estudo, além de possibilitar transformações em suas atitudes e habilidades, o que favoreceu o alcance da autonomia conquistada por meio do conhecimento (REGO, 2008).

Mediante a diferença entre ter conhecimento sobre o cuidado e, de fato, pratica-lo, o presente estudo investigou entre os participantes, a intenção de cuidar dos pés, a qual pode ser considerada a primeira fase da execução do cuidado (AJZEN; FISHBEIN, 1970). 
A informação sobre as atividades benéficas para a saúde pode desencadear intenções e atitudes mais positivas em relação ao autocuidado (FERREIRA; PEREIRA, 2014). Ajzen (2002) afirma que é possível saber quais serão as ações e comportamentos das pessoas frente as suas intenções, pois de acordo com Martins, Serralvo e João (2014), as intenções antecedem as ações.

Desta forma, torna-se necessário avaliar a intenção de realizar as atividades de autocuidado com os pés em complemento ao conhecimento. Assim, neste estudo, observa-se que os grupos eram homogêneos em relação a intenção de cuidar dos pés no T1. Contudo, apresentaram diferença significativa, relacionada à melhores médias do GI em relação ao GC nos $\mathrm{T} 2$ e Tfu. Na análise intragrupo os dois grupos apresentaram melhoras significativas em T1 e T2 e T1 e Tfu e, especificamente o GC no T2 e Tfu.

O ensaio clínico, desenvolvido na cidade de Boa Esperança, Minas Gerais, por Moreira (2017), cujo objetivo foi avaliar o efeito do grupo operativo no ensino do autocuidado com os pés para prevenção do pé diabético, apresentou resultados semelhantes a este estudo, uma vez que ao avaliar a intenção global de comportamento planejado no cuidado com os pés de pessoas com DM, foram encontradas diferenças significativas no grupo tratado quando comparados os grupos em T2 e T3. O mesmo ocorreu na análise intragrupo no T1 e T3 (MOREIRA, 2017). Já o estudo de Fonseca (2018), citado anteriormente, apresentou diferenças significativas apenas no domínio Planejamento do coping, o que está relacionado aos esforços comportamentais e cognitivos para lidar com uma situação específica.

Apesar de não ser objetivo do presente estudo, foram realizadas análises de correlaçãoteste de Spearman (dados não apresentados nos resultados) entre as variáveis conhecimento e intenção de cuidar dos pés. Os resultados mostraram não haver relação entre variáveis conhecimento e intenção de cuidar dos pés no GI, nos T1 (p=0,2778), T2 (p=0,1692) e Tfu $(\mathrm{p}=0,1995)$, bem como no GC entre os T1 ( $\mathrm{p}=0,5930), \mathrm{T} 2(\mathrm{p}=0,1907)$ e Tfu $(\mathrm{p}=0,4006)$.

Os resultados apresentados indicaram que a intervenção educativa, embasada em metodologias ativas, tais como a problematização por meio do Arco de Charles Maguerez, contribuiu para a melhora de vários indicadores de risco de pé diabético (integridade tissular prejudicada), no conhecimento e intenção de cuidar, por meio da implementação do autocuidado, o que deve ser difundido e replicado nas unidades básicas de saúde, especificamente para os profissionais que atuam com pessoas com DM. 
$\mathrm{Na}$ caracterização da amostra do presente estudo, observou-se nas variáveis sociodemográficas, maior frequência de pessoas do sexo feminino, idosos, estado civil com cônjuge/companheiro, aposentados e que viviam em média com duas a três pessoas na mesma residência. Os participantes também apresentavam baixa/média escolaridade e baixa renda.

Os dados antropométricos apresentaram homogeneidade dos grupos, com destaque para o sobrepeso entre os participantes do estudo.

Referente aos hábitos de vida destacou-se uma maior frequência de pessoas que referiram não ser tabagista e da mesma forma para o consumo de bebidas alcoólicas e para a prática de exercícios físicos.

Nas variáveis clínicas, para o tempo de diagnóstico de DM, os grupos possuíam médias de 11,71 (DP=7,75) anos e 10,72 (DP=5,47) anos para o GI e GC respectivamente, e o tipo de tratamento referido com maior frequência entre os participantes foram os antidiabéticos orais. Entre as morbidades referidas, a HA manteve maiores frequências, seguida, pela dificuldade visual, grau de dor ou desconforto em MMII e com menores frequências história de úlceras em MMII. E, em relação a variável glicemia capilar intergrupo os grupos apresentaram diferenças, assim como para a análise intragrupo no GI $(\mathrm{p}<0,05)$.

No presente estudo os participantes de ambos os grupos, referiram não terem tido os pés avaliados por profissionais da saúde e em proporções semelhantes, referiram não terem recebido orientações sobre cuidados e, portanto, não praticavam o autocuidado com os pés.

Dados da caracterização da amostra se assemelham aos de estudos desenvolvidos em unidades de atenção primária.

Em relação aos indicadores da integridade da pele preservada, observa-se diferenças intergrupo, com maior frequência de melhores médias do GI, após a intervenção "ensino do cuidado com os pés" ( $p<0,05)$. E ainda, destaca-se maior frequência de melhora do GI, em relação ao GC, nas análises intragrupo dos indicadores da integridade da pele preservada $(\mathrm{p}<0,05)$.

Para variável sensibilidade e deformidades anatômicas dos pés não foram observadas diferenças $(\mathrm{p}>0,05)$.

Ao avaliar os resultados dos indicadores de condições vasculares/arteriais neste estudo, destaca-se que em relação ao edema, varizes e cor da pele, não foram encontradas diferenças entre os grupos e intragrupo $(p>0,05)$. Referente aos pulsos tibiais não foram encontradas diferença intergrupo $(p>0,05)$, somente intragrupo $(p>0,05)$. Diferenças também foram encontradas nas análises intergrupo e intragrupo dos pulsos pediosos $(\mathrm{p}>0,05)$. 
Não foram observadas diferenças na análise da variável temperatura dos pés ( $p>0,05)$. E referente aos escores finais da classificação do risco do pé diabético (integridade tissular prejudicada) o GI apresentou diferença na análise intragrupo entre os tempos T1 e Tfu e T2 e $\mathrm{T} f u(\mathrm{p}<0,05)$, o que não foi identificado na análise intergrupo $(\mathrm{p}>0,05)$.

Destaca-se que a melhora do GI no escore final do risco do pé diabético (integridade tissular prejudicada) pode ser atribuída aos aspectos das condições dermatológicas, principalmente devido aos indicadores "integridade da pele", "presença de lesões esfoliativas", "presença de hidratação", "xerodermia", "fissura (rachadura)", "corte de unhas corretos", "presença de umidade e maceração interdigitais" e "presença de micoses", após a intervenção educativa "ensino do cuidado com os pés".

O conhecimento referido sobre as atividades de autocuidado com os pés em ambos os grupos foi considerado "baixo" no T1, contudo, após as intervenções educativas, o GI apresentou diferença significativa quando comparado ao GC, atribuído ao maior conhecimento dos participantes do grupo no T2 e Tfu. Diferenças também foram encontradas em ambos os grupos na análise intragrupo.

A variável intenção de cuidar dos pés mostrou que os grupos eram homogêneos no T1. Contudo, apresentaram diferença significativa, relacionada à melhores médias do GI em relação ao GC nos T2 e Tfu. Na análise intragrupo os dois grupos apresentaram melhoras.

O presente estudo possibilitou identificar a necessidade de investimentos na promoção da atenção à pessoa com DM focada na prevenção e no diagnóstico precoce do pé diabético. Desta forma, ressaltam-se estratégias como a avaliação dos pés por meio do aplicativo "Cuidando do pé” e intervenções educativas embasadas em referenciais teóricos que contribuem no processo de ensino do cuidado, os quais possuem baixo custo e simplicidade na execução.

Destaca-se a importância da educação em saúde realizada de forma sistematizada e organizada, embasada na metodologia do Arco de Magueres, o que foi efetivo na melhora dos escores do risco de pé diabético, atribuído, principalmente, aos indicadores relacionados às condições dermatológicas, o que deve ser replicada e difundida entre os profissionais de saúde. 
As limitações principais do estudo podem ser atribuídas a não homogeneidade dos registros nos prontuários das pessoas com DM acompanhadas na unidade de saúde, as quais estão relacionadas às variáveis clínicas de interesse para o presente estudo, tais como, valores da hemoglobina glicada e os diagnósticos das morbidades decorrentes do DM.

O aplicativo mostrou-se eficaz na avaliação do risco de pé diabético (integridade tissular prejudicada), contudo, apresentou aspecto que precisa ser revisto, o que está relacionado ao registro da temperatura entre os membros direito e esquerdo, para avaliação comparativa entre eles, o que no presente estudo não comprometeu os resultados, uma vez que os participantes não apresentaram assimetria entre as temperaturas dos MMII. 
ABBOTT, P. A.; BARBOSA, S. F. F. Using information technology and social mobilization to combat disease. Acta paulista de Enfermagem, v. 28, n. 1, 2015. Disponível em: <http://dx.doi.org/10.1590/1982-0194201500001>. Acesso em: 22 jul. 2017.

ABOYANS, V. et al. Diagnosis of peripheral arterial disease in general practice: can the ankle-brachial index be measured either by pulse palpation or an automatic blood pressure device? International jornal of clinical practice, v. 62, n. 7, p. 1001-7, 2008. Disponível em: https://doi.org/10.1111/j.1742-1241.2008.01784.x. Acesso em: 21 set. 2019.

ABREU, J. R. P. Contexto Atual do Ensino Médico: Metodologias Tradicionais e AtivasNecessidades Pedagógicas dos Professores e da Estrutura das Escolas. 2011. 105f.

Dissertação (Programa de Pós-Graduação em Ciências da Saúde) - Universidade Federal do Rio Grande do Sul, Porto Alegre, 2009.

AJZEN, I. Residual Effects of Paston Later Behavior: Habitual and Reasoned Action Perspectives. Personality and Social Psychology Review, v. 6, n. 2, p. 107-122, 2002. Disponível em: https://doi.org/10.1207/S15327957PSPR0602_02. Acesso em 10 agost. de 2016.

The theory of planned behavior. Organizational Behavior and Human Decisions Processes. University of Massachusetts, Academic Press, p. 179-211, 1991.

Disponível em: <http://www.people.umass.edu/aizen/>. Acesso em 01 mar. 2016.

AJZEN, I; DRIVER, B. L. Prediction of Leisure Participantion From Behavioral, Normative, and Control Beliefs: an application of the theory of planned behavior. Leisure Sciences, v. 13, n.3, p. 185-204, 1991. Disponível em:

https://www.researchgate.net/publication/233896565. Acesso em 01 mar. 2016.

AJZEN, I.; FISHBEIN, M. The prediction of behavior from attitudinal and normative variables. Journal of Experimental Social Psychology, v. 6, n. 6, 466-487, 1970. Disponível em: https://doi.org/10.1016/0022-1031(70)90057-0. Acesso em 10 marc. 2016.

AJZEN, I.; MADDEN, T. J. Prediction of Goal-Directed Behavior: attitudes, intentions and perceived behavioral control. Journal of Experimental Psychology, v. 22, n. 5, 1986, p.453474. Disponível em: https://doi.org/10.1016/0022-1031(86)90045-4. Acesso em 02 mar. 2016.

AJZEN, I.; MANSTEAD, A. S. R. Changing health-related behaviors: An approach based on the theory of planned behavior. In HEWSTONE, J. D. M. The scope of social psychology: Theory and applications. New York: Psychology Press, 2007. p. 43-63. Disponível em: https://www.researchgate.net/publication/232451543. Acesso em 03 mar. 2019.

ALVES, J. E. D. A polemica Malthus versus Condorcet reavaliada à luz da transição demográfica. Rio de Janeiro: Escola Nacional de Ciências Estatísticas, 2002. Disponível em: http://sociales.cchs.csic.es/jperez/pags/Teorias/Textos/Diniz2002.pdf. Acesso em: 16 dez. 2018. 
ALVIM, N. A. T.; FERREIRA, M. A. Perspectiva problematizadora da educação popular em saúde e a enfermagem. Texto Contexto Enfermagem, v. 16, n. 2, p. 315-9. 2007. Disponível em: http://dx.doi.org/10.1590/S0104-07072007000200015. Acesso em 10 mar. 2016.

ALLET, L. et al. An exercise intervention to improve diabetic patients' gaitinar eallife environment. Gait Posture, v.32, n. 2, p. 185-90, 2010. Disponível em: https://www.ncbi.nlm.nih.gov/pubmed/20471273. Acesso em: 15 set. 2019.

AMERICAN DIABETES ASSOCIATION. Prevention or delay of type 2 diabetes. Diabetes Car, v. 40, suppl 1, 2017. Disponível em: https://doi.org/10.2337/dc17-S008. Acesso em: 16 dez. 2017.

. Standards of Medical Care in Diabetes-2006. Diabetes Care, v. 29, n. suppl 1, p. s4-s42, 2006. Disponível em: https://care.diabetesjournals.org/content/29/suppl_1/s4. Acesso em: 16 dez. 2017.

Peripheral arterial disease in people with diabetes and impact of peripheral arterial disease in people. Diabetes Care, v. 26, n.4, p. 3333-41, 2003. Disponível em: https://doi.org/10.2337/diacare.26.12.3333. Acesso em: $10 \mathrm{dez} 2018$.

Standards of medical care in diabetes-2013. Diabetes Care, v. 36, Suppl 1, p. 1166, 2013. Disponível em: https://doi.org/10.2337/dc13-S011. Acesso em: 16 dez. 2017.

ANDRADE, N. H. S. et al. Pacientes com diabetes mellitus: cuidados e prevenção do pé diabético em atenção primária à saúde. Revista de Enfermagem UERJ, v. 18, n. 4, p. 616$621,2010$.

ARMSTRONG, D. G. et al. Diabetic foot ulcers and vascular insufficiency: our population has changed, but our methods have not. Journal of Diabetes Science and Technology, v. 5, n. 6, p. 1591-5, 2011. Disponível em: <http://dx.doi.org/10.1177/193229681100500636>. Acesso em: 19 Fev. 2017.

ARMSTRONG, D. G. et al. Skin Temperature Monitoring Reduces the Risk for Diabetic Foot Ulceration in High-risk Patients. The American Journal of Medicine, v. 120, n. 12, p. 1042-1046, 2007. Disponível em: https://doi.org/10.1016/j.amjmed.2007.06.028. Acesso em: 20 out. 2019.

ARMSTRONG, D. G.; LAVERY, L. A.; HARKLESS, L. B. Validation of a diabetic wound classification system. The contribution of depth, infection, and ischemia to risk of amputation. Diabetes Care, v. 21, n. 5, p. 855-859, 1998. Disponível em: https://doi.org/10.2337/diacare.21.5.855. Acesso em: 28 dez 2018.

AZAMBUJA, M. I. R. et al. Saúde urbana, ambiente e desigualdades. Revista Brasileira de Medicina de Família e Comunidade, v. 6, n.19, p. 110-115, 2011. Disponível em: https://doi.org/10.5712/rbmfc6(19)151. Acesso em: 16 mar. 2017. 
BAKKER, K.; DOOREN, J. A specialized outpatient clinic for diabetic patients reduces the number of amputations and saves costs. Ned Tijdschr Geneeskd, v. 138, n. 11, p. 565-569, 1994. Disponível em: https://www.ncbi.nlm.nih.gov/pubmed/8139722. Acesso em: 18 aout. 2019.

BANDIK, D. F. The diabetic foot: Pathophysiology, evaluation, and treatment. Ned Tijdschr Geneeskd, v. 12, n.138, p. 565-9, 1994. Disponível em:

https://www.ncbi.nlm.nih.gov/pubmed/8139722. Acesso em: 10 jan. 2019.

BANUELOS-BARRERA, P.; ARIAS-MERINO, E. D.; BANUELOS-BARRERA, Y. Risk factors of foot ulceration in patients with Diabetes Mellitus type 2. Investigación y

Educación en Enfermería, v. 31, n. 3, p. 442-449, 2013. Disponível em: http://www.scielo.org.co/pdf/iee/v31n3/v31n3a12.pdf. Acesso em: 15 fev. 2019.

BECK, L.; AJZEN, I. Predicting Dishonest Actions Using The Theory of Panned Behavior. Journal of Research in Personality, v. 25, n. 3, p.285-301, 1991. Disponível em: https://doi.org/10.1016/0092-6566(91)90021-H. Acesso em 03 mar. 2019.

BERBEL, N. A. N. A Metodologia da Problematização no ensino superior e sua contribuição para o plano da práxis. Semina, v. 17, n. esp, p. 7-17, 1996.

- A metodologia da problematização em três versões no contexto da didática e da formação de professores. Revista Diálogo Educacional, v.12, n.35, p.101-18, 2012. Disponível em:

<http://www2.pucpr.br/reol/pb/index.php/dialogo?dd1=5904\&dd99=view\&dd98=pb>. Acesso em: 12 Nov. 2017.

A problematização e a aprendizagem baseada em problemas:

diferentes termos ou diferentes caminhos? Interface, v. 2, n. 2, p. 139-54, 1998. Disponível em: < http://www.scielo.br/pdf/icse/v2n2/08.pdf>. Acesso em: 11 Nov. 2017.

BERBEL, N. A. N.; GAMBOA, S. A. S. A metodologia da problematização com o Arco de Maguerez: uma perspectiva teórica e epistemológica. Filosofia e Educação, v. 3, n. 2, 2012. Disponível em: https://doi.org/10.20396/rfe.v3i2.8635462. Acesso em: Acesso em: 11 nov. 2017.

BERTOLUCCI, P. H. F. et al. O mini-exame do estado mental em uma população geral: impacto da escolaridade. Arquivos da Neuropsiquiatria, v. 52, n. 1, p. 1-7, 1994. Disponível em: http://dx.doi.org/10.1590/S0004-282X1994000100001. Acesso em: Acesso em: Acesso em: 11 jan. 2016.

BEZERRA, G.C. et al. Avaliação do risco para desenvolver pé diabético na atenção básica. Brazilian Journal of Enterostomal Therapy, v. 13, n. 3, 2015. Disponível em: https://www.revistaestima.com.br/index.php/estima/article/view/108. Acesso em: 30 ago. 2019. 
BHARARA, M.; COBB, J. E.; CLAREMONT, D. J. Thermography and thermometry in the assessment of diabetic neuropathic foot: a case for furthering the role of thermal techniques. Int J Low Extrem Wounds, v. 5, n. 4, p. 250-260, 2006. Disponível em: https://doi.org/10.1177/1534734606293481. Acesso em: 20 ago. 2019.

BOIKE, A. M.; HALL, J. O. A practical guide for examining and treating the diabetic Foot. Cleveland Clinic Journal of Medicine, v. 69, n. 4, p. 342-8, 2002. Disponível em: https://www.ncbi.nlm.nih.gov/pubmed/11996205. Acesso em: 17 mar. 2019.

BONA, S. F. et al. Prevalência do pé diabético nos pacientes atendidos na emergência de um hospital público terciário de Fortaleza. Revista Brasileira de Clinica Médica, v.8, n. 1, p. 15, 2010. Disponível em: http://files.bvs.br/upload/S/1679-1010/2010/v8n1/a001.pdf. Acesso em: 10 fev. 2019.

BORDENAVE, J. D.; PEREIRA, A. M. Estratégias de ensino aprendizagem. 4th ed. Petrópolis: Vozes, 1982.

Estratégias de ensino-aprendizagem. 19a ed. Petrópolis: Vozes; 1998.

Estratégias de ensino-aprendizagem. 25 a ed. Rio de Janeiro: Vozes, 2004.

BORK, A. M. T. Enfermagem de excelência: da visão à ação. Rio de Janeiro: Guanabara Koogan; 2003.

BOULTON, A. J. M. et al. Diabetic neuropathies: a position statement by the American Diabetes Association. Diabetes Care, v. 28, p. 956-62, 2005.

BOULTON, A. J. et al. Comprehensive foot examination and risk assessment: a report of the task force of the foot care interest group of the American Diabetes Association, with endorsement by the American Association of Clinical Endocrinologists. Diabetes Care, v. 31, n. 8, p. 1679-1685, 2008. Disponível em: <https://www.ncbi.nlm.nih.gov/pmc/articles/PMC2494620/?report=reader>. Acesso em: 05 Mar. 2017.

BOULTON, A. J. M. Lowering the risk of neuropathy, foot ulcers and amputations. Diabetic Medicine, v. 15, n. 4, p. 57-59, 1998. Disponível em: https://onlinelibrary.wiley.com/doi/epdf/10.1002/\%28SICI\%2910969136\%281998120\%2915\%3A4\%2B\%3CS57\%3A\%3AAID-DIA741\%3E3.0.CO\%3B2-D. Acesso em: 16 jan. 2016.

BRAGANÇA, C. M. et al. Evaluation of preventive practices for the diabetic foot. Journal of the Health Sciences Institute, v. 28, n. 2, p. 159-163, 2010. Disponível em: http://dx.doi.org/10.1590/1677-5449.006416. Acesso em: 05 Mar. 2017.

BRASIL. Conselho Nacional de Saúde. Resolução no 196, de 1996, versão 2012. Diretrizes e Normas Regulamentadoras sobre pesquisas envolvendo seres humanos. Brasília: Ministério da Saúde, 2012a. 
Lei $\mathrm{n}^{\mathrm{o}} 7.498$ de 25 de junho de 1986. Dispõe sobre a regulamentação do exercício da Enfermagem e dá outras providências. Diário oficial da União. Brasília: Ministério da Saúde, 1986.

Ministério da Saúde. Manual do pé diabético. Estratégias para o cuidado da pessoa com doença crônica. Brasília: Ministério da Saúde, 2016.

BRASIL. Ministério da Saúde. Secretaria de Atenção à Saúde. Departamento de Atenção Básica. Manual do pé diabético: estratégias para o cuidado da pessoa com doença crônica. Brasília: Ministério da Saúde, 2016.

Ministério da Saúde. Secretaria de Atenção à Saúde. Departamento de Atenção Básica. Política Nacional de Atenção Básica. Brasília: Ministério da Saúde, 2012b.

Ministério da Saúde. Secretaria de Atenção à Saúde. Departamento de Atenção Básica. Estratégias para o cuidado da pessoa com doença crônica: diabetes mellitus. Brasília: Ministério da Saúde, 2013.

Ministério da Saúde. Secretaria de Políticas de Saúde. Departamento de Ações Programáticas Estratégicas. Plano de reorganização da atenção à hipertensão arterial e ao diabetes mellitus: hipertensão arterial e diabetes mellitus. Brasília: Ministério da Saúde; 2001 .

Ministério da Saúde. Secretaria de Vigilância em Saúde. Departamento de Análise de Situação de Saúde. Plano de Ações Estratégicas para o Enfrentamento das Doenças Crônicas Não Transmissíveis (DCNT) no Brasil 2011-2022. Série B. Textos Básicos de Saúde, Brasília, DF, 2011.

Ministério da Saúde. Vigitel Brasil 2018: vigilância de fatores de risco e proteção para doenças crônicas por inquérito telefônico. Brasília: Ministério da Saúde, 2019.

BULECHECK, G. M. et al. Classificação das Intervenções de Enfermagem (NIC). 6. ed. São Paulo: Elsevier, 2016.

BUS, S. A. et al. Intrinsic muscle atrophy and to edeformity in the diabetic neuropathic foot: a magnetic resonance imaging study. Diabetes Care, v. 25, n. 8, p. 1444-50, 2002.

CAIAFA, J. S. et al. Atenção integral ao portador de pé diabético. Jornal Vascular Brasileiro, v. 10, n. 4, p. 1-32, 2011. Disponível em: http://dx.doi.org/10.1590/S167754492011000600001. Acesso em: 18 jan. 2017.

CARVALHO, W. N.; BOMFIM, M. S. S.; DOMICINIANO, C. S. The systematization of nursing care to the victim patient of stroke. Brazilian Journal of Surgery and Clinical Research, v. 19, n. 2 , p. 45-50, 2017. Disponível em: https://www.mastereditora.com.br/periodico/20170706_115443.pdf. Acesso em: 16 mar. 2018. 
CAVANAGH, P. R.; BUS, S. A. Off-loading the diabetic foot for ulcer prevention and healing. Journal of the American Podiatric Medical Association, v. 100, n. 5, p. 360-368, 2010. Disponível em: https://www.ncbi.nlm.nih.gov/pubmed/20804932. Acesso: 12 fev. 2019.

CHAND, G. et al. Diabetic foot. Clinical Queries: Nephrology, v. 1, n. 2, p. 144-150, 2012.

CHANTELAU, E. The perils of procrastination: effects of early vs. delayed detection and treatment of incipient Charcot fracture. Diabetic Medicine, v. 22, n. 12, p.1707 - 1712.

CISNEROS, L. L. Avaliação de um programa para prevenção de úlceras neuropáticas em portadores de diabetes. Revista Brasileira de Fisioterapia, v. 14, n. 1, p. 31-7, 2010. Disponível em: http://www.scielo.br/pdf/rbfis/v14n1/06.pdf. Acesso em: 10 out. 2019.

COLLINS, T. C.; SUAREZ-ALMAZOR, M.; PETERSON, N. J. An absent pulse is not sensitive for the early detection of peripheral arterial disease. Family Medicine, v. 38, n. 1, p. 38-42, 2006. Disponível em:

https://fammedarchives.blob.core.windows.net/imagesandpdfs/fmhub/fm2006/January/Tracie 38.pdf. Acesso em: 18 nov. 2019.

CORDOVA, P. B. et al. Using the nursing interventions classification as a potential measure of nurse workload. Journal of Nursing Care Quality, v. 25, n. 1, p. 39-45, 2010. Disponível em: https://www.ncbi.nlm.nih.gov/pmc/articles/PMC2869293/. Acesso em: 10 dez 2017.

CONSELHO REGIONAL DE ENFERMAGEM DE MINAS GERAIS. Legislação e

Normas. COREN-MG, v. 15, n. 1, 2016. Disponível em:

<http://www.corenmg.gov.br/anexos/legislacao_normas_pb.pdf.>. Acesso em: 10 Out. 2017.

DEALEY, C. Cuidando de feridas. 3 ed. São Paulo: Atheneu, 2006.

DEWEY, J. Vida e educação. 10. ed. São Paulo: Melhoramentos, 1978.

DOAK, C. C.; DOAK, L. G.; ROOT, J. H. Teaching patients with low literacyskills. 2nd ed. Philadelphia: Jb Lippincott, 1995.

DIABETES CONTROL AND COMPLICATIONS TRIAL RESEARCH GROUP. The effect of intensive treatment of diabetes on the development and progression of long-term complications in insulin-dependent diabetes mellitus. The New England Journal of Medicine, v. 329, n.14, p. 977-86, 1993. Disponível em: https://www.nejm.org/doi/full/10.1056/NEJM199309303291401. Acesso em 15 jan. 2017.

DOTTO, J. I. et al. Sistematización de la asistencia de enfermería: orden, desorden o (re) organización? Revista de enfermagem UFPE on line, v. 11, n. 10, p. 3821-9, 2017. Disponível em: 10.5205/reuol.12834-30982-1-SM.1110201716. Acesso em: 16 mar. 2017.

DUARTE, N.; GONÇALVES, A. Pé diabético. Angiologia e Cirurgia Vascular, v. 7, n. 2, p. 65-79, 2011. Disponível em: http://www.scielo.mec.pt/pdf/ang/v7n2/v7n2a02.pdf. Acesso em: 10 out. 2019. 
FAGUNDES, C. N.; CORSO, A. C. T.; GONZÁLEZ-CHICA, D. A. Epidemiological profile of hypertensive and diabetics registered in basic health care, Florianopolis - SC.

Revista Pesquisa e Saúde, v. 18, n. 1, p. 28-34, 2017. Disponível em: http://www.periodicoseletronicos.ufma.br/index.php/revistahuufma/article/view/7877/4871. Acesso em 25 mar. 2017.

FERNANDES, B. S. M.; REIS, I. A.; TORRES, H. C. Evaluation of the telephone intervention in the promotion of diabetes selfcare: a randomized clinical trial. Revista LatinoAmericana de Enfermagem, v. 24, p. 1-9, 2016. Disponível em: http://dx.doi.org/10.1590/1518-8345.0632.2719. Acesso em: 16 jan. 2017.

FERREIRA G.; PEREIRA, M. G. Validação do questionário do comportamento planeado na diabetes- atividade física. Psicologia, saúde e doenças, v. 15, n. 2, p. 409-426, 2014.

FERREIRA, A. P. S.; SZWARCWALD, C. L.; DAMACENA, G. N. Prevalência e fatores associados da obesidade na população brasileira: estudo com dados aferidos da Pesquisa Nacional de Saúde, 2013. Revista Brasileira de Epidemiologia, v. 22, p. 1- 14, 2019. Disponível em: http://dx.doi.org/10.1590/1980-549720190024. Acesso em: 05 out. 2019.

FERNANDES, T. F. et al. Morbimortalidade por diabetes no município de Montes Claros MG. Revista de Administração e Saúde, v. 18, n. 71, p. 1-19, 2018. Disponível em: http://dx.doi.org/10.23973/ras.71.100. Acesso em: 10 fev. 2016.

FOLSTEIN, M.; FOLSTEIN, S.; MCHUGH, P. "Mini-mental state". A practical method for grading the cognitive state of patients for the clinician. Journal of Psychiatric Research, v. 12, n. 3, p. 189-198, 1975. Disponível em: https://doi.org/10.1016/0022-3956(75)90026-6. Acesso em: 10 jan. 2016.

FOLTYNSKI, P. et al. The influence of ambient temperature on foot temperature in patients with diabetic foot ulceration. Biocybern Biomed Eng, v. 34, n. 3, p. 178-183, 2014.

FONSECA, N. M. Intervenções educativas para o autocuidado dos pés de pacientes com diabetes mellitus: estudo quase experimental. 2018. 124f. Dissertação (Mestrado em Enfermagem) - Escola de Enfermagem, Universidade Federal de São Paulo, São Paulo, 2018.

FREIRE, P. Pedagogia da autonomia: saberes necessários à prática educativa. 25 th ed. Rio de Janeiro: Paz e Terra, 2002.

Pedagogia do oprimido. 47th ed. Rio de Janeiro: Paz e Terra, 2005.

FREITAS, R. A. M. M. Ensino por problemas: uma abordagem para o desenvolvimento do aluno. Educação e Pesquisa, v.38, n.2, p.403-18, 2012. Disponível em: http://dx.doi.org/10.1590/S1517-97022011005000011. Acesso em: 15 mar. 2017.

FUNNELL, M. M. National Standards for Diabetes Self-Management Education. Diabetes Care, v. 31, n. 1, p. 12-56, 2008. 
GAMBAA, M. A. et al. Amputações de extremidades inferiores por diabetes mellitus: estudo caso-controle. Revista de Saúde Pública, v. 38, n. 3, p. 399-404, 2004. Disponível em: http://dx.doi.org/10.1590/S0034-89102004000300010. Acesso em: 17 fev. 2017.

GOMES, L. C. et al. Contribution of family social support to the metabolic control of people with diabetes mellitus: A randomized controlled clinical trial. Applied Nursing Research, v. 36, p. 68-76, 2017. Disponível em: https://www.ncbi.nlm.nih.gov/pubmed/28720242. Acesso em: 16 nov. 2018.

GOMES, M. B. et al. Prevalence of type 2 diabetic patients within the targets of care guidelines in daily clinical practice: a multi-center study in Brazil. Review of Diabetic Studies, v. 3, n. 2, p. 73-8, 2006.

GUARIGUATA L. et al. Global estimates of diabetes prevalence for 2013 and projections for 2035. Diabetes Research and Clinical Practice, v. 103, n. 2, p.137-49, 2014. Disponível em: https://doi.org/10.1016/j.diabres.2013.11.002. Acesso em: 10 jan. 2016.

GRUPO DE TRABALHO INTERNACIONAL SOBRE PÉ DIABÉTICO. Consenso Internacional sobre Pé Diabético. Brasília: Secretaria de estado de saúde de Brasília, 2001.

GROSS, J. L.; NEHME, M. Detecção e tratamento das complicações crônicas dodiabetes melito: Consenso da Sociedade Brasileira de Diabetes e Conselho Brasileiro de Oftalmologia. Revista da Associação Médica Brasil, v. 45, n. 3, p. 279-84, 1999.

HAUSENBLAS, H. A.; CARRON, A. V.; MACK, D. E. Application of the theories of reasoned action and planned behavior to exercise behavior: a meta-analysis. Journal of Sport e Exercise Psychology, v. 19, n. 1, p.36-51, 1997. Disponível em:

https://www.researchgate.net/publication/232506254_Application_of_the_Theories_of_Reaso ned_Action_and_Planned_Behavior_to_Exercise_Behavior_A_Meta-Analysis. Acesso em: 10 fev. 2016.

HERDMAN, H.; KAMITSURU, S. Diagnósticos de Enfermagem da NANDA-I: Definições e Classificação - 2018/2020. 11 ${ }^{\text {a }}$ ed. Porto Alegre: Artmed, 2018.

HULLEY, S. B. et al. Delineando a pesquisa clínica. 4. ed. Porto Alegre: ArtMed, 2015.

HUNTLEY, A. C. The cutaneous manifestations of diabetes mellitus. Journal of the American Academy of Dermatology, v. 7, n. 4, p. 427-455, 1982. Disponível em: https://doi.org/10.1016/S0190-9622(82)80248-X. Acesso em: 10 fev. 2017.

INTERNACIONAL DIABETES FEDERATION. IDF Diabetes Atlas. 7th ed. Bélgica: Internacional Diabetes Federation, 2015. Disponível em: https://www.diabetesatlas.org/en/. Acesso em: 10 ago. 2016.

IDF Diabetes Atlas. 8th ed. Bélgica: Internacional Diabetes Federation, 2017.

Disponível em: https://www.diabetesatlas.org/en/. Acesso em: 5 mar. 2018. 
The Diabetes Atlas. 3rd ed. Brussels: International Diabetes Federation, 2006. Disponível em: <http://www.diabetesatlas.org/content/global-burden>. Acesso em: 29 fev. 2016.

IDF Diabetes Atlas. 5th ed. Brussels: International Diabetes Federation, 2011.

Disponível: https://www.idf.org/e-library/epidemiology-research/diabetes-atlas/20-atlas-5thedition.html. Acesso em: 15 mar. 2017.

JEFFCOATE, W. J. Charcot neuro-osteoarthropathy. Diabetes Metabolic Research Review, v. 24, n. 1, p. 2-5, 2008.

JEFFCOATE, W.; LIMA, J.; NOBREGA, L. The Charcot foot. Diabetic Medical, v. 17, p. 253-258, 2000.

JELINEK, J. E. Cutaneous manifestations of diabetes mellitus. International Journal

Dermatololy, v. 33, n. 9, p. 605-17, 1994. Disponível em: https://doi.org/10.1111/j.13654362.1994.tb02915.x. Acesso em: 10 fev. 2017.

KWAMOTO, E. E. Enfermagem comunitária. São Paulo: EPU; 1995.

LANDEIRO, M. J. L. et al. Educational technology in care management: technological profile of nurses in Portuguese hospitals. Revista da Escola de Enfermagem USP, v. 49, n. spe2, p. 150-155, 2016. Disponível em: http://dx.doi.org/10.1590/S0080-623420150000800021. Acesso em: 28 fev. 2017.

LAVERY, L. A. et al. Home monitoring of foot skin temperatures to prevent ulceration. Diabetes Care, v. 27, n. 11, p. 2642-2647, 2004.

LEE, K. M. et al. Risk factors of treatment failure in diabetic foot ulcer patients. Archives of Plastic Surgery, v. 40, n. 2, p. 123-8, 2013. Disponível em: <http://dx.doi.org/10.5999/aps.2013.40.2.123>. Acesso em: 19 Fev. 2017.

LEITE, I. C. et al. Carga de doença no Brasil e suas regiões, 2008. Cadernos de Saúde Pública, v. 31, n. 7, p. 1551-1564, 2015.

LEONE, E. T.; MAIA, A. G.; BALTAR, P. E. Mudanças na composição das famílias e impactos sobre a redução da pobreza no Brasil. Economia e Sociedade, v. 19, n. 1, p. 59-77, 2010. Disponível em: http://dx.doi.org/10.1590/S0104-06182010000100003. Acesso em: 19 mar. 2019.

LEVIN, M. E; O’NEAL, E. O pé diabético. 6 ed. Rio de Janeiro: DI livros, 2001.

LEVIN, M. E. Foot lesions in patients with diabetes mellitus. Endocrinology \& Metabolism Clinics of North America Journal, v.25, n.2, p. 47-62, 1996. Disponível em: https://doi.org/10.1016/S0889-8529(05)70333-9. Acesso em: 10 out. 2017.

LEVIN, M. E. Diabetic Foot Wounbds: Pathogfenesis and Management. Advances in Wound Care, v. 10, n. 2, p. 24-30, 1997. 
LIPSKY, B. A. et al. Diagnosis and Treatment of Diabetic Foot Infections. Plastic and Reconstructive Surgery, v. 117, n. 7, p. 212-238, 2006. Disponível em: https://www.ncbi.nlm.nih.gov/pubmed/16799390. Acesso em: 15 out. 2019.

LUCOVEIS et al. Grau de risco para úlceras nos pés por diabetes: avaliação de enfermagem. Revista Brasileira de Enfermagem, v. 71, n. 6, p. 3217-23, 2018. Disponível em: http://dx.doi.org/10.1590/0034-7167-2017-0189. Acesso em: 1 dez. 2018.

LUNNEY, M. NANDA diagnoses, NIC interventions, and NOC outcomes used in anelectronic health Record with elementary school children. Journal of School Nursing, v. 22, n. 2, p. 94-101, 2006. Disponível em:

<https://www.ncbi.nlm.nih.gov/pubmed/16563032>. Acesso em: 10 Ser. 2017.

MACIEL, M. E. D. Educação em saúde: conceitos e propósitos. Cogitare Enfermagem, v. 14, n. 4, p. 773-776, 2009. Disponível em: 〈http://dx.doi.org/10.5380/ce.v14i4.16399>. Acesso em: 25 Out. 2017.

MADUREIRA, V. S. F. Os saberes da enfermagem. Revista Brasileira de Enfermagem, v. 57, n. 3, p. 357-60, 2004. Disponível em: <http://dx.doi.org/10.1590/S003471672004000300021>. Acesso em: 10 Out. 2017

MAFFEI, F. H. A. et al. Diagnóstico clínico das doenças arteriais. In: Doenças vasculares periféricas. 2 ed. Rio de Janeiro: Medsi, 1995. p. 285-304.

MAGALHÃES, N. J. S. et al. Perfil epidemiológico do diabetes mellitus na população de um município maranhense. Revista Eletrônica Acervo Saúde, v. Sup. 9, p. 795-802, 2017. Disponível em: https://www.researchgate.net/publication/320712652_Perfil_epidemiologico_do_diabetes_me llitus_na_populacao_de_um_municipio_maranhense. Acesso em: 12 Out. 2018

MAKKIAWOUDA, F. O.; ELMUKASHFI, T. A.; AL-TOM, S. A. H. Effects of Health Education of Diabetic Patient's Knowledge at Diabetic Health Centers, Khartoum State, Sudan: 2007-2010. Global Journal of Health Science, v. 6, n. 2, p. 221-6, 2014. Disponível em: <https://www.ncbi.nlm.nih.gov/pmc/articles/PMC4825225/>. Acesso em: 02 Dez. 2017.

MALERBI, D. A.; FRANCO, L. J. Multicenter study of the prevalence of diabetes mellitus and impaired glu-cose tolerance in the urban Brazilian population aged 30-69 yr. The Brazilian Cooperative Group on the Study of Diabetes Prevalence. Diabetes Care, v. 15, n. 11, p. 1509-16, 1992. Disponível em: https://www.ncbi.nlm.nih.gov/pubmed/1468278. Acesso em: 10 mar. 2017.

MALTA, C. M. et al. Tendência temporal da prevalência de obesidade mórbida na população adulta brasileira entre os anos de 2006 e 2017. Cadernos de Saúde Pública, v. 35, n. 9, p. 18, 2019. Disponível em: http://dx.doi.org/10.1590/0102-311x00223518. Acesso em: 20 out. 2019.

MARTINS, E. C. B.; SERRALVO, F. A.; JOÃO, B. N. Teoria do comportamento planejado: uma aplicação no mercado educacional superior. Gestão e Regionalidade, v. 30, n. 88, p. 107122, 2014. 
MENEZES, L. C. G. Eficácia de filme educativo de curta-metragem para o autocuidado com o pé diabético: ensaio clínico controlado randomizado. 2016. 263 f. Tese (Pósgraduação em cuidados clínicos), Universidade Estadual do Ceará, Fortaleza, Ceará, 2016.

MENEZES, K. K. P.; AVELINO, P. R. Grupos operativos na Atenção Primária à Saúde como prática de discussão e educação: uma revisão. Cadernos de Saúde Coletiva, v. 24, n. 1, p. 124-130, 2016. Disponível em: <http://dx.doi.org/10.1590/1414-462X201600010162〉. Acesso em: 11 Out. 2017.

MINELLI, L. et al. Diabetes mellitus e afecções cutâneas. Anais brasileiros de Dermatologia, v. 78, n. 6, p. 735-747, 2003.

MONAMI, M. et al. Effects of a Short Educational Program forthe Prevention of Foot Ulcers in High-Risk Patients: A Randomized Controlled Trial. International Journal of Endocrinology, v. 2015, p. 1-6, 2015. Disponível em: pageshttp://dx.doi.org/10.1155/2015/615680. Acesso em: Acesso em: 11 Out. 2017.

MONTEIRO, C. A.; MONDINI, L.; COSTA, R. B. L. Mudanças na composição e adequação nutricional da dieta familiar nas áreas metropolitanas do Brasil (1988-1996). Revista de Saúde Pública, v. 34, n. 3, p. 251-258, 2000. Disponível em: http://dx.doi.org/10.1590/S0034-89102000000300007. Acesso em: 11 Out. 2017.

MONTEIRO, L. A. A contribuição do "Ensino do cuidado com os pés" na redução do risco de integridade da pele prejudicada dos pés e na qualidade de vida de pessoas com Diabetes Mellitus tipo 2. 2015. 120 f. Dissertação (Mestrado em Enfermagem) - Escola de Enfermagem, Universidade Federal de Alfenas, Minas Gerais, 2015a.

MONTEIRO, L. A. et al. Questionário do comportamento planeado no Diabetes - cuidado com os pés (QCP-CP): Adaptação e validação. Online Brazilian Journal, v.14, n.3, p.25562, 2015b. Disponível em:

<http://www.objnursing.uff.br/index.php/nursing/article/view/5159/html_870>. Acesso em: 02 mar. 2017.

MONTEIRO, L. M. et al. Atividades para o "ensino do autocuidado com os pés" de pessoas com diabetes mellitus. Nursing (edição portuguesa), v. dig., p. 1-17, 2018. Disponível em: https://www.nursing.pt/atividades-para-o-ensino-do-autocuidado-com-os-pes-de-pessoascomdiabetes-mellitus/. Acesso em: 02 dez. 2018.

MOORHEAD, S. et al. Classificação dos Resultados de Enfermagem (NOC). 5. ed. São Paulo: Elsivier, 2016.

MORAES, S. A. et al. Prevalência de diabetes mellitus e identifi cação de fatores associados em adultos residentes em área urbana de Ribeirão Preto, São Paulo, Brasil, 2006: Projeto OBEDIARP. Cadernos de Saúde Pública, v. 26, n. 5, p. 929-941, 2010.

MOREIRA, J. B. et al. Efeito do grupo operativo no ensino do autocuidado com os pés de diabéticos: ensaio clínico randomizado. Revista da Escola de Enfermagem da USP, 2019. No Prelo. 
MURO, E. S. Avaliação das propriedades psicométricas de um aplicativo paraoexame dos pés da pessoa com diabetes mellitus. 2018. 99 f. Dissertação (Mestrado em Enfermagem) - Escola de Enfermagem, Universidade Federal de Alfenas, Minas Gerais, 2018.

NEWRICK, P. International consensus on the diabetic foot. British Medical Journal, v. 9, $\mathrm{n}$. 7261, p. 321-642, 2000. Disponível em: https://doi.org/10.1136/bmj.321.7261.642/a. Acesso em: 15 mar. 2017.

NISHIDE, K. et al. Ultrasonographic and thermographic screening for latent inflammation in diabetic foot callus. Diabetes Research and Clinical Practice - Journal, v. 85, n. 3, p. 304309, 2009.

OCHOA-VIGO, K.; PACE, A. E. Pé diabético: estratégias para prevenção. Acta Paulista de Enfermagem, v. 18, n. 1, p. 100-109, 2005. Disponível em: http://dx.doi.org/10.1590/S010321002005000100014. Acesso em: 17 mar. 2017.

OCHOA-VIGO, KATTIA.; PACE, A. E. Preventing feet complications in people with diabetes mellitus: A health care proposal. Revista Medica Herediana, v. 20, n. 2, p. 77-88, 2009. Disponível em: http://dev.scielo.org.pe/scielo.php?script=sci_arttext\&pid=S1018130X2009000200005\&lng=en\&nrm=iso. Acesso em: 12 out. 2019.

OLIVEIRA, M. A. P.; PARENTE, R. C. M. Entendendo Ensaios Clínicos Randomizados. Brazilian Journal of Video endoscopic Surgery, v. 3, n. 4, p. 176-180, 2010. Disponível em: https://www.sobracil.org.br/revista/jv030304/bjvs030304_176.pdf. Acesso em: 15 ago. 2016.

OMRAM, A. R. The epidemiologic transition: a theory of the epidemiology of population change. Bulletin of the World Health Organization, v. 79, n. 2, p. 161-170, 2001. Disponível em: https://www.ncbi.nlm.nih.gov/pmc/articles/PMC2690264/. Acesso em: Acesso em: 17 mar. 2018

OSÓRIO, L. C. Psicologia grupal: uma nova disciplina para o advento de uma era. Porto Alegre: Artmed, 2003.

PACE, A. E. Fatores de risco para complicações em membros inferiores em pacientes com diabetes mellitus. Revista Brasileira de Enfermagem, v. 55, n. 5, p. 514-21, 2002. Disponível em: http://www.scielo.br/pdf/reben/v55n5/v55n5a06.pdf. Acesso em: 10 fev. 2016.

PARISI, M. C. R. et al. Baseline characteristics and risk factors for ulcer, amputation and severe neuropathy in diabetic foot at risk: the BRAZUPA study. Diabetology \& Metabolic Syndrome, v. 8, n. 25, p. 1-8, 2016. Disponível em:

<https://www.ncbi.nlm.nih.gov/pmc/articles/PMC4794830/pdf/13098_2016_Article_126.pdf $>$. Acesso em 19 Dez. 2017.

PEDROSA, H. C. et al. O desafio do projeto salvando o pé diabético. Terapia em Diabetes, v. 4, n. 19, p. 1-10, 1998. 
PEEPLES, M. et al. Evolution of the American Association of Diabetes Educators' Diabetes Education Outcomes Project. Diabetes Educator, v. 33, n. 5, p. 794-817, 2007.

PEREIRA, A. L. F. As tendências pedagógicas e a prática educativa nas Ciências da Saúde. Cadernos de Saúde Pública, v. 19, n. 5, p. 1527-1534, 2003. Disponível em: http://dx.doi.org/10.1590/S0102-311X2003000500031. Acesso em: Acesso em 19 Dez. 2016.

PEREIRA, D. A. et al. Efeito de intervenção educativa sobre o conhecimento da doença em pacientes com diabetes mellitus 1. Revista Latino-Americana de Enfermagem, v. 20, n.3, p. 478-85, 2012. Disponível em: <http://www.scielo.br/pdf/rlae/v20n3/a08v20n3.pdf>. Acesso em: 11 Set. 2017.

PEREIRA, M. G.; COSTA, V.; ARAÚJO-SOARES, V. Versão de Investigação do Questionário Sócio-Cognitivo nos Auto-Cuidados com a Diabetes- Cuidados Com os Pés. Livro de Actas da XIII Conferência Internacional de Avaliação Psicológica: Formas e Contextos, 2009.

PÉREZ-RODRÍGUEZ, M. C. Conocimiento s y hábito s de cuidado: Efecto de una intervención educativa para disminuir El riesgo de pie diabético. Ciencia y EnfermerIa, v. 21, n. 3, p. 23-36, 2015. Disponível em: http://dx.doi.org/10.4067/S071795532015000300003. Acesso em: 05 mar. 2019.

PETRIE, J. R. Y et al. Diabetes, Hypertension, and Cardiovascular Disease: Clinical Insights and Vascular Mechanisms. Canadian Journal of Cardiology, v. 34, p. 575584, 2018. Disponível em: https://doi.org/10.1016/j.cjca.2017.12.005. Acesso: 13 fev. 2019.

PINHEIRO, S. J. et al. Conceptions of health education practices in the context of Nursing Education. Revista Rene, v. 17, n. 4, p. 545-52, 2016. Disponível em: https://www.researchgate.net/publication/307950094_Conceptions_of_health_education_prac tices_in_the_context_of_Nursing_Education. Acesso em: 17 fev. 2017.

PISSAIA, L. F. et al. Tecnologias da informação e comunicação na assistência de enfermagem hospitalar. Revista de Epidemiologia e Controle de Infecção, v. 7, n. 4, p. 203207, 2017. Disponível em: http://dx.doi.org/10.17058/reci.v7i4.8959. Acesso em: 18 mar. 2018.

POLIT, D. F.; BECK, C. T. Essentials of Nursing Research: Appraising Evidence for Nursing Practice. 8 ed. Philadelphia: Wolters Kluwer Health /Lippincott Williams \& Wilkins, 2014.

POLIT, D. F.; BECK, C. T.; HUNGLER, B. P. Fundamentos de Pesquisa em Enfermagem: métodos, avaliação e utilização. 5th ed. Porto Alegre: Artmed, 2004.

POPKIN, B. M. The nutrition transition and obesity in the developing world. Journal of Nutrition, v. 131, n. 3, p. 871-873, 2001. Disponível em:

https://www.ncbi.nlm.nih.gov/pubmed/11238777. Acesso em: 17 fev. 2017. 
REDA, A. et al. Effect of a preventive foot care program on lower extremity complications in diabetic patients with end-stage renal disease. Foot and Ankle Surgery, v. 18, p. 283-286, 2012. Disponível em: http://dx.doi.org/10.1016/j.fas.2012.05.002. Acesso em: 19 out. 2019.

REGO, M. A. B. Educação para saúde como estratégia de intervenção de enfermagem junto às pessoas portadoras de diabetes. Revista Eletrônica de Enfermagem, v. 10, n. 1, p. 263265, 2008. Available from: http://www.fen.ufg.br/revista/v10/n1/v10n1a30.htm. Acesso em: 19 mar. 2017.

REGO M. A. B.; NAKATANI, A. Y. K.; BACHION, M. M. Educação para a saúde como estratégia de intervenção de enfermagem às pessoas portadoras de diabetes. Revista Gaúcha de Enfermagem, v. 27, n.1, p.60-70, 2006. Disponível em: <https://www.fen.ufg.br/revista/v10/n1/pdf/v10n1a30.pdf>. Acesso em: 10 Jul. 2017.

REIBER, G. E. Causal pathways for incident lower-extremity ulcers in patients with diabetes from two settings. Diabetes Care, v. 22, p. 157-62, 1999.

RENERO, C. F. J. The thermoregulation of healthy, overweight-obese and diabetic individuals from the plantar skin thermogram: a clue to predict diabetic foot. Diabetic Foot \& Ankle, v. 8, n. 1, 2017. Disponível em: https://www.ncbi.nlm.nih.gov/pmc/articles/PMC5560411/. Acesso em: 10 out. 2019.

RHEE, M. K. et al. Barriers to diabetes education in urban patients: perceptions, patterns, and associated factors. The Diabetes Educucator, v. 31, n. 3, p. 410-7, 2005. Disponível: <http://journals.sagepub.com/doi/pdf/10.1177/0145721705277022>. Acesso em: 15 Out. 2017.

ROULEAU, G. et al. Impacts of information and communication technologies on nursing care: an overview of systematic reviews. Journal of Medical Internet Research, v.4, n.75, p.1-8, 2015. Disponível em: Available from: https://www.ncbi.nlm.nih.gov/pmc/articles/PMC4449960/pdf/13643_2015_Article_62.pdf. Acesso em: 29 out. 2017.

SACCO, I. C. et al. Role of ankle mobility in foot rollover during gait in individual swith diabetic neuropathy.Clinical Biomech, v. 24, n. 8, p. 687-92, 2009.

SANTOS, L. M. et al. Grupos de promoção à saúde no desenvolvimento da autonomia, condições de vida e saúde. Revista de Saúde Pública, v. 40, n. 2, p. 346-52, 2006. Disponível em: <http://www.scielo.br/pdf/rsp/v40n2/28543.pdf>. Acesso em: 12 Out. 2017.

SANTOS, I. C. R. V. et al. Prevalência e fatores associados a amputações por pé diabético. Ciência \& Saúde Coletiva, v. 18, n. 10, p. 3007-3014, 2013.

SANTOS, A. D. et al. Epidemiological profile of patients with diabetes mellitus. Brazilian Journal of Surgery and Clinical Research, v. 24, n. 2, p. 40-46, 2018. Disponível em: https://www.mastereditora.com.br/periodico/20150630_212010.pdf. Acesso em: 20 dez. 2018. 
SARTOR, C. D. et al. Effects of acombined streng thening, stret chingand functional training program versus usual-careonga it biomechanics and foot function for diabetic neuropathy: a randomized controlled trial. BMC Musculoskelet Disord, v. 3, n. 21, p. 13-36, 2012.

SARTORELLI, D. S.; FRANCO, L. J. Tendências do diabetes mellitus no Brasil: o papel da transição nutricional. Cadernos de Saúde Pública, v. 19, suppl. 1, p. 29-36. Disponível em: http://dx.doi.org/10.1590/S0102-311X2003000700004. Acesso em 21 out. 2018.

SAURABH, S. et al. Effectiveness of foot care education among people with type 2 diabetes in rural Puducherry, India. Indian Journal of Endocrinology and Metabolism, v. 18, n. 1, p. 106-110, 2014.

SAYE, D. E. The foot: corns, calluses, ingrown nails and diabetec ulcers. Ostomy Wound Manage, v. 40, n. 1, p. 22-7, 1994.

SCHEFFEL, R. S. et al. Prevalence of micro and macroangiopatic chronic complications and their risk factors in the care of out patients with type 2 diabetes mellitus. Revista da Associação Médica Brasileira, v. 50, n. 3, p. 263 - 267, 2004.

SCHRAMM, J. M. A. et al. Transição epidemiológica e o estudo de carga de doença no Brasil. Ciência e saúde coletiva, v. 9, n. 4, p. 897-908, 2004. Disponível:

http://dx.doi.org/10.1590/S1413-81232004000400011. Acesso em: 15 mar. 2018.

SCHULZ, K. F.; ALTMAN, D. G.; MOHER, D. CONSORT 2010 statement: Updated guidelines for reporting parallel group randomised trials. Journal of Clinical Epidemiology, p. 1-7, 2010. Disponível em: https://doi.org/10.1136/bmj.c332. Acesso em: 11 jan. 2016.

SCHULZ, K. F.; GRIMES, D. A. Epidemiological methods 8: blinded randomized trial: what one covers up is what one obtains. German Journal for Quality in Health Care, v. 101, n. 9, p. 630-607, 2007. Disponível em: https://www.ncbi.nlm.nih.gov/pubmed/18269055. Acesso em: Acesso em: 11 jan. 2016.

SECRETARIA DE ESTADO DE MINAS GERAIS. Atenção à saúde do adulto: Linha-guia de Hipertensão Arterial Sistêmica, Diabetes Mellitus e Doença Renal Crônica. 3. Ed. Belo Horizonte, 2013.

SHARONI, S. K. A. The effects of self-efficacy enhancing program on foot self-care behaviour of older adults with diabetes: A randomised controlled trial in elderly care facility, Peninsular Malaysia. PLoS ONE, v. 13, n. 3, 2018. Disponível em: https://doi.org/10.1371/journal. Acesso em: 10 out. 2019.

SIBBALD, R. G. The skin and diabetes mellitus. Anais Brasileiros de Dermatologia, v. 92, n. 1, p. 567-3, 1984. Disponível em: http://dx.doi.org/10.1590/abd1806-4841.20175514. Acesso em: 18 mar. 2018.

SIEGEL, S. Estatística não-paramétrica para as ciências do comportamento. São Paulo: McGraw-Hill, 1975. 
SILVA, F. M. et al. Contribuições de grupos de educação em saúde para o saber de pessoas com hipertensão. Revista Brasileira de Enfermagem, v. 67, n. 3, p. 347-53, 2014. Disponível em: http://www.scielo.br/pdf/reben/v67n3/0034-7167-reben-67-03-0347.pdf. Acesso em: 10 fev. 2019.

SILVA, N. C. M. et al. Instrumento para avaliação da integridade tissular dos pés de portadores de Diabetes Melittus. Acta Paulista de Enfermagem, v. 26, n. 6, p. 535-541, 2013. Disponível em: http://dx.doi.org/10.1590/S0103-21002013000600005. Acesso em: 10 jan 2016.

SILVA, N. C. M. et al. Reflexologia podal no comprometimento dos pés de pessoas com diabetes mellitus tipo 2: ensaio randomizado. Revista Latino-Americana de Enfermagem, v. 23, n. 4, p. 603-10, 2015. Disponível em: http://www.scielo.br/pdf/rlae/v23n4/pt_01041169-rlae-23-04-00603.pdf. Acesso em: 15 mar. 2017.

SIVANANDAM, S. et al. Medical thermography: a diagnostic approach for type 2 diabetes based on non-contact infrared thermal imaging. Endocrine, v. 42, n. 2, p. 343-351, 2012.

SMANIOTO, F. N.; HADDAD, M. C. F. L.; ROSSANEIS, M. A. Self-care into the risk factors in diabetic foot ulceration: cross-sectional study. Online brazilian jornal of nursing, v. 13, n. 3, p. 343-52, 2014. Disponível em: http://www.objnursing.uff.br/ index.php/nursing/article/view/4680. Acesso em: 17 mar. 2018.

SOCIEDADE BRASILEIRA DE DIABETES. Diretrizes da Sociedade Brasileira de Diabetes 2017-2018. São Paulo: Editora Clannad, 2017.

SOUZA, M. F. M. S. Changes in health and disease in Brazil and its States in the 30 years since the Unified Healthcare System (SUS) was created. Ciência \& Saúde Coletiva, v. 23, n. 6, p. 1737-1750, 2018. Disponível em:

https://www.ncbi.nlm.nih.gov/pubmed/29972483. Acesso em: 19 mar. 2018.

SOUZA; IGLESIAS; PAZIN-FILHO, 2014 SOUZA, C. S.; IGLESIAS, A. G.; PAZINFILHO, A. Estratégias inovadoras para métodos de ensino tradicionais - aspectos gerais. Medicina, v.47, n.3, p. 284-92, 2014. Disponível em: revista.fmrp.usp.br/2014/vo147n3/6_Estrategias-inovadoras-para-metodos-de-ensinotradicionais-aspectos-gerais.pdf. Acesso em: 10 Out. 2017

STANLEY, J.; COLLIER, A. Charcot osteo-arthropathy. Current Orthopaedics, v. 22, p. 428-433, 2008.

THE EXPERT COMMITTEE ON THE DIAGNOSIS AND CLASSIFICATION OF DIABETES MELLITUS. Report of the Expert Committee on the diagnosis and classification of diabetes mellitus. Diabetes Care, v.20, n.7, p. 1183-97, 1997.

TORQUATO, M. T. C. G. et al. Prevalência de diabetes mellitus e intolerância a glicose na população urbana de 30 a 69 anos em Ribeirão Preto (SP) - Brasil. São Paulo Medical Journal, v. 121, n. 6, p. 224-230, 2003. Disponível em: http://dx.doi.org/10.1590/S151631802003000600002. Acesso em: 20 mar. 2019. 
TRAJANO, S. S. et al. Percepção de pacientes com diabetes sobre o autocuidado. Revista Brasileira de Promoção em Saúde, v. 31, n. 3, p. 1-10, 2018. Disponível em: http://dx.doi.org/10.5020/18061230.2018.7598. Acesso em: 12 out 2019.

TREVISO, P. et al. Competências do enfermeiro na gestão do cuidado. Revista de Administração em Saúde, v.17, n.69, p.1-15, 2017. Disponível em: <http://dx.doi.org/10.23973/ras.69.59>. Acesso em: 10 dez. 2017.

TSCHIEDEL, B. Chronic diabetes complications. Jornal Brasileiro de Medicina, v. 102, n. 5, p. 7-12, 2014. Disponível em: http://files.bvs.br/upload/S/00472077/2014/v102n5/a4502.pdf. Acesso em: 17 out. 2017.

UK PROSPECTIVE DIABETES STUDY GROUP. Intensive blood-glucose control with sulphonylureas or insulin compared with conventional treatment and risk of complications in patients with type 2 diabetes (UKPDS 33). The Lancet, v. 352, n. 9131, p. 837-853, 1998. Disponível em: https://doi.org/10.1016/S0140-6736(98)07019-6. Acesso em: 15 jan. 2017.

UK PROSPECTIVE DIABETES STUDY GROUP. Tight blood pressure control and risk of macrovascular and microvascular complications in type 2 diabetes: UKPDS 38. British Medical Journal, v. 318, n. 7175, p. 703-713, 1998 Disponível em: https://www.ncbi.nlm.nih.gov/pubmed/9732337. Acesso em: 15 jan. 2017.

VASCONCELOS, E. M. Educação popular e atenção à saúde da família. São Paulo: Hucitec; 1999.

VASCONCELOS, A. M. N.; GOMES, M. M. F. Transição demográfica: a experiência brasileira. Epidemiologia e Serviços de Saúde, v. 21, n.4, p.10, 2012. Disponível em: http://dx.doi.org/10.5123/S1679-49742012000400003. Acesso em: 16 dez. 2018.

VÁZQUEZ, M. Y. G. et al. Mobile Phones and Psychosocial Therapies with Vulnerable People: a First State of the Art. Journal of Medical Systems, v. 40, n. 6, p. 1-12, 2016.

VIEIRA, C. P.; ARAÚJO, M. E. Prevalência e fatores associados a feridas crônicas em idosos na atenção básica. Revista da Escola de Enfermagem USP, v. 52, 2018. Disponível em: http://dx.doi.org/10.1590/S1980-220X2017051303415. Acesso em: 16 mar. 2019.

VIRGINI-MAGALHÃES, C. E.; BOUSKELA, E. Pé diabético e doença vascular - entre o conhecimento acadêmico e a realidade clínica. Arquivo Brasileiro de Endocrinologia e Metabologia, v. 52, n. 7, p. 1073-1075, 2008. Disponível em: http://dx.doi.org/10.1590/S0004-27302008000700002. Acesso em: 15 mar. 2019.

WILLIAMS, D. T.; PRICE, P.; HARDING, K. G. The influence of diabetes 4. and lower limb arterial disease on cutaneous foot perfusion. Journal Vascular Surgery, v. 44, n. 4, p. 770775, 2006. Disponível em: https://doi.org/10.1016/j.jvs.2005.06.040. Acesso em: 15 jan. 2019.

WORLD HEALTH ORGANIZATION. Definition, diagnosis and classification of diabetes mellitus and its complications: report of a WHO consultation. Geneva, World Health Organization, 1999;59p. 
World health statistics 2018: monitoring health for the SDGs, sustainable development goals. Geneva: World Health Organization; 2018. 
APÊENDICES 


\section{APÊNDICE A}

\section{FICHA DE IDENTIFICAÇÃO E INFORMAÇÕES \\ COMPLEMENTARES DE PESSOAS COM DM}

Nome:

Data: Local:

Endereço: Tel:

1) Sexo:

1 - Masculino 2 - Feminino

2) Idade: (anos completos)

3) Estado civil:

1 - Com cônjuge/companheiro (a) 2-Sem companheiro(a)

4) Escolaridade:

1 - baixa $(<8$ anos $) \quad 2$ - média $(8-12$ anos $) \quad 3$ - alta $(\geq 12$ anos $)$

5) Ocupação:

6) Qual o número de membros residentes na casa onde o senhor (a) mora:......

7) Qual é aproximadamente a renda mensal familiar, reais:

8) Há quanto tempo o senhor (a) tem diabetes? Anos completos:

9) O senhor (a) fuma?

1 - um maço ou mais por dia 2 - menos de um maço por dia

3 - apenas cig de palha/cach. 4 - não/ parou há menos de 1 ano

5 - não/ parou há 1 ano ou mais 6 - nunca fumou

10) Por quanto tempo o senhor (a) fumou/fuma (em anos)?

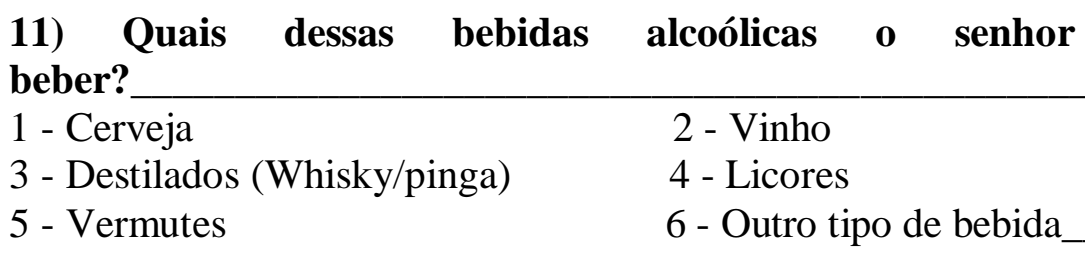

12) Com qual frequência o senhor (a) faz uso da (s) bebida alcoólica (s) referida (s)?

1 - 4 a 7 vezes por semana (diariamente ou quase)

2 - até 3 vezes por semana (fins de semana)

(a) costuma
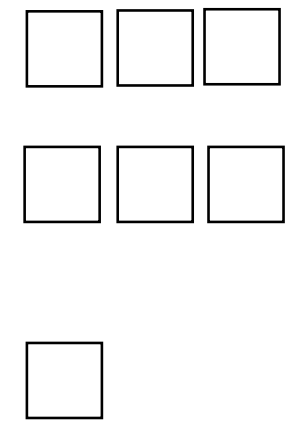
3 - eventualmente / raramente

4 - não bebe

13) Quais desses exercícios físicos o $\mathrm{Sr}$ (a) costuma praticar?

1 - Dança

3 - Futebol

5 - Tenis

7 - Caminhadas

9 - Nenhum
2 - Snooker

4 - Natação

6 - Basquete/Volei

8 - Bicicleta

10 - Outro esporte

14) Com qual frequência o $\mathrm{Sr}$ (a) faz atividades físicas?

1 - 5 a 7 vezes por semana (diariamente ou quase)

2 - 34 vezes por semana

3 - até 2 vezes / apenas nos fins de semana

4 - eventualmente ( sem constância )

5 - não pratica

15) Uso de insulina:

1 - Sim

2 - Não

16) Tempo (em anos)

17) Frequência diária de aplicação

18) Tipos de insulina que utiliza:

1 - LISPRO

3 - NPH/lenta

5 - Pré-mistura

7 - Outra resposta
2 - Regular

4 - Ultra lenta

6 - NPH+R

8 - NSA

19) Uso de antidiabético oral:

1 - Sim

2 - Não

20) Tempo (em anos)

21) Freq. Diária.

22) Tipo de antidiabético oral que utiliza?

1 - Sulfoniluréias

3 - Toglitazone

5 - Associações

2 - Biguanidas

4 - Acarbose

6 - NSA

23) $\mathrm{OSr}$ (a) já teve os pés avaliados por um profissional de saúde?

0 - nunca

$1-\operatorname{sim}$

24) O Sr (a) já recebeu orientações sobre os cuidados com os pés?

0 - nunca

$1-\operatorname{sim}$

26) $\mathrm{O} \mathrm{Sr}$ (a) possui outra doença?

1 - Não 2 - Hipertensão arterial 3 -Cardiopatia 4-Outra. Qual? 
OBSERVAÇÕES

Fonte: Adaptado do instrumento utilizado pelo Grupo de Pesquisa na Atenção Multiprofissional em Diabetes, coordenado pela professora Ana Emília Pace (aepace@eerp.usp.br) e de outro elaborado por Monteiro (2015). 


\title{
APÊNDICE B
}

\section{AUTORIZAÇÃO DA INSTITUIÇÃO CO-PARTICIPANTE}

\author{
PEDIDO DE AUTORIZAÇÃO À INSTITUIÇÃO CO-PARTICIPANTE
}

Ribeirão Preto, 16 de novembno, 2016.

Ilmo. Sr. Anderson Vilela de Figueiredo Secretário de Saúde

Venho por meio deste, solicitar a autorização para realizar a coleta de dados do estudo intitulado "O "Ensino do cuidado com os pés" na redução do risco de integridade da pele prejudicada de pessoas com diabetes mellitus tipo 2: ensaio clínico controlado e randomizado", de autoria da doutoranda Lidiane Aparecida Monteiro, sob orientação da Prof ${ }^{a}$. Dra ${ }^{a}$. Ana Emilia Pace e futura co-orientação da Prof ${ }^{a}$. $\mathrm{Dr}^{\mathrm{a}}$. Érika de Cássia Lopes Chaves. O presente estudo tem o objetivo de avaliar a contribuição do "Ensino do cuidado com os pés" para a redução do risco de integridade da pele prejudicada de pessoas com Diabetes Mellitus tipo 2. A coleta de dados será realizada junto aos voluntários com diabetes cadastrados no HIPERDIA da Policlínica Municipal de Boa Esperança-MG. Esclarecemos que as normas da resolução n 196/96 versões 2012 do Conselho Nacional de Saúde, do Ministério da Saúde, que trata das diretrizes e das normas de pesquisa envolvendo seres humanos, serão seguidas.

Desde já agradeço a atenção dispensada a presente solicitação.

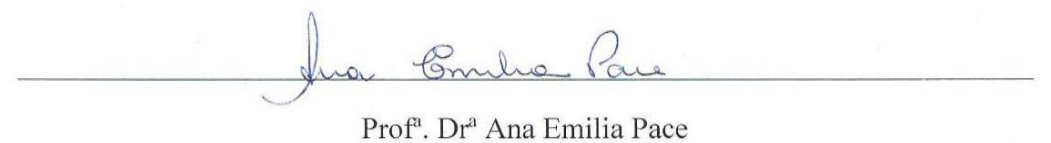

Docente da Escola de Enfermagem de Ribeirão Preto da Universidade de São Paulo

Declaro ter lido e concordado com o pedido de autorização acima,

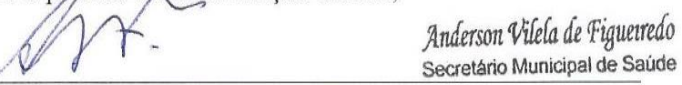

Secretário Municipal de Saúde

Secretário da Saúde do município de Boa Esperança

Respondente: Lidiane Aparecida Monteiro

Contato do pesquisador responsável: Telefone: (35) 9985-6810

E-mail: $\underline{\text { lidianemonteiro22@hotmail.com }}$ 


\section{APÊNDICE C \\ TERMO DE CONSENTIMENTO LIVRE E ESCLARECIDO}

Meu nome é Lidiane Aparecida Monteiro, sou enfermeira e aluna do doutorado da Universidade de São Paulo no Programa de Pós Graduação Fundamental da Escola de Enfermagem da Universidade de São Paulo (USP), e desenvolvo uma pesquisa que tem como objetivo geral avaliar a contribuição do "Ensino do Cuidado com os Pés" para a redução do risco de integridade tissular prejudicada de pessoas com Diabetes Mellitus tipo 2.

O estudo é orientado pela Prof ${ }^{a}$. Dr ${ }^{\mathrm{a}}$. Ana Emília Pace, docente na Universidade de São Paulo - USP e co-orientado pela Prof ${ }^{a}$. Dr ${ }^{a}$. Érika de Cássia Lopes Chaves, docente na Universidade Federal de Alfenas - UNIFAL/MG.

Assim, solicito sua autorização para participar desta pesquisa. O que será muito importante para a aquisição de conhecimentos sobre as atividades de autocuidado com os pés. Sua autorização para participar desta pesquisa é voluntária e você terá a liberdade de desistir do consentimento de participação a qualquer momento, caso deseje, sem algum tipo de prejuízo. Informo ainda, que você não terá nenhum gasto por participar do estudo.

A intervenção educativa será realizada por meio de três intervenções em grupo, na Policlínica Municipal, onde serão fornecidas informações sobre o autocuidado com os pés. Nesta perspectiva, poderá haver risco de constrangimento devido a adaptação de comportamento e cuidados com os pés, o que será minimizado com o esclarecimento da importância dos cuidados e principalmente da mudança de hábitos nocivos. Logo no primeiro encontro estabeleceremos vínculo e confiança, na tentativa excluir a possibilidade de constrangimento. A intervenção é importante para diminuir os riscos de desenvolvimento de lesões nos pés e consequente amputação de membros inferiores.

As avaliações serão realizadas no seu domicilio, com data previamente agendada, em três sessões, por meio de questionários, pela utilização do monofilamento de nylon para mensurar a sensibilidade (fio de nylon que será levemente encostado nos pés), pelo diapasão (metal que será encostado no osso do dedo do pé) e pelo martelo (martelinho que será encostado no tendão próximo ao calcanhar). Esclareço que não haverá risco de desconforto durante as avaliações, contudo, caso sinta algum tipo de incomodo, a avaliação poderá ser interrompida. 
Os participantes deste estudo serão divididos em dois grupos, Grupo Controle e Grupo Intervenção. O Grupo Controle continuará recebendo o cuidado de rotina da unidade e será avaliado em três sessões, contudo, ao final da coleta de dados receberá a intervenção para o autocuidado com os pés. O Grupo Intervenção receberá a intervenção para o autocuidado com os pés e também serão avaliados em três sessões. É necessário que você saiba que todos os participantes serão sorteados, com a mesma possibilidade de participar de ambos os grupos.

Agradeço sua colaboração e informo que o resultado deste estudo será apresentado sem a divulgação do nome dos participantes e da instituição co-participante, pois, o objetivo da pesquisa é colaborar para o avanço da área de conhecimento em relação às medidas preventivas para o risco de integridade tissular de pessoas com Diabetes Mellitus tipo 2.

Caso sinta necessidade de qualquer esclarecimento, durante ou após a coleta de dados, segue os telefones e endereços eletrônicos para contato com os pesquisadores: Telefones (35) 9985-6810; (16) 3315-4321; (35) 3299-1380

Endereços eletrônicos: lidianemonteiro@hotmail.com; aepace@eerp.usp.br; echaves@usp.br

Após ter lido e compreendido as informações acima, concordo em participar desta pesquisa de forma voluntária e autorizo a utilização dos dados para o presente estudo, que poderá ser divulgado em eventos científicos e em revistas de âmbito nacional e/ou internacional.

Declaro ainda ter recebido uma cópia deste documento.

Boa Esperança, de de

Eu,

Assinatura do voluntário

Assinatura do pesquisador 
ANEXOS 
ANEXO A

MINI EXAME DO ESTADO MENTAL (MEEM)

Quadro 1 - Miniexame do estado mental (MEEM)

\begin{tabular}{|c|c|}
\hline \multirow{5}{*}{$\begin{array}{l}\text { Orientação temporal } \\
\text { ( } 5 \text { pontos) }\end{array}$} & Qual a hora aproximada? \\
\hline & Em que dia da semana estamos? \\
\hline & Que dia do mês é hoje? \\
\hline & Em que mês estamos? \\
\hline & Em que ano estamos? \\
\hline \multirow{5}{*}{$\begin{array}{l}\text { Orientação espacial } \\
\text { (5 pontos) }\end{array}$} & Em que local estamos? \\
\hline & Que local é este aqui? \\
\hline & Em que bairro nós estamos ou qual é o endereço daqui? \\
\hline & Em que cidade nós estamos? \\
\hline & Em que estado nós estamos? \\
\hline Registro (3 pontos) & Repetir: CARRO, VASO, TIJOLO \\
\hline $\begin{array}{l}\text { Atenção e cálculo } \\
\text { (5 pontos) }\end{array}$ & Subtrair: $100-7=93-7=86-7=79-7=72-7=65$ \\
\hline $\begin{array}{l}\text { Memória de evocação } \\
\text { (3 pontos) }\end{array}$ & Quais os três objetos perguntados anteriormente? \\
\hline $\begin{array}{l}\text { Nomear } 2 \text { objetos } \\
(2 \text { pontos })\end{array}$ & Relógio e caneta \\
\hline $\begin{array}{l}\text { REPETTR } \\
(1 \text { ponto })\end{array}$ & "Nem aqui, nem ali, nem lá" \\
\hline $\begin{array}{l}\text { Comndo de estágios } \\
\text { (3 pontos) }\end{array}$ & Apanhe esta folha de papel com a mão direita, dobre-a ao meio e coloque-a no chão \\
\hline $\begin{array}{l}\text { Escrever uma frase completa } \\
\text { (1 ponto) }\end{array}$ & Escrever uma frase que tenha sentido \\
\hline $\begin{array}{l}\text { Ler e executar } \\
(1 \text { ponto })\end{array}$ & Feche seus olhos \\
\hline $\begin{array}{l}\text { Copiar diagrama } \\
\text { (1 ponto) }\end{array}$ & Copiar dois pentágonos com interseção \\
\hline
\end{tabular}




\section{ANEXO B}

\section{AUTORIZAÇÃO PARA UTILIZAR O MINI-EXAME DO ESTADO MENTAL}

De: bertolucci.paulo <bertolucci.paulo@unifesp.br>

Enviado: sexta-feira, 15 de fevereiro de 2018 12:53

Para: Lidiane Monteiro

Assunto: Re: Mini Exame do Estado Mental

Cara Lidiane

Tenho uma autorização VERBAL do Dr Folstein para este uso. Várias pessoas já usaram esta versão sem problema.

Att

Paulo Bertolucci

Em 2018-02-13 20:33, Lidiane Monteiro escreveu:

> Prezado Dro Paulo Henrique Bertolucci,

$>$

> Sou doutoranda da Universidade de São Paulo - Ribeirão Preto e estou

$>$ desenvolvendo um estudo que visa avaliar o efeito do ensino do autocuidado

$>$ com os pés junto a pessoas com Diabetes Mellitus. Desta forma, necessito da sua

> autorização para utilizar o MEEM, uma vez o declínio cognitivo será um critério

$>$ de exclusão.

$>$ Tenho dúvidas quanto a solicitar a permissão do autor da versão

$>$ original do MEEM. Seria necessário?

$>$

$>$ Certa de sua colaboração, fico aguardando seu retorno.

$>$

$>$ Att,

$>$

$>$ Lidiane A. Monteiro

$>$ Enfermeira - Mestre pela Escola de Enfermagem da Universidade Federal

$>$ de Alfenas

> Doutoranda Universidade de São Paulo - USP - Ribeirão Preto 
ANEXO C

\section{APLICATIVO "CUIDANDO DO PÉ"}

TELA INICIAL

(

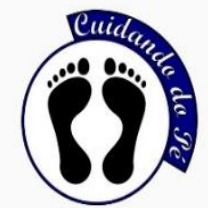

Este aplicativo é uma ferramenta para avaliação dos pés de pessoas com Diabetes Mellitus, baseados nas orientaçőes do Ministério da Saúde

\section{SOBRE O APLICATIVO \\ INSTRUÇŌES DE USO}

Versão 1.0 avançar $\rightarrow$
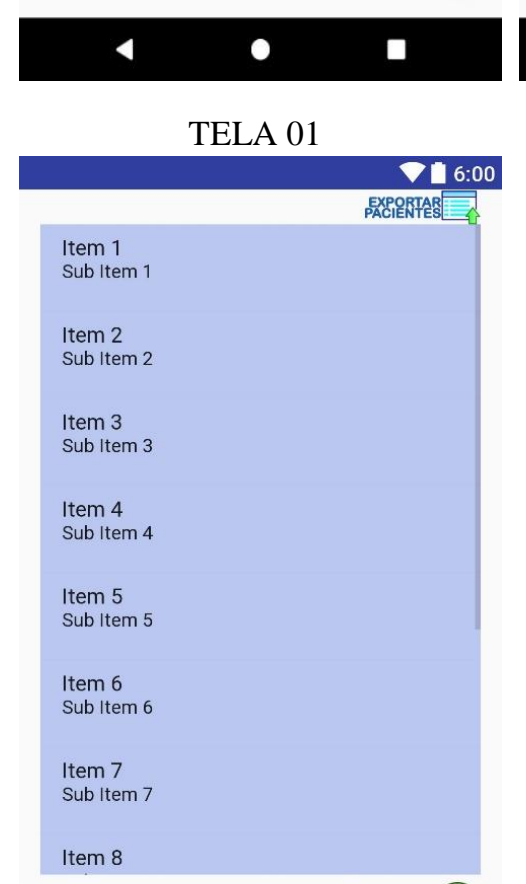

(-) voltar ADICIONAR (9ACIENTES
O
SOBRE O APLICATIVO

PQ 6:00

Sobre o Aplicativo

Esse aplicativo foi desenvolvido no Programa de Pós Graduação en Ciências da Reabilitaçăo em conjunto com o Programa de Pós Alfenas.

Autores:

Profa. Dra. Denise Hollanda lunes (Orientadora)

Profa. Dra. Enka de Cassia Lopes Chaves (Orientadora)

Profa. Dra. Jullana Bassalobre Carvalho Borges (Orientadora)

Financiamento:

FAPEMIG (Fundação de Amparo à

Pesquisa do Estado de Minas Gerais)

Agradecimento:

gradeço à Universidade Federal de Alfenas, pela oportunidade ao

Federal de Educação Ciência e Tecnologia do S de Minas Gerais pelo apolo.

Aradeço também à Fundação de Amparo à Pesquisa do Estado de

Minas Gerais pelo apoio financeiro ao projeto.
INSTRUÇÕES DE USO

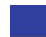

PQ:00

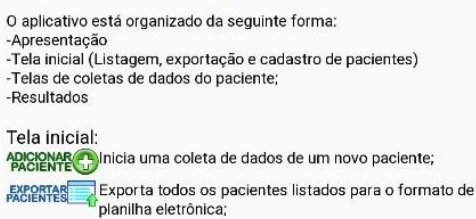

0 aplicativo está organizado da seguinte forma:

-Apresentação
- Tela inicial (Listagem, exportação e cadastro de pacientes) de coletas de dados do paciente:

Tela

Tela iniclal:

ADACIONAR (H)Inicia uma coleta de dados de um novo paciente;

EXPOBAR Exporta todos os pacientes listados para o formato de
PACIERTES

Instruçoes de uso

Para visualizar os dados coletados de um paciente, basta clicar sobre o nome correspondente;

Telas de coletas de dados:

(2) Indica que existe uma foto para ajudar a identificar o

(?) Abre a ajuda passo-a-passo sobre o processo de avaliação Atenção, quando inserir ou alterar um paciente, os dados só serão salvos quando se avança até a tela de

Resultados: Resultados.

Envia os resultados por e-mail

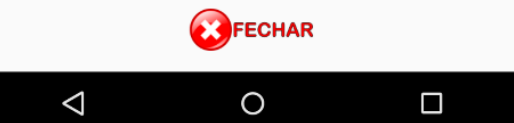

$\triangleleft$

TELA 02

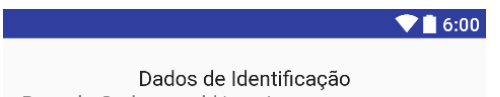

Data do Cadastro: $\mathrm{dd} / \mathrm{mm} /$ aaaa

Z EXCLUIR

№ cartão do SUS

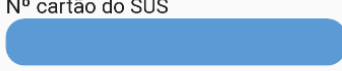

Nome do paciente

Data de nascimento

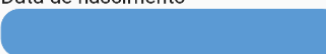

Sexo Tempo de diagnóstico

O Masculino O Dias

$O$ Feminino $O$ meses

Onos

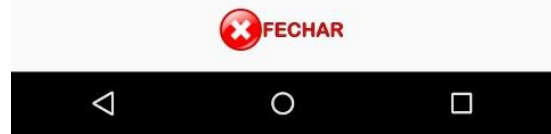

TELA 03

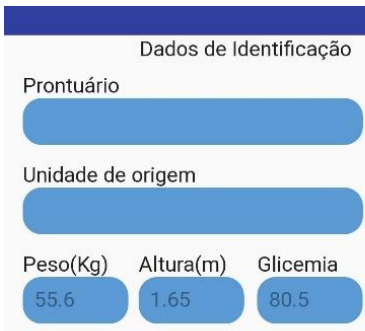

Glicemia feita em

O jejum $\bigcirc$ pós prandial

Usuário de

$\square$ hipoglicemiante oral

$\square$ insulina

\section{\&voltar}

$\triangleleft$ avançar $\rightarrow$

$\square$

\&voltar

avançar $\rightarrow$ 
TELA 04

TELA 05

TELA 06

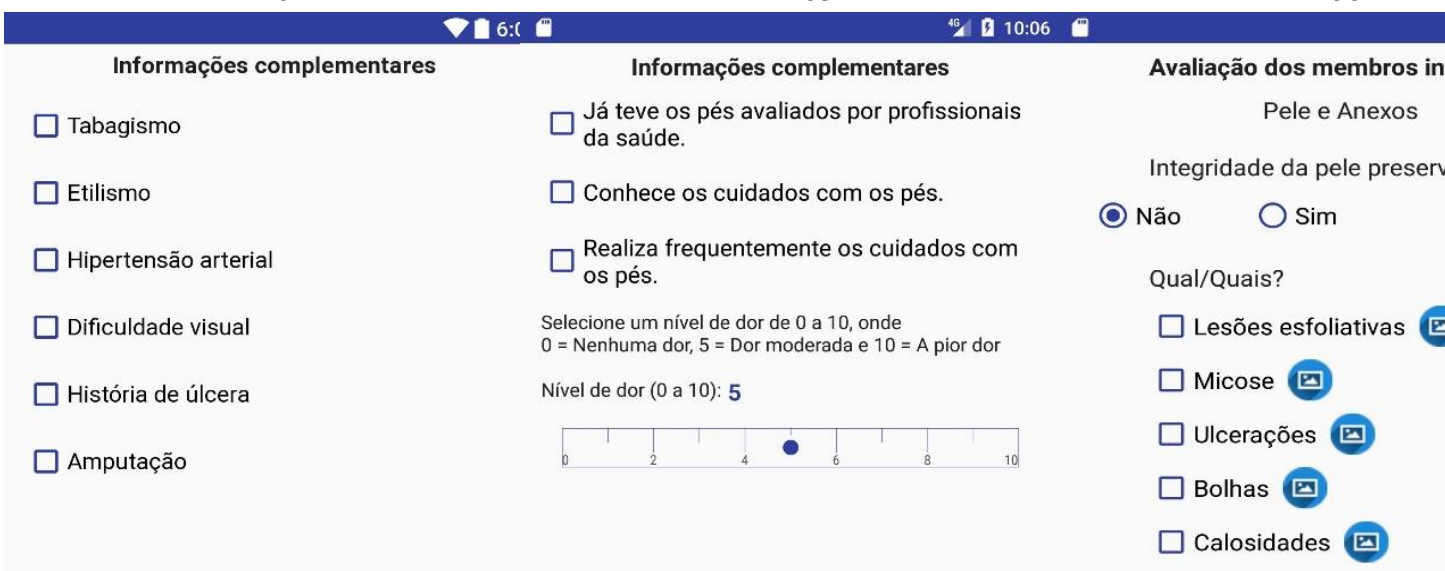

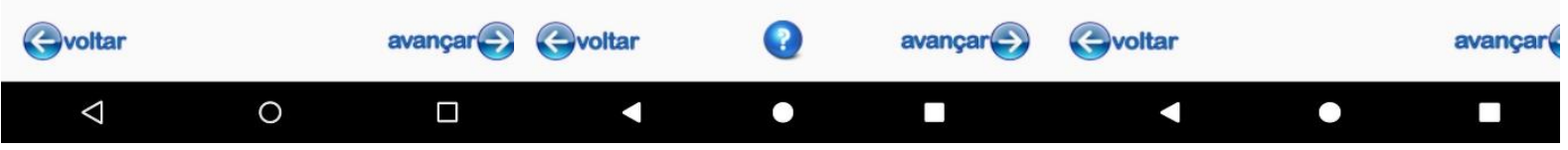

Tela 05 - AJUDA

Tela 06 - Foto 1

Tela 06 - Foto 2

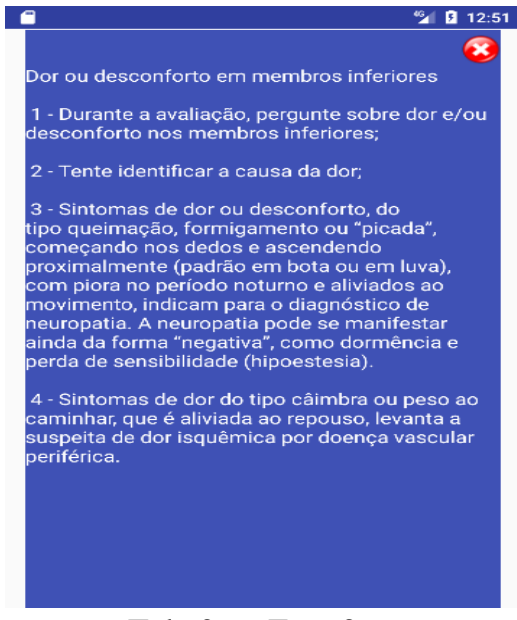

Tela 06 - Foto 3

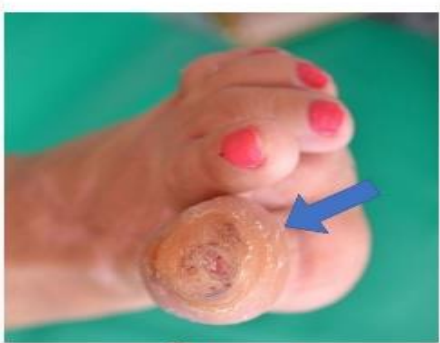

๔) FECHAR

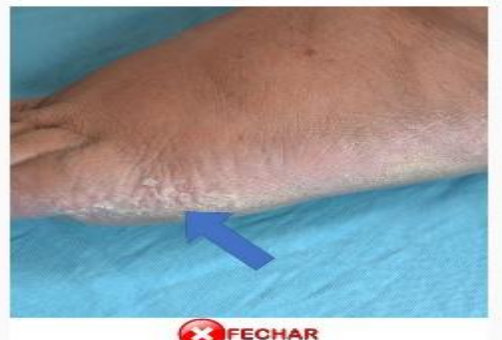

\& FECHAR
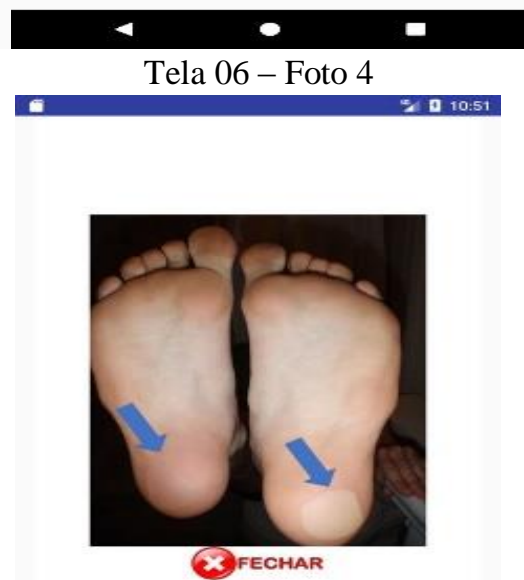

(3) FECHAR

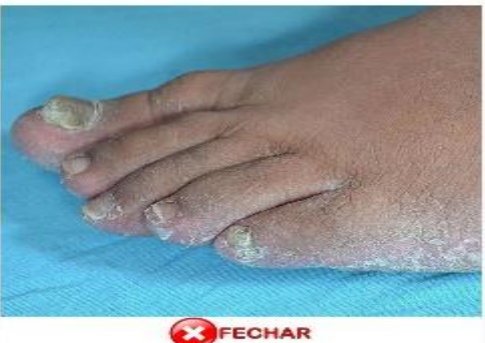

XetFechar
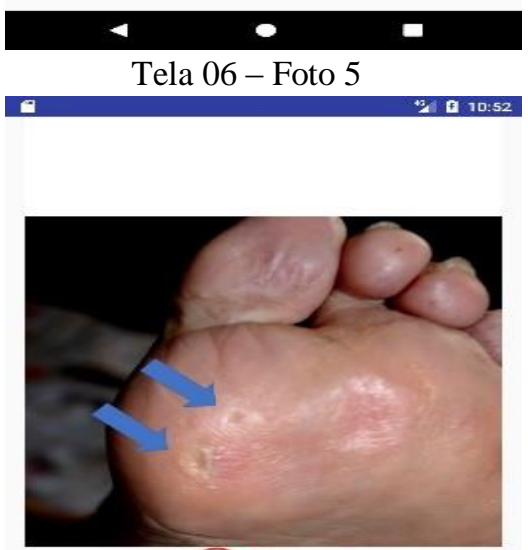

(3) FECHAR 
TELA 07

TELA 08

TELA 09

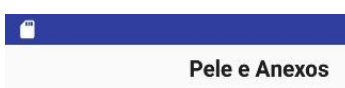

Cor

Cor normal?

ก Não $\bigcirc$ Sim

Qual?

Pálida

Azulada/Arroxeada

Avermelhada
40. $10: 22$

\section{c}

Pele e Anexos

Pilificação
46/ B 10:2

Pele e Anexos

Hidratação

Hidratação preservada?

○ Não $\bigcirc$ sim

Especifique:

$\square$ Xerodermia/Seca Q

Atenção:

Perguntar se o paciente fez depilação ou tricotomia recentemente.

$\square$ Rachadura @

미

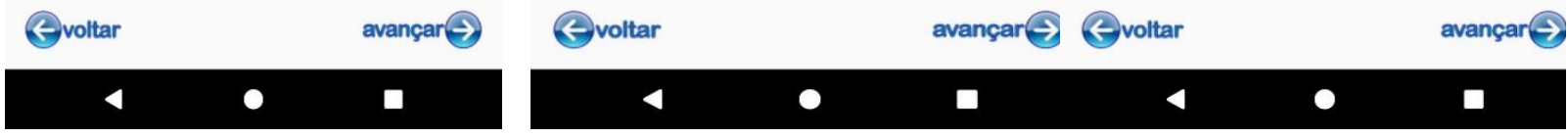

Tela 07 - Foto 1

Tela 07 - Foto 2

Tela 07 - Foto 3

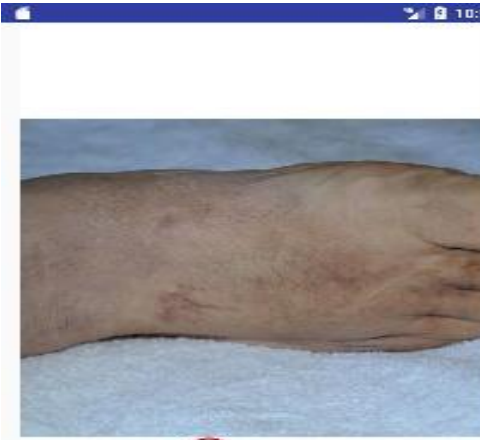

Q a fechar

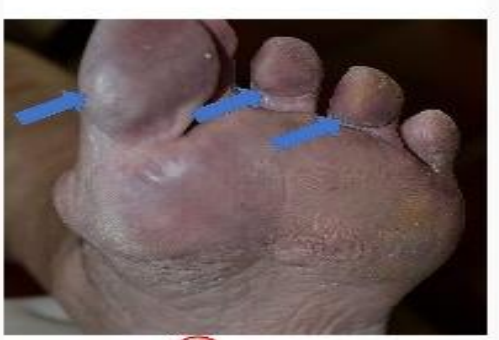

Q FECHAR

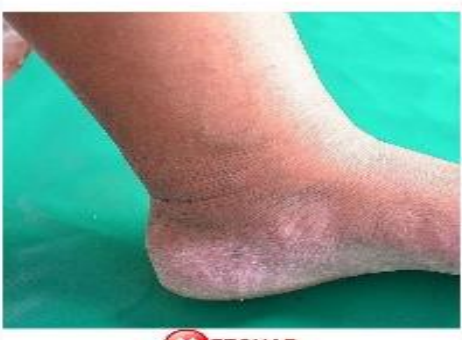

(3) FECHAR
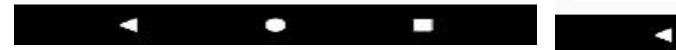

Tela 09 - Foto 1
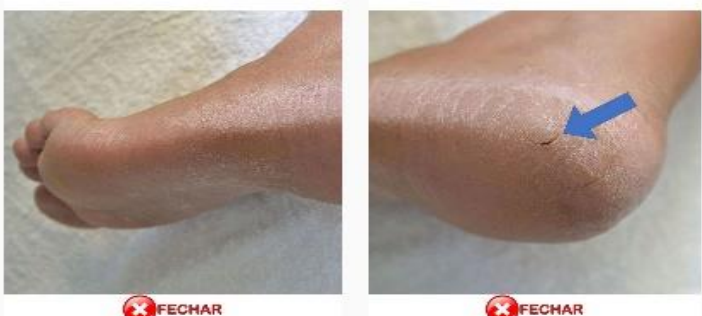

(3) FECMAR

3) FECHAR 
TELA 10

Pele e Anexos

Unhas

Unhas preservadas?
○ Não
$\bigcirc \mathrm{Sim}$

Especifique:

$\checkmark$ Hipotróficas/Encravadas

$\square$ Hipertróficas/Espessadas $\square$
TELA 11

40. $10: 28$

웅

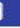

Pele e Anexos

Espaços interdigitais

Espaços preservados?
O Não
Sim

Especifique:

$\square$ Úmidos

$\checkmark$ Maceração

\section{Corte das unhas: \\ $\bigcirc$ correto}

○ Incorreto

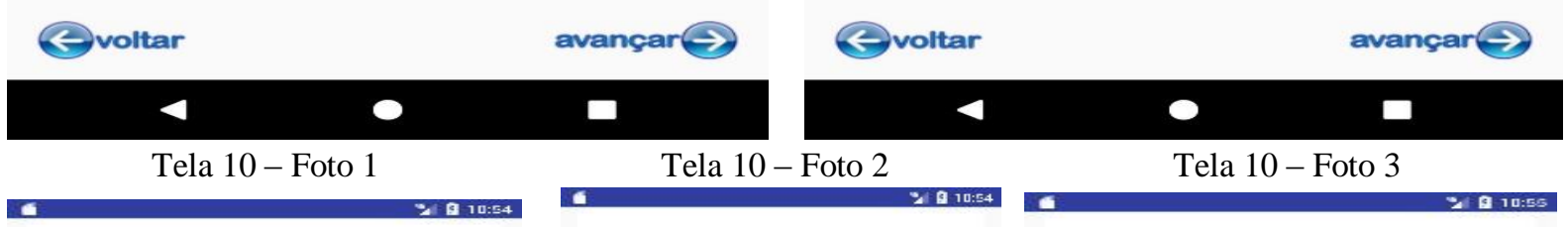

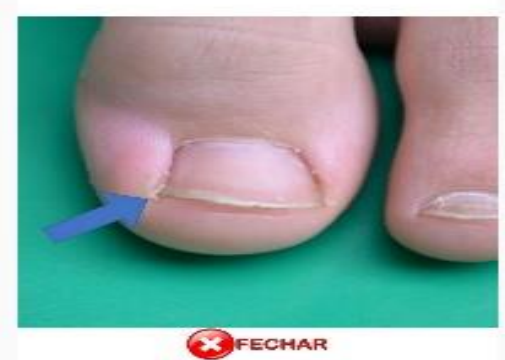

(3) FECHAR

4

Tela 10 - Foto 4
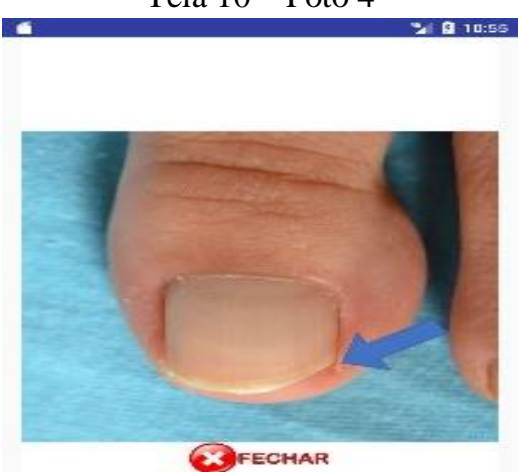

3) FECMAR

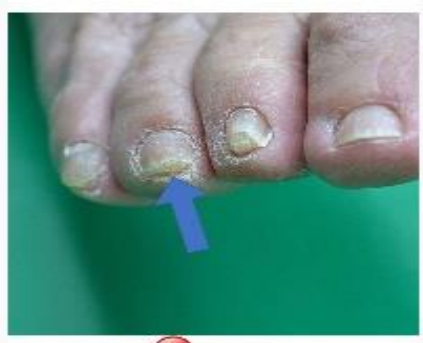

(3) FECMAR
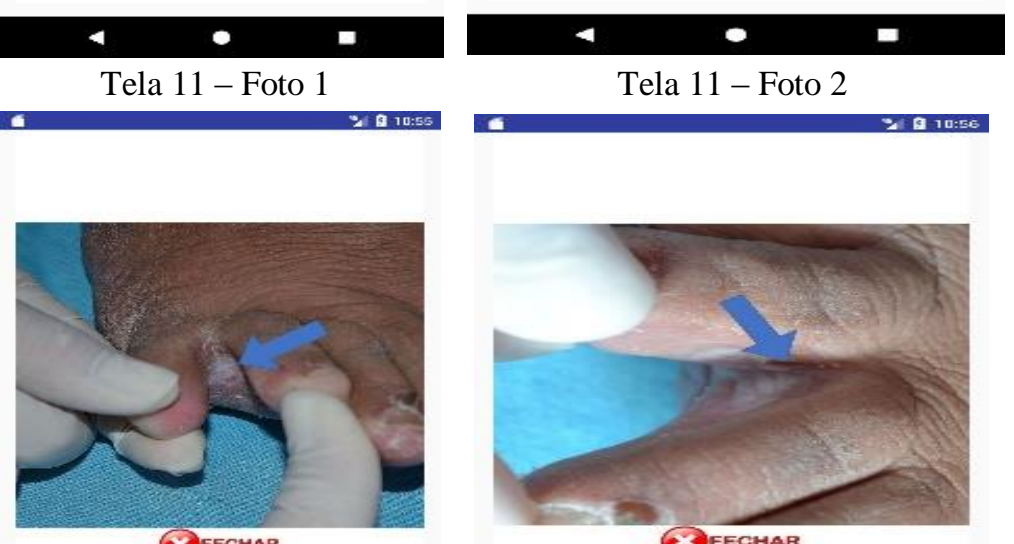

(x) FECMAR
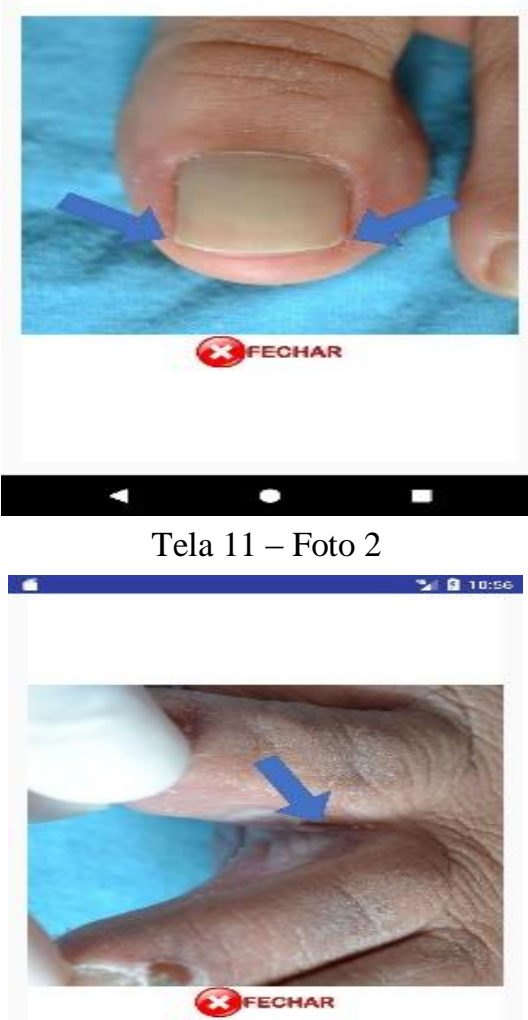

๔)FEhAR

3) FECHAR 
TELA 12

TELA 13

TELA 14

Avaliação da Sensibilidade

Teste do monofilamento de

Semmes-Weinstein $10 \mathrm{~g}$

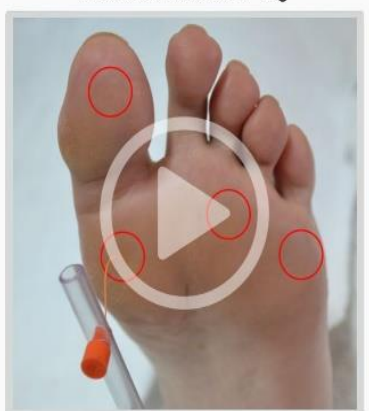

Sensibilidade preservada em

todos os pontos

Sensibilidade alterada em pelo

menos um dos quatros pontos
Avaliação da Sensibilidade Sensibilidade vibratória: Diapasão $128 \mathrm{~Hz}$

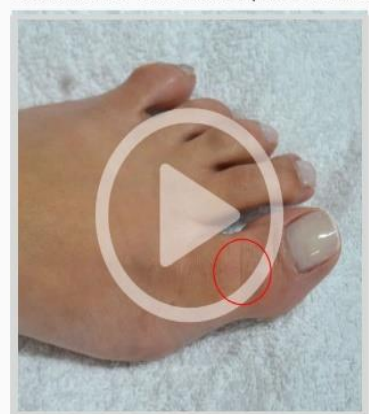

Percepção vibratória presente em:

pelo menos duas vezes da avaliação

apenas uma ou nenhuma da avaliação

(1)

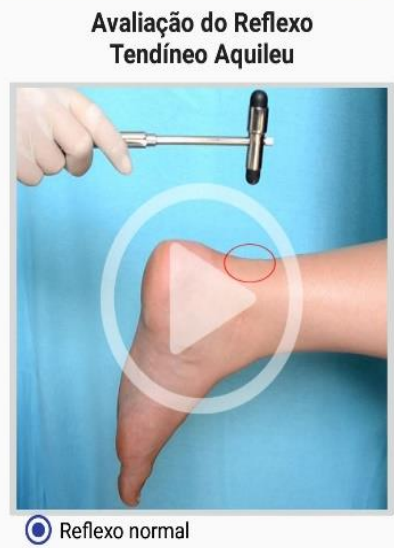

Reflexo alterado

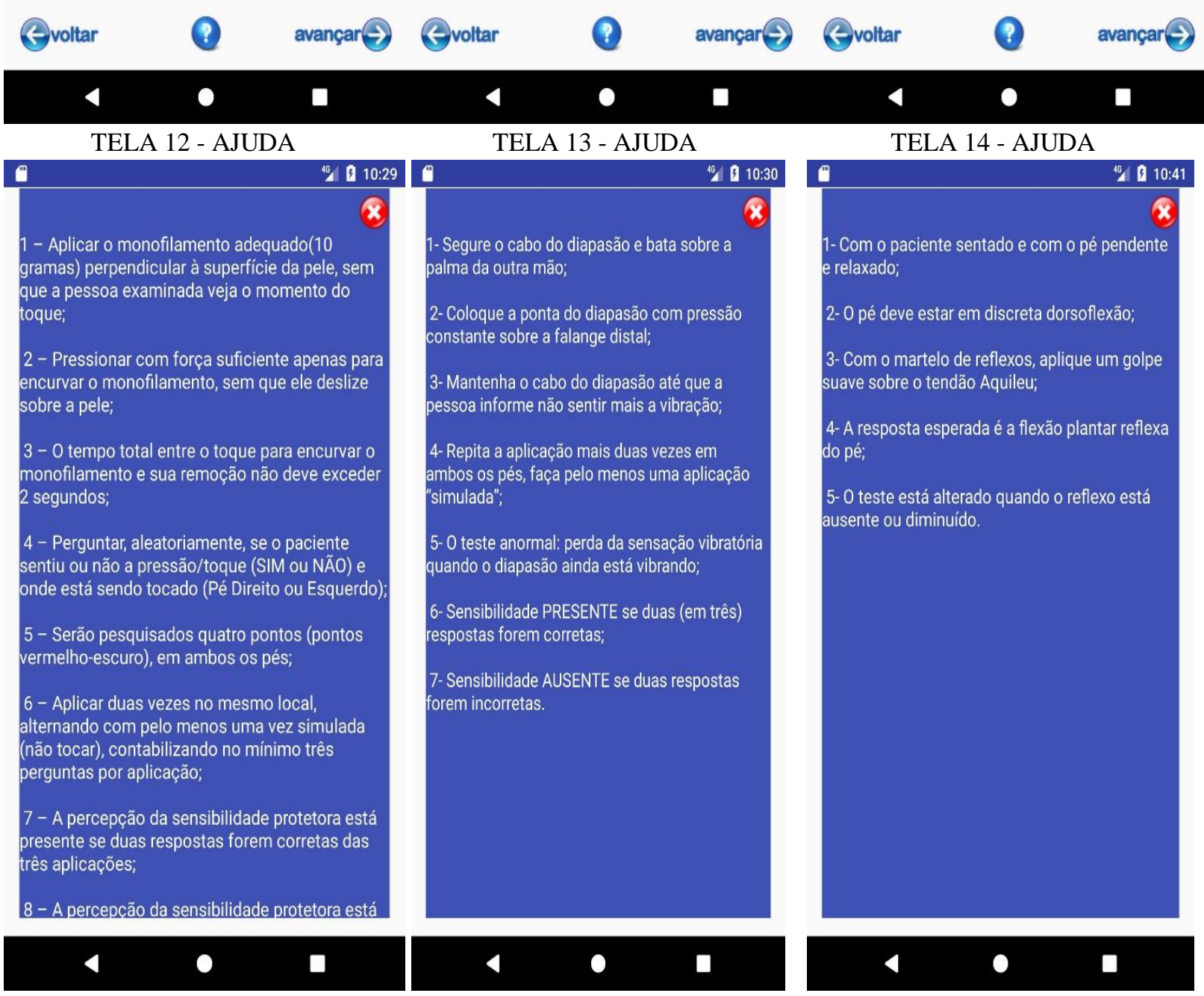


TELA 15

TELA 16

TELA 17

$\begin{array}{cc}\text { Avaliação Vascular } & \text { Avaliação Vascular } \\ \text { Sinais de insuficência venosa? } & \text { Temperatura }\end{array}$

A temperatura está:

Qual/Quais?

$\checkmark$ Edema

$\square$ Varizes 므
O Normal
Quente
O Fria

41 10 10:42

Tibiat
Diminuído
$\bigcirc$ Ausente
O Presente
$\bigcirc$ Diminuído
$\bigcirc$ Ausente

Pedioso E 뭉

○ Presente

$\bigcirc$ Diminuído

$\bigcirc$ Ausente

Pedioso D

Presente

O Diminuído

O Ausente
Avaliação Vascular

Pulsos (Esquerdo/Direito)

4บ 9 10:43

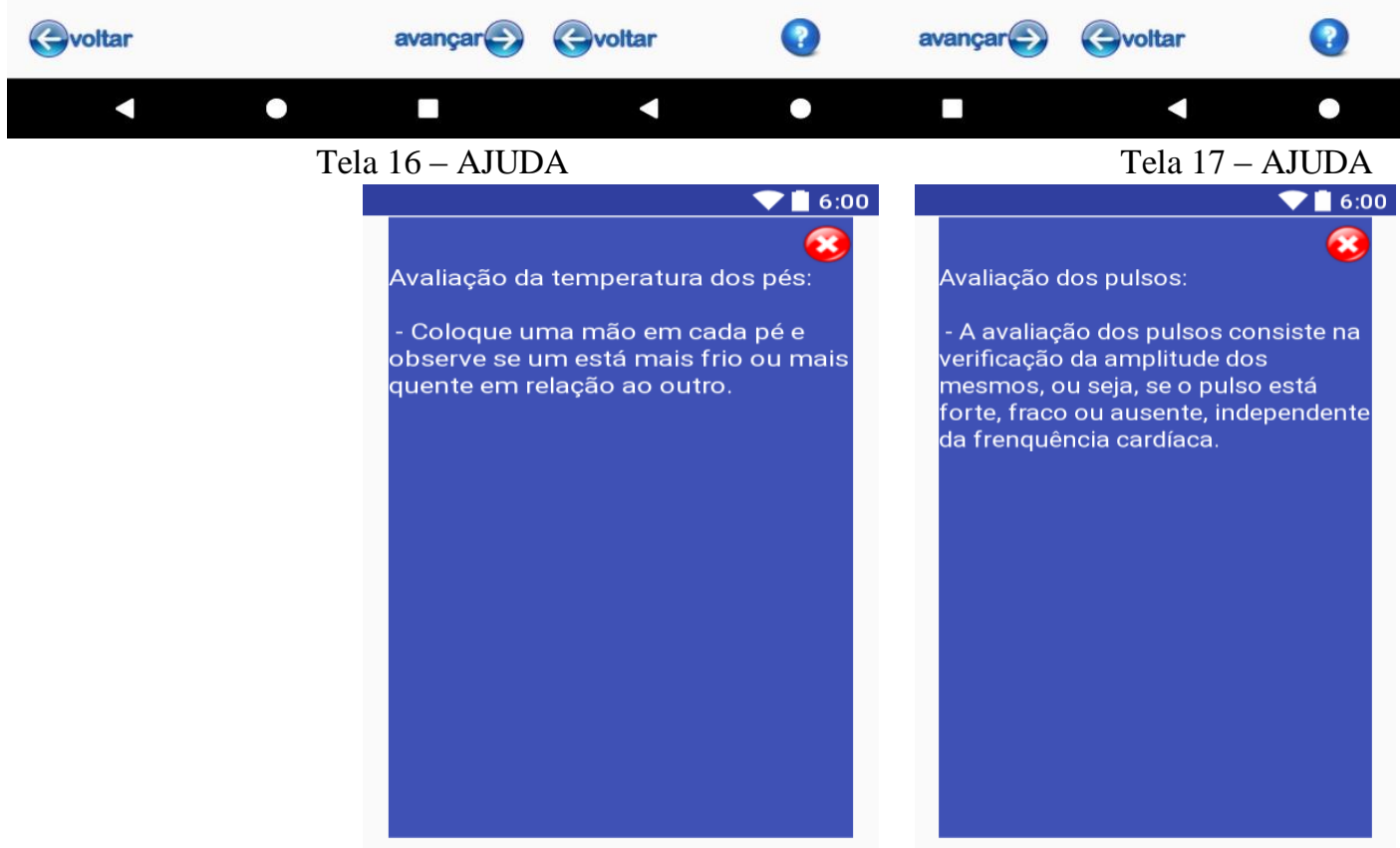

Tela 15 - Foto 1
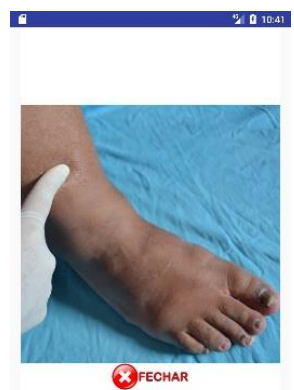

x fechar
Tela 15 - Foto 2
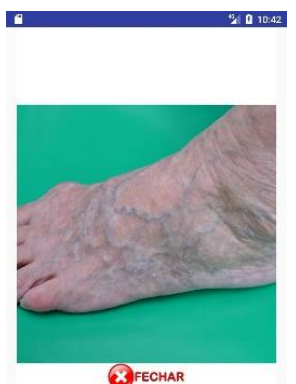

(x) FECHAR
Tela 17 - Foto 1
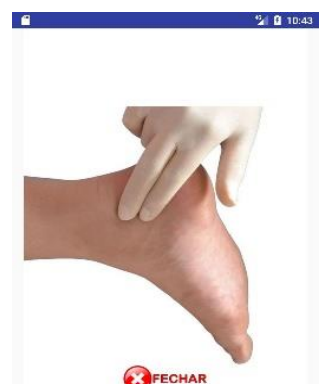

Tela 17 - Foto 2
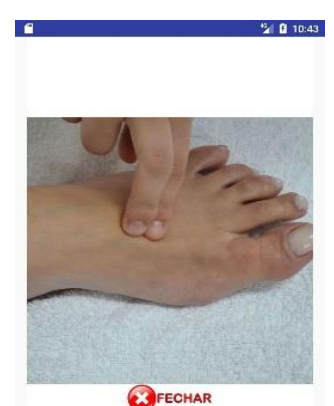

× Fechar a

口


TELA 18

$\begin{gathered}\text { Deformidade dos pés } \\ \text { Apresenta deformidades? }\end{gathered}$
Não $\quad$ Sim
Qual/Quais?
$\square$ Garra $\square$
$\square$ Martelo $\square$
$\square$ Hálux Valgo D/E $\square$
$\square$ Artropatia de Charcot $\square$

Svoltar

avançar $\rightarrow$

40. B 10:44

?

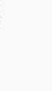




\section{ANEXO D}

\section{AUTORIZAÇÃO PARA UTILIZAR O APLICATIVO “CUIDANDO DO PÉ”}

Eliene Muro<elienemuro@gmail.com>

Seg, 09/12/2017 00:23

Prezada Lidiane

Eu autorizado a utilização do aplicativo cuidando do pé em seu estudo.

Sucesso em seu trabalho!

Em seg, 9 de dez de 2017 00:01, Lidiane Monteiro< <idianemonteiro22@hotmail.com> escreveu:

Boa noite prezada Eliene,

Sou doutoranda pela Universidade de São Paulo e estou desenvolvendo um estudo cujo objetivo é avaliar a contribuição do ensino do autocuidado com os pés junto a pessoas com diabetes mellitus. Desta forma, necessito da sua autorização para utilizar o aplicativo "Cuidando do pé", o qual será utilizado nas avaliações da integridade da pele e anexos, sensibilidade, condições vasculares, temperatura, deformidades.

Certa de sua colaboração, fico aguardando seu retorno.

$$
\begin{aligned}
& \text { Lidiane A. Monteiro } \\
& \text { Enfermeira - Coordenadora de Imunização }
\end{aligned}
$$

Mestre pela Escola de Enfermagem da Universidade Federal de Alfenas

Doutoranda pela Universidade de São Paulo - USP - Ribeirão Preto 
ANEXO E

\section{QUESTIONÁRIO DE AVALIAÇÃO DO CONHECIMENTO SOBRE O AUTOCUIDADO COM OS PÉS}

\begin{tabular}{|c|c|c|}
\hline O SR(A) SABE QUE POR CAUSA DO DIABETES............. & SIM & NÃO \\
\hline $\begin{array}{l}\text {.....tem que examinar ou solicitar que alguém (familiar) } \\
\text { examine seus pés diariamente? }\end{array}$ & & \\
\hline $\begin{array}{l}\text {.....deve avisar o médico quando apresenta calos, rachaduras, } \\
\text { alterações de cor ou úlceras nos pés? }\end{array}$ & & \\
\hline .....tem que usar sempre meias limpas? & & \\
\hline .....tem que usar meias de algodão ou de lã? & & \\
\hline .....tem que usar meias sem elástico? & & \\
\hline .....tem que calçar sapatos que não apertam os pés? & & \\
\hline .....tem que usar calçado de couro macio ou de tecido? & & \\
\hline .....tem que usar sapatos só com meias? & & \\
\hline .....deve usar sapatos novos poucas horas por dia? ( 2 horas) & & \\
\hline ......não pode andar descalço? & & \\
\hline ......deve lavar os pés diariamente? & & \\
\hline .....deve secar os pés e entre os dedos? & & \\
\hline ......deve hidratar os pés? & & \\
\hline .....deve cortar as unhas de forma reta (horizontalmente)? & & \\
\hline $\begin{array}{l}\text {.....deve procurar um profissional para remover calos ou unhas } \\
\text { encravadas? }\end{array}$ & & \\
\hline $\begin{array}{l}\text {.....deve procurar os profissionais da saúde quando precisar de } \\
\text { orientação? }\end{array}$ & & \\
\hline
\end{tabular}

Fonte: Monteiro (2015). 


\section{ANEXO F}

\section{QUESTIONÁRIO DO COMPORTAMENTO PLANEJADO NO DIABETES - CUIDADO COM OS PÉS (QCP-CP), (VERSÃO BRASILEIRA, 2014)}

LEIA COM ATENÇÃO: Pessoas com Diabetes Mellitus devem cuidar adequadamente dos pés. Este cuidado implica em lavar e secar os pés todos os dias, bem como verificar a existência de alterações significativas (como por exemplo alterações na cor, presença de manchas e feridas).

1. Coloque uma cruz (x) na resposta que melhor descreve a sua opinião.

\begin{tabular}{|l|l|l|l|l|l|}
\hline $\begin{array}{l}\text { Nos próximos seis } \\
\text { meses... }\end{array}$ & $\begin{array}{c}\text { Discordo } \\
\text { completamente }\end{array}$ & Discordo & $\begin{array}{l}\text { Nem discordo } \\
\text { nem concordo }\end{array}$ & Concordo & $\begin{array}{c}\text { Concordo } \\
\text { completamente }\end{array}$ \\
\hline $\begin{array}{l}\text { a) Eu tenho a intenção de } \\
\text { lavar, secar bem e } \\
\text { observar os pés todos os } \\
\text { dias. }\end{array}$ & & & & & \\
\hline $\begin{array}{l}\text { b) O meu objetivo é lavar, } \\
\text { secar bem e observar os } \\
\text { pés todos os dias. }\end{array}$ & & & & & \\
\hline
\end{tabular}

2. Lavar, secar bem e observar os pés todos os dias é (coloque um círculo na resposta que melhor descreve a sua opinião):

\begin{tabular}{|l|c|c|c|c|c|}
\hline a) & Muito bom & Bom & $\begin{array}{r}\text { Nem Bom nem } \\
\text { Ruim }\end{array}$ & Ruim & Muito Ruim \\
\hline b) & Muito Útil & Útil & Nem Útil nem Inútil & Inútil & Muito Inútil \\
\hline c) & Muito agradável & Agradável & $\begin{array}{c}\text { Nem agradável } \\
\text { nem desagradável }\end{array}$ & Desagradável & $\begin{array}{c}\text { Muito } \\
\text { desagradável }\end{array}$ \\
\hline d) & Muito Saudável & Saudável & $\begin{array}{c}\text { Nem Saudável } \\
\text { nem Maléfico }\end{array}$ & Maléfico & Muito Maléfico \\
\hline e) & Muito Importante & Importante & $\begin{array}{c}\text { Nem Importante } \\
\text { nem Insignificante }\end{array}$ & Insignificante & $\begin{array}{c}\text { Muito } \\
\text { Insignificante }\end{array}$ \\
\hline
\end{tabular}

3. Complete as frases com a opção que melhor descreve a sua opinião, relativamente a lavar, secar bem e observar os pés todos os dias ...

a) A maioria das pessoas que são importantes para mim pensam que eu...

\begin{tabular}{|c|c|c|c|c|}
\hline Devia & Talvez devesse & $\vec{E}$ indiferente & Talvez não devesse & Não devia \\
\hline \multicolumn{5}{|c|}{ b) O meu médico pensa que eu... } \\
\hline Devia & Talvez devesse & $\dot{E}$ indiferente & Talvez não devesse & Não devia \\
\hline
\end{tabular}

...lavar, secar bem e observar os pés todos os dias.

c) O meu/minha companheiro(a) pensa que eu...

\begin{tabular}{|c|c|c|c|c|}
\hline Devia & Talvez devesse & É indiferente & Talvez não devesse & Não devia \\
\hline
\end{tabular}

...lavar, secar bem e observar os pés todos os dias. 
4. Agora, gostaríamos de saber o que pensa sobre lavar e secar bem os pés todos os dias.

\begin{tabular}{|l|c|c|c|c|c|}
\hline $\begin{array}{l}\text { a) Para eu lavar, secar } \\
\text { bem e observar os pés } \\
\text { todos os dias é... }\end{array}$ & Muito difícil & Difícil & $\begin{array}{c}\text { Moderadamente } \\
\text { difícil }\end{array}$ & Fácil & Muito fácil \\
\hline $\begin{array}{l}\text { b) Se eu quisesse } \\
\text { poderia lavar, secar bem } \\
\text { e observar os pés todos } \\
\text { os dias. }\end{array}$ & $\begin{array}{c}\text { Discordo } \\
\text { completamente }\end{array}$ & Discordo & $\begin{array}{c}\text { Nem discordo } \\
\text { nem concordo }\end{array}$ & Concordo & $\begin{array}{c}\text { Concordo } \\
\text { completamente }\end{array}$ \\
\hline $\begin{array}{l}\text { c) Quanto controle } \\
\text { acredito ter sobre lavar, } \\
\text { secar bem e observar os } \\
\text { pés todos os dias? }\end{array}$ & $\begin{array}{c}\text { Nenhum } \\
\text { controle }\end{array}$ & $\begin{array}{c}\text { Algum } \\
\text { controle }\end{array}$ & $\begin{array}{c}\text { Controle } \\
\text { moderado }\end{array}$ & $\begin{array}{c}\text { Muito } \\
\text { controle }\end{array}$ & $\begin{array}{c}\text { Controle } \\
\text { completo }\end{array}$ \\
\hline $\begin{array}{l}\text { d) lavar, secar bem e } \\
\text { observar os meus pés } \\
\text { depende apenas de mim. }\end{array}$ & $\begin{array}{c}\text { Discordo } \\
\text { completamente }\end{array}$ & Discordo & $\begin{array}{c}\text { Nem discordo } \\
\text { nem concordo }\end{array}$ & Concordo & $\begin{array}{c}\text { Concordo } \\
\text { completamente }\end{array}$ \\
\hline
\end{tabular}

5. Gostaríamos de saber se tem planos concretos para lavar, secar bem e observar os pés todos os dias nos próximos seis meses.

Para os próximos seis meses tenho um plano relativamente a...

\begin{tabular}{|c|c|c|c|c|c|}
\hline & & & & & \\
\hline \multicolumn{6}{|l|}{$\begin{array}{l}\text { a)...quantas vezes vou lavar, secar bem e observar os } \\
\text { pés. }\end{array}$} \\
\hline \multicolumn{6}{|l|}{$\begin{array}{l}\text { b)...em que momento do dia vou lavar, secar bem e } \\
\text { observar os pés }\end{array}$} \\
\hline \multicolumn{6}{|l|}{ c)...onde vou lavar, secar bem e observar os pés. } \\
\hline \multicolumn{6}{|l|}{ d)...como vou lavar, secar bem e observar os pés. } \\
\hline $\begin{array}{l}\text { 6. Gostaríamos de saber se tem planos concretos } \\
\text { quanto à forma como vai lidar com alguns } \\
\text { problemas que possam surgir ao tentar colocar em } \\
\text { ação os planos para lavar, secar bem e observaros } \\
\text { pés todos os dias nos próximos seis meses. } \\
\text { Para os próximos seis meses tenho um plano } \\
\text { relativamente... }\end{array}$ & $\begin{array}{l}\frac{0}{\frac{0}{0}} \\
\frac{0}{0} \\
\frac{\pi}{0} \\
\frac{0}{10} \\
\frac{\pi}{0} \\
\frac{\pi}{2}\end{array}$ & $\begin{array}{l}\frac{0}{0} \\
\frac{0}{0} \\
\frac{0}{0} \\
\frac{0}{0} \\
0 \\
0 \\
0 \\
0 \\
0 \\
0\end{array}$ & 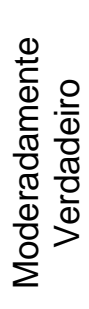 & 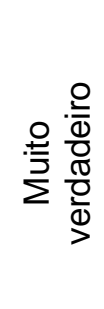 & 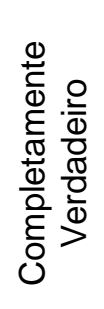 \\
\hline \multicolumn{6}{|l|}{$\begin{array}{l}\text { a)... ao que fazer para organizar o meu tempo para } \\
\text { lavar, secar bem e observar os pés todos os dias. }\end{array}$} \\
\hline \multicolumn{6}{|l|}{ b)... ao que fazer para ter ajuda de outra pessoa. } \\
\hline \multicolumn{6}{|l|}{$\begin{array}{l}\text { c)... ao que fazer para me lembrar das vantagens de } \\
\text { lavar, secar bem e observar os pés todos os dias. }\end{array}$} \\
\hline $\begin{array}{l}\text { d)...ao que fazer para ter vontade de lavar, secar bem e } \\
\text { observar os pés todos os dias. }\end{array}$ & & & & & \\
\hline
\end{tabular}

Fonte: Monteiro (2015) 
ANEXO G

PARECER CONSUBSTANCIADO DO CEP

\section{UNIVERSIDADE FEDERAL DE Q Platoformo
ALFENAS}

\section{PARECER CONSUBSTANCIADO DO CEP}

\section{DADOS DO PROJETO DE PESQUISA}

Título da Pesquisa: O "ENSINO DO CUIDADO COM OS PÉS" NA REDUÇÃO DO RISCO DE INTEGRIDADE DA PELE PREJUDICADA DE PESSOAS COM DIABETES MELLITUS TIPO 2: ENSAIO CLÍNICO RANDOMIZADO

Pesquisador: Erika de Cássia Lopes chaves

Área Temática:

Versão: 2

CAAE: 78125516.5 .0000 .5142

Instituição Proponente: UNIVERSIDADE FEDERAL DE ALFENAS - UNIFAL-MG

Patrocinador Principal: Financiamento Próprio

\section{DADOS DO PARECER}

Número do Parecer: 2.398 .216

Apresentação do Projeto:

Segunda versão de proposta de doutorado da Universidade de São Paulo no Programa de Pós Graduação Fundamental da Escola de Enfermagem da Universidade de São Paulo (USP), orientado pela Profa. Dra. Ana Emília Pace, docente na Universidade de São Paulo - USP e co-orientado pela Profa. Dra . Érika de Cássia Lopes Chaves, docente na Universidade Federal de Alfenas - UNIFAL/MG. A Secretaria de Saúde de Boa Esperança será a Instituição coparticipante. Terá financiamento próprio. Não foram identificados conflitos de interesses. As três pendências da primeira versão foram sanadas.

Objetivo da Pesquisa:

OBJETIVO GERAL

Avaliar a contribuição do "Ensino do Cuidado com os Pés" para a redução do risco de integridade da pele prejudicada de pessoas com DM tipo 2.

\section{OBJETIVOS ESPECÍFICOS}

- Avaliar o conhecimento de pessoas com DM tipo 2 sobre as atividades de autocuidado com os pés, antes e após a intervenção de enfermagem "Ensino do Cuidado com os Pés";

- Avaliar a intenção de pessoas com DM tipo 2 de realizar as atividades de autocuidado com os

Endereço: Rua Gabriel Monteiro da Silva, 700

Bairro: centro

UF: MG Município: ALFENAS

CEP: $37.130-000$

Telefone: (35)3299-1318 Fax: (35)3299-1318

E-mail: comite.etica@unifal-mg.edu.br 


\section{UNIVERSIDADE FEDERAL DE Olatoforma ALFENAS}

Continuação do Parecer: 2.398.216

pés, antes e após a intervenção de enfermagem "Ensino do Cuidado com os Pés";

- Avaliar a contribuição do "Ensino do Cuidado com os Pés" sobre a glicemia, a pele e os anexos; a sensibilidade; as características vasculares e as deformidades plantares de pessoas com DM tipo 2.

a. claros e bem definidos;

b. coerentes com a propositura geral do projeto;

c. exequíveis (considerando tempo, recursos, metodologia).

\section{Avaliação dos Riscos e Benefícios:}

Risco:

"risco de desconforto durante a coleta de sangue, sendo justifica pela importância de verificar os níveis de glicose sanguínea."

Benefício:

"colaborar para o avanço da área de conhecimento em relação às medidas preventivas para o risco de integridade da pele de pessoas com Diabetes Mellitus tipo 2.

a. o risco de execução do projeto é bem avaliado, realmente necessário, mas está descrito no apenas no TCLE;

b. os benefícios oriundos da execução do projeto justificam o risco corrido;

c. a pesquisadora não apresentou uma correta ação minimizadora/corretiva desse risco.

\section{Comentários e Considerações sobre a Pesquisa:}

Trata-se de um ensaio clínico, randomizado, controlado e mascarado, a ser realizado em uma Policlínica, do município de Boa Esperança - MG, com 460 pessoas com DM, cadastradas na Unidade e no SISAB. À saber, pessoas com idade acima de dezoito anos e com DM tipo 2 diagnosticadas há, no mínimo, cinco anos. Não participarão pessoas com DM tipo 2 que apresentarem lesões nos pés; amputações nos membros inferiores e déficit na capacidade cognitiva, identificado pelo Mini-Exame do Estado Mental (MEEM). Os voluntários serão randomizados em dois grupos distintos, denominados Grupo Tratado (GT) e Grupo Controle (GC). O GT receberá a intervenção educativa "Ensino do Cuidado com os Pés", enquanto o $G C$, receberá acompanhamento conforme a rotina do serviço.

a. Metodologia da pesquisa - adequada aos objetivos do projeto, atualizada

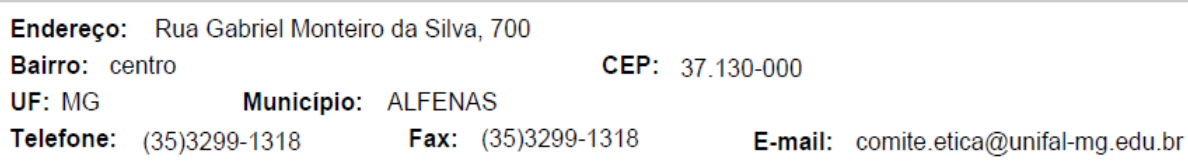




\section{UNIVERSIDADE FEDERAL DE Plotoformo ALFENAS}

Continuação do Parecer: 2.398.216

b. Referencial teórico da pesquisa - atualizado e suficiente para aquilo que se propõe;

c. Cronograma de execução da pesquisa - coerente com os objetivos propostos e adequado ao tempo de tramitação do projeto.

Considerações sobre os Termos de apresentação obrigatória:

a. Termo de Consentimento Livre e Esclarecido (TCLE): presente e adequado;

b. Termo de Assentimento (TA): Não se aplica.

c. Termo de Assentimento Esclarecido (TAE): Não se aplica.

d. Termo de Compromisso para Utilização de Dados e Prontuários (TCUD): ausente.

e. Termo de Anuência Institucional (TAI): presente e adequado.

f. Folha de rosto: presente e adequada;

g. Projeto de pesquisa completo e detalhado: presente e parcialmente adequado;

h. Outro (Termo de Anuência da Instituição Coparticipante): presente e adequado.

Recomendações:

Não há.

Conclusões ou Pendências e Lista de Inadequações:

Recomenda-se a aprovação do projeto.

Considerações Finais a critério do CEP:

O Colegiado do CEP acata o parecer do relator.

Este parecer foi elaborado baseado nos documentos abaixo relacionados:

\begin{tabular}{|c|c|c|c|c|}
\hline Tipo Documento & Arquivo & Postagem & Autor & Situação \\
\hline $\begin{array}{l}\text { Informações Básicas } \\
\text { do Projeto }\end{array}$ & $\begin{array}{l}\text { PB_INFORMAÇÖES_BASICAS_DO_P } \\
\text { ROJETO 795229.pdf }\end{array}$ & $\begin{array}{c}11 / 11 / 2017 \\
08: 30: 21\end{array}$ & & Aceito \\
\hline Outros & TCUD.png & $\begin{array}{l}11 / 11 / 2017 \\
08: 21: 56\end{array}$ & $\begin{array}{l}\text { Erika de Cássia } \\
\text { Lopes chaves }\end{array}$ & Aceito \\
\hline Outros & TCUD.jpg & $\begin{array}{c}11 / 11 / 2017 \\
08: 04: 29 \\
\end{array}$ & $\begin{array}{l}\text { Erika de Cássia } \\
\text { Lopes chaves }\end{array}$ & Aceito \\
\hline $\begin{array}{l}\text { Projeto Detalhado / } \\
\text { Brochura } \\
\text { Investiaador }\end{array}$ & PROJETO.docX & $\begin{array}{c}31 / 10 / 2017 \\
16: 19: 16\end{array}$ & $\begin{array}{l}\text { Erika de Cássia } \\
\text { Lopes chaves }\end{array}$ & Aceito \\
\hline $\begin{array}{l}\text { TCLE / Termos de } \\
\text { Assentimento / } \\
\text { Justificativa de }\end{array}$ & TCLE.docx & $\begin{array}{c}31 / 10 / 2017 \\
16: 18: 36\end{array}$ & $\begin{array}{l}\text { Erika de Cássia } \\
\text { Lopes chaves }\end{array}$ & Aceito \\
\hline
\end{tabular}

Endereço: Rua Gabriel Monteiro da Silva, 700

Bairro: centro

CEP: $37.130-000$

UF: MG Município: ALFENAS

Telefone: (35)3299-1318 Fax: (35)3299-1318 E-mail: comite.etica@unifal-mg.edu.br 


\section{UNIVERSIDADE FEDERAL DE Plotoforma ALFENAS}

Continuação do Parecer: 2.398.216

\begin{tabular}{|l|l|c|l|c|}
\hline Ausência & TCLE.docx & $\begin{array}{c}31 / 10 / 2017 \\
16: 18: 36\end{array}$ & $\begin{array}{l}\text { Erika de Cássia } \\
\text { Lopes chaves }\end{array}$ & Aceito \\
\hline $\begin{array}{l}\text { Declaração de } \\
\text { Instituição e } \\
\text { Infraestrutura }\end{array}$ & TAl.pdf & $02 / 10 / 2017$ & $\begin{array}{l}\text { Erika de Cássia } \\
\text { Lopes chaves }\end{array}$ & Aceito \\
\hline $\begin{array}{l}\text { Declaração de } \\
\text { Instituição e } \\
\text { Infraestrutura }\end{array}$ & Instituicao_Coparticipante.pdf & $02 / 10 / 2017$ & $\begin{array}{l}\text { Erika de Cássia } \\
\text { Lopes chaves }\end{array}$ & Aceito \\
\hline Folha de Rosto & & $17: 07: 14$ & \\
& Folha_de_rosto.pdf & $02 / 10 / 2017$ & $\begin{array}{l}\text { Erika de Cássia } \\
\text { Lopes chaves }\end{array}$ & Aceito \\
\hline
\end{tabular}

Situação do Parecer:

Aprovado

Necessita Apreciação da CONEP:

Não

ALFENAS, 24 de Novembro de 2017

Assinado por:

Marcela Filié Haddad

(Coordenador) 
